\title{
Gluttony \& Sloth: The Moral Politics of Obesity Discourse
}

\author{
William James Hoverd
}

\author{
A thesis \\ submitted to the Victoria University of Wellington \\ in fulfilment of the requirements of the degree of \\ Doctor of Philosophy \\ in Religious Studies
}

Victoria University of Wellington

July 2011 


\begin{abstract}
In this dissertation, I investigate why 'official obesity discourse' discusses obesity in terms of the sins of gluttony and sloth. This question leads me to survey the moral politics of 'official obesity discourse' in New Zealand between 1997 and 2009. I claim that 'official obesity discourse' is not neutral, and contains various ideological biases. I map the overall range of these ideologies onto a schema of three models of obesity causality. I demonstrate that each of these three models corresponds to certain general policy positions of respective governments; to certain specific health policies (issued by the Ministry of Health); and to certain medical understandings of causality. I further show how each ideological model moralises obesity, in a manner that casts various groups and forces in the role of scapegoat. Finally, I argue that the three models of obesity causality I have identified discriminate against people on low incomes and in certain ethnic groups. My study concludes with a research model which can be used by other researchers to reveal the ideological and moral dimensions of obesity discourse in their own contexts.
\end{abstract}




\section{Acknowledgements}

Kosal Kong,

Thank you for all your love, patience and support during the dissertation process. Without you I could not have faced all early starts or the dark nights of doubt. This thesis is as much yours as it is mine.

Dr Michael Radich,

Thank you for being an exemplary mentor. You consistently challenged me to improve, be clearer, more disciplined, and to always work towards my best. You perfectly balance your academic expertise, challenge, and, rigour with patience, support, and kindness. One could not ask for a better role model.

Prof Paul Morris,

You have guided all of my academic study over the long years. Your passion for knowledge is inspirational. Your ideas, teachings and intellectual tradition are instrumental to my academic study of religion. Thank you for always welcoming me into your office whenever I knocked.

Alan and Barbara Hoverd, thank you for your long suffering support for my postgraduate study. I love you both very much.

Dr Chris Sibley and A/Prof Marion Maddox, your guidance and friendship were essential to this dissertation.

Dr Stefanie Head and Jan Bunting, thank you for reading and discussing my drafts with me.

Mr Leon Grandy and Aliki Kalliabetsos, I can't begin to count the ways you have supported me.

Thanks also to Negar Partow, Rebecca Frost, Prof Chris Marshall, Annie Mercer, Dr Mike Lloyd, Dr Rick Weiss, and Dr Geoff Troughton who have particularly supported this process.

I also want to formally acknowledge the people who have generously provided me with the emotional, logistical, collegial, and critical support that I drew upon to write this document.

Elise Hoverd, Alex Hoverd, Kevin Francis, Dr Andrew Robertson, Philippa Robertson, Akvilina Cicenaite, Lisa Eyre, Dr Rob Keyzers, Charlotte Boyer, Dr Michael Grimshaw, Dr Joseph Bulbulia, Brook Powell, Kate Thomas, Amanda Crump, Charlotte Glynan, Emmett Gracie, Nick Milne, James Stewart, Glen Burfield, Brendan Partington, Mike Mawson, Jonathan Brookes, Thom Appleton, Dr Sophie Parker, Kim Dixon, Dr Scott Carver, A/Prof Jim Veitch, Prof Rosalind Hackett, Dr Matt Gerry, Dr Kirsty Weir, Prof Kevin Dew, Dr Heather Kavan, Dr Michael Symons, Prof John Davidson, A/Prof Matthew Trundle, Prof Charles Crothers, Dr Cat Pause, Aaron Jones, Prof Bob Wear, David Wallace, Allan McShane, Jonny Clifford, Dr Michael Gard, Susanne Liebich, Anushka Perinpanayagam, Tim McVicar, Katja Strehle, Eda Czarnecki, Amy Searfoss, Caitlin Dalzell, Daniel Dowling, Atsushi Iseki, and Chris Slane. Final thanks to my extended Kong Family.

My research was assisted by:

Victoria University of Wellington Postgraduate Scholarship for PhD study

Reverend William Wallace Gibson Memorial Prize for Religious Studies

Victoria University PhD Submission Scholarship 


\section{Contents}

Gluttony \& Sloth: The Moral Politics of Obesity Discourse 1

Abstract 2

Acknowledgements 3

$\begin{array}{ll}\text { Contents } & 4\end{array}$

Glossary of Acronyms, Abbreviations, Definitions and Terms 8

Chapter One: Why do Modern Commentators Ascribe Obesity to the Sins of 'Gluttony and Sloth?'

1.0 Preamble $\quad 9$

$\begin{array}{ll}1.1 \text { Introduction } & 14\end{array}$

1.2 The Original Research Question 14

1.3.0 Religious Studies Literature Reviews 16

1.3.1 Sociology of the Body Literature 16

$\begin{array}{ll}\text { 1.3.2 The History of the Deadly Sins } & 17\end{array}$

1.3.3 Christianity and the Body: The Problem of Context 19

1.3.4 Christianity, Sport, Anorexia and Devotional Dieting 20

$\begin{array}{ll}\text { 1.3.5 Obesity Prevalence and Religious Identification } & 21\end{array}$

1.3.6 Lessons from the Literature Reviews 22

1.4.0 Critical Analyses of Scholarship on the Obesity Epidemic, and in Fat Studies 24

1.4.1 Critical Scholarship on the Obesity Epidemic 25

1.4.2 Fat Studies Scholarship $\quad 26$

1.4.3 The Moral Dimensions of Social Scientific Investigations into Obesity and Fatness 27

$\begin{array}{ll}\text { 1.4.4 Critical Literature Summary } & 29\end{array}$

1.5 Situating My Research as an Investigation into the Moral Politics of Obesity Discourse 29

$\begin{array}{ll}1.6 \text { Research Methodology } & 31\end{array}$

1.7 Dissertation Chapter Outlines $\quad 32$

Part One: The Ideological Dimensions of Obesity Discourse 35

Chapter Two: The Behavioural Causality Model and the Origins of Obesity Discourse 36

2.0 Introduction $\quad 36$

2.1 The Behavioural Causality Model 37

2.2 The Medical Basis of the Behavioural Causality Model 39

2.3 The Welfare State and Universal Free Health Care 40

2.4 Developing Concerns with Cardiovascular Disease and Population Health 41

2.5 Demographic Studies of the Population: National Diet Survey 1977

2.6 Concerns with Nutrition and Physical Inactivity in the 1980s 44

2.7 Individual Responsibility and Lifestyle Disease $\quad 47$ 
2.8 Changing Nutritional Language: The Life in New Zealand Survey 1989

2.9 The Emergence of the Behavioural Causality Model 50

2.10 The Green and White Paper: The Individual as a Consumer of Health Services 52

2.11 The 1993 New Right Health Reforms 55

2.12 Behavioural Causality Policy $1996-1998 \quad 56$

2.13 Obesity Emerges as a Significant Health Problem in 1997

$\begin{array}{ll}2.14 \text { Conclusion } & 60\end{array}$

Chapter Three: The Multiple Causality Model and the Obesity Epidemic as Fact 63

3.0 Introduction 63

3.1 The Multiple Causality Model $\quad 64$

3.2 The Medical Basis for the Multiple Causality Model 65

$\begin{array}{ll}3.3 \text { An Inequality Focus and 'Third Way' Politics } & 67\end{array}$

3.4 The New Zealand Health Strategy $2000 \quad 70$

3.5 Development of the Healthy Eating Healthy Action Strategy 73

3.6 HEHA and Multiple Determinants of Obesity $\quad 74$

3.7 Behavioural Obesity Policy with Environmental Labelling 76

3.8 The Emergence of Full MCM Policy in $2004 \quad 79$

3.9 Multiple Causality Model Policy $\quad 80$

3.10 The Obesity Epidemic as Fact $\quad 84$

3.11 The Historical Revision of the Obesity Epidemic 87

$\begin{array}{ll}3.12 \text { Conclusion } & 90\end{array}$

Chapter Four: The Environmental Causality Model: Obesity Budgets and the Select

Committee $\quad 93$

4.0 Introduction 93

4.1 The Environmental Causality Model 94

4.2 Origins of the Environmental Causality Model 95

4.3 The Medical Basis of the Environmental Causality Model 97

4.4 Budget 2006: the Largest Campaign in New Zealand's History to Fight Obesity 100

4.5 Soft Drink Advertising: the Transition from the Multiple to Environmental Causality $\begin{array}{ll}\text { Models } & 102\end{array}$

4.6 The Select Committee Inquiry into Obesity and Type 2 Diabetes in New Zealand 104

4.7 Anti-Free Market ECM Critiques and the Select Committee 110

4.8 Environmental Causality Model Obesity Policy in $2008 \quad 113$

$\begin{array}{ll}4.9 \text { Conclusion } & 116\end{array}$

$\begin{array}{ll}\text { Chapter Five: The Politics of Obesity Discourse } & 119\end{array}$

$\begin{array}{ll}5.0 \text { Introduction } & 119\end{array}$

$\begin{array}{ll}\text { 5.1.0 Obesity Policy in the November 2008 General Election } & 120\end{array}$

$\begin{array}{ll}\text { 5.1.1 ECM Policy - The Green Party } & 121\end{array}$ 
5.1.2 Educating Individuals About Health Risks - The New Zealand Labour Party

5.1.3 Warrant of Fitness Checks - The Maori Party

5.1.4 Healthy People/Healthy Economy - New Zealand National Party

5.1.5 The Association of Consumers and Taxpayers Party

5.2 The Political Spectrum of Obesity Causation Models

5.3.0 The Removal of Obesity as a Health Target

5.3.1 Healthy Food in Schools - National Administration Guideline Clause Removal

5.3.2 New Zealand $3^{\text {rd }}$ Most Obese Country in the World

5.3.3 Physical Activity: The Emphasis on Sport

5.3.4 Recent Obesity Politics: The Voluntary Schools Beverage Statement

5.4 National Coalition Obesity Policy Reversal

Part Two: The Moral Dimensions of Obesity Discourse

Chapter Six: The Moral Dimensions of Obesity Discourse

6.0 Introduction

6.1 ECM - Communal Morality

6.2 Obesity Burden Language

6.3 BCM - Individual Morality

6.4 Coexisting Individual and Communal Moralities

6.5 Scapegoating the Obese

6.6 Moralising against the Obese: "It's Your Fault If You're A Fatty"

6.7 Conclusion

Chapter Seven: Obesity Economics, Morals, and, Income Inequality

7.0 Introduction

7.1 The Economic Burden of Obesity

7.2 New Zealand Economics of Obesity

7.3 Capitalism and Nutritional Efficiency

7.4 Obesity, Class, and Critiques of Capitalism

7.5 The Relationship Between Income and Health Inequality

7.6 Income and Health Inequality Today

7.7 Conclusion

Chapter Eight: Ethnic Inequality and Obesity

8.1 Two Forms of Inequality 
8.6 Pacific Island Health and BMI 212

8.7 Asian Health and BMI 216

8.8 The Orewa Speech: Equal Access to Health 219

8.9 Ethnic Mobility and Identification 222

$\begin{array}{ll}8.10 \text { Conclusion } & 225\end{array}$

Chapter Nine: The Moral Politics of Official Obesity Discourse 229

9.0 Introduction 229

9.1 The Research Question 229

9.2 The Ideological Dimensions of Obesity Discourse 230

9.3 A Brief Comment about Agency in Obesity Discourse 234

9.4 The Moral Dimensions of Obesity Discourse 234

9.5 Modelling the Moral Politics of Official Obesity Discourse 238

9.6 Future Research Directions 242

$\begin{array}{ll}\text { Bibliography } & 244\end{array}$

$\begin{array}{ll}\text { Publications } & 244\end{array}$

New Zealand Ministry of Health Sources 255

New Zealand Medical Journal Articles $\quad 259$

Websites 263

$\begin{array}{ll}\text { New Zealand Legislation and Treaties } & 267\end{array}$

$\begin{array}{ll}\text { Filmography } & 267\end{array}$ 


\section{Glossary of Acronyms, Abbreviations, Definitions and Terms}

ACT
BCM
BMI
CHE/s
CNS02
CVD
DHB/s
ECM
FOE
GBD Framework
GP
HEHA
HHS92/93
LINZ89
MCM
MOH
NAG Guidelines
NCNS2002
NDS77
NNS97
NZCMS
NZDep
NZHS96/97
NZHS 2002/03
NZHS 2006/07
NZMA
NZMJ
OAC
OECD
PHO/s
SES
SPARC
T2DM
The Select Committee
The Spectrum
WHO
WOF
YLD
YLL
\%BF
HCH

The Association of Consumers and Taxpayers

Behavioural Causality Model

Body Mass Index

Crown Health Enterprise/s

Children and Nutrition Survey 2002

Cardiovascular Disease

District Health Board/s

Environmental Causality Model

Fight Against the Obesity Epidemic

Global Burden of Disease Framework

General Practitioner

Healthy Eating, Healthy Action Plan 2002/2003

The Household Health Survey 1992-93

Life in New Zealand Survey 1989

Multiple Causality Model

Ministry of Health

National Administrative Guidelines

National Children's Nutrition Survey 2002

National Heart Foundation National Diet Survey 1977

New Zealand National Nutrition Survey 1997

New Zealand Census Mortality Study

New Zealand Deprivation Index

New Zealand Health Survey 1996/1997

New Zealand Health Survey 2002/2003

New Zealand Health Survey 2006/2007

New Zealand Medical Association

New Zealand Medical Journal

Obesity Action Coalition

Organisation for Economic Cooperation and Development

Primary Health Organisation /s

Socio-Economic Status

Sports and Recreation New Zealand

Type 2 Diabetes Mellitus

House of Representatives. Inquiry into Obesity and Type 2 Diabetes

The Political Spectrum of Obesity Causation Models

World Health Organisation

Warrant of Fitness Policies

Years Lost to Disability

Years of Life Lost

Percentage of Body Fat

Definitions

Weight Classifications ${ }^{12}$

Normal Weight: Those individuals who have a BMI measurement between $18.5<25$.

Overweight: Those individuals who have a BMI measurement between $26<30$.

Obese I: Those individuals who have a BMI measurement between $30<40$.

Obese II: Those individuals who have a BMI measurement between $40+$

\footnotetext{
${ }^{1}$ BMI classifications have been taken from Barry Wilson, Noela C Wilson, David Russell, "Obesity and Body fat Distribution in the New Zealand Population,” The New Zealand Medical Journal 114 no. 1128 (March 23, 2001): 127. These ranges are provided by the World Health Organisation, Obesity: Preventing and Managing the Global Epidemic (Geneva, World Health Organisation 2000)

${ }^{2}$ Please note that the BMI range for Maori and Pacific Islanders has been increased slightly from that of the European population in New Zealand. See Boyd Swinburn, “Using the Body Mass Index: Weight Then Weigh Up," New Zealand Medical Journal 111: (9 October 1998): 377.
} 


\title{
Chapter One: Why do Modern Commentators Ascribe Obesity to the Sins of 'Gluttony and Sloth?'
}

\begin{abstract}
But the serpent said to the woman, "You will not die; for God knows that when you eat of it your eyes will be opened, and you will be like God, knowing good and evil." So when the Woman saw that the tree was good for food, and that it was a delight to the eyes, and that the tree was to be desired to make one wise, she took of its fruit and ate; and she also gave some to her husband, who was with her, and he ate. Then the eyes of both were open and they knew that they were naked and they sewed fig leaves together and made loincloths for themselves. ${ }^{2}$
\end{abstract}

Should obesity be blamed on gluttony, sloth [sic] or both?

\subsection{Preamble}

Any study of gluttony, sloth, and the moral dimensions of obesity discourse must begin with the original sin of Adam. Adam and Eve's sin of gluttony ${ }^{4}$ led to the Fall from Eden, a new knowledge of sin, and an acute awareness the frailty of the body. Some millennia following the Fall, obesity research ${ }^{5}$ and policy ${ }^{6}$ are still telling us to be ashamed of the unrestrained desire of the body and the sins of gluttony and sloth. Indeed, the very terms gluttony and sloth are still used to describe obese bodies as, literally, being in the grips of a very deadly sin.

My original thesis question, the title for this chapter, asked why modern commentators ascribe obesity to the sins of Gluttony and Sloth. In the process of my research, the association between sin language and obesity discourse became a sub-question rather than the driving question. I found that sin language was applied by researchers, policy makers and politicians to obesity discourse for ideological reasons and that the use of such language is related to perceived behavioural failings on the part of the obese. Moreover, I discovered that this indicated that obesity discourse had other moral and ideological dimensions, which were not identified or clearly classified by researchers. The dissertation's driving question became: What are the moral and political dimensions of 'official obesity discourse?'

This chapter explains why the primary dissertation question changed and how my answer to this revised question fills gaps in our knowledge about obesity discourse. Indeed, the matter of gaps and omissions in obesity discourse is central to my research given the sudden disappearance of obesity from New Zealand health discourse in 2008. Despite insisting for ten

\footnotetext{
${ }^{1}$ An earlier version of this chapter was published as: W. Hoverd, "Deadly Sin, Gluttony, Obesity and Health policy," in Medicine, Religion and the Body, ed Elizabeth Burns Coleman and Kevin White, International Studies in Religion and Society, (Leiden: Brill, 2010).

${ }^{2}$ Genesis 3:4-3:7. All biblical quotations are from the New Revised Standard Version (New York: American Bible Society, 1991)

${ }^{3}$ House of Commons, Health Committee Report on Obesity: Third Report of Session 2003-04, Vol 1, 23.

${ }^{4}$ In the deadly sin schema of John Cassian (360CE - 430CE) gluttony is the primary sin that produces the other deadly sins. See J. Cassian,

The Conferences, (New York: The Newman Press, 1997), 183.

${ }^{5}$ Andrew Prentice and Susan Jebb, “Obesity in Britain, Gluttony or Sloth?” British Medical Journal;311(12 August 1995): 437.

${ }^{6}$ House of Commons, Health Committee Report.
} 
years that our nation was in the grips of an 'obesity epidemic,' the Government suddenly omitted any mention of obesity from its health discourse. This abrupt change generated a number of pressing questions: Did the 'obesity epidemic' go away overnight? Did it ever exist at all? Or was it an ideological tool used to justify certain types of Governmental policy approaches and understandings of citizens?

To answer the revised question, I claim that all official obesity discourse is ideological. This relationship is predicated on the notion that discourse can contain within it several conflicting ideologies. ${ }^{7}$ The term ideology is used here to convey the contesting medical and political positions which I demonstrate exist within official obesity discourse. I show that official obesity discourse contains a contestation of power relations and hierarchies, concerned with political dominance, responsibility, economics and scientific understandings of the aetiology of disease.

In Part One of this dissertation I map the overall range of ideology at work in obesity discourse onto a schema of three models of obesity causality. Part One closely analyses the evolution of official obesity discourse to illustrate that this entire discourse, and even the notion of an 'obesity epidemic', are politically contested notions. I show that the power relations within obesity discourse are divided into these three models, which roughly coincide with the ideological interests of the political parties which constituted New Zealand Governments between the years 1997 and 2010. These three models correspond to the policies of certain Governments, health policy, and medical understandings of obesity causality which exist within this research period. Thus, when I use the terms ideology or ideological within the dissertation I refer to the political positions and corresponding obesity causality models which I develop and identify in chapters Two - Four.

Chapter Two defines the Behavioural Causality Model (BCM), Chapter Three defines the Multiple Causality Model (MCM), and Chapter Four defines the Environmental Causality Model (ECM). Each of the causality models developed in Chapters Two, Three and Four represents a particular ideological position I find within official obesity discourse. These models are then later used as conceptual and heuristic tools to explain, in later chapters, the moral and social problems that exist within official obesity discourse.

\footnotetext{
${ }^{7}$ Terry Eagleton, An Introduction to Ideology, (London, Verso Press 1991), 194.
} 
My obesity causality models are developed through a chronological and systematic analysis of official obesity discourse. The chronological study begins in 1997 when the 'obesity epidemic' was first argued to exist, using quantitative population survey data. The purpose of the chronological study is twofold. First, it traces the history of official obesity discourse which allows the thesis to show how official obesity discourse has been constructed and reconstructed between the period 1997 and 2010. Second, it allows each chapter, somewhat artificially, to isolate the particular ideological dimensions of official obesity discourse represented by each of the three causality models.

Thus in each of these three chapters I show how as new medical understandings of obesity causality were developed they merged with the dominant ideological views of the governments of the period forming a particular obesity causality model. Thus each of chapters Two - Four show the dimensions of a particular obesity causality model when it was at its most politically dominant. These models are a unique contribution to the way in which the language of 'obesity epidemic' has been considered by the academy. It is important to note here that the dominance of one model did not mean the elimination of the others and I illustrate this coexistence of the three models in Chapter Five.

In my analysis of the 2008 New Zealand general election in Chapter Five, I argue that these obesity models are all still present within official obesity discourse. This then allows the obesity models to be used as heuristic models to explain the ideological dimensions of contemporary official obesity discourse. Various positions in official obesity discourse can thus be mapped across a dynamic 'political spectrum of obesity causation models.' Chapter Five shows how the models conflict with each other within both the general election and in criticisms of the National government's health policy between 2009 and 2010.

The obesity causality models and the understanding of official obesity discourse as ideologically divided allows the thesis, in Part Two, to expand its discussion to show how morality, power, truth, and oppression exist together within official obesity discourse and how the political spectrum of obesity causation models scapegoats the obese and victimises certain economic and ethnic sectors of New Zealand's society.

In Part Two, I undertake thematic critiques of the three obesity models outlined in Part One. In Chapter Six, I show how each of these ideological understandings of causality contains 
within it a morality used to scapegoat the obese. In Chapter Seven, I analyse the economic dimensions of the obesity models and argue that the models discriminate against people on low income. My study of this discrimination is important because I show that those in the most socially deprived groups have higher rates of obesity than other socio-economic groups. In Chapter Eight, I highlight the ethnic dimensions of obesity, which are neglected by the obesity models. I show how generalised measurements of obesity and the moral dimensions of obesity discourse fail to note that the majority of New Zealand's obese come from the Maori and Pacific Island ethnic groups.

In Chapter Nine, I argue that my study of the moral politics of 'official obesity discourse' shows that we need a more nuanced model to understand all the ideological and moral dimensions. I conclude the dissertation by drawing together the findings of Chapters OneEight to outline my 'Model of the Moral Politics of Official Obesity Discourse.'

This dissertation maps the moral politics of all New Zealand 'official obesity discourse' through a research period covering the years 1997 to 2009. I define 'official obesity discourse' as including every document and discussion of obesity produced by the Ministry of Health, $(\mathrm{MOH})$, the New Zealand Medical Journal (NZMJ), politicians, political parties, national nutrition surveys and other the significant pieces of international research or policy produced in the research period. Official obesity discourse also extends, although not systematically, to the World Health Organisation (WHO) and lobby groups such as Fight Against the Obesity Epidemic, The Obesity Action Coalition, and the Food and Beverage Industry.

My definition of official obesity discourse is tied to the actions of the State. In particular, I refer to the Ministry of Health, the political parties and individuals that constituted specific Governments, and New Zealand's medical and political experts who produced, collected and disseminated axiomatic knowledge about population health both in their official documents, statements, and in other circumstances where they were more candid about their views on obesity. This allows the thesis to review the locations of governance which holds the power to influence and disseminate official obesity discourse.

I stress that there is a relationship which exists between official obesity discourse and ideology. Thus, I use the term ideology, within the dissertation, to counter any possible assumption that 
official obesity discourse is scientifically positivistic or that Governments employ politically neutral health policies to identify and treat potential threats to the health of the nation.

I use the term 'official' to indicate that the institutions and experts who dictate and influence health and obesity policy are the producers of this discourse. As such, I do not systematically engage with or critique health practitioners, the obese themselves, Fat Studies, media reports, and popular culture interpretations of obesity.

The sphere of influence of official obesity discourse does have limits and should not be confused with popular discourses about weightloss and/or obesity causality. Official obesity discourse should be understood to be the language of the institutions and experts that dispense health policy and care to the population. The general population, which I do not study here, holds its own understandings of obesity causality. The general population will draw its own views from a number of areas in addition to that provided by official obesity discourse; these will likely include various forms of media, myths and cultural traditions. Thus, the sphere of influence for official obesity discussed in this thesis will be limited to the power structures of health research, health politics and the services offered by hospitals and other health providers.

I use the term 'obesity' rather than 'fat' or 'fatness' because it is the term used by official discourses. Due to the basic premise of the thesis that 'discourse' is ideologically contested, I reject the idea of a unitary obesity discourse as a misnomer. I use the term 'obesity epidemic' in a qualified manner because, as I demonstrate in Chapter Five, that this term is politically contested. Finally, I use the term 'inequality' to describe the negative consequences associated with poor health and low income.

Before I shift to discussing the research further I want to qualify my research position. I am a Religious Studies scholar conducting an investigation into the moral dimensions of official obesity discourse. Consequently, apart from my own fatness, I am an outsider when it comes to conducting this research. As an outsider, I am fortunate not to be bound by the disciplinary restrictions of medical researchers, historians, medical sociologists, or Fat Studies scholars. However, as a Religious Studies scholar I possess the interdisciplinary capability and advantage to trace and explain the usage of sin language within modern culture and across widely different groups. I hope that my fresh viewpoint on this modern problem will counterbalance 
any particular disciplinary conventions I might have inadvertently violated in my approach to this subject area.

\subsection{Introduction}

The preamble provided an outline of the thesis while this section introduces the particular content of this chapter. This chapter explains how and why I came to write a thesis on the moral politics of obesity discourse. I begin with my original research question and then situate my study as a unique and systematic contribution to the research investigating the moral politics of obesity through a series of literature reviews. As I examine literature from Religious Studies and Fat Studies, I show how these fields have shaped my research into its current form. I conclude with a discussion of the research methodology and a thesis outline.

\subsection{The Original Research Question}

My original research question asked why obesity is ascribed to the sins of gluttony and sloth. I first came to this question through my earlier research into gymnasiums and their promise of bodily and spiritual transformation and salvation for their members. ${ }^{8} \mathrm{I}$ became interested in how and why gym members, and the industry more broadly, portrayed the obese as sinners or immoral. This early research led to a subsequent investigation into whether or not an implicit relationship existed between Christian moral discourse and the modern body. ${ }^{9}$ The results of that collaborative research indicated that when people made cognitive claims about obesity, they preferred to utilise discourse derived from Christianity to claim that it was immoral. ${ }^{10}$ However, the results of this research showed only that this preference existed, but could not explain why.

In searching for further examples of the relationship between the modern body and sin language, I discovered that both medical research and health policy linked gluttony, sloth, and obesity together in a number of cases. In 1995, the British Medical Journal published an article by Andrew Prentice and Susan Jebb entitled 'Obesity in Britain: Gluttony or Sloth? ${ }^{11}$ Utilising a wide literature review, Prentice and Jebb begin by disputing the metabolic genetic causality conditions of obesity, stating that the causal factors of obesity can either be understood as

\footnotetext{
${ }^{8}$ W. Hoverd, Working Out My Salvation: The Contemporary Gymnasium and the Promise of 'Self' Transformation (Aachen: Meyer and Meyer Sport, 2005).

${ }^{9}$ William Hoverd and Chris Sibley, "Immoral Bodies: The Implicit Association between Moral Discourse and the Body," Journal for the Scientific Study of Religion, 46 no 3, (2007): 391-403.

${ }^{10}$ Ibid., 402

${ }^{11}$ Prentice and Jebb, "Gluttony or Sloth?"
} 
gluttony or sloth or a combination of the two. ${ }^{12}$ They conclude by arguing that it is sloth, associated with sedentary lifestyles, which is slightly more of a causal factor than gluttony. The Prentice and Jebb article simplistically associates the language of deadly sin with the causal factors of obesity without critical awareness of the wider implications that the obese were immoral. Moreover, this paper has been cited more than eight hundred times in the late 1990s and 2000s medical research, obesity research, health policy and critical obesity scholarship.

Notably, the Prentice and Jebb article influenced the 'House of Commons Health Committee Report on Obesity: Third Report of Session 2003-04 Vol 1' (HOC). ${ }^{13}$ Under the title 'Gluttony or Sloth?' the document examines the causes of obesity in Britain. This section of the HOC report is almost solely reliant upon Prentice and Jebb. The HOC report uses Prentice and Jebb's original phrase, but places the terms 'gluttony' and 'sloth' in bold in its title. The report authors do not note this additional emphasis and the manipulation of the original text. However, this emphasis further stresses the association between the language of sin and the causal factors of obesity. There appears to be no awareness that the language reinforces a connection between moral fault and obesity. It is an odd disjunction that the HOC report, which one would assume to be objective, highlighted sin language to describe obesity causality. Other British, ${ }^{14}$ American, ${ }^{15}$ and Australian ${ }^{16}$ examples also link this language of sin and moral fault with obesity.

Other researchers have noted this language association. Professor Stephen O’Rahilly, a geneticist at the University of Cambridge was concerned about the HOC report's language, arguing that it vilified sick people and implied that obese individuals are a product of their own faults. ${ }^{17}$ He points out that this discourse of fault would be unthinkable in application to other illnesses such as cancer. O'Rahilly argues that the HOC report demonstrates that blaming people for obesity is publically and politically permissible.

The lack of acknowledgement of the moral dimensions or religious connotations of the terms 'gluttony' and 'sloth' presented an intriguing research problem as I began this study. The

\footnotetext{
${ }^{12}$ Ibid.

${ }^{13}$ House of Commons, Health Committee Report.,

${ }^{14}$ Iain Stewart and Romesh Vaitilingam, Seven Deadly Sins: A New Look at Society Through An Old Lens (Swindon: Economic and Social Research Council, June 2005).

${ }^{15}$ Charles Clark Jr, "Combating Sloth as Well as Gluttony: The Role of Physical Fitness in Mortality Among Men With Type 2 Diabetes." Annals of Internal Medicine, 132, no 8 (2000).

${ }^{16}$ Jane Dixon and Dorothy Broom, The Seven Deadly Sins of Obesity: How the Modern World is Making Us Fat (Sydney: University of New South Wales Press, 2007).

${ }^{17}$ Vivian Perry, “Bottom Line on Obesity," The Guardian Unlimited Newspaper, (Thursday June 17 $\left.7^{\text {th }} 2004\right)$.
} 
deadly sin language ascribed to obesity causality implied moral fault and it appeared fertile ground upon which to base my research. Consequently, Prentice and Jebb's article formed the departure point for my research to investigate the original research question.

\subsubsection{Religious Studies Literature Reviews}

I began the dissertation research by conducting a series of Religious Studies literature reviews. Such research, however, demonstrated the need to shift the immediate scholarly context of the dissertation away from Religious Studies. Each review indicated that I needed to situate and answer the research question directly within a context of 'official obesity discourse.' The need for this shift will become evident as I consider existing Religious Studies scholarship exploring the intersections between the body, sin, and morality. In each of the following subsections, I investigate five different approaches to such questions, moving through 1. Sociology of the Body Literature; 2. A History of the Seven Deadly Sins; 3. Christianity and the Body; The Problem of Context; 4. Christianity, Sport, Anorexia and Devotional Dieting; 5. Obesity Prevalence and Religious Identification.

\subsubsection{Sociology of the Body Literature}

The $1980 \mathrm{~s}^{18}$ saw a wave of sociological interest in the body. This literature demonstrates the strangeness of the turn to religious language to describe obesity causality. Sociological research on the body, such as that inspired by Michel Foucault and Bryan Turner demonstrated that medical authority moved to employ methods of observation that utilised empirical language and methods of describing disease some 400 years ago. The sociology of the body argues that in the $16^{\text {th }}$ and $17^{\text {th }}$ centuries, doctors replaced priests as the experts who managed the authority of the body. ${ }^{19}$ Health ceased to be described in terms of sin and was described in terms of sickness. ${ }^{20}$ The medical establishment thereby also became responsible for pastoral care, but through ensuring the this-worldly salvation of healthy populations rather than the other-worldly salvation of souls. ${ }^{21}$ This change in authority for governing bodies saw the language used to describe the body move away from sin language to the objective, empirical medical language used today. ${ }^{22}$ The fact that sin language has re-emerged in discussions of obesity causality despite this shift to objective medical authority demonstrates the necessity of a study assessing why medical language was employing religious terminology.

\footnotetext{
${ }^{18}$ B. Turner, The Body and Society: Explorations in Social Theory, Second Edition (London, Sage Publications, 2004).

${ }^{19}$ M. Foucault, The Birth of the Clinic: An Archaeology of Medical Perception, (London: Routledge, 1997).

${ }^{20}$ B. Turner, Medical Power and Social Knowledge, (London: Sage Publications: 1987), 37.

${ }^{21}$ M. Foucault, Power: Essential Works of Foucault 1954-1984, Volume 3 (London: Penguin Books, 2000), 333.

${ }^{22}$ It is relevant to note this language change coincided roughly with the historical diminishment of the Deadly Sins.
} 


\subsubsection{The History of the Deadly Sins}

At first glance, it appeared that a history of the deadly sins would be useful to illuminate the original research question. Thus, I looked to the ancient contexts of these concepts to investigate why obesity discourse was linked to the Christian tradition of $\sin .{ }^{23}$ I found that two distinct Deadly Sin literatures exist: first, analyses of the Deadly Sin history; second, nonanalytical pop psychological applications of the Deadly Sin schema to the discussion of modern social problems. ${ }^{24}$ At this point, however, I encountered several practical problems with this research approach. The Seven Deadly sins were not an immutable concept and are no longer central to the Christian tradition. As a result, this section explains why these modern usages of deadly sin language are not directly related to Christian theology and, in turn, why the dissertation required broader explanations to analyse the operations of 'gluttony' and 'sloth' in obesity discourse.

The ancient history of the Seven Deadly Sins, or logismoi ${ }^{25}$, is non-biblical, as they originate from eastern traditions older than Christianity. ${ }^{26}$ An eightfold sin schema entered the Christian tradition in the ascetic work of Evagrius Ponticus ${ }^{27}$ and was then altered to a Sevenfold schema in the monastic tradition through the works of John Cassian ${ }^{28}$ and Gregory the Great. ${ }^{29}$ Subsequently, the Fourth Lateran Council incorporated Pope Gregory the Great's Seven Deadly Sin schema into lay Catholic confessional practice in $1215^{30}$. This final shift remains the order of sins we are familiar with today. In the late Middle Ages, the Seven Deadly Sins were used in communal public teachings and moral teaching materials ${ }^{31}$ to popularise the moral systems of Catholic Christianity to the laity. ${ }^{32}$ They were also used in annual public confessional practice. However, because the deadly sins had no direct link to God or direct scriptural authority, they were increasingly supplemented with the teaching of the Decalogue ${ }^{33}$ in the period $1215-1517 .^{34}$

\footnotetext{
${ }^{23}$ Hoverd, "Deadly Sin," 205.

${ }^{24}$ For typical examples see: H. Farlie, The Seven Deadly Sins Today, (Washington: New Republic Books, 1978); A. Macguire, Seven Deadly Sins: The Dark Companions of the Soul (London: Free Association Books, 2004). For a more analytical example see: S. Schimmel, The Seven Deadly Sins, Jewish, Christian and Classical Reflections on Human Psychology (New York: Oxford University Press, 1997)

${ }^{25}$ Evil thoughts

${ }^{26}$ M. Bloomfield, The Seven Deadly Sins. An Introduction to the History of a Religious Concept with Special Reference to English Literature (Michigan: Michigan State University Press, 1967), 72.

${ }^{27}$ E. Ponticus, The Praktikos: Chapters on Prayer, Translated by J. E. Bamberger (Michigan: Cistercian Publications, 1981), 20-26.

${ }^{28}$ Cassian, The Conferences, 19.

${ }^{29}$ Bloomfield, The Seven Deadly Sins, 91.

${ }^{30}$ Ibid., 91.

${ }^{31}$ See: M. Haren, Sin and Society in Fourteenth-Century England. A Study of the Memoriale Presbiterorum (Oxford: Clarendon Press, 2000), 67; Joanne Norman, "Lay Patronage and the Popular Iconography of the Seven Deadly Sins," in ed Fisher, Carol Garrett, and Kathleen L. Scott, Art into Life: Collected Papers from the Kresge Art Museum Medieval Symposia (East Lansing: Michigan State University Press, 1995$), 214$. ${ }^{32}$ D. Myers, Poor Sinning Folk: Confession and Conscience in Counter-Reformation Germany (Ithaca: Cornell University Press, 1996$), 38$.

${ }^{33}$ The Ten Commandments

${ }^{34}$ John Bossy, "Moral Arithmetic: Seven Sins into Ten Commandments," in Conscience and Casuistry in Early Modern Europe, ed. Edmund Lietes (Cambridge: Cambridge University Press, 1988), 215.
} 
One consequence of the Protestant Reformation and the Catholic Counter Reformation was that the deadly sins slipped out of direct Christian teaching. Martin Luther's attack on the Catholic Church involved a critique of confessional practice and the use of non-scriptural religious teachings. ${ }^{35}$ In response to these criticisms, reformers in both the Protestant and Catholic traditions began to emphasise the teachings of the Decalogue. ${ }^{36}$ In Protestant communities, the decline of the practice of confession, a Biblical scriptural concentration, and the toning down of Church imagery led to the decline in the relevance of the 'Seven Cardinal Sins. ${ }^{37}$ While the 'Sins' became increasingly irrelevant in Protestant communities, they were never entirely eliminated, as they were firmly ensconced in other areas of life, including traditional practices, literature, and moral teachings. For the Catholic Church, the 'Seven Cardinal Sins,' as they had become, still constituted mortal sins which sinners were required to acknowledge in the privacy of the confessional, but not necessarily explicitly in public. ${ }^{38}$ The sins became incorporated into long lists of other mortal and venial sins for private confessional purposes.

After the $16^{\text {th }}$ century, public expressions and discussions of the 'Seven Deadly Sins' still remained in popular literature ${ }^{39}$ and some moral handbooks, but they tended to become increasingly imaginative and divorced from their religious origins. In the $20^{\text {th }}$ century, the Deadly Sin schema has proved popular for lay psychology books (referred to as pop-psychology) discussing contemporary moral problems, but there is little to indicate that these modern applications have any link to Christian tradition. Much of the modern Deadly Sin literature is either incoherent ${ }^{40}$ or is concerned with emotions and behaviours. ${ }^{41}$ The one thing which these modern interpretations of the Deadly Sin schema agree upon is that the sins remain useful for understanding morality today. ${ }^{42}$ Soloman Schimmel wrote in relation to the Deadly Sin schema that these older moralities remain useful for understanding why humans perpetrate bad behaviour. He argued that modern scientific determinism needs to acknowledge these

\footnotetext{
${ }^{35}$ Myers, Poor Sinning Folk, 69.

${ }^{36}$ Bossy, Moral Arithmetic, 217.

${ }^{37}$ Ibid., 228.

${ }^{38}$ Myers, Poor Sinning Folk, 110.

${ }^{39}$ See G. Chaucer, The Canterbury Tales (London: Arnold, 1980); D. Alighieri, Dante's Inferno: The Vision of Hell (London: Cassell and Company, 1892).

${ }^{40}$ M. Fox, Sins of the Spirit, Blessings of the Flesh: Lessons for Transforming Evil in Soul and Society (New York: Three Rivers Press, 1999)

${ }^{41}$ See: S. Lyman, The Seven Deadly Sins: Society and Evil (New York: St Martins Press, 1978); R. Soloman, Wicked Pleasures: Meditations on the

Seven "Deadly" Sins (Maryland: Rowman and Littlefield Publishers, 1999); G. Taylor, Deadly Vices (New York: Oxford University Press, 2006).

${ }^{42}$ Schimmel, The Seven Deadly Sins, 244.
} 
traditions once more in order to gain further insights that can direct empirical study of behaviour. ${ }^{43}$

This history shows that it would be unwise to apply the Christian tradition's use of the Seven Deadly Sins to modern obesity discourse because these concepts fell out of direct use some four hundred years ago. In the modern era, the deadly sins have been decoupled from their religious tradition. They now form a publically available schema from which people can make unsystematic moralised statements about people's behaviour, for example, by implying that gluttony and sloth are bad, immoral, or evil. Thus, in order to answer my research question I have turned to alternative explanations for the association of sin language with obesity discourse.

\subsubsection{Christianity and the Body: The Problem of Context}

In an attempt to find a broader framework to answer the original research question I reviewed a series of studies of the relationship between Christianity and the body. From the late 1980s, Religious Studies scholars, drawing upon Turner and Foucault, began to investigate the Christian relationship with the body ${ }^{44}$ and combined this approach with studies of faith communities. I found, however, this literature did not provide a framework to answer the original question, but it did provide the important lesson that it would be necessary to confine religious or moral studies of the body and bodily practices within their specific context and milieu.

The definitive work in the historical literature remains Peter Brown's research into sexual renunciation in ancient Christianity. ${ }^{45}$ Brown's study of concupiscence showed the ancient Christian preference for understanding the flesh as the root of desire, understood as sinful, which must be governed by the human will. ${ }^{46}$ Brown's work emphasises how fasting was understood as one virtuous way to undo the sin of Adam which was the sin of gluttony. ${ }^{47}$ Brown's work established how in the ancient Christian tradition the body was understood as a site of danger and that food was a powerful spiritual tool for controlling this body.

\footnotetext{
${ }^{43}$ Ibid., 244

${ }^{44}$ See S. Coakley, Religion and the Body (Cambridge: Cambridge University Press, 1997).

${ }^{45}$ P. Brown, The Body and Society: Men, Women, and Sexual Renunciation in Early Christianity (New York: Columbia University Press, 1988)

${ }^{46}$ Ibid., 434 .

${ }^{47}$ Ibid., 220
} 
One could argue naively, after reading Brown's work, that the ancient understanding of Christian bodies has been a constant concern throughout history through to today. However, Caroline Walker Bynum's peerless work on the religious significance of food to medieval women suggests an alternative reading. Walker Bynum stresses the importance of studying religious phenomena within their context: ${ }^{48}$ "The practices and symbols of any culture are so embedded in that culture as to be inseparable from it." ${ }^{\not 49}$ Walker Bynum observes that specific studies need to be located in the milieu in which they are created, and as an example, urges that modern studies of anorexia should not be "wrenched from the modern context and applied to the fourteenth and fifteenth centuries. ${ }^{~}{ }^{50}$ Walker Bynum warns that studying the body within its context is essential and thus it would be a mistake to infer that modern obesity language is repeating a Christian tradition which could be traced back to medieval women saints and ancient concerns with concupiscence.

This left me with the problem of explaining why sin language is being applied to the problem of the body in my modern context. This is a general problem for all Religious Studies approaches to studying modern bodies. Sarah Coakley has argued that the post-modern study of religion and the Western body has become elusive and infinitely problematised.$^{51}$ She further noted that there is tension between cultural specificity and what she calls a "lurking religiosity of our present 'bodily' interests." 52 Similar to Walker Bynum, Coakley emphasises that the study of religion and the body must be located and embedded in a specific context. ${ }^{53}$ The recommendations of Walker Bynum and Coakley confirmed that I must situate my investigation of the application of deadly sin language within a contextualised and systematic case study.

\subsubsection{Christianity, Sport, Anorexia and Devotional Dieting}

In contextualising my research question in contemporary Western society, I turned to address modern Christian relationships with exercise, fitness, and the body. Modern Christian dieting discourse provides strong case studies which demonstrate that these communities use sin language to describe the negative dimensions of slimming, ${ }^{54}$ anorexia, ${ }^{55}$ sport, ${ }^{56}$ and body

\footnotetext{
${ }^{48}$ C. Walker Bynum, The Religious Significance of Food to Medieval Women (California: University of California Press, 1988), 299.

${ }^{49}$ Ibid., 299.

${ }^{50}$ Ibid., 299.

${ }^{51}$ Coakley, Religion and the Body, 3.

${ }^{52}$ Ibid., 6.

${ }^{53}$ Ibid., 8 .

${ }^{54}$ M. Lelwica, Starving for Salvation: The Spiritual Dimensions of Eating Problems Among American Girls and Women (New York: Oxford University Press, 1999).

${ }^{55}$ R. Bell, Holy Anorexia (Chicago: The University of Chicago Press, 1985).
} 
fitness. ${ }^{57}$ Scholars have yet to directly address the strong aversion to fatness that appears within this literature. I find this absence curious because fatness is the body type against which each of these studies of bodily perfectionism are constructed. The fact that fatness is a problem for modern Christians is usually discussed in terms of ideal body types which are antithetical to obese bodies, such as the body types of athletes or anorexics.

The place where modern Christian aversions to fatness are most obvious is in studies of Christian dieting. Since the $19^{\text {th }}$ century there are many examples of Christian dieting writers actively campaigning against fatness. ${ }^{58}$ In a study of related mentalities, Griffiths focuses on 'devotional dieters', whom she defines as individuals who believe that the fitness and condition of the body is directly related to Christian worship. Griffiths provides an analysis of a particularly poignant example of modern Christian aversions to fatness in the claim of evangelist Gwen Shamblin, who controversially proclaimed that "Fat People don't go to heaven." ${ }^{59}$ Shamblin portrayed the obese as so sinful that they were not worthy of salvation. This reinterpretation of gluttony and sloth shows that for some Christian dieters, any usage of the terms gluttony and sloth are not metaphors - they are very real indicators of physical grace.

Modern Christian research did not offer a clear answer to my research question. The difficulty with these Christian dieters is that they are making faith-based claims which still do not have a direct context applicable to the supposedly objective 'official obesity discourse.' This modern literature further contributed to the need for a broader interpretative framework to address the question of why deadly sins are ascribed to obesity.

\subsubsection{Obesity Prevalence and Religious Identification}

A secondary Religious Studies literature consists of empirical investigations into potential relationships between obesity prevalence amongst religious individuals and communities. This literature appears to be unconsciously grappling with questions concerning whether a relationship exists between obesity causality and religious belief. This research into whether religious people are fatter or slimmer than non-religious people has, so far, produced mixed results.

\footnotetext{
${ }^{56}$ See: Michael Grimshaw, "I can't Believe My Eyes!!! The Religious Aesthetics of Sport as Postmodern Salvific Moments,” Implicit Religion, 3, no 2 (2000): 87-99; J, Parry, M Nesti, S Robinson, and N, Watson, Spirituality and Sport: An Introduction (London: Routledge, 2007).

${ }^{57}$ T. Ladd and J Mathieson, Muscular Christianity, Evangelical Protestants and the Development of American Sport (Grand Rapids: Baker Book House, 1999).

${ }^{58}$ See: F. Hunter, God's Answer to Fat...Loose it! (Houston: Hunter Ministries, 1976); M Chapian and N Coyle, Free to Be Slim, A Christian Approach to Losing Weight (Minneapolis: Bethany House Publishers, 1989).

${ }_{59}$ Quoted in M. Griffith, Flesh and Spirit in American Christianity: Born Again Bodies (California: University of California Press, 2004$), 2$.
} 
Karen Kim and Jeffery Sobal could not find a result in their investigation into the possible relationship between religious belief and body weight. However, this did not stop them from claiming that there is such a thing as a general religiosity, which encompasses theological teachings surrounding the 'body as a temple' that may affect health-related behaviours. ${ }^{60}$ In an earlier article, the same authors had claimed that religious theology may discourage obesity in believers. ${ }^{61}$ In 1999, Kenneth Ferraro found a positive correlation between religious practice and obesity, ${ }^{62}$ a correlation that Ferraro and Krista Cline found in further research in $2006 .{ }^{63}$ However, work such as that by Lee Ellis and David Biglione ${ }^{64}$ has failed to find any relationship between Christian belief and body weight. A more recent study showed that "at least for Korean Women, religion may help prevent obesity via religious based social mechanisms.” ${ }^{65}$

In sum, these quantative studies have produced contradictory results. It appears that these researchers want to search for a potential relationship between Christian ideas and obesity, but have not made concrete correlations between obesity prevalence and religious belief. These studies informed my own research question by demonstrating that other scholars also were having difficulties making concrete observations about the relationship between religious belief and obesity prevalence.

\subsubsection{Lessons from the Literature Reviews}

These reviews provided me with a series of lessons from which I concluded that these sets of literature did not offer a concrete set of theoretical models upon which to investigate my thesis question.

The Sociology of the Body's explanation of how medicine took authority for the body from the Christian Church in the $16^{\text {th }}$ century allowed me to argue that it was an odd disjunction that the supposedly objective discourse of medicine was utilising Sin language to describe obesity causality. I could not locate a connection between today's usage of this sin language and the Christian tradition of the Seven Deadly Sins. I found that the Seven Deadly Sins fell out of

\footnotetext{
${ }^{60}$ Karen Kim and Jeffery Sobal, "Religion, Social Support, Fat Intake and Physical Activity," Public Health Nutrition 7, no 6 (2004): 773.

${ }^{61}$ Karen Kim, Jeffery Sobal and E Wethington, "Religion and Body Weight," International Journal of Obesity 27, (2003): 469.

${ }^{62}$ Kenneth Ferraro, "Firm Believers? Religion, Body Weight, and Well Being," Review of Religious Research 39, no 3 (1998): 225.

${ }^{63}$ Krista Cline and Kenneth Ferraro, "Does Religion Increase the Prevalence and Incidence of Obesity in Adulthood?" Journal for the Scientific Study of Religion 45, no 2 (2006): 278.

${ }^{64}$ Lee Ellis and David Biglione, "Religiosity and Obesity: are Overweight People More Religious?” Personality and Individual Differences 28, (2000).

${ }^{65}$ John Ayers, Richard Hofstetter, Veronica Irvin, Yoonju Song, Hae Ryun Park, Hee-Yong Paik and Melbourne Hovell,

"Can Religion Help Prevent Obesity? Religious Messages and the Prevalence of Being Overweight or Obese Among Korean Women in California," Journal for the Scientific Study of Religion 48, no 3 (2010):536.
} 
common usage some 400 years ago and the main way that these sins were being employed today was as publically available schema from which it is possible to make unsystematic moralised statements about human behaviour.

The review of the historical Christian and Body literature showed that inferring a Christian tradition of sin from one historical context into a modern context would be a naïve treatment of the sin language application to obesity discourse. We saw that Walker Bynum argued that it was unproductive to apply modern understandings of anorexia to the fasting practices of medieval women. She argued these practices should be understood within their context. The same is true of applying notions of Deadly Sins to a modern context of obesity despite the temptation to infer that there is a direct transfer of meaning in these terms.

Because the reviews had stressed the importance of contextualising the study I briefly reviewed two modern Christian treatments of the body and fatness. This review showed that it is difficult to imagine that devotional Christian language is transferred to the language of medicine and health policy. Indeed, my case material did not provide strong evidence of Christian language being used in official obesity discourse which is why the content of the dissertation focuses specifically on the political and moral dimensions of official obesity discourse. Finally, I addressed the fact that researchers are looking to correlate religious identification with obesity prevalence. The lesson here was that other researchers were finding it problematic to develop evidence from which to voice their suspicions that there may be relationships between modern Christian understandings of the body and obesity.

Consequently, this thesis argues that one cannot treat the Christian tradition as a continuous globalised and seamless communicator of notions of value and the moral truth about the body, decoupled from the contextual variations of region, theology, and language. I find any claim that there is a Christian tradition of the body at play in contemporary body politics persuasive at only a superficial level and such an argument is potentially essentialist. Context and a systematic case study are necessary in order to make any claims about relationships between sin language and obesity discourse: to understand modern bodies as vehicles of morality in ways which are analogous to the Christian tradition but no longer directly related to it. For these reasons the dissertation content shifts away from focusing upon applying Christian theology, religion or views into the case material. As a result, discussions of Christianity are 
replaced by discussions of ideology in Part One and discussions of morality in Part Two. I explore these ideas in the following section.

\subsubsection{Critical Analyses of Scholarship on the 'Obesity Epidemic' and in Fat}

\section{Studies}

The previous section concluded that a case study was necessary to answer the dissertation question. With the lessons of the previous literature review in mind, I chose to undertake a systematic study of New Zealand's 'official obesity discourse' between the years 1997 and 2009. This choice of case study sent me to review the recent social science literature critiquing obesity language and policy.

The critical study of obesity is a relatively new area in the humanities. Until the 2000s, the study of 'fat' and 'obesity' was a small area of study broadly covered by the work of historians ${ }^{66}$ and third wave feminists. ${ }^{67}$ However, rising concerns with 'obesity' and the 'obesity epidemic' have produced two further types of critical work analysing this 'obesity discourse' and its effects. First, fatness and the ideological construction of the 'obesity epidemic' has become an area of interest for social scientists. Second, Fat Studies has emerged out of gender studies and deconstructionist theory as a radical advocacy for embodied fat rights, fat diversity, and fat acceptance. ${ }^{68}$ While undertaking these reviews I found a subset of the literature in these two fields was concerned with the moral dimensions of obesity discourse. It was in relation to this subset of literature that I was able to locate my research.

In this section I outline the two primary literatures before moving to discuss the subset of literature pertaining to the moral dimensions of obesity. Informed by the limitations of the earlier literature reviews, my goal was to locate the case study and research question in relation to these analyses of the moral dimensions of obesity discourse.

\footnotetext{
${ }^{66}$ H. Schwartz, Never Satisfied; A Cultural History of Diets, Fantasies and Fat. (New York, :Doubleday, 1986); P. Stearns, Fat History: Bodies and Beauty in the Modern West (New York: New York University Press, 1997); A. Scott Bellar, Fat and Thin: A Natural History of Obesity (New York: Farrar, Strauss and Giroux, 1997).

${ }^{67}$ S. Bordo, Unbearable Weight: Feminism, Western Culture, and the Body (California: University of California Press, 1993); S. Orbach, Fat is a Feminist Issue: How to Lose Weight Permanently Without Dieting (London: Arrow Books, 1978); N. Wolf, The Beauty Myth: How Images of Beauty Are Used Against Women (London: Vintage Books, 1991).

${ }^{68}$ Charlotte Cooper, "Fat Studies: Mapping the Field," 4/12, Sociology Compass (2010): 1020.
} 


\subsubsection{Critical Scholarship on the 'Obesity Epidemic'}

Several social scientists have recently subjected the language of the 'obesity epidemic' to close analysis. ${ }^{69}$ Lee Monaghan, Robert Hollands, and Gary Pritchard argue that the 'obesity epidemic' has been promoted by obesity entrepreneurs who have constructed and medicalised fatness as a social issue or crisis known as the 'obesity epidemic' ${ }^{70}$

[T] he construction of the obesity epidemic is a complex process which requires pulling together a range of theoretical concepts and empirical material into a classificatory typology in order to begin to illuminate and critique its various constituent parts ${ }^{71}$

This questioning of the veracity of the 'obesity epidemic' has been repeated by others. ${ }^{72}$ Roel Pieterman draws three conclusions about the 'obesity epidemic': 1. Medical science discussing obesity is flawed and contradictory; 2. There are potentially no methods for effectively controlling or reducing obesity; and 3. Obesity policy is used to produce and legitimise discriminatory practices. ${ }^{73}$ Recent work from Michael Gard considers that the 'end of the obesity epidemic ${ }^{, 74}$ might have already occurred.

These analyses of the 'obesity epidemic' provided useful tools with which to reconsider my original research question. I found that obesity discourse diffused agency over a whole range of fields, institutions, individuals - a dispersion of authority and agency that is problematic in itself. This meant that sin language was potentially being applied by medical researchers and policy makers in pursuit of a particular agenda. It also indicated that these obesity discourses are used by Governments to legitimately discriminate against the obese. This suggested that sin language might be being ascribed to obesity causality to discriminate against the obese.

Moreover, it appeared that there are contesting agendas at play in this obesity discourse. Sin language in this context is only one of several types of languages which are being employed to discriminate against the obese. Importantly, I also noted that these current analyses are missing robust and systematic national case studies and that this opened further space for my work to contribute to this type of literature.

\footnotetext{
${ }^{69}$ See: Lee Monaghan, Robert Hollands and Gary Pritchard, “Obesity Epidemic Entrepreneurs: Types, Practices and Interests,” Body and Society 16, no 37 (2010); Roel Pieterman, “The Construction of Fat: Care and Control in the Public Concern for Healthy Behaviour," Sociology Compass, 1, (2007); M. Gard and J Wright, The Obesity Epidemic: Science Morality and Ideology (New York: Routledge, 2005); M. Gard, The End of the Obesity Epidemic (New York: Routledge, 2011).

${ }^{70}$ Monaghan et al, "Obesity Epidemic Entrepreneurs," 38.

${ }^{71}$ Ibid., 38.

${ }^{72}$ See: S. Murray, The Fat Female Body (Basingstoke: Palgrave McMillan, 2008); Pieterman, "The Construction of Fat,” 310; P. Campos, The Obesity Myth, Why America's Obsession With Weight is Hazardous to Your Health (New York: Gotham Books, 2004).

${ }^{73}$ Pieterman, "The Construction of Fat," 310.

${ }^{74}$ Gard, The End of the Obesity Epidemic.
} 


\subsubsection{Fat Studies Scholarship}

'Fat Studies' is a critique of medicalised concepts of obesity. ${ }^{75}$ This emerging area of research is still defining itself and contains a series of viewpoints. Most scholars in this area are critical of the pathologising of fat bodies and question the social value of such labelling. This discipline also contains a strong activist strain of scholars who hold that there is social value in fat bodies. ${ }^{76}$ Kathleen Lebesco's Fat Studies scholarship urges that Fat activists start thinking about fat bodies as politically subversive and work to undermine hegemonic medical ideas about the dangers of fatness. ${ }^{77}$

It is, however, the non-activist strain of Fat Studies scholarship that is particularly valuable for my research. This approach assists my investigation because it opens room for arguments to contest the association between sin language and obesity. I am particularly interested in applying the idea that fat bodies can be subversive and applying it to discussions of inequality. In addition, I am concerned that there is a lack of reflective case studies underpinning this scholarship and that more detailed work needs to be conducted like that of Finnish researcher Hannelle Harjunen. Harjunen based her Fat Studies analysis upon data gained from within school environments ${ }^{78}$ and qualitative data including the writings of, and interviews with, Finnish women. ${ }^{79}$ This is the type of research I try to emulate.

Fat Studies discourse initially arose out of the United States, but there has recently been a call for non-American perspectives to be developed. ${ }^{80}$ Given the importance of context, I want to briefly touch on Fat Studies work occurring closer to New Zealand. Macquarie University's Samantha Murray has fought for a strong research presence for Fat Studies Australia. ${ }^{81}$ Murray is critical of the way dominant medical hegemonies construct bodies as normal or abnormal, arguing that such binary views miss the complexity of what it is to live as an embodied person in modern life. ${ }^{82}$ New Zealand-based Fat Studies critical work is nascent. Massey University has Fat Studies scholar Cat Pausé. ${ }^{83}$ Caroline Daley from Auckland University has worked on

\footnotetext{
${ }^{75}$ Charlotte Cooper, “Fat Studies," 1022.

${ }^{76}$ Ibid., 1022

${ }^{77}$ K. Lebesco, Revolting Bodies? The Struggle to Redefine Fat Identity (Boston: University of Massachusetts Press, 2004).

${ }^{78}$ Hannelle Harjunen, "The construction of an acceptable Female Body in Finnish Schools," in Gendered and Sexualised Violence in Educational Environments (eds) Vappu Sunari, Jenny Kangasvuo and Mervi Heikkinen (Oulu: Oulo University Press, 2003).

${ }^{79}$ Hannelle Harjunen, Women and Fat: Approaches to the Social Study of Fatness (Jyvaskyla: University of Jyvaskyla, 2009).

${ }^{80}$ Charlotte Cooper, "Maybe it should be called Fat American Studies," in The Fat Studies Reader, ed. Esther Rothblum and Sondra Solway (New York: New York University Press, 2009), 327.

${ }^{81}$ Samantha Murray, “(Un/Be) Coming Out? Rethinking Fat Politics,” Social Semiotics 15, no. 2 (2005): 153.

${ }^{82}$ Samantha Murray, "Corporeal Knowledges and Deviant Bodies: Perceiving the Fat Body,” Social Semiotics 17 no. 3 (July 2007$): 372$.

${ }^{83}$ C. Pausé, "Invisible women: Exploring weight identity in morbidly obese women," PhD dissertation, Texas Tech University, 2007.
} 
New Zealand body image. ${ }^{84}$ Sarah Shieff ${ }^{85}$ has produced work on deviance and women's bodies in literature. However, there is yet to be a comprehensive Fat Studies analysis set within a New Zealand context and my study begins to fill this gap.

My own work is informed by Fat Studies' detailed critique of obesity language, discrimination, and medical power. However, in the second half of this thesis, I take an approach inspired by questions about inequality which is a theoretical approach that has not been taken so far by Fat Scholars. I am particularly concerned about the correlation of obesity prevalence with inequality, and I worry that Fat Studies is, to some extent, an exclusive discourse that promotes a politics of radical individualism. In this dissertation, I show that New Right individualism and 'official obesity discourse' tends to ignore and even perpetuate social inequality. While it is outside the bounds of this thesis to explore this problem, I think that in the future Fat Studies must engage with the correlation between obesity prevalence and income and ethnic inequality in order to address these broader concerns.

\subsubsection{The Moral Dimensions of Social Scientific Investigations into Obesity and}

\section{Fatness}

In addressing the critical scholarship on the 'obesity epidemic' and Fat Studies literature I found that I could locate my study in a subset of the literature in these two fields concerned with the moral dimensions of obesity discourse.

I first encountered the argument that there were moral dimensions of obesity discourse in an article written by Bethan Evans in an article entitled “'Gluttony or Sloth’: Critical Geographies of Bodies in (Anti) Obesity Policy." ${ }^{86}$ In her article, Evans analyses the language used in the House of Commons Report. Evans argues that understandings of obesity are contestable. She finds the House of Commons Report creates and reproduces certain moralities of obesity. Evans states: "A critical reading of the HOC report; reading for and highlighting the points at which it draws on and reproduces certain moralities regarding (fat) bodies; such as the notion of sin implicated in using the terms "Gluttony" and "Sloth" ${ }^{87}$ She elaborated on this concept, nothing that 'ideas about 'right' and 'wrong,' and the association of guilt with some practices are formed through and rooted in the discourse surrounding medical interpretations of

\footnotetext{
${ }^{84}$ C. Daley, Leisure and Pleasure: Reshaping and Revealing the New Zealand Body 1900-1960 (Auckland: Auckland University Press, 2003). ${ }^{85}$ Sarah Shieff, "Devouring Women, Corporeality and Autonomy in Fiction by Women since 1960," in Bodies Out of Bounds: Fatness and Transgression, ed. Jana Braziel and Kathleen Lebesco (California: University of California Press, 2001).

${ }^{86}$ Bethan Evans, “Gluttony or Sloth': Critical Geographies of Bodies and Morality in (Anti) Obesity Policy,” Area 38, no.3 (2006): 261. ${ }^{87}$ Ibid., 261.
} 
obesity". ${ }^{88}$ Evans argued that the power of this language of health categories justifies and constructs social frameworks in which individuals are to constitute themselves in hierarchies of right and wrong as fat/thin, rich/poor, and morally good/bad. Evan's work allows me to revise my approach. The application of deadly Sin language to obesity causality allows me to think about my research question as offering a window into moral dimensions of obesity discourse.

An analysis of the moral dimensions of obesity discourse had been undertaken by New Zealander Annemarie Jutel in an article entitled 'Weighing Health: The Moral Burden of Obesity". ${ }^{89}$ Jutel $^{90}$ attempted to trace a moral connection between historical Christian practices and contemporary discrimination against the obese. She claimed that the contemporary fixation with body fat has historical precedents. She argued that bodily appearance and how it is viewed has long been understood as the primary indicator of individual purity. She suggests that beauty and Christian understandings of truth and, in the case of women, were equivocated with moral goodness. Thus, individuals who are ugly are understood to have some sort of moral deficiency. Jutel's argument here is useful because it points to the existence of modern moral dimensions of official obesity discourse. However, I have already discussed the limitations of these types of comparisons.

In their study of obesity ideology and morality, Australians Jan Wright ${ }^{91}$ and Michael Gard ${ }^{92}$ usefully argue that “'obesity talk' has more to do with preconceived moral and ideological beliefs about fatness than a sober assessment of the existing evidence." ${ }^{93}$ They find that the 'obesity epidemic' is a modern-day story of gluttony and sloth "which we have not the selfdiscipline or moral fibre to resist." ${ }^{94}$ They are of the opinion that there is a particular morality of the 'obesity epidemic' "which sees [obesity] as a product of individual failing and weakness. ${ }^{~} 95$ Gard and Wright's description of this morality and its association with Gluttony and Sloth is tied to concerns about the behavioural causality of obesity. I agree with Gard and Wright that obesity discourse contains this morality. However, in my case study, the morality of gluttony and sloth occurs only explicitly in instances of this discourse concerned with

\footnotetext{
${ }^{88}$ Ibid., 262.

${ }^{89}$ Annemarie Jutel, "Doctors Orders: Diagnosis, Medical Authority, and the Exploitation of the Fat Body," in Biopolitics and the Obesity

Epidemic: Governing Bodies, ed. J. Wright and V Harwood (New York: Routledge, 2009).

${ }_{90}$ Annemarie Jutel, "Weighing Health: The Moral Burden of Obesity," Social Semiotics, 15, no 2 (2005) 113-125.

${ }^{91} \mathrm{~J}$. Wright and V. Harwood, ed., Biopolitics and 'The Obesity Epidemic': Governing Bodies (New York: Routledge, 2009).

${ }^{92}$ Gard and Wright, The Obesity Epidemic.

${ }^{93}$ Ibid., 3.

${ }^{94}$ Ibid., 6-7.

${ }^{95}$ Ibid., 7.
} 
behaviour. This morality is almost completely decoupled from the Christian tradition except in that, as we saw earlier, the Christian tradition was concerned with disciplining the unruly desire of the body. The problem with Gard and Wright's work is that they appear to assume that there is a singular morality associated with obesity discourse. As we saw in the critical scholarship on the 'obesity epidemic', it is apparent that there are contesting moralities at work in obesity discourse. From my review of this secondary literature, it is clear there is a need for a more informed approach to the moral dimensions of obesity discourse.

\subsubsection{Critical Literature Summary}

In my review of the emerging critical scholarship on the 'obesity epidemic' and Fat Studies I found that both literatures used the term 'morality' to explain discrimination against the obese. I found that scholarly explanations of this morality were tied directly into the Christian tradition or assumed that morality was a unitary concept. This gave the conceptual tools to situate my study as an investigation into the moral dimensions of obesity discourse. Moreover, because this sub-section of the literature still inadequately addresses the question of morality it situates my study as a unique and systematic contribution to the research investigating the moral dimensions of obesity.

\subsection{Situating My Research as an Investigation into the Moral Politics of Obesity}

\section{Discourse}

I argue that an analysis of the application of sin language to obesity discourse indicates that there are several moral and ideological views at work within 'official obesity discourse.' Gard and Wright offer the analysis that obesity morality is tied to ideology and, as such, their work will serve to help me draw out the moral dimensions of obesity discourse. Thus, a study of the moral dimensions of obesity discourse will also highlight its ideological dimensions.

Consequently, the dissertation's driving question has become: What are the moral and political dimensions of 'official obesity discourse?'

It is apparent that there is a relationship between ideology and morality in obesity discourse. However, this relationship has not been closely examined through a systematic national case study. Instead, it has been analysed in such a way that authors can potentially select their evidence and not make a systematic attempt to check their findings. My project, by contrast, is a systematic case study of 'official obesity discourse' in one particular national case. It provides 
both a hitherto unreported history of New Zealand obesity discourse and a critical analysis of this discourse.

I hope to demonstrate that the moralisation of obesity is a far broader problem than is noted in Gard and Wright's observations. I supplement the literature by showing that three ideologies and moralities exist within official obesity discourse. I argue that each ideology has its own perspective on obesity causality, which, in turn, provides each political view with its own form of obesity morality. I then explore the moral dimensions in a detailed manner to show that obesity morality is based in the economics of the 'obesity epidemic' and it moralises specifically against the poor and certain ethnic groups. Thus, when I refer to the moral politics of 'official obesity discourse' I will be extending my discussion of obesity causality to broader ideological notions of economics, the role of the citizen, the role of the State, and systems of health provision.

I find support for the notion that each ideological position in New Zealand has its own morality in Janieswski and Morris's analysis of the reform of the New Zealand Welfare State. Janieswski and Morris argue that a key part of the ideological reform of the New Right was a moralising project. ${ }^{96}$ "[Morality]...concerns the rules which govern our conduct towards each other, the provision of health and education and how we view the relative importance of economic freedom, consumer choice and the rights of citizens." ${ }^{27}$ These authors provide a broad definition of morality tied directly to different ideological beliefs.

Last, I want to acknowledge and discuss the work of Louise Townend. ${ }^{98}$ Townend recently published an article which contains similar methods and conclusions to my own. Townend observes, in her Australian context, that the Prentice and Jebb ${ }^{99}$ article exemplifies the position of those who prefer behavioural explanations of obesity. She notes that the aetiology of obesity is contested ${ }^{100}$ and contrasts the behavioural position with Garry Egger and Boyd Swinburn's ${ }^{101}$ ecological understanding of obesity which holds there are multiple causes of obesity and people might not be fully responsible for their condition. ${ }^{102}$

\footnotetext{
${ }^{96}$ D. Janieswski and P. Morris, New Rights New Zealand: Myths, Moralities and Markets (Auckland: Auckland University Press, 2005$), 6$.

${ }^{97}$ Ibid., 6.

${ }^{98}$ Louise Townend, "The Moralizing of Obesity: A New Name for an Old Sin?" 29 Critical Social Policy (2009): 171.

${ }^{99}$ Prentice and Jebb, "Gluttony and Sloth."

100 Townend, "The Moralizing of Obesity," 176.

${ }^{101}$ Garry Egger and Boyd Swinburn, “An ecological approach to the obesity pandemic,” British Medical Journal, 315 (23 August 1997$)$

${ }^{102}$ Townend, "The Moralizing of Obesity," 175.
} 
Townend's work touches directly on two of the models of obesity causality that I find in my case study. However, unlike Townend, I engage in a systematic historical case study of 'official obesity discourse' and provide a more detailed analysis of each causality model. I hold that Prentice and Jebb's behavioural work forms the basis of the Behavioural Causality Model (BCM) that I discuss in Chapter Two. I argue that Egger and Swinburn's ecological model of obesity underpins the Multiple Causality Model which I discuss in Chapter Three. However, I find also a third model of obesity causality, which I discuss in Chapter Four, namely the Environment Causality Model (ECM). I suspect that Townend conflates the MCM and ECM, and in Chapter Four I will explain how these models differ. Townend is concerned with finding alternatives to what I call the BCM and its behavioural morality. In Chapter Five, I show that this BCM viewpoint is one extreme of a 'Political Spectrum of Obesity Causality Models' each of which contains specific ideologies, morality, and understandings of casualty. I find it comforting that Townend is making similar arguments to mine from an Australian context as her research supports my own findings.

\subsection{Research Methodology}

This dissertation is a study of all 'official obesity discourse' produced in New Zealand between 1997 and 2009. I chose to study New Zealand's obesity discourse because I am a citizen and because the small size of the nation meant it was possible to undertake a systematic national review of every item of 'official obesity discourse' produced over the period, within the scope of a doctoral dissertation. I chose 1997-2009 as my research period because I found that the 'obesity epidemic' emerged after the publication of the 1997 National Nutrition Survey Results, which showed dramatic increases in average population Body Mass Index (BMI). ${ }^{103}$

This period of thirteen years coincides with the changeover of three different Governments. These Governments each had their own particular ideological priorities and this historical analysis allows my research to assess how different ideological priorities, funding choices, and forms of health provision affected obesity discourse.

My primary research began with a survey of everything written in the New Zealand Medical Journal (NZMJ) about obesity, Cardiovascular Disease and Type 2 Diabetes. ${ }^{104}$ The NZMJ is a

\footnotetext{
${ }^{103}$ Ministry of Health, New Zealand Food: New Zealand People: Key Results of the 1997 National Nutrition Survey (Wellington: Ministry of Health, 1999.

${ }^{104}$ All online NZMJ articles are available at http://www.nzma.org.nz/ (accessed $11^{\text {th }}$ July 2011). The NZMJ issues were available online from the Issue $1099,12^{\text {th }}$ November 1999 Volume 112. All articles prior to this are in hardcopy. In addition, later in the research period the
} 
New Zealand based peer-reviewed journal concerned with medical health and population health. I surveyed the content of the NZMJ from No 1036 (24 ${ }^{\text {th }}$ January 1997, Volume 110$)$ to Issue No 1305 (30 ${ }^{\text {th }}$ October 2009, Volume 122) inclusive, some 269 issues in all. ${ }^{105}$ This NZMJ research is intended to both supplement, and be a counterweight to, the qualitative obesity policy produced by the MOH. It is also intended to measure the depth, historicity, and development of medical concerns with obesity over this period.

In addition to the NZMJ research, I systematically reviewed every national nutrition survey produced in New Zealand. I also used the Ministry of Health's (MOH) website to view every policy document produced between 1997 and 2010 which concerned obesity, nutrition, physical activity, Type 2 Diabetes, social inequality, and ethnic inequality. ${ }^{106}$ The extension of the investigation through to 2009/2010 has allowed me to trace the evolution and divergence of official obesity discourse into three distinct models of causality.

\subsection{Dissertation Chapter Outlines}

The dissertation is presented in two parts. Part One 'The Ideological Dimensions of Obesity Discourse' is chronological and outlines the previously unwritten political history of 'official obesity discourse.' Part Two: 'The Moral Dimensions of Obesity Discourse' contains thematic chapters discussing the moral dimensions and consequences of 'official obesity discourse.'

Part One contains Chapters Two-Five. Each chapter is chronological and outlines how the three different obesity discourses evolved. Chapters Two, Three, and Four detail the emergence of three obesity causality models.

In Chapter Two, I explain how obesity discourse and the 'obesity epidemic' emerged into the public sphere with specific focus on the National Governments of the 1990s. I explain also how Prentice and Jebb's understanding of obesity causality relates to the Behavioural Causality Model (BCM) and I argue that in the 1980s and 1990s obesity causality was understood as behavioural.

NZMJ stopped consistently using page numbers for articles, each article has its own page numbers starting from 1. Consequently, the dissertation contains inconsistency in recording NZMJ page numbers.

${ }^{105}$ I ceased surveying articles relating to cardiovascular disease and Type 2 Diabetes because of the sheer volume of NZMJ content.

${ }^{106}$ All online MOH resources are available at http://www.moh.govt.nz/moh.nsf (accessed 11th July 2011). 
Chapter Three defines the Multiple Causality Model (MCM) and traces the development of MCM obesity policy by the Labour Government in the period 2000-2005. It shows how Labour began to actively develop policy that addressed both behavioural and environmental causes of obesity.

Chapter Four defines the Environmental Causality Model (ECM) and traces the emergence of this model between 2006 and 2007. The ECM holds that obesity is caused by unhealthy environments. ECM policy was a result of the Green Party influencing the Labour Government's obesity policy. In addition, this period saw obesity declared as 'the greatest health threat facing New Zealand ${ }^{, 07}$ and the Select Committee Inquiry in Obesity and Type 2 Diabetes in New Zealand. ${ }^{108}$

Chapter Five contains two distinct discussions. The first relates to the 2008 New Zealand general election while the second discusses the National Government's 2009 removal of obesity policy from their health policy. In the first discussion, I provide an analysis of health policy of all the political parties contesting the 2008 New Zealand general election, I argue that the three obesity models are all still present within official obesity discourse and can be mapped across a dynamic 'political spectrum of obesity causation models.' Chapter Five's second discussion applies the spectrum developed in the first half of the chapter to demonstrate the ideological nature of the 'obesity epidemic' and explain why the National Government completely reversed the previous Government's obesity policy.

Part Two consists of Chapters Six - Eight. These thematic chapters analyse and critique the ideological priorities of the dominant discourses, demonstrating that inequality is neglected by the dominant obesity discourses. In Chapter Six, I apply some light Religious Studies lenses to lay bare the moral contours of obesity discourse. I show how each of the obesity causality models outlined in Chapters Two-Four contains its own specific morality and I argue that each obesity model misassigns blame for obesity onto various scapegoats.

In Chapters Seven and Eight, I highlight how the moral dimension of obesity discourse obscures the intersections between obesity, income inequality, and ethnicity. Official obesity discourse fails to recognise that the majority of the obese who are cast as 'immoral' come from

\footnotetext{
${ }^{107}$ M. Cullen, Budget Speech 2006 (Wellington: Treasury, $18^{\text {th }}$ May, 2006), 28

${ }^{108}$ House of Representatives, Inquiry into Obesity and Type 2 Diabetes in New Zealand, Report of the Health Committee Chairperson Sue Kedgley (Wellington: House of Representatives, August 2007).
} 
low income groups and the Maori and Pacific Island ethnic groups. Chapter Seven shows the correlation between income inequality and obesity prevalence which tends to be ignored by obesity morality. Additionally, I claim that the reason obesity is considered to be a problem by all of the causality models is because it 'burdens' a society with a variety of avoidable costs that are estimated to be hundreds of millions of dollars. Chapter Eight argues that ethnicity is an additional variable neglected by the dominant obesity discourses. I show how Maori and Pacific Island peoples are significantly more obese than the population average. Consequently, I claim that discourse which discriminates against obesity based on behavioural rationales is effectively masking racism.

In Chapter Nine, I argue that we must acknowledge the ideological limitations inherent in 'official obesity discourse.' Once these limits are defined we can then unpack the moral discriminations inherent in these discourses and begin to speak about obesity in more nuanced terms. Chapter Nine endeavours to sketch the contours of such methods and implications of such discussions as I develop a 'Model of the Moral Politics of Official Obesity Discourse.' 
Part One: The Ideological Dimensions of Obesity Discourse 


\section{Chapter Two: The Behavioural Causality Model and the Origins of Obesity Discourse}

\subsection{Introduction}

In this chapter, I argue that the sins of gluttony and sloth are applied to a New Right ideological and moral understanding of obesity causality. However, this finding has opened up a broader investigation surveying all the moral and political dimensions of obesity discourse. These sins were linked to one specific ideological and behavioural discourse of the State, citizenship and health. This link indicated that other ideological, medical, historical and moral understandings of obesity discourse existed. As a result, this chapter, in addition to answering the initial research question, provides a chronological analysis of obesity discourse from the 1960s through to 1997. In doing so it tracks the emergence of obesity as a population health concern.

First, I outline the Behavioural Causality Model (BCM) of obesity and explain how it emerged from New Right critiques of the Welfare State. I argue that a combination of population health concerns with cardiovascular disease and New Right political and social reform of the Welfare State informed the development of this BCM. This chapter has both a primary and secondary objective. Its primary objective is to define the $\mathrm{BCM}$ and demonstrate how it was linked with the emergence of New Right politics. My secondary objective is to outline how obesity emerged as a population problem. Mostly, these two objectives do not require separate discussion, but at times, I specifically focus on one objective before switching back to the other.

The chapter begins with a definition of the BCM and an analysis of its medical basis. This discussion highlights how the sins of gluttony and sloth are used as descriptors for the behavioural causes of obesity. The remainder of my content is chronological. I begin my chronological discussion by explaining how health care was distributed under the Welfare state. This is a logical starting point for my analysis because New Right discourse emerged as a critique of the Welfare state.

Obesity discourse originates in the 1960s and 1970s rising concerns with cardiovascular disease (CVD) related mortality rates. This worldwide concern resulted in an increasing global focus upon population health and nutritional health research. These CVD concerns would subsequently produce significant amounts of NZMJ research concerned with nutritional 
consumption and population BMI. Obesity prevalence would be revealed as a population health problem, as a consequence of these concerns with CVD. My analysis finds that, by the late-1980s, health researchers and policy makers clearly considered the behaviours of physical inactivity and nutrition as contributing to 'lifestyle diseases.' In these official discourses obesity was portrayed as a lifestyle factor that combined with other risks to exacerbate diseases with high mortality rates such as CVD, Type 2 Diabetes, ${ }^{1}$ and cancer. ${ }^{2}$ Increased individual responsibility for health was emphasised as a response to the concerns about lifestyle disease.

Individual responsibility was also central to New Right ideology and economics. This chapter shows how New Right ideology and the new language of population health became intertwined. This New Right view of the individual, health provision, and health economics formed the ideological underpinnings of the BCM and also instigated a moral code of individualised health concentrated upon notions of personal responsibility. I discuss how New Right reform, such as the Green and White Paper ${ }^{3}$ and the Health and Disabilities Act 1993 attempted to commercialise health care and rewrite the "patient" as a "consumer" which applied a BCM economics and morality to health. It is also demonstrated that the New Right viewed being physically activity as essential to individual citizenship and participation in the community. The chapter finally concludes its chronological discussion by illustrating how obesity was shown to be a population health problem as a result of National Nutritional Survey 1997 findings. ${ }^{4}$

\subsection{The Behavioural Causality Model}

A definition of the BCM is necessary, before I chronologically outline the emergence of the BCM from New Right discourse. The BCM of obesity is the earliest ${ }^{5}$ model of obesity causality emerging from my case studies. This understanding of health originates in the New Right critique of the Welfare state. Central to BCM discourse are the notions of individual discipline, behaviour and responsibility. The BCM holds that obesity is caused by individuals eating too much (gluttony), exercising too little (sloth), or exhibiting a combination of these two behaviours. The rationale of this model finds that individuals directly determine their own personal health and moral worth through their behaviour. Proponents of the BCM hold that

\footnotetext{
${ }^{1}$ Ministry of Health, Taking the Pulse, The 1996/97 New Zealand Health Survey (Wellington: Ministry of Health, 1999), 99.

${ }^{2}$ Chronic disease mortality contributed to “... approximately 9000 potentially avoidable early deaths per year in 1996 and 1997 , which is about 70 percent of all deaths occurring in people under 75 years of age.” See: National Health Committee, Improving Health for New Zealanders by Investing in Primary Health Care, National Health Committee (Wellington: December 2000), 10.

${ }^{3}$ S. Upton, Your Health and the Public Health (Wellington: Minister of Health, July 1991).

${ }^{4}$ Ministry of Health, 1997 National Nutrition Survey.

${ }^{5}$ Emerging in the 1980s and 1990s.
} 
the physical health of their body is a signifier of personal responsibility and social grace. As a consequence, this model views the chronic disease of obesity as a self-induced problem caused by a lack of healthy behaviours, self-indulgence and failure of personal responsibility. Thus, the BCM utilises the sin language of gluttony and sloth to indicate the moral failings of the obese individual's responsibility to maintain their good health.

BCM health policy tends to emphasise that individuals should undertake physical activity or sport for both personal health reasons as well as for community participation. Such emphasis allows governments using the BCM to devolve responsibility for health provision onto individuals and encourage privatisation of health care. In this model, the individual functions as a rational consumer who is responsible for his or her present and future health.

Physical activity, in addition to promoting health and competition, also acts as a form of insurance against the development of illness. Proponents of BCM rationality view the individual as a consumer who must take active responsibility for health to insure against mortality risk and the future costs of ill-health. This model emphasises that the practice of healthy behaviour and the resultant 'fitness' as essential to good citizenship. Here, notions of capitalist industry and perhaps even social Darwinian ideas nominally inform conceptions of fitness. Under the BCM, an individual signals their social 'fitness' through physical activity and healthy competition which, ideally, results in health and economic success.

Health, fitness, and, calorific efficiency ${ }^{6}$ are related to the economic rationality of the New Right. New Right economics focus on the individual as a rational consumer of goods and services and assumes that individuals, like markets, seek to become efficient. For the New Right, the role of Government in health is to provide public health programmes, which are understood as "investments" which will slowly decrease the costs of primary care. These public health programmes save Government's costs in a number of ways: healthy employees are less likely to be a tax burden, individuals bear the costs and responsibility for their own treatment and, ideally, the public health system encounters less preventable illnesses enabling it to be more economically efficient. As a consequence, the BCM applies economic models of efficiency to notions of personal health. These notions will be evident in the 1991 - 1999 National Government policy discussed later in this chapter.

\footnotetext{
${ }^{6}$ This association is discussed further in Chapter Seven.
} 


\subsection{The Medical Basis of the Behavioural Causality Model}

The BCM, with its concentration upon personal responsibility, views the medical causes of obesity to be related to individual behaviour. An exemplary medical exposition of the BCM can be found in the 1995 Andrew Prentice and Susan Jebb obesity article entitled Obesity in Britain: Gluttony or Sloth ${ }^{7}$ which I discussed in Chapter One. Prentice and Jebb's review article surveyed obesity causality research from the 1980s and 1990s. The review finds that, at that time, obesity was understood to be caused by a combination of the individual behaviours of overeating and a lack of physical activity. This behavioural understanding of obesity causality emphasised that individuals caused obesity themselves through a lack of self-control.

A closer reading of Prentice and Jebb's analysis shows that they regard physical inactivity as more of a causal factor than overeating. ${ }^{8}$ They challenge what they call the simple assumption: “...that obesity in affluent societies is largely a matter of greed, encouraged by a highly palatable diet backed by persuasive advertising and available at ever diminishing cost relative to average income." Instead, they prefer the explanation that low rates of physical activity are the dominant cause of obesity. BCM policy emphasises that it is work, industry, or physical activity that will reduce obesity prevalence. This explains the medical rationale behind BCM policy promoting sport or exercise as obesity solutions. Moreover, this focus on physical activity allows proponents of the BCM to argue that the unregulated free-market cheap accessibility of high calorie, high fat, and high sugar fast foods are not the primary cause of obesity. Proponents of this model hold that obesity is not caused by economic consumption, but that it is instead caused by individuals who do not exercise enough or make poor choices. Under the BCM, individuals, rather than the State, are responsible for obesity.

Prentice and Jebb's article is an overt example of the morality governing the BCM. They argue that it is the sinful behaviours of gluttony and sloth that produce obesity. The allocation of the deadly sins of gluttony and sloth to the causal factors of obesity emphasise the immorality of the obese. These sins function as metaphors that stress a lack of personal responsibility. As a result, the obese, through their irrational desires of gluttony and sloth, have failed in their personal responsibility for managing their own health. Given the BCM emphasis on an unrestricted free market, individual choice, and physical activity, these moral explanations

\footnotetext{
${ }^{7}$ Prentice and Jebb, “Gluttony and Sloth?"

${ }^{8}$ Ibid.

${ }^{9}$ Ibid.
} 
quickly imply that the obese are fat because they are lazy and lack the personal discipline to fully participate in society.

\subsection{The Welfare State and Universal Free Health Care}

A brief outline of how health provision ${ }^{10}$ occurred under the Welfare State, prior to 1992 is important, because it outlines the departure point for the models of obesity detailed in the dissertation. For example, the BCM emerged as a direct critique of Welfare State health provision. Certain New Zealand political writers and commentators have been described as viewing the Welfare state as a mythical golden egalitarian past. ${ }^{11}$ This was an Eden-like context where the population was unencumbered by knowledge of the dangers of obesity, poor nutrition, and the lack of exercise. This "past" was shattered by new knowledge of disease and the New Right reforms of the 1980s and 1990s.

The target of New Right BCM reform was the universal health provision provided by this Welfare State. Universal free health care was provided by the State between 1941 and 1992. This began when Michael Savage's Labour Government passed The Social Security Act $1938 .{ }^{12}$ This Act established what became known as the "Welfare state". The Welfare state promoted a collective form of health which took responsibility for providing care of citizens. Savage used the term "applied Christianity" to describe his intentions for the scheme. ${ }^{13}$ His creation of a State-based welfare system was intended to administer the charitable tenets of the social gospel evenly, to the whole community, through state-based and tax-funded institutions. It provided universal free health care for the entire population. All citizens received the same standard of care regardless of their total income ${ }^{14}$ and they were all (theoretically) ${ }^{15}$ able to access identical benefits and health services regardless of income or location.

The Welfare State viewed the Government as a form of equal provider and protector of the whole community. In the Welfare State hospitals citizens were viewed as patients.

Government institutions held authority over hospital treatment and determined what care would be provided to these patients. The individual patient had little agency and tended to

\footnotetext{
10 "Health provision" describes how Government's distributed and fund the resources of the health system.

${ }^{11}$ The Garden of Eden is invoked to describe this pre-1984 Welfare state. See: Janieswski and Morris, New Rights New Zealand.

${ }^{12}$ Social Security Act 1938

${ }^{13}$ Barry Gustafson, "Savage, Michael Joseph." The Dictionary of New Zealand Biography.

www.dnzb.govt.nz.http://www.dnzb.govt.nz/DNZB/alt essayBody.asp?essayID=4S9 (accessed $25^{\text {th }}$ November 2009).

${ }^{14}$ This disparity between the amount of tax paid by the wealthy and the poor was emphasised by those seeking to develop private insurance based models of health.

${ }^{15}$ For a discussion of Maori health disparities see: M. Durie, Whaiora: Maori Health Development, $2^{\text {nd }}$ Edition (Auckland: Oxford University Press, 1998)
} 
conform to the model of being an object of medical scrutiny. ${ }^{16}$ The Welfare State was focused on primary care and public health rather than preventative medicine. This meant that disease was treated primarily through hospitals, sanitation, and GPs rather than through health promotion messages.

In the late 1980s, this health system came under New Right scrutiny in the face of external demands for economic rationalisation and changes in health priorities which focused on lifestyle and individual determinants of illness. In the light of these demands the roles of the citizen and the patient evolved. Welfare state ideology was slowly refocused toward the participating citizen as the centre of public policy. ${ }^{17}$ Michael Belgrave described this shift from social to individual citizenship as follows: "With the neo-liberal reforms of the late 1980s and early 1990s, the ideal of social citizenship was replaced by that of the consumer and consumer choice." 18 These political health reforms and new medical research would rewrite the provision of health and the moral responsibility of the citizen. The BCM would draw upon these notions of the individual consumer choice to critique the Welfare state and explain the causes and solutions to obesity.

\subsection{Developing Concerns with Cardiovascular Disease and Population Health}

Health policy focusing on individual behaviour originated in the late 1960s. This concern began with medical researchers and policy makers recognising that one of the leading causes of mortality in the Western World was cardiovascular disease (CVD). One particular response to these rising population levels of CVD was developed by Canadian Minister Marc Lalonde. Lalonde outlined a system of health provision called "population health" in his 1974 Lalonde Report. ${ }^{19}$ Lalonde demonstrated there were lifestyle and environmental risks to health requiring management at a population level. Specifically, the report noted of the 58,000 Canadians between the ages of 35 and 70 who die each year, there were 25,700 deaths due to CVD. ${ }^{20}$ The report found that many of these deaths were preventable because they were caused by poor individual behaviour and self-imposed risks. ${ }^{21}$ As a consequence, exponents of population health highlighted the threat of cardiovascular mortality rates and demanded that individuals take responsibility for managing preventable behavioural determinants of disease. Population

\footnotetext{
${ }^{16}$ Foucault, The Birth of the Clinic.

${ }^{17}$ Michael Belgrave, "A Historical Perspective on the Politics of Health Care," in Understanding Health Inequalities in Aotearoa New Zealand, ed. Kevin Dew and Anna Matheson (Dunedin: Otago University Press, 2008), 71.

${ }^{18}$ Belgrave, “A Historical Perspective," 71.

${ }^{19}$ M. Lalonde, A New Perspective on the Health of Canadians: A Working Document (Ottawa: Minister of Supply and Services, 1974)

${ }^{20}$ Ibid., 15.

${ }^{21}$ Ibid., 16.
} 
health emphasised individual responsibility and would influence New Right approaches to health, and later, dictate BCM approaches to obesity.

The Lalonde Report was indicative of growing global recognition ${ }^{22}$ that non-communicable diseases, specifically CVD, were a major cause of population mortality in the late $20^{\text {th }}$ century. The Lalonde Report recommended that State-based health provision needed to change focus from primary care towards treating the risks to the health of entire populations. It argued that there was a need to accumulate extensive quantitative knowledge of these risks. Wide-ranging demographic studies of the determinants of mortality and other health risk factors were going to be required in the late $20^{\text {th }}$ century. ${ }^{23}$ The Lalonde Report had a lasting impact because it was the first report to highlight the need for widespread national and international demographic research into the behavioural determinants and risks associated with smoking, alcohol, nutrition, physical activity and obesity.

The Lalonde Report's demand for population level research resonated in New Zealand where, in the 1960s, there was little knowledge about the demographic components of chronic disease prevalence. The majority of medical data came from the quinquennial census mortality data, localised hospital data, or disease registers rather than from representative national datasets. In 1969, the Medical Research Council stated: "[M]edical statistics in New Zealand are inadequate in scope and extent - both for domestic needs and as regards contributions to the world store of knowledge of disease as it occurs in human populations.” ${ }^{24}$ The Council further acknowledged that, at that time, the incidence of many illnesses and diseases in the population were "largely unknown." 25 The Medical Research Council recognised that the primary causes of population mortality had altered. Communicable diseases, accidents, and warfare no longer dominated mortality rates. Reflecting other Western demographic changes, our population was living longer and mortality rates were increasingly dominated by non-communicable diseases such as cardiovascular diseases and cancer. ${ }^{26}$ Concerns with CVD and a lack of information about its prevalence produced numerous subsequent investigations into its risk

\footnotetext{
${ }^{22}$ In 1960, heart disease was recognised primary killer of Americans. See: Schwartz, Never Satisfied, 216.

${ }^{23}$ Lalonde, A New Perspective, 38 .

${ }^{24}$ The Medical Research Council of New Zealand, Adequacy of Medical Statistics in New Zealand (Wellington: The Medical Research Council of New Zealand, November 1969), 16.

${ }^{25}$ Ibid., 19.

${ }^{26}$ Ian Pool, “Cross-Comparative Perspectives on New Zealand's Health,” in Social Dimensions of Health and Disease: New Zealand Perspectives, ed. John Spicer, Andrew Trlin, Jo Ann Walton (Palmerston North: Dunmore Press, 1994), 35.
} 
factors. ${ }^{27}$ It was apparent that new population level research was required to develop detailed knowledge about the nature of these diseases. Population based research would quickly focus on the individual determinants of disease which, in turn, would develop the BCM.

\subsection{Demographic Studies of the Population: National Diet Survey 1977}

One by-product of population health concerns with CVD was the production of detailed information about nutrition and the prevalence of overweight and obesity. The National Heart Foundation of New Zealand was instrumental in producing this research. The National Heart Foundation had been established in 1968 as a response to growing concerns with cardiovascular disease. In 1970, and again in 1975, the National Heart Foundation published reports on coronary heart disease distribution in the nation. ${ }^{28}$ Both these reports emphasised the possible importance of dietary factors in causing heart disease in the population. From these recommendations, the National Heart Foundation sponsored the first National Diet Survey 1977 [NDS77]..$^{29}$

The NDS77 was implemented by Dr John Birkbeck ${ }^{30}$ and is the earliest representative measure of population obesity in New Zealand. This survey included a measure of BMI and a 24 hour diet recall. ${ }^{31}$ The NDS77 results suggested that there was a high prevalence of overweight and obesity in the population. Birkbeck made the following claim about the NDS77 results: "Although one can manipulate the values by choosing one's criteria, it is clear that many New Zealand adults are obese, especially in their forties, and in general the problem is greater in women." ${ }^{32}$ The NDS77 report did not use today's standardised BMI measures. Instead, it used measures $20 \%$ and $40 \%$ respectively over the median BMI to determine classifications of overweight and obese. Consequently, it is difficult to compare the NDS77's results with today's measures of obesity.

\footnotetext{
27 "The emergence of the cardiovascular disease epidemic in the early part of this century is a central feature of the epidemiology of health and disease in New Zealand." See Beaglehole, Robert \& Ruth Bonita, "Cardiovascular Disease," in Social Dimensions of Health and Disease: New Zealand Perspectives, ed. John Spicer, Andrew Trlin, Jo Ann Walton (Palmerston North: Dunmore Press, 1994), 55.

${ }^{28} \mathrm{~J}$. Birkbeck, New Zealanders and their Diet: A Report to the National Heart Foundation of New Zealand on the National Diet Survey 1977, ${ }^{\text {nd }}$ Edition (Dunedin: Otago University Press, 1983), 2.

${ }^{29}$ In a 1975 a pilot survey into developing testing methodology for a larger nutritional survey of New Zealand was tested in Milton, Otago by Mrs K. Christie. This study was not published.

${ }^{30}$ In Chapter Six I return to discuss a 2009 obesity controversy caused Birkbeck.

${ }^{31}$ The NDS77 also unsuccessfully attempted to provide socio-economic and ethnic measures of nutritional health.

${ }^{32}$ Birkbeck, New Zealanders and their Diet, 11.
} 
Moreover, the findings of the NDS77 were conflicted. They indicated that there was a high prevalence of obesity in the population ${ }^{33}$ while also noting that was no widely-utilised value of BMI to separate the obese from the non-obese. The survey also evidenced uncertainty about the actual health danger of this prevalence of obesity. Even as late as 1983, when the revised second edition of the NDS77 was published it stated that: "there is no agreement as to what value might be used as a definition of overweight." ${ }^{34}$ Furthermore, the report did not find a relationship between the obese and an over-consumption of calories. ${ }^{35}$ It did find, however, that the highest forms and source of energy consumption came from fats and alcohol consumption rates. ${ }^{36}$ As a result, 1980s CVD-related health promotion efforts concentrated on reducing population levels of fat and alcohol consumption. These nutritional foci would, in turn, contribute to the development of policies focused on the behavioural determinants of obesity.

\subsection{Concerns with Nutrition and Physical Inactivity in the 1980s}

In early 1980s New Zealand, obesity and its related behavioural causes were not prominent health priorities. However, by the late 1980s, the BCM causal behaviours of poor nutrition and physical inactivity had become national concerns, but obesity had not. One the one hand, in the early 1980s, obesity was recognised by medical researchers as deleterious to health ${ }^{37}$ and as an important variable for cardiovascular diseases. On the other hand, they also recognised that there were more immediate and easier treatment priorities for cardiovascular disease such as the effects of alcohol, cholesterol, and smoking. Professor John Scott, of Auckland Medical School, stated in 1987 that: "Far more overall harm to health is induced in New Zealanders by excessive alcohol and tobacco intake, and excessive energy input, than is caused specifically by fat in the diet." ${ }^{38}$ As a consequence of the focus on CVD in the mid 1980s, nutritional health promotion tended to focus on reducing fat consumption rather than sugars or carbohydrates. This approach was focused on heart health rather than reducing obesity.

An additional reason that the dangers of obesity were not a primary target of health discourse until the late 1990s was that, in the mid 1980s, our medical professionals were wary of the

\footnotetext{
${ }^{33}$ John Birkbeck, “Obesity, Socioeconomic Variables and Eating Habits in New Zealand,” Journal of Biosocial Science 13, Great Britain (1981): 299.

${ }^{34}$ Birkbeck, New Zealanders and their Diet, 20

${ }^{35}$ Ibid., 3.

${ }^{36}$ Ibid., 9.

${ }^{37}$ John Scott, "The Relationship of Dietary Fats to Health," in Are We Really What We Eat? Food Choice as a Basis for Better Health, ed. John Birkbeck (Auckland: Dairy Advisory Bureau, 1987).

${ }^{38}$ Ibid., 95.
} 
conflicting nature of discussions and myths surrounding diet and exercise. At that time, recommended calorific measures were noticeably lacking. ${ }^{39}$ For example, Professor John Scott highlighted that there was a lack of accurate information about the percentages of daily dietary intake which should come from fats, sugars, etc. ${ }^{40}$ Associate Professor Anne Hall of Wellington Medical School argued that obesity causality, prevention and treatment were far from simple. ${ }^{41}$ Further, Hall suggested that, at that time, the greatest danger of obesity was how others perceived the obese rather than obesity posing any particularly imminent risk to health. As Hall noted:

Anorexia Nervosa and Bulimia are clinical disorders, whereas obesity is a social handicap associated with increased morbidity and mortality... Obesity creates an enormous psychological burden. In fact, in terms of suffering this burden may be the greatest adverse effect of obesity. ${ }^{42}$

It was clear that in the mid 1980s the lack of consensus and a lack of informed research led medical experts to stress that more scientific investigation into genetics, nutrition, and exercise were required before hard and fast conclusions about the dangers of obesity could be made. In 1987, the Department of Health did release a pamphlet entitled Weight and Health which used BMI ratios and emphasised that people with BMI measurements over 30 had a health problem. However, there was no indication that obesity was a serious health policy priority. ${ }^{43}$

While, in the mid 1980s, there was uncertainty about the dangers of obesity itself, a strong discourse surrounding dietary control was emerging. In the later 1980s and into the 1990s the dangers of atherosclerosis, fat consumption, and cholesterol were central targets of health promotion. By 1988, the National Heart Foundation had ensured that pamphlets displaying healthy food pyramids were widely available to the public. ${ }^{44}$ By 1992 , industry interest groups such as the Dairy Advisory Bureau were producing extensive pamphlets in depth measurements of the amount of fat in food down to the nearest gram. ${ }^{45}$ Such pamphlets

\footnotetext{
${ }^{39}$ Ibid., 89.

${ }^{40}$ Ibid., 92.

41 "There is incontrovertible evidence that accumulating excess fat tissue (presumably a biological advantage to the human race during its early development) is associated in food rich cultures with increased mortality and morbidity. The relationship is, however, complex, with genetic factors, type and distribution of fat certainly implicated. The prevention and treatment of obesity are far from simple. Greater research is beginning to explain why some individuals become obese and why achieving and maintaining weight reduction is not easy." See Anne Hall, "Anorexia Nervosa, Bulimia and Obesity," Are We Really What We Eat? Food Choice as a Basis for Better Health, ed. John Birkbeck (Auckland: Dairy Advisory Bureau, 1987), 104.

${ }^{43}$ Department of Health New Zealand, Health Facts: Weight and Health (Wellington: Department of Health New Zealand, 1987), 2.

${ }^{44}$ See: The National Heart Foundation of New Zealand, Eat to Beat: Guidelines for Healthy Eating (Auckland: The National Heart Foundation of New Zealand, 1988) and, The National Heart Foundation of New Zealand, Eat Well, Weight Less Using the Healthy Food Pyramid (Auckland: 1990)

${ }^{45}$ The Dairy Advisory Bureau, Fat in Your Food (Wellington: The Dairy Advisory Bureau, 1992).
} 
heightened a growing awareness of the detailed calorific dangers of eating 'bad foods.' People were encouraged to change their eating behaviours towards healthier foods and to reduce consumption of foods high in fat and/or cholesterol. The BCM focus on dietary control has its origins in this type of population health material. However, this material was focused on controlling cholesterol and CVD rather than obesity.

The other primary behavioural cause of obesity, physical inactivity, became a State concern after the Hilary Commission for Recreation and Sport (known today as Sport and Recreation New Zealand [SPARC]) was established in 1987. It was charged with encouraging community health and wellbeing through physical activity. ${ }^{46}$ Given that so little was known about the physical activity rates in the nation, the Hillary Commission authorised a review of physical activity rates entitled The Cost of Doing Nothing. ${ }^{47}$ This review claimed that "Lifestyle is now known as a major factor in premature death" ${ }^{\prime 4}$ and that $47 \%$ of all deaths are due to cardiovascular related diseases. Moreover, the report concluded that inactive people are more likely than active people to develop cardiovascular problems. It also noted that overweight people are more likely to develop coronary heart disease. Physically inactive lifestyles were recognised by the Hillary Commission as having mortal consequences.

"Lifestyle" meant the behaviours which individuals practiced in their everyday lives which might produce risk factors for early mortality i.e., smoking, alcohol, over eating and being physically inactive. In an article in the Evening Post, Ngaire Hopper commented that the findings suggested that the study "highlighted that large proportions of Dunedin's population have unhealthy lifestyles and are at risk of incurring health disorders such as obesity and coronary heart disease. ${ }^{\text {"9 }}$ Hopper's emphasis on "lifestyles" is worth noting, however, given the currency of the term in national health discourse.

"Lifestyle" was recognised as a major avoidable factor in premature cardiovascular disease related death rates, so much so that by the end of the 1980s, there were a number of large national bodies promoting healthy eating and exercise. These organisations encouraged individuals to practice healthy behaviours as part of their lifestyle in order to reduce their cardiovascular risk and cholesterol. The ground was set for BCM explanations of obesity

\footnotetext{
${ }^{46}$ In 1988, the Hillary Commission's Kiwisport program was established to encourage young people into sport.

${ }^{47}$ David Russell, Anthony Worsley, and Noella Wilson, The Cost of Doing Nothing: An Assessment of Initiatives in Fitness and Health for the Hillary Commission (Dunedin: University of Otago Press, July, 1987).

${ }^{48}$ Ibid., 2.

${ }^{49}$ Ngaire Hopper, "Pilot Study provides a glimpse of Kiwi diet, health.” in Evening Post (Wellington: Tuesday December 19, 1989).
} 
causality to emerge. However, conflicting scientific research and other more immediate health priorities obscured obesity as a health problem in the 1980s. ${ }^{50}$

\subsection{Individual Responsibility and Lifestyle Disease}

BCM notions of the individual began to emerge in the late 1980s, when the notion of a healthy lifestyle was related to New Right understandings of the individual and personal responsibility. The origins of this relationship surfaced in 1987. The Hillary Commission's The Cost of Doing Nothing stated:

Widespread promotion of physical activity can be seen as part of a process of social change, as well as being based on a concern with therapeutic, preventative, and health promotion goals. Exercise is a point of entry into a healthier lifestyle, since it can positively affect other factors such as diet, stress and the risk behaviour associated with smoking and the over consumption of alcohol. ${ }^{51}$

In the report, physical activity is described by the authors as part of a healthy lifestyle.

Moreover, they describe physical activity on the part of individuals as essential to social change intended at increasing personal responsibility for health.

The Hillary Commission report maintained that personal responsibility extended to physical activity and health. Lifestyle models of disease prevention using health promotion campaigns increasingly focused on the need for individual responsibility. This link would eventually contribute to the viewpoint that poor individual behaviour could be seen as the cause of disease. Historian Michael Belgrave stated: “...in the 1980s a new breed of individualism with its focus on neo-liberal reform could blame these health characteristics on the failings of individuals making poor choices about their own lives. ${ }^{~} 52$ New moral codes emerged from this discourse focused on individual responsibility. Significantly, these new individualised ways of understanding choice, responsibility, and the causes of illness were at odds with the welfare system of collective social responsibility. One new consequence of this individualised code was the implication that one actually chose to be ill and that the prevention of illness was, to a certain extent, a matter of personal responsibility.

Individual responsibility was a cornerstone of the New Right political reforms that had begun in the 1980s. New Right free market liberal ideology is predicated upon the notion of choice.

\footnotetext{
${ }^{50}$ The more immediate and easier to fix priorities for health promotion included smoking, alcohol and drunk driving.

${ }^{51}$ See: Russell et al, The Cost of Doing Nothing.

${ }^{52}$ Belgrave, A Historical Perspective, 78.
} 
Individuals are tasked to both dictate demand for services through their choices and to take responsibility for these choices. Belgrave explains the emergence of this individualised approach to health:

By the middle of the 1980s, choice and the belief that need could not be understood on a population basis, but was differentiated by the varied wants of individuals became a leading driver of health policy, as it was in most other areas of social policy. The emphasis on individual citizenship rights, guaranteed by the state which had underpinned the 1960s and 1970s, readily metamorphosed into faith in individual consumer choice, guaranteed by the market. ${ }^{53}$

Poor health could be understood as a consequence of poor choices which involved obesity, alcohol, tobacco, poor diet, and a lack of exercise. One consequence of such a view was that governments did not need to be responsible for evening out the costs of disease on a society; instead they could apportion the costs of illness onto individuals themselves.

The health sector was not exempt from the intense New Right scrutiny and economic rationalisation of the 1980s Welfare state. In 1987, Alan Gibbs headed a Government taskforce investigating the health sector ${ }^{54}$ which, in 1988, published what became known as The Gibbs' Report. The Gibbs' Report claimed that economic inefficiencies and a lack of financial accountability existed in the hospital system. The report indicated that there should be a split between provider and supplier of health services based on the competition for funding and the supply of services. The Gibbs' Report recommendations would influence the National Government's 1990s health policy.

The Gibbs' Report was the first indicator that the universal free health system of the Welfare state faced strong challenges from new economic and service oriented demands based on understandings of individual choice and personal responsibility. This threat of reform was compounded by new individualised understandings of disease treatment which sought to treat lifestyle and the behavioural determinants of illness. New Right understandings of disease, economics, and individual responsibility had profound effects upon the way the health of the body was conceptualised. The BCM emphasis upon individual responsibility set the background to the 1990s health reforms.

\subsection{Changing Nutritional Language: The Life in New Zealand Survey 1989}

\footnotetext{
${ }^{53}$ Ibid., 76.

${ }^{54}$ Alan Gibbs, Dorothy Fraser, and John Scott, Unshackling the Hospitals, Hospital and Related Services Taskforce (Wellington: 1988).
} 
By the end of the 1980s, BCM language and concerns were apparent in nutritional health discourse. Such language is found in The Cost of Doing Nothing which had, in turn, given the Hillary Commission the impetus to fund a second representative national survey on the physical activity, nutrition, and health of the nation. This survey was entitled the "Life in New Zealand Survey 1989" [LINZ89] and was published in 1991. The LINZ89 was intended to measure the extent of the problem of inactive lifestyles in the nation. ${ }^{55}$ Its objective was to gather a base of data ${ }^{56}$ on the physical activity and health patterns of the population and to analyse whether there had been significant changes in nutritional intake since the NDS77 survey. ${ }^{57}$ The LINZ89 report provided the baseline population BMI data against which the 'obesity epidemic' would be declared by a follow-up survey in 1997. The LINZ89 report is important for both its BCM language and because its BMI measurements would be used, in comparison with 1997 findings, to show a rapid increase in population obesity prevalence over a period of less than 10 years.

The LINZ89 report provided reliable representative data about the prevalence of obesity in the population. It found, using today's standardised BMI measurements, that $10 \%$ of males and $13 \%$ of females surveyed were considered obese. A further $43 \%$ of males and $27 \%$ of females were considered to be overweight but not obese. ${ }^{58}$ However, while measures of obesity were considered important it was only because they were considered as giving further insight into CVD. The LINZ89 stated: "Measures of obesity and fatness are considered important because of the established relationship between obesity, and morbidity and mortality, particularly with respect of coronary heart disease. ${ }^{59}$ The LINZ89 connects CVD mortality rates with obesity prevalence and while cardiovascular disease still remained the focus of research, obesity measurements were now an important independent measure of population health. ${ }^{60}$

BCM language was evident in the LINZ89 report. In the foreword, John Banks, then Minister for Recreation and Sport stated, "Physical activity is important to individual health and social wellbeing. ${ }^{\prime 61}$ This statement aligned physical activity to the individual pursuit of health. Here, Banks portrayed the practice of exercise and health to be part of responsible citizenship. He

\footnotetext{
${ }^{55}$ Jim Mann et al., Life in New Zealand Commission Report, Volume V: Health (Dunedin: Otago University Press, 1991), v.

${ }^{56}$ Phase one of LINZ89 survey had some 7,942 respondents to a series of questionnaires. The second phase involved a separate group of 3,363 participants who underwent a physical health check, interview and completed the questionnaires.

${ }^{57}$ Wilson, et al. Life in New Zealand Summary Report.

${ }^{58}$ Ibid., 31 .

${ }^{59}$ Mann et al. Life in New Zealand Commission Report, Volume V, 3.

${ }^{60}$ In the early 1990s CVD concerns began to focus on behaviour. CVD accounted for 44\% of all deaths in 1991. See: Beaglehole and Bonita,

"Cardiovascular Disease," 58.

${ }^{61}$ Banks, John, "Forward," in Life in New Zealand Summary Report, ed. Noella Wilson, David Russell, and Judy Paulin, et al. (Dunedin: University of Otago Press, 1990), iv.
} 
framed exercise as a means of facilitating individuals' "healthy" social relationships and contributions to a "healthy" society. Thus, it seems for Banks, exercise was an important activity for individual health and it was considered beneficial for the community. Such an emphasis on physical activity and sport creating healthy relationships and behaviours is consistent with the BCM focus on physical activity being essential to active citizenship.

Also in the foreword of the LINZ89, Simon Upton, then Minister for Health, expressed a view of a social benefit relating to a healthy lifestyle:

Our understanding of the health and lifestyles of New Zealanders will increase significantly through this unique project. It is my wish that all organisations involved in the health education and delivery will use this data base and will co-operate for the benefit of our community. ${ }^{62}$

Upton outlines a causal relationship that assumes that accumulating knowledge of the "lifestyles" (behaviours) of individuals is a beneficial contribution to the wellbeing of the greater community. This appears to be construed as a providential relationship in which healthy individuals, making healthy lifestyle choices, benefit the community as a whole. In this example, individual practices of nutrition and exercise are linked to notions of personal responsibility and good citizenship. For these New Right politicians, Banks and Upton, the practice of a healthy lifestyle has social benefits for both the individual and the greater community.

\subsection{The Emergence of the Behavioural Causality Model}

The BCM was evident in the Household Health Survey 1992-93 [HHS92 /93]. This was because BCM lifestyle determinants, for all forms of poor health, were officially noted in the HHS92 /93. Published in 1993, the HHS92/93 was the first report to highlight a new focus on behavioural health risks and lifestyle diseases and the way in which individuals took responsibility for their health. This survey was intended to be a "first step" in setting up a comprehensive nationwide database of health. ${ }^{63}$ It aimed to provide benchmark indicators of the current health status of the population and to indicate the prevalence of particular health risk factors or "lifestyle" risks. The HHS92/93 is not particularly important for its results. ${ }^{64}$

\footnotetext{
${ }^{62}$ Upton, Simon, "Forward," in Life in New Zealand Summary Report, ed. Noella Wilson, David Russell, and Judy Paulin, et al. (Dunedin: University of Otago Press, 1990), iv.

${ }^{63}$ Statistics New Zealand \& Ministry of Health, A Picture of Health (Wellington: Ministry of Health, October 1993$), 17$.

${ }^{64}$ The HHS92/93 asked 7,000 people if they had participated in 'vigorous exercise" or sport in the last week. The survey found that well over half the population aged 15 years or older reported that they had no vigorous exercise in the past week.
} 
Rather, this report is important because its language demonstrates the changing focus of health in the mid-1990s. ${ }^{65}$

One particularly interesting element of the survey is its concentration on lifestyle and health risk behaviour. By 1993, interest in health promotion had changed significantly to focus on new improvements in health care and health status through a consideration of lifestyle disease. The lifestyle factors that the HHS92/93 prioritised included smoking and alcohol consumption followed by exercise levels. ${ }^{66}$ The HHS92/93 report acknowledged this shift:

[T] here is a growing awareness that future improvements in health are going to depend very much more upon the adoption of healthy life-styles and the avoidance of health-risk behaviour. These are changes which cannot be readily documented. Firstly, there may be a time lag of years or decades before the benefits of a healthy lifestyle and behaviour show up in improved health status for population groups, Secondly, such changes reflect the everyday behaviour of more-or-less healthy individuals at home and in the community. ${ }^{67}$

The HHS92/93 indicated that future directions in health care would come from the monitoring of individual health risk behaviour. The risk language of this report focuses more intently on 'individuals' than previous reports. Exercise is described in the HHS92/93 as: "one of a number of behavioural factors, such as healthy diet, adequate rest and relaxation, and reduction of stress, which have long term consequences for the health of the individual." Here we see that the HHS92/93 directly identifies that nutrition and physical activity are behaviours understood as risks to health.

In addition, the HHS92/93 also linked obesity prevalence to the behavioural risks associated with physical inactivity. The report employed self-reported height-to-weight ratios to form a BMI measure of the survey population. This survey found that $9 \%$ of the population selfreported themselves as obese and 19\% of the population self-reported as being overweight. ${ }^{69}$ The report noted that the HHS92/93 findings were comparable to the results of the LINZ89. ${ }^{70}$ However, an important additional step had been made because it was now evident that the high rate of physical inactivity was a potential causal factor for obesity prevalence. At this time the $\mathrm{BCM}$ was not directly applied to obesity but was tied to understandings of individual

\footnotetext{
${ }^{65}$ In 1991, the National Government did not view nutrition and physical activity as primary health goals. See Jo Rutledge, Sandy Brinsdon, Trace McLennnan, and Barry Borman, Information on New Zealand Health Goals: Update (Wellington: Department of Health, Health Statistical Services, 1991), V.

${ }^{66}$ Statistics New Zealand \& Ministry of Health. A Picture of Health, 16

${ }^{67}$ Ibid., 57.

${ }^{68}$ Ibid., 57.

${ }^{69}$ Ibid., 62.

${ }^{70}$ Ibid., 62.
} 
responsibility. The HHS92/93 set the scene for BCM language to be applied to the 'obesity epidemic' of the late 1990s.

\subsection{The Green and White Paper: The Individual as a Consumer of Health}

\section{Services}

In 1991, individual choice was to become inextricably linked to New Right visions of health care when National Party Minister of Health Simon Upton released a Governmental discussion document entitled Your Health and the Public Health. ${ }^{71}$ Upton's document is more commonly known as the 'Green and White Paper.' The paper offered a New Right alternative to the way in which health provision, individual health, and the citizen were conceptualised under the Welfare state. The vision of this Green and White Paper would presage the 1993 New Right structural changes to health provision.

The Green and White paper used economic rationality to offer an alternative market based model of health. It argued that the quality of healthcare had been decreasing since $1960^{72}$ and contentiously ${ }^{73}$ claimed that health spending was becoming unsustainable. ${ }^{74}$ It stated: "Between 1980 and 1991 the Department of Health's budget increased from $\$ 1.1$ billion to $\$ 3.8$ billion, an increase of some 27 percent more than the increase of consumer prices over that period." ${ }^{75}$ The Green and White Paper used these cost and quality of care problems as a platform to promote a wide range of structural changes to the health system. Upton argued that health provision should become an efficient and economic process. Rather than being dictated by centralised decision makers, in this new system health services would be driven by economic demand and the principles of efficiency. The goal of the Green and White Paper's proposals was to improve health care access and waiting times ${ }^{76}$ and to offer an ideological and structural critique of the Welfare model of health. The paper opened the door to wholesale change based on principles of efficiency and an insurance-based model where those on higher incomes pay a premium for immediate health care.

\footnotetext{
${ }^{71}$ Upton, Your Health and the Public Health.

${ }^{72}$ It was claimed that in 1960 New Zealand had one of the best healthcare systems in the world. See: Ibid, 7.

${ }^{73}$ This statement was later refuted. See: Robert Bowie and Ian Shirley, "Political and Economic Perspectives on Recent Health Policy," in Social Dimensions of Health and Disease: New Zealand Perspectives, ed. John Spicer, Andrew Trlin, Jo Ann Walton (Palmerston North: Dunmore Press, 1994), 311

${ }^{74}$ Philip Bagshaw, "Mangerialism in public hospitals and universities in New Zealand," The New Zealand Medical Journal 113, no. 1106 (April 14, 2000): 114 .

${ }^{75}$ Upton, Your Health and the Public Health, 7-8.

${ }^{76}$ Ibid., 3 .
} 
The Green and White paper, replaced the term patient with the term “consumer". Upton's paper promoted a clear understanding of the citizen as a consumer of health products and services through the suggestion that after the Cartwright report into Cervical Cancer: ${ }^{77}$ “...health care services generally must be made more responsive to diverse and changing consumer needs." ${ }^{78}$ The sick were now portrayed to be rational and choosing consumers of health services and goods. Individual choice and agency was essential to the economics of this new approach to health.

The work of Toni Ashton is useful for outlining how economic understandings of efficiency and choice were viewed in the early 1990s New Zealand health sector. Ashton argued that choice is central to economics. For Ashton, the health sector faced the challenge of allocating scarce resources and, as such, needed to formulate a way to do so efficiently. ${ }^{79}$ 'Efficiency,' in Ashton's view, marked the point at which allocated resources produce maximum health benefits. This economic model thus required consumers and providers to make choices about their health care or provision based on this understanding of efficiency. The problem with this approach was that consumers did not always behave efficiently.

The New Right understanding of consumers and individual responsibility did not completely alleviate the State of all responsibility for the health of its citizens. The shift to a competitive health market recognised and required that individuals still needed to be educated, by the State, about the risks to their health. Cost efficient population health education was required to temper the risks of creating a competitive health market and individual choice. Consequently, the New Right viewed health education as an investment:

Public health programmes are essential long-term investments in health for the whole population. These activities need to be more visible to the public, with their funding specifically defined and protected. ${ }^{80}$

Upton considered health promotion an investment because money spent now would decrease the future costs of care. This rationale is evident in Upton's elaboration of his vision of public health:

The Government, as a principal funder of health services, has an interest in effective public health activities because they reduce publicly-funded treatment costs. Some

\footnotetext{
${ }^{77}$ For information about the Cervical Cancer enquiry see: S. Coney, The Unfortunate Experiment: the Full story Behind the Inquiry into Cervical Cancer Treatment (Auckland: Penguin Books, 1988).

${ }^{78}$ Upton, Your Health and the Public Health, 27.

${ }^{79}$ T. Ashton, The Economics of Health Promotion (Auckland: Premier Print, 1992), 4.

${ }^{80}$ Upton, Your Health and the Public Health, 1-2.
} 
campaigns bring rapid benefits, for instance, drink drive campaigns over holiday weekends aimed at reducing motor vehicle crashes. In other case, it will take longer for benefits to show up, for example, campaigns to reduce rates of smoking and lower the incidence of lung cancer, or nutrition and exercise campaigns aimed at lowering the incidence of heart disease. ${ }^{81}$

Upton's emphasis on public health meant that organisations such as the Hillary Commission became increasingly important for delivering health campaigns to the public. It was no accident that after 1992, the Hillary Commission began to emphasise "fitness" as a long term population priority. ${ }^{82}$ The broadness of the term 'fitness' moved its implications beyond health care discourse, to invoke ideas of success, natural selection, and social inclusion.

The Green and White Paper argued for notions of choice, personal responsibility, smaller government (public service), and economic efficiency to be applied to the health sector. Under its auspices, the Government attempted to educate and create financial incentives for individuals to exercise healthy behaviours. Public health programmes became understood as investments that would slowly decrease the costs of primary care to Governments. Public health programmes save Government's costs in a number of ways: healthy employees are less likely to be a tax burden, individuals bear the costs and responsibility for their own treatment and, ideally, the public health system encounters less preventable illnesses, allowing it to be more efficient in providing other services. The Green and White Paper created a vision of rational consumers who bore responsibility for their health, any future health costs, and who must actively work to insure against ill-health. This vision implied that the practice of healthy behaviour and the notion of 'fitness' were essential to good citizenship.

Under the Welfare system the patient had received standardised free care rather than their choice of care. Now, the consumer needed to be able to choose their type of care because it was no longer free and eventually they (or their family) would have to pay for the services and goods consumed through the provision of care. This system incentivised individuals to maintain their health/avoid getting sick because they, the consumer, would bear the cost of care rather than the State; it promoted individual personal responsibility rather than a Statebased collective social responsibility. This shift attests to a new awareness of the consumer's

\footnotetext{
${ }^{81}$ Ibid., 107.

${ }^{82}$ In 1992, reflecting the Green and White Paper proposals, the Recreation and Sport Act was amended and renamed the Sport, Fitness and Leisure Act. This emphasised the Hillary Commission's responsibility to promote the concept of 'fitness'. See Sports, Fitness, and Leisure Amendment Act 1992
} 
body in which New Right notions of economic efficiency were tied to the health and bodies of the population.

\subsection{The 1993 New Right Health Reforms}

The Green and White Paper's health reform proposals were implemented in the second term of the National Government. Bill Birch ${ }^{83}$ replaced Simon Upton as Minister of Health, in late March 1993, and in July 1993 the general principles of the Green and White Paper were incorporated into the Health and Disability Services Act 1993. The Health and Disability Services Act 1993 established 23 providers of health in New Zealand (Crown Health Enterprises or CHEs) who were separate entities from their funders (regional health authorities or RHAs). Many core health services were centralised into the larger urban hospitals. ${ }^{84}$ The new model of health $^{85}$ was competitive in nature and promoted fewer larger technologically advanced hospitals in combination with other new forms of health care such as health promotion. A new Public Health Commission independently located within the Department of Health supported these competing primary service providers. The Public Health Commission was responsible for health promotion primarily through public education about health and healthy behaviours.

The new model of health provision encouraged private insurance for individuals and made a distinction between private and publicly provided health services. Individuals were able to choose what health services and products they required or they could opt out entirely from the CHEs into private insurance schemes. Belgrave explains that the 1993 health reforms provided: "[F]inancial incentives for healthy behaviour, encouraging private insurance, placing user charges on services and reducing the proportion of funding provided for health care by the State." ${ }^{86}$ The National Government intended these changes to bring a business model into the health sector. This reform was intended to make CHEs profit making institutions that would provide health consumers with a series of health products and services. This New Right model of health was based on economic efficiency, cost reduction, and individual choice.

\footnotetext{
${ }^{83}$ Bill Birch was known, by his critics, as the toughest administrator in Cabinet. See B. Easton, The Commercialisation of New Zealand (Auckland: Auckland University Press, 1997), 161.

${ }^{84} 17$ New Zealand hospitals were closed and 2700 beds were lost between 1990 and 1994 from mostly rural areas. Similar closure of British hospitals was viewed as the physical removal of Welfare state health care delivery. See: Helmut Karcher et al, "Hospital closures," British Medical Journal 309 (15 October 1994); Tim Brown, "Towards an Understanding of Local Protest: Hospital Closure and Community Resistance," Social and Cultural Geography 4, no. 4 (December 2003).

${ }^{85}$ Bowie and Shirley divide the 1993 National Government reforms into eight categories. See: Bowie and Shirley, "Political and Economic Perspectives on Recent Health Policy," 306.

${ }^{86}$ Belgrave, A Historical Perspective, 78.
} 
Thus, equal access to health care had been replaced. The new system distributed health services between those who could and could not pay. Behavioural understandings of disease causality hold that all humans were equal but the health system in which this BCM model now existed gave preference to the wealthy. These health reforms made an economic distinction between rich and poor and the quality of care that an individual received. This economic distinction had a profound influence upon obesity rates in the 2000s. For example, certain researchers found that those who could afford to buy into a form of social insurance were thinner than those lacking insurance. ${ }^{87}$ Chapter Three shows that the 2000 Labour government, subsequently, revised these reforms based upon the rationale that they had produced serious socio-economic and ethnic inequalities in health.

\subsection{Behavioural Causality Policy $1996-1998$}

The BCM now functioned as a direct product of New Right health reform. The National Government focused on physical inactivity, developing several policies from 1996 onwards that cast physical inactivity and overeating as socially irresponsible and as indicative of a lack of moral judgement and personal responsibility. Healthy lifestyles functioned as a form of health insurance, mitigating future health risk and potential costs of care as well as generating a form of individual virtue.

Nutritional health was one area where virtue developed through restraint and it was one area MOH health promotion in the period 1996 - 1998. The MOH produced several generational investigations of nutritional health focused upon children, ${ }^{88}$ adolescents, ${ }^{89}$ and older people. ${ }^{90}$ These reports made generalised claims about obesity and nutrition such as obese children become obese adults. ${ }^{91}$ The reports suggested older people needed to be aware that a risk relationship exists between obesity and cardiovascular diseases, diabetes, hypertension and arthritis. ${ }^{92}$ Moreover, the reports noted that adolescents entering into a realm characterised by freedom of choice must develop strong personal controls over what they ate. ${ }^{93}$ It was clear that overeating was dangerous and resulted from poor choices, ill-discipline, or ignorance on the

\footnotetext{
${ }^{87}$ Andrew Kerr, Andrew McLachlan, Sue Furness et al, "The Burden of Modifiable Cardiovascular Risk Factors in the Coronary Care Unit by Age, Ethnicity, and Socio-Economic Status - Predict CVD-9,” The New Zealand Medical Journal, 121, no 1285 (November 7, 2008 ): 20.

${ }^{88}$ Ministry of Health, Food and Nutrition Guidelines for Healthy Children Aged $2-12$ years: A Background Paper (Wellington: Ministry of Health, Second Edition, June 1997), 8.

${ }^{89}$ Ibid., 1.

${ }^{90}$ Ibid., 22.

${ }^{91}$ Ibid., 8.

${ }^{92}$ Ibid., 22.

${ }^{93}$ Ministry of Health, Food and Nutrition Guidelines for Healthy Adolescents: A Background Paper (Wellington: Ministry of Health, June 1998)
} 
part of individuals. The implication of this language was that gluttonous individuals were irrationally causing their own ill-health and mortality risks.

However, it was physical inactivity which the National Government considered to be the largest modifiable behavioural contributor to lifestyle disease. This attitude appears to have followed the findings of the1996 US Surgeon General's report ${ }^{94}$ and it was also consistent with the findings of Prentice and Jebb. ${ }^{95}$ In Taking the Pulse, The 1996/97 New Zealand Health Survey, $36 \%$ of adults were described as being physically inactive. The survey claimed that:

Social and economic costs related to physical health are

- an increased burden on public health

- morbidity and impaired functional capacity in the workplace setting. ${ }^{96}$

The survey portrayed the individual's physical inactivity as having significant social and economic costs for a society. The argument was that physical inactivity placed an economic burden $^{97}$ on the health sector and increased the costs to employers. Poor choices on the part of consumers were economically inefficient and had greater social and economic implications for the community. ${ }^{98}$

Earlier it was demonstrated that a key component of the BCM is a preference for physical activity and sport as both social insurance and as an important part of active participation in the community. In the late 1990s, the National Government began to promote regular physical activity as being part of good citizenship. In early 1997, the Minister of Sport, Fitness and Leisure, the Hon Murray McCully commissioned research into finding ways to motivate New Zealanders to become more active. The National Health Committee's research Active for Life: A Call for Action ${ }^{99}$ produced a finding that argued: "[A]ll New Zealanders can improve their health and quality of life by including regular moderate amounts of physical activity in their daily lives." ${ }^{100}$ In April 1999, Murray McCully (Minister of Sport, Fitness and Leisure) and Wyatt Creech (Minister of Health) published a policy statement on physical activity. ${ }^{101}$ In this statement, these Ministers committed to work together with their two portfolios to promote

\footnotetext{
${ }^{94}$ See: U.S. Department of Health and Human Services. "Physical Activity and Health: A Report of the Surgeon General, 1996 (U.S. Department of Health and Human Services, 1996). This report argued that physical activity was the passport to good health for all Americans.

${ }^{95}$ Prentice and Jebb, "Gluttony or Sloth?"

${ }^{96}$ Ministry of Health, Taking the Pulse, The 1996/97 New Zealand Health Survey (Wellington: Ministry of Health, April 1999$), 8$.

${ }^{97}$ Chapter Six discusses how official obesity discourse utilises burden language.

${ }^{98}$ Chapter Seven discusses the economic debates in obesity discourse.

${ }^{99}$ National Health Committee, Active for Life: A Call for Action (Wellington: Ministry of Health, 1997)

${ }^{100}$ Ibid., 4.

${ }^{101}$ Murray McCully and Wyatt Creech, Physical Activity, Joint Policy Statement by the Minister of Sport, Fitness and Leisure and the Minister of Health (Wellington: Ministry of Health, April 1999).
} 
physical activity. In a joint statement: "[They] recognise that the benefits of increased participation in physical activity can make a contribution to the physical, mental, social and economic wellbeing of New Zealanders." ${ }^{102}$ The message was that physically active citizens contribute to the social and economic wellbeing of the country. The implication of this message was that the physically inactive were not contributing to national wellbeing. By 1999, those who were physically fit were being portrayed as a positively contributing to society, whereas the physically inactive obese were a burden on society.

In summary, the BCM focuses nutrition and exercise policy on encouraging individuals to take responsibility for their health. The State plays a limited role in this model. The State then encourages participation in the Nation through responsible exercise on the part of citizens. New Right rhetoric encourages citizens to exercise responsible choices when it comes to the food that they consume. Both physical activity and healthy food choices are a form of social insurance which protects both the individual and the institutions of the State (hospitals) from having to deal with the consequences of poor choices. The BCM strongly favours agency on the part of individuals but this focus has consequences. Poor choices on the part of the individual could be read as a personal failure to uphold their responsibility for individual and community health. The BCM was firmly established in the health policy of the 1990s, a political environment that established obesity as a significant health problem.

\subsection{Obesity Emerges as a Significant Health Problem in 1997}

I now shift focus, in this final section of Chapter Two, to argue that the results of the National Nutrition Survey 1997 (NNS97) would fuel the widespread New Zealand-specific concern with population rates of obesity which occurred in the 2000s. The NNS97 demonstrated that significant increases in population obesity rates had occurred in the short period since the LINZ89. This rapid increase in obesity was highly publicised and gave further impetus to the development health promotion campaigns promoting 'healthy lifestyles.' It also spurred further research into obesity which later produced the two alternate models of obesity causality discussed in Chapters Three and Four.

The 2000s research was wide-ranging because the NNS97 data was more methodologically sophisticated than the earlier nutrition surveys in that it provided data on ethnicity and

\footnotetext{
${ }^{102}$ Ibid., 2.
} 
deprivation. The NNS97 was a subset of the New Zealand Health Survey 1996/1997 $7^{103}$ and surveyed 4,363 New Zealanders aged 15 years and above. The survey was to "provide information on the inter-relationship of health, social, economic and nutrition variables in selected population subgroups for policy development." 104 The results of the NNS97 aimed to outline baseline data on the nutritional status and food security of the population and form a basis of comparison for future surveys. ${ }^{105}$ The NNS97 included representative data which correlated BMI and nutrition data with representative data regarding an individual participant's deprivation level and ethnicity. This is correlation is important because, as I explore in Chapters Seven and Eight, it would allow for more in-depth analysis of obesity prevalence within certain population subgroups.

The NNS97 results spurred concerns about an 'epidemic of obesity' because they indicated that the obesity and overweight affected almost half the population. The NNS97 measurements of BMI found that: "Thirty five percent of the population ( $40.4 \%$ males, $30.1 \%$ females) were classified as overweight and a further 17 percent were considered obese (14.7\% males, 19.2\% females). ${ }^{106}$ Together these results indicated that $51.1 \%$ of men and $49.3 \%$ of women were either overweight or obese. Approximately half the population were considered to embody a risk for cardiovascular disease. Furthermore, the authors compared these results, in a qualified manner, ${ }^{107}$ with those from the LINZ89. ${ }^{108}$ The NNS97 noted that: "Mean body weight has increased in the New Zealand population from $71.3 \mathrm{~kg}$ in 1989 to $74.5 \mathrm{~kg}$. The increase for males and females was $2.6 \mathrm{~kg}$ and $3.6 \mathrm{~kg}$ respectively." ${ }^{109}$ The NNS97 used these increases in average weight to argue that: "Mean body weight has increased by $3.2 \mathrm{~kg}$ since 1989 .

Associated with this increase was an increase in obesity levels from 11 percent in 1989 to 17\% in 1997." 110 These alarming statistics represented significant increases in the population weight and obesity rates over a very short period of time. Moreover, there were no indications, before the NNS97 results were released, that anticipated such a drastic increase in population weight.

\footnotetext{
${ }^{103}$ The survey was conducted in 1996/97 and measured 7862 adults. See: Ministry of Health, Taking the Pulse, 1.

${ }^{104}$ Ministry of Health, 1997 National Nutrition Survey, 3.

${ }^{105}$ Ibid., 4.

${ }^{106}$ Ibid., 164.

${ }^{107}$ The two surveys had different research methodologies, distributions of ethnicity, and distributions of age.

${ }^{108}$ Ministry of Health, 1997 National Nutrition Survey, 177.

${ }^{109}$ Ibid., 183.

${ }^{110}$ Ibid., 178.
} 
The increase in New Zealand's population obesity rates was paralleled in many other Western countries. In the UK the percentage of obese people had risen from $7 \%$ of the population in 1980 to $20 \%$ of the population by $2000 .{ }^{111}$ Similar increases in population obesity were measured in Canada between 1985 and 1998 with the numbers of classifications of obese more than doubling between 1985 (5.6\% of the population) and 1998 (14.8\% of the population). ${ }^{112}$ By the end of the 1990s, Western obesity rates were recognised as a global health priority and quickly resulted in rhetoric which explained obesity in terms of an 'epidemic', ${ }^{113}$ even coining the term 'globesity.',

The NNS97 results constitute a New Zealand example of this global trend of increasing population BMI levels. International concerns with this global trend together with local concerns with obesity prevalence clearly established that obesity would be a central public health problem for the 2000s. These NNS97 gave a mandate to health researchers, policy makers, and politicians to produce a wide range of obesity related research and regulation throughout the 2000s. Once this significant research into obesity prevalence and causality began, alternative causality explanations began to challenge the BCM.

\subsection{Conclusion}

The BCM developed out of population concerns with CVD and the New Right reforms of the Welfare State. In this chapter, I have shown that the New Right critique of the Welfare State produced a new awareness of the citizen as consumer. In the New Right model, political reform and health promotion combine in a political project that makes individuals more responsible for the risks to their health. Borrowing the negative associations of gluttony and sloth, poor nutrition and physical inactivity were the two of the primary targets of this new moralised project of health.

Understood as such, obesity discourse cannot be read as an objective medical discourse, as it often combines medical, political, economic, and moral discourses. Medical research into cardiovascular disease had demonstrated that nutrition, physical inactivity, and obesity were modifiable risks which could potentially reduce CVD mortality rates. This medical knowledge

\footnotetext{
${ }^{111}$ John Speakman, “Obesity Part one - The greatest health threat facing mankind,” Biologist Journal 50, no 1 (2003): 13.

${ }_{112}$ Peter Katzmarzyk, “The Canadian Obesity Epidemic 1985-1998,” Canadian Medical Association Journal 166, no. 8 (2002): 1039

${ }^{113}$ Highly cited examples of this rhetoric include Barry Popkin \& Colleen Doak, "The Obesity Epidemic is a Worldwide Phenomenon," Nutrition Reviews (April 1998); Phillip James, Rachel Leach, Eleni Kalamara \& Maryam Shayegi, “The Worldwide Obesity Epidemic,” Obesity Research 9 (2001).

${ }^{114}$ Speakman, "The Greatest Health Threat Facing Mankind,” 13.
} 
developed simultaneously with political projects to reduce the role of the State. The intention of these political projects was to place the cost of health care on consumers rather than the State. The notion of purchasing insurance was instrumental to New Right health politics. One could insure against CVD or other illnesses through a healthy lifestyle to mitigate the risk of becoming sick later in life. Under the BCM it became an important part of one's citizenship to exercise.

The realisation that sin, in the form of gluttony and sloth, could permanently affect our material success and our spiritual or physical health went hand in hand with this new awareness of our the body as an economic entity. The body and health became moralised. Physical fitness and healthy food choices became positive lifestyle characteristics of the New Right citizen consumer. Personal health discipline became a moral duty and those who did not practice this discipline lacked responsibility. Obese bodies physically transgressed these new rules of healthy conduct and, under the BCM, became the embodied location of political and medical discourses concerned with their lack of personal responsibility.

This discussion of the BCM is the departure point for the remainder of this dissertation. In the following chapter I consider a model of obesity causality which emerged as a direct ideological critique of the BCM. The BCM, its moral dimensions, and the emergence of the 'obesity epidemic' in 1997 often form the objects of critique for the content of this thesis. Many researchers and policy makers effectively contest the BCM because it is a poorly nuanced explanation of obesity. One fault of the BCM is that it assumes that society is equal and that each individual possesses identical opportunities and conditions in which to pursue health. In Chapter Three, it is apparent an equal playing field does not exist for health because socioeconomic and ethnic inequality exists within our society. A further fault of the BCM, as demonstrated in Chapter Four, is that it does not take into account the fact that certain food environments are structured in such a way that healthy food and exercise choices are, at times, almost impossible.

I want to stress, however, that despite these following critiques, the BCM still remains an incredibly powerful causal explanation because, in its unsubtle way, it focuses on the two primary controllable variables of obesity causality, gluttony and sloth. Crucially, unlike other models, the BCM holds that individuals retain the full agency to control these behaviours through personal discipline. The BCM always allows for the possibility of individual conversion, 
redemption, and salvation from obesity as long as a person sees the light of economic rationalisation. Chapter Five will demonstrate that the BCM is not an ideological artefact restricted to a 1990s context and that, in fact, the 2009 National Government applied this model to its own obesity policy. 


\section{Chapter Three: The Multiple Causality Model and the 'Obesity Epidemic' as Fact}

\subsection{Introduction}

In this chapter I discuss the second model of obesity causality arising from official obesity discourse. I argue that the Labour Government's obesity policy was founded upon a Multiple Causality Model (MCM) between the years 2000 and 2005. By demonstrating the emergence of the MCM the chapter continues its chronological analysis of obesity discourse. I show that the MCM emerged as a part of Labour's ideological critique of the former National Government's BCM health policy I outlined in Chapter Two. This chapter also traces how between 2000 and 2005 obesity prevalence was described as being of 'epidemic' proportions by the $\mathrm{MOH}$. The chapter critically analyses the reasons why this epidemic language was applied to obesity prevalence.

The discussion begins by defining the MCM, which holds that there are three causes of obesity: behaviour, biology and the environment. It then discusses the medical research which supports the MCM model. Next, it reviews the ideological and policy framework from which the MCM emerged. Two sections then follow discussing the Healthy Eating Healthy Action (HEHA) strategy which I argue was the premier example of MCM policy. First, I document the development of HEHA. I then explain how HEHA encapsulated early MCM approaches to obesity. Early MCM discourse focused upon an active State and did not prioritise physical activity over other causal factors. However, this early discourse utilised tokenistic environmental language whilst still, ultimately, relying on behavioural explanations for obesity causality. I then shift to demonstrate that MCM understandings of obesity evolved as these HEHA initiatives developed. Later MCM discourse (2004-2005) became more evenly weighted between the behavioural, biological and environmental causes of obesity. The final two sections of this chapter outline how obesity prevalence came to be portrayed as an 'epidemic.' I argue that Labour's identification of obesity as a health problem of 'epidemic proportion' provided a mandate to develop a series of obesity-related prevention programmes. These two final sections also seek to question the motivations behind $\mathrm{MOH}$ publications proclaiming the existence of an 'obesity epidemic.' 
This chapter offers a critique of the BCM view of disease causality. It explores how the BCM fails to account for the social inequalities that exist within a society. Thus, this discussion of the MCM opens space in obesity discourse for other environmental and structural determinants of disease to be considered alongside that of behaviour. This chapter also illustrates how an active State regulates against the dangers of disease. Because this State has an active role in society, the MCM does not emphasise individual responsibility to the same extent as the BCM. Rather for the MCM, responsibility for obesity causality can be found in a dynamic between individual behaviour and the effects of the environment. One consequence of this dynamic is that disadvantaged social groups can, to a certain extent, be absolved blame for their obesity due to their social inequality. MCM morality is more nuanced than the BCM individualised morality which blames obesity upon the behaviours of gluttony and sloth.

\subsection{The Multiple Causality Model}

The Multiple Causality Model of obesity (MCM) holds that there are three interrelated causes of obesity: behaviour, genetics, and the environment, rather than identifying any factor as a singular cause. The MCM treats nutrition and physical inactivity as equal behavioural causes of obesity, whereas the BCM, views physical inactivity as the major cause of obesity.

The MCM initially emerged as a refinement of the BCM. The MCM has two key differences from the BCM. First, the MCM advocates an active role for the State in treating obesity. Second, the MCM acknowledges that systematic factors such as socio-economic position, technology, food supply and ethnicity affect choice and behaviour. Thus the MCM is typically concerned with treating physical inactivity and poor nutrition, but this is tempered by statements that inequality is also a causal factor for obesity.

The MCM contains a disputed concept - the notion of the 'environment.' In this model, the word 'environment' generally refers to structural factors in society which contribute to obesity causing behaviour. Researchers and policy-makers do use the term 'environmental' in early MCM discourse but the term is essentially behavioural in emphasis. By 2004/05, however, MCM obesity policy began to shift toward prioritising a more balanced combination of environmental and behavioural causes of obesity. The concept of 'environment' changed further in 2006 when a new causality model located the sole cause of obesity in the environment (See Chapter Four). 
In Chapter Two, we saw that the BCM is primarily focused upon individual responsibility. Individual responsibility is still a key feature of the MCM but, in certain cases, it can be combined with other factors. The MCM assumes that most individuals have the capacity to make healthy choices but also recognizes that, in some circumstances, individual choice is subverted by socio-economic position, ethnicity, and/or other features of the social structure. Advocates of this model tend to believe that society is not equal, acknowledging that disease is distributed unevenly through the population. As a consequence, the MCM also acknowledges that some people may not be obese through choice. Thus, MCM discourse often tones down the language of choice, whereas such language is, by contrast, a central component of the BCM.

MCM discourse was prominent in the obesity policy of the New Zealand Labour Government between 2000 and 2005/06. The foremost example of MCM policy was the Healthy Eating Healthy Action Strategy ${ }^{1}$ (HEHA, discussed below). The MCM model casts Government in the role of an agent that actively intervenes through policy to mitigate structural inequalities in a society. While it stops short of arguing that the free market or capitalism produce obesity, it still acknowledges that lower-socio-economic groups have higher obesity prevalence. As a result, MCM discourse does not make the arguments for restricting the free-market or certain foods that are made by proponents of other models (See Chapter Four).

\subsection{The Medical Basis for the Multiple Causality Model}

The MCM views the primary medical cause of obesity to be a combination of individual behaviour and an obesogenic environment. Medical support for the MCM comes from work of Garry Egger and Boyd Swinburn. From the mid-1990s, Egger and Swinburn's research focused on the spread of obesity in the New Zealand and Australian populations. In $1997^{2}$ \& $1999^{3}$ Egger and Swinburn argued that obesity is a normal response to an abnormal environment ${ }^{4}$ and they promoted an 'ecological model' of obesity aetiology. This argument was critical of purely behavioural understandings of weight gain, claiming that they do not account for the other social and environmental influences. ${ }^{5}$

\footnotetext{
${ }^{1}$ A. King, Implementing the New Zealand Health Strategy 2002: The Minister's second report on progress on the New Zealand Health Strategy (Wellington: Ministry of Health, December 2002).

${ }^{2}$ Garry Egger and Boyd Swinburn, “An Ecological Approach to the Obesity Pandemic,” British Medical Journal 315 (23 August 1997)

${ }^{3}$ Boyd Swinburn, Garry Egger and Fezeela Raza, "Dissecting Obsesogenic Environments: The Development and Application of a Framework for Identifying and Prioritising Environmental Interventions for Obesity,” Preventative Medicine 29 (1999)

${ }^{4}$ Ministry of Health, Healthy Eating, Healthy Action, Oranga Kai - Oranga Pumau: A background 2003 (Wellington: Ministry of Health, March 2003), 39.

${ }^{5}$ Swinburn, Egger and Raza, "Dissecting Obsesogenic Environments," 563.
} 
Egger and Swinburn proposed a model that conceived of obesity causality as an equation. In this equation, the variables of biology and the environment affect individual behaviour. In discussing behaviour, Egger and Swinburn quote Prentice and Jebb's ${ }^{6}$ claim that the behavioural determinants of obesity are sloth and gluttony ${ }^{7}$ and a lack of willpower. This connection allows us to see how the MCM was related to the BCM. The medical basis of the MCM still moralises against the behavioural causes of obesity, in a similar way to the BCM, while simultaneously acknowledging the existence of circumstances where behaviour is influenced by factors relating to biology or the environment. For this reason, the moral dimensions of MCM discourse can be confused; at times MCM discourse blames behaviour, the environment or, more commonly, a combination of the two.

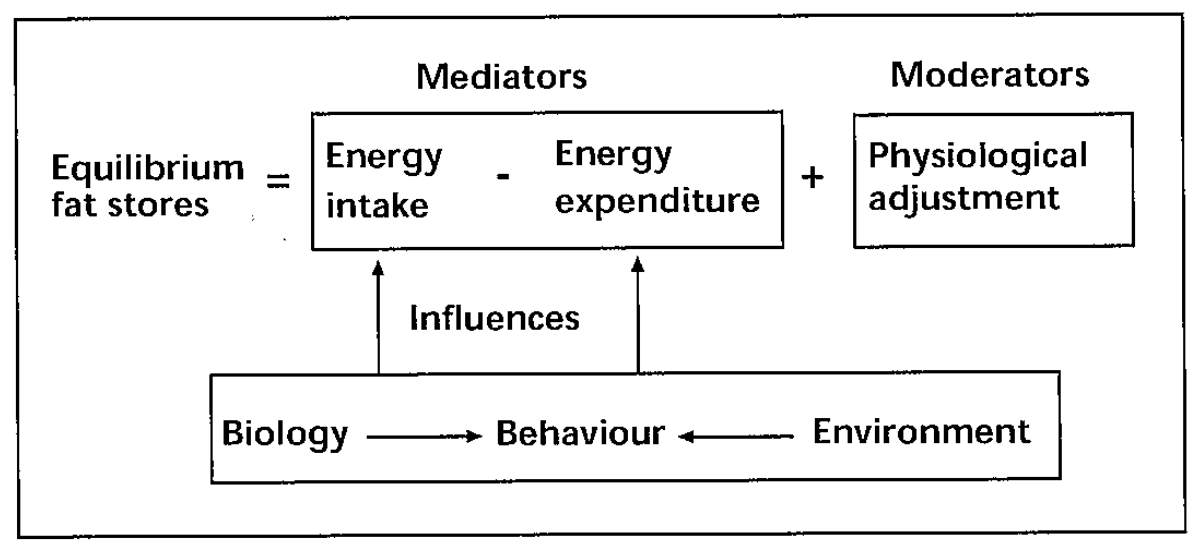

Source: Egger and Swinburn 1997

Egger and Swinburn's model added a third factor to the biological and behavioural determinants of obesity: the environment. ${ }^{8}$ They argued that the environmental factors affecting what and how much an individual eats are highly underrated. They claim that if a macro environment is "obesogenic", then without Governmental intervention, the population will inevitably become obese. Significantly, while Egger and Swinburn present their model as 'ecological,' a closer reading of their work reveals that they are still primarily interested in behaviour rather than emphasising the environment. This approach is characteristic of early MCM policy which uses environmental language in a tokenistic way whilst retaining a behavioural focus.

\footnotetext{
${ }^{6}$ Prentice and Jebb, "Gluttony or Sloth?"

${ }^{7}$ Swinburn, Egger and Raza, “An Ecological Approach,” 1.

${ }^{8}$ Ibid., 1 .
} 
The terms 'ecological' and 'environment' require clarification, because 'environment' is a contested term. Usages of the term 'Environment' in obesity discourse can at times refer to, physical environments, food supply, capitalism, the free-market, socio-economic inequality and socio-cultural environments. To further add to this confusion, Egger and Swinburn themselves use these two terms fairly interchangeably. The ambiguity surrounding this term would eventually led to the development of the Environmental Causality Model which took a broader view of environmental determinants of obesity and was influenced by Green party ideology.

MCM discourse originally located the primary environmental factors affecting obesity prevalence in socio-economic and socio-cultural inequality. This focus is consistent with the social inequalities policy approach taken by the Labour Government until this approach was criticised by Don Brash in 2004. ${ }^{9}$ Importantly, while the language of MCM discourse is environmental, the treatments are still primarily behavioural. From 2005, however, the MCM balanced environmental causal factors in combination with biological and behaviour causality. Late MCM policy discourse would rewrite Egger and Swinburn's work into an equal dynamic between the three variables.

\subsection{An Inequality Focus and 'Third Way' Politics}

The MCM began as an ideological response to the perceived failings of the BCM approach to health provision and policy promoted by the National Government in the 1990s. The MCM was formed by a combination of 'third way' politics and concerns about structural inequality. In 2000, the Labour Government was particularly concerned about inequalities in health. The MOH's incoming Minister's briefing papers identified obesity as both a cultural and a socioeconomic risk factor for poor health. ${ }^{10}$ These papers emphasised the need to reach Maori and Pacific Island peoples ${ }^{11}$ and the need to treat preventable diseases (no mention of obesity) through treatment of underlying factors such as diet and physical activity. ${ }^{12}$ The early MCM combination of behavioural, genetic, and environmental concerns was already evident in this policy approach and five years later, obesity became a primary concern of this Government.

\footnotetext{
${ }^{9}$ Chapter Eight analyses Don Brash's criticisms of ethnic inequality policy.

${ }^{10}$ Ministry of Health, Health Opportunities, Leading in Health and Disability: Briefing Paper for the Incoming Minister of Health (Wellington: Ministry of Health, January 21, 2000), 8.

${ }^{11}$ Ministry of Health, Social Inequalities in Health, 1999 (Wellington: Ministry of Health, September 2000).

${ }^{12}$ Ibid., 3.
} 
The Labour party's focus on inequality signalled the implementation of a 'third way,' social inclusionary ideological approach to health. This 'third way' was located between New Right approaches and the old social welfare-based position of the Left. ${ }^{13}$ 'Third way' politics have their origins in Britain and in the theory of Anthony Giddens. Giddens' work attempts to find a balance between two ways of approaching social policy. Michael Belgrave argued that 'third way' Governments did not replace the structural reforms of their New Right predecessors; rather, they replaced ideas of choice, competition, and the consumer with notions of social inclusion, coordination of services, and community cooperation. Belgrave states:

The first, a social democratic tradition, with an emphasis on state management and control and egalitarian outcomes, had roots in the Fabian movement which favoured gradualist and evolutionary socialism. The other way rested in neo-liberal social and economic reform, which emphasised markets and community and individual responsibility and denigrated state planning. The third way was an attempt to find compromise between these apparently mutually exclusive approaches. ${ }^{14}$

Labour's 'third way' was a political response to the New Right reforms of the 1980s and 1990s. Structural concerns with income and ethnic inequality were initial characteristics of Labour's 'third way' politics. Helen Clark's Closing the Gaps Budget ${ }^{15}$ in 2000 was an initial example of 'third way' politics as it was acutely concerned about ethnic inequality.

This transition from New Right politics to 'third way' politics brought along a new understanding of disease treatment. The ideological differences between the BCM and Labour's new model of health can be found the table below, taken from the Primary Health Care Strategy. ${ }^{16}$

\footnotetext{
${ }^{13}$ Belgrave, A Historical Perspective, 71

${ }^{14}$ Ibid., 80.

${ }^{15}$ M. Cullen, Minister of Finance Budget Policy Statement 2000 (Wellington: The Treasury, $8^{\text {th }}$ March 2000).

${ }^{16}$ A. King, The Primary Health Care Strategy (Wellington: Ministry of Health, February 2001).
} 
The table below shows, in broad-brush terms, some of the differences between most existing arrangements and the vision.

\begin{tabular}{|l|l|}
\hline Focuses on individuals & Looks at health of populations as \\
& well \\
Provider focused & Community and people-focused \\
Emphasis on treatment & Education and prevention \\
& important too \\
Doctors are principal providers & Teamwork - nursing and \\
& community outreach crucial \\
Fee-for-service & Needs-based funding for \\
Service delivery is monocultural & population care \\
& Attention paid to cultural \\
Providers tend to work alone & competence \\
& Connected to other health and \\
& non-health agencies \\
\hline
\end{tabular}

New Zealand Primary Health Care Strategy, P 7.

This table shows how Labour understood itself to be modifying the former consumer-based, competition funded, fee-for-service hospital model of health care. The table promotes a vision of health which concentrates on communities, culture, and identifying and funding specific health needs. Health funding would be funded on the basis of need, thereby setting the scene for treatment of diabetes and obesity in specific groups. ${ }^{17}$

This table further illustrates that health care delivery was ideologically divided. The 'Old' New Right approach is accused of treating New Zealanders through primary care, choice, and on a "monocultural" (equal) system rather than through a socially inclusive community-based model Labour's "New" view was that disease was distributed unequally and that health systems based on individual approaches should, instead, prioritise certain communities and cultural groups. Treaty of Waitangi obligations to Maori and the reduction of all ethnic disparities in health were an immediate priority. ${ }^{18}$ The Closing the Gaps budget ${ }^{19}$ was directly aimed at reducing the social and economic inequalities affecting Maori and Pacific Islanders.

\footnotetext{
${ }^{17}$ Ibid., 7.

${ }^{18}$ Cullen, Budget Policy Statement 2000, 6.

${ }^{19}$ Ibid.
} 
This focus on ethnic inequality brought concerns with obesity to the fore, because this was a disease linked with inequality. Quantitative data had been published that suggested ethnicity and socio-economic status were correlated with health inequality. ${ }^{20}$ This review also contained estimates of avoidable mortality. It claimed that physical inactivity accounted for about $8 \%$ of avoidable deaths and that obesity and diabetes each separately accounted for an additional 4-5\% of deaths. ${ }^{21}$ In total, these avoidable mortalities accounted for approximately 4500 deaths in $1996 .^{22}$ The risks of obesity, physical inactivity, and poor nutrition were now being made public but these statistics were not sensationalised as they would be in 2005/06. The primary claim of the 2000 review was that the groups that experienced inequality also had comparatively high rates of avoidable deaths due to physical inactivity, nutrition and obesity. This meant that policy that focused on mitigating the effects of inequality must also focus upon obesity.

One important consequence of this health inequality focus was that BCM approaches to disease would require modification, because BCM approaches assumed that individuals were all equal and that illness was distributed evenly throughout the population. In contrast, the 'third way' approach to health argued that inequality represented a structural (environmental) determinant of health that affected the distribution and prevalence of mortality or illness in the general population. This different approach to causality provided the ideological ground for Labour to develop and implement MCM policy.

\subsection{The New Zealand Health Strategy 2000}

The policy implementation of Labour's concerns with inequality occurred in the New Zealand Health Strategy 2000 (NZHS2000). The NZHS2000 was the foundation document determining the overall health policy approach between 2000 and $2008 .{ }^{23}$ This document would guide the replacement of a system of BCM health provision with MCM health provision. Released in December 2000, the NZHS2000 strategy focused on restoring confidence in the health system $^{24}$ and providing access to care for all, regardless of socio-economic status or ethnicity. ${ }^{25}$ The NZHS2000 signalled that privatised care and personal responsibility would not be central components of future health policy. It stressed the need to reduce the health inequalities and

\footnotetext{
${ }^{20}$ Ministry of Health, Key Findings from Our Health Our Future - Hauora Pakari Koiora Roa: The Health of New Zealanders (Wellington: Ministry of Health, January 21, 2000).

${ }^{21}$ Ibid., 4.

${ }^{22}$ Ibid., 4

${ }^{23}$ A. King, The New Zealand Health Strategy, 2000 (Wellington: Ministry of Health, December 2000).

${ }^{24}$ This health strategy promised to reform the health system after the "failure" of 1990s decentralised market based model of health.

${ }^{25}$ King, The New Zealand Health Strategy 2000, iii.
} 
disparities that it argued had increasingly appeared in the population. Under the broad heading 'Inequalities in Health', ${ }^{26}$ the NZHS2000 identified Maori, Pacific Islanders, and those in lower socio-economic groups as the groups experiencing health inequality. It was apparent that this Government viewed itself has having an active responsibility to increase the health and wellbeing of the population through collective and integrated health strategies.

The NZHS2000 also designated the management of obesity as an official health objective. This signalled the origin of Labour's MCM approach to the disease. The NZHS2000 presented 13 population health objectives. These objectives included improving nutrition, reducing obesity, increasing physical activity, reducing the incidence of impact of cardiovascular disease, and diabetes. ${ }^{27}$ The NZHS2000 noted that the diseases targeted by these 13 objectives were to some extent avoidable and could be reduced through effective Governmental action. ${ }^{28}$ Thus, Labour's concern with obesity escalated throughout the 2000s as they worked toward achieving their population health objectives.

It quickly became apparent in the NZHS2000 that the problem of inequality necessitated revisions of purely BCM explanations of obesity. In 2001, Annette King discussed obesity in her first report on the progress of the New Zealand Health Strategy. ${ }^{29}$ She pointed to the NNS97 increase in obesity prevalence using BCM language: "The major causes of obesity and overweight are related to nutritional factors and a lack of physical activity." ${ }^{30}$ However, she then linked behavioural causality notions to discussions of socio-economic position and ethnic inequality:

Socio-economic disadvantage increases the likelihood of poor nutrition, overweight and obesity. The 1997 National Nutrition Survey showed that those living in more deprived areas, and Maori and Pacific peoples, were more likely to have a poor nutrition. The diet of households of lower socioeconomic status tends to be energy dense; high fat intakes are a prominent feature while vegetables, fruit, and whole grain cereals are eaten more sparingly. ${ }^{31}$

King's comments demonstrate that the MCM was already evident in obesity discourse early in the term of this new Labour government. Here, King shifts attention to one understanding of

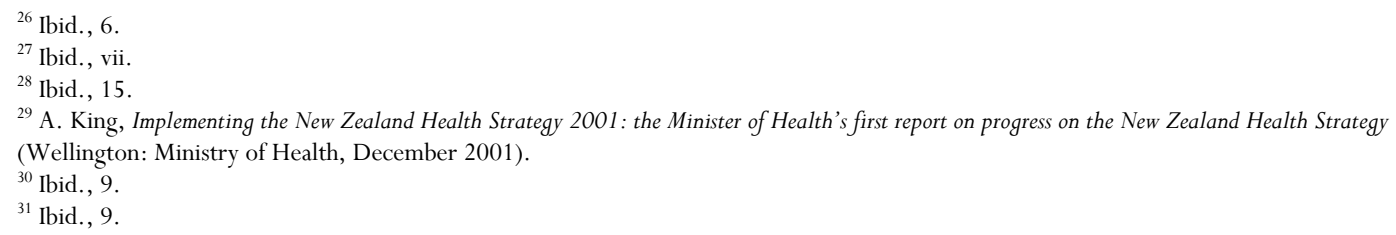


the environmental (inequality) determinants of obesity, arguing that those people who were economically disadvantaged had an increased likelihood of being overweight and/or obese.

Nutrition was one of the first areas targeted by the MCM approach because it was identified as an area where ethnic inequality was a systemic influence. King noted in her NZHS2000 report that poor nutrition was a determining factor both in causes of death and in the prevalence of obesity, diabetes, and hypertension. ${ }^{32}$ Moreover, she reported that poor nutrition was more prevalent in Maori and Pacific Islands people than other ethnic groups. ${ }^{33}$ King further stated:

There is considerable scope for reducing health inequalities by improving lifestyle choices such as diet. It is recognised, however, that policies aimed at changing habitual behaviours need to be sensitive to different socio-cultural contexts and to address the underlying social inequalities themselves. ${ }^{34}$

King made it clear that Labour considered structural inequality as affecting behavioural explanations of obesity. The BCM's creed of individual responsibility thus needed to be tempered by other external considerations such as socio-economic position and ethnic inequality. The focus on socio-cultural context made Labour policy in this period a relatively early example of a non-behavioural explanation of obesity and related disease prevalence. ${ }^{35}$ The MCM did not continue the BCM's privileging of physical inactivity over poor nutrition as a causal factor of obesity. Instead, Labour policy treated both behavioural factors evenly.

The NZHS2000 set out the ideological and structural ground from which the MCM was developed. The NZHS2000 was developed in response to the criticism that the BCM did not account for structural inequality. Moreover, this focus on inequality put obesity on the health agenda of the Labour government. Labour viewed itself as having an active role in implementing obesity interventions aimed at improving physical activity and nutrition and reducing the socio-economic and ethnic inequality determinants of obesity. This active State was a very different to the decentralised State of the BCM. MCM policy required an active state which saw itself as having a significant role in preventing and treating obesity.

\footnotetext{
${ }^{32}$ Ibid., 8.

${ }^{33}$ Ibid., 8 .

${ }^{34}$ Ibid., 8.

${ }^{35}$ King noted that further material on nutrition, healthy weight and physical activity is being developed by the MOH under the banner Health Food: Healthy Action. See: Ibid., 10.
} 


\subsection{Development of the Healthy Eating Healthy Action Strategy}

The development of the Healthy Eating, Healthy Action (HEHA) strategy led the Labour Government to take an active MCM role in the management of obesity. A key language change occurred in obesity discourse which indicated that Labour would take an active role. In $2002^{36}$ the Labour Government signalled that they would treat obesity as a widespread general population problem rather than an issue associated with inequality. Annette King indicated that a national integrated strategy to improve nutrition, increase physical activity, and reduce obesity would be released in $2003 .^{37}$ This HEHA strategy was to be the cornerstone for further nutrition policy and programmes. ${ }^{38}$ Additionally, the report claimed that obesity was "a burgeoning public health problem"39 and that it would be a health priority of this term of government. In framing obesity as a general health threat requiring regulation, the Labour effectively generated a mandate to undertake an active MCM role.

HEHA was an umbrella strategy that mandated a variety of potential Government interventions for obesity. The HEHA strategy focused on treating and improving nutrition, physical activity rates, and obesity prevalence. HEHA was also a response to the growing prevalence of Type 2 Diabetes. ${ }^{40}$ The HEHA strategy document outlined three goals: 1 ) Improve Nutrition, 2) Increase physical activity, 3) Reduce Obesity. ${ }^{41}$ The HEHA document attempted to prevent and treat the health concerns identified in the NZHS2000 as it combined approaches to combat nutrition, physical inactivity, cardiovascular disease, Type 2 Diabetes, and obesity. HEHA followed the MCM approach by treating nutrition and physical inactivity as equal causes.

HEHA linked global concerns and approaches to obesity prevention with New Zealand specific obesity concerns. It took the principles of the population health outlined 1986 Ottawa

\footnotetext{
${ }^{36}$ The second term of the Helen Clark led Labour Collation Government began in July 2002.

${ }^{37}$ HEHA originated in February 2002, when the Ministry of Health asked for submissions on a new nutrition and physical activity framework. See: Ministry of Health, Healthy Action - Healthy Eating Oranga Pumau - Oranga Kai: Towards an Integrated Approach to Physical Activity, Nutrition and Healthy Weight for New Zealand, Submission Booklet (Wellington: Ministry of Health, February 2002).

${ }^{38}$ King, Implementing the New Zealand Health Strategy 2002, 9.

${ }^{39}$ Ibid., 11.

${ }^{40}$ The Health Funding Authority in March 2000 released the Diabetes 2000 Report. The report noted that Diabetes is a health problem which could potentially affect every New Zealander with some 115,000 (104,000 of which were Type 2 Diabetics) diagnosed in 2000 with estimates of a further 50-60,000 undiagnosed diabetics in the population. Type 2 Diabetes primary causal factors are identical to the aetiological causes of obesity. Most Type 2 diabetics were also obese or overweight and that the amount of diabetics in the population is expected to rise strongly. The Diabetes 2000 report was focused specifically on Maori and Pacific Islands peoples. The report viewed the responsibility for the management of Diabetes residing in the actions of the diabetic individual themselves. This report applied a MCM approach to Diabetes with the caveat that certain economic and ethnic factors affect its prevalence. In this report the links existing between health disparities, Type 2 Diabetes, obesity, physical inactivity, and poor nutrition were all made explicit. See: Health Funding Authority, Diabetes 2000 (Wellington: Health Funding Authority, Te Mana Putea Hauora O Aotearoa, March 31, 2000)

${ }^{41}$ Ministry of Health, Healthy Action - Healthy Eating Submission Booklet, 3.
} 
charter $^{42}$ and applied them to the principles of the Treaty of Waitangi. In December 2002, the $\mathrm{MOH}$ published a summary of the feedback regarding the proposed HEHA framework. ${ }^{43}$ The submissions were varied and included consultation with both Maori and Pacific Island groups. ${ }^{44}$ In this feedback, two-thirds of respondents indicated their preference that disadvantaged groups should be a priority area. ${ }^{45}$ The HEHA submissions acknowledged that Maori and Pacific Islands people were disadvantaged and as a result their consultation was required in developing a more general population strategy. This is an example of how general approaches to obesity and Type 2 Diabetes were developing out of Labour's concern with inequalities.

In summary, the development of the HEHA framework saw further integration of formerly targeted health inequality issues into a general population approach to health. The HEHA strategy targeted four of the population health goals identified by the NZHS2000. These were Type 2 Diabetes, physical inactivity, poor nutrition, and obesity. The HEHA legislation signalled that obesity was now a primary focus of health policy. In the following section, I elaborate on the MCM approach taken by the HEHA strategy.

\subsection{HEHA and Multiple Determinants of Obesity}

While the MCM approach of HEHA, at this time, did not privilege nutrition over physical activity, it emphasised these behavioural causal factors at the expense of attending to environmental causes of obesity. Although the HEHA used environmental language, it still retained a strong behavioural focus for its policy. The HEHA background document was a formal review of the established scientific, medical, and policy literature pertaining to obesity and focused upon Egger and Swinburn's ecological model of obesity causality. ${ }^{46}$ As such, HEHA followed Egger and Swinburn's differentiation between the biological, behavioural, and environmental influences on obesity causality. ${ }^{47}$

HEHA described the biological influences as ethnicity, gender, age, hormonal factors and genetics. In Egger and Swinburn's model these factors are described as genetic factors. The HEHA document discussed the environmental influences on the 'obesity epidemic' as follows:

\footnotetext{
${ }^{42}$ First International Conference for Health Promotion, Ottawa Charter for Health Promotion (Ottawa, First International Conference for Health Promotion, November $21^{\text {st }}, 1986$ ).

${ }^{43}$ Ministry of Health, Healthy Action - Healthy Eating Submission Booklet.

${ }^{44}$ Ibid., 7 .

${ }^{45}$ Ibid., 18.

${ }^{46}$ Ibid.

${ }^{47}$ Ibid., 46.
} 
Probably the most important cause of the rapid global rise in obesity rates lies in the profound and rapid changes to the environment and society now affecting large parts of the world. Modernisation, urbanisation and changing occupational structures are creating societies in which physical activity levels are low and the availability of highfat, high sugar, energy-dense foods has increased. Populations now live in environments that inadvertently promote sedentary lifestyles and over consumption of energy-dense foods. Maintaining a healthy weight and optimal fat stores requires considerable effort, which is difficult to maintain in an unsupportive environment. ${ }^{48}$

The HEHA report emphasised these environmental causes as equal causes with the behavioural causes of obesity. The report discusses the rapid increase in national obesity rates ${ }^{49}$ and acknowledged that the real causes of obesity were still not properly understood. It also noted that certain people could be more disposed to weight gain than others. However, it was quick to state that genetic explanations do not effectively explain the rapid growth in obesity rates in the prior two decades. ${ }^{50}$ The report concluded by stating that strategies which address the environmental influences on obesity rates will be essential in the future. ${ }^{51}$ Thus, HEHA signalled that an MCM approach to obesity would be followed which balanced causality equally between environmental, behavioural, and biological factors.

However, this shift towards environment factors and a true MCM approach was, in fact, more rhetorical than actual. While noisily proclaiming that it would focus on the larger environmental causes of obesity, HEHA still primarily focused on treatment of the behavioural causes of obesity (physical inactivity and poor nutrition). Two of the three goals of HEHA focused on the behavioural determinants of obesity: improving nutrition and reducing physical inactivity. This focus is also evident in Egger and Swinburn's research which employs environmental language but still primarily focuses on behaviour. Both the HEHA and Egger and Swinburn acknowledge that environmental factors affect behaviour but, in both cases, they do not override the pre-eminence of individual choice and responsibility.

This underlying behavioural approach, Michael Belgrave argues, remained a broad characteristic of the third-way political model. While third-way governments softened their emphasis on the market, competition, and consumer choice, Belgrave claims that they never reversed or dismantled the major reforms of their neo-liberal processors. Third-way

\footnotetext{
${ }^{48}$ Ibid., 46.

${ }^{49}$ Ibid., 45.

${ }^{50}$ Ibid., 45.

${ }^{51}$ Ibid., 46.
} 
governments, for instance, continued to devolve responsibilities for health onto individuals. ${ }^{52}$ Similarly, for the early MCM examples, the environment was a causal factor but the behavioural determinants of obesity remained central to the problem of obesity.

This section has shown that HEHA applied the MCM approach to obesity. However, certain MCM characteristics were more pronounced than others. On the one hand, the State was taking an active role and some of the responsibility for treating and preventing obesity causality. In addition, HEHA did not follow the BCM preference for physical inactivity as the primary behavioural causal factor. Nutrition and physical inactivity were both treated as equally relevant causal factors. On the other hand, HEHA continued to privilege nutrition and physical inactivity over genetic and environmental causality. Environmental language and Egger and Swinburn's ecological model were being trumpeted by the MOH but this early MCM policy remained, at its core, focused upon behavioural modification solutions.

\subsection{Behavioural Obesity Policy with Environmental Labelling}

MCM obesity policy released y the MOH in the period $2003-2005^{53}$ was, at best, tokenistic in its environmental approach. This combination of environmental language with a primarily behavioural focus was central to early MCM policy. Significantly, other HEHA contemporary policies also repeated this approach. As with early MCM policy, when these policies did refer to 'environmental' causes it remained unclear what was meant by the term. The term environment was slippery, it implied that this policy was addressing structural determinants of disease when, at that time, it was simply new language being applied to the old behavioural approaches. Two examples of this early MCM approach can be found in the DHB toolkit Physical Activity ${ }^{54}$ and the Food and Nutrition Guidelines for Healthy Adults. ${ }^{55}$

In addition to providing an example of the environmental labelling of behavioural approaches, The DHB toolkit Physical Activity reframed physical activity. Where BCM policies had previously cast physical activity as an essential part of citizenship, the DHB toolkit instead argued that physical activity required a relationship between an active state and communities. DHBs were required to play an active role in increasing physical activity in their communities.

\footnotetext{
${ }^{52}$ Belgrave, A Historical Perspective, 81.

${ }^{53} \mathrm{MOH}$ documents released over this period were nested in the NZHS2000 and HEHA frameworks.

${ }^{54}$ Ministry of Health, DHB Toolkit: Physical Activity, To Increase Physical Activity (Wellington: Ministry of Health, June 2003).

${ }^{55}$ Ministry of Health, Food and Nutrition Guidelines for Healthy Adults: A Background Paper (Wellington: Ministry of Health, October 2003).
} 
The toolkit ${ }^{56}$ argued that DHBs can use a framework based in "settings" such as schools and workplaces to increase physical activity in their communities. This community-oriented approach was an early interpretation of the environmental (emphasising that communities were environments) approach to treating physical activity behaviours. The toolkit encouraged DHBs to promote the Green Prescription, ${ }^{57}$ and specifically to promote exercise among Maori and Pacific Islanders. The DHB toolkit is another example of the transition of obesity policy away from unequal population subgroups to a focus on the entire population. The toolkit also indicated that SPARC's Push Play programme ${ }^{58}$ and the Green Prescription are two national programmes that were being used to promote exercise.

The 2003 Food and Nutrition Guidelines for Healthy Adults ${ }^{59}$ (Nutrition Guidelines) also critiques $\mathrm{BCM}$ approaches to obesity, whilst still retaining a behavioural approach to obesity treatment. The Nutrition Guidelines argued that, until recently, behavioural understandings of the aetiology of obesity were over-simplified. Such BCM oversimplification, the Nutrition Guidelines suggested, was responsible for a general failure to address obesity as a health issue. ${ }^{60}$ These guidelines are critical of the BCM model of obesity governance and the emphasis upon individual responsibility. They imply that it was the failure of this BCM model, as well as the failure on the part of citizens to treat behavioural causes of obesity, that led the Government to promote further investigation into obesity causality. The Nutrition Guidelines analysed obesity causality using Egger and Swinburn's ecological model of obesity. ${ }^{61}$ The guidelines reinforced how regular physical activity reduces the risks of various diseases, yet also argued that exercise behaviours are influenced by external environmental, individual, and socio-economic factors. Following the MCM approach, the Nutrition Guidelines described physical activity as an equal partner to nutrition. ${ }^{62}$

However, a closer analysis of the Nutrition Guidelines shows that they were still primarily focused on behavioural causes of obesity. The Nutrition Guidelines background paper aimed to support three of the key priorities outlined by the NZHS2000, that of nutrition, physical activity, and obesity. The Nutrition Guidelines set out to provide general population dietary

\footnotetext{
${ }^{56}$ Ministry of Health, DHB Toolkit: Physical Activity.

57 The Green Prescription is described fully later in this chapter. See Ibid., 27.

${ }^{58}$ Push Play began in 2000 and it was SPARC's nationwide social marketing campaign aimed at increasing physical activity. He Oranga Poutama was held up as a Maori physical activity initiative. Ministry of Health, Healthy Eating - Healthy Action Oranga Kai - Oranga Pumau: Progress on Implementing the HEHA Strategy 2007 (Wellington: Ministry of Health, March 2007), 15.

${ }^{59}$ Ministry of Health, Food and Nutrition Guidelines for Healthy Adults.

${ }^{60}$ Ibid., 49.

${ }^{61}$ Ibid., 49.

${ }^{62}$ Ibid., 73.
} 
standards so everyday people could maintain a healthy body weight. The paper emphases the necessity for behavioural determinants ${ }^{63}$ of health: "Good nutrition, physical activity and maintaining a healthy body weight are fundamental to health and to the prevention of disease and disability. ${ }^{64}$ The paper then continues to focus upon these behavioural factors in detail without relating them to the wider environmental causes of obesity.

The Nutrition Guidelines did not completely omit environmental explanations, but the environmental explanations offered are unclear and undeveloped. For example, they promoted the need for integrated public health approaches and stated that there are powerful societal and environmental forces which influence energy intake and expenditure. They also emphasised the need for Government-based public health interventions targeting food consumption environments, industries, and communities. ${ }^{65}$ However, the Nutrition Guidelines did not explore or develop these factors. Instead, the Nutrition Guidelines clearly foreground the individual's responsibility for monitoring their nutrition and physical activity. Again, this move is characteristic of the early MCM approaches, which used environmental considerations in a tokenistic way.

The Food and Nutrition Guidelines and the DHB Toolkit show that the MCM model had begun to employ environmental language to argue that obesity was also caused by structural factors. However, at this time, it was extremely unclear what was implied by these “environmental" factors. Socio-economic and ethnic inequality were two early examples of these factors, but it was clear that these documents were implying that there were further structural determinants of health inequality. It appears that the ambiguity of this language was one reason that the behavioural determinants of obesity continued to be regarded as treatable causal factors of obesity. Another more plausible reason might have been that the behavioural determinants of disease remained the easiest causal factors of obesity to treat while effective treatments and diagnosis of "environmental" causes of obesity were difficult to implement.

\footnotetext{
${ }^{63}$ The Nutrition Guidelines emphasised the need for balance between energy consumption and expenditure. It stated that changes in energy balance are assessed by changes in body weight and body composition and noted that the mean body weight of adults increased from $71.3 \mathrm{~kg}$ in 1989 to $74.5 \mathrm{~kg}$ in 1997 . This quantitative approach to obesity suggests that the behavioural causes of obesity can be measured and known. See: Ibid.,

${ }^{64}$ Ibid, , iii.

${ }^{65}$ Ibid., 56.
} 


\subsection{The Emergence of Full MCM Policy in 2004}

The MCM fully emerged with the final release of HEHA Healthy Eating - Healthy Action: Oranga Kai - Oranga Pumau, Implementation Plan: 2004-2010 in June 2004. Its vision was “[a]n environment and society where individuals, families and communities are supported to eat well, live physically active lives and attain a healthy body weight." ${ }^{66}$ In addition to highlighting HEHA's three goals of improving nutrition, increasing physical activity, and reducing obesity, the implementation plan also supplied a financial dimension to obesity policy. Accordingly, in the foreword, Annette King stated:

Obesity, and the impact of diseases such as cardiovascular disease, cancer and Type 2 Diabetes, can be modified by the actions outlined in the Healthy Eating - Healthy Action: Oranga Kai - Oranga Pumau, Implementation Plan: 2004-2010. The burden of these diseases and the downstream health care costs of doing nothing to reduce illness and premature death due to poor nutrition, physical inactivity and obesity are unsupportable. We must act now in a coordinated way to reduce this impact. ${ }^{67}$

In this statement, King conflates two distinct 'costs' to the nation, framing obesity as a cost to the mortality of population and, consequently, as the source of an increasing financial cost to the nation. It is the Labour Government, she suggests, that must avoid having to bear both of these costs by taking responsibility for treating obesity at a population level.

The 2004 HEHA signalled the final development of MCM approaches to obesity by defining how specific environments actually affected obesity-related behaviour. The HEHA Implementation Plan stated that the health sector could not achieve success against obesity on its own. It recommended an inter-sectorial approach to the 'obesity epidemic,' which required cooperation from the public sector, the private sector, NGOs, and communities themselves. This broader framework of HEHA heralded the beginning of attempts to alter wider determinants of obesity at the environmental level. The HEHA Implementation Plan offered a six year plan beginning with a public health information campaign intended to promote messages about healthy eating, physical activity, and the dangers of obesity. The Implementation Plan was divided into three distinct phases, each taking a two year period in a timeframe between 2004 and 2010. The first phase involved adopting the WHO's Global Strategy on Nutrition and Physical Activity ${ }^{68}$, intervening in high risk groups, and promoting inter-sectorial and community awareness of nutrition and physical activity. This phase had already been

\footnotetext{
${ }^{66}$ Ministry of Health, Healthy Eating - Healthy Action: Oranga Kai - Oranga Pumau, Implementation Plan: 2004-2010 (Wellington: Ministry of Health, June 2004), 19.

${ }^{67}$ Ibid., iii.

${ }^{68}$ World Health Organisation, Global Strategy on Diet, Physical Activity and Health, http://apps.who.int/gb/ebwha/pdf files/WHA57/A57 R17-en.pdf (accessed 1st April 2010)
} 
enacted at the time of the Plan's publication as the behavioural treatments interventions were already in place. Thus, it was signalled that latter phases of HEHA would shift towards environmental prevention of obesity.

The MCM model of obesity causality had reached its final stage. Future phases of the HEHA implementation plan focused to a greater degree upon modifying social and physical environments to promote nutrition and physical activity. Interestingly, these changes began to ignore behavioural interpretations of disease and consequently became what I explore in Chapter Four as ECM approaches to obesity. These environmental approaches had a specific focus upon children and involved implementing specific policies within schools and regulating advertising aimed at children. ${ }^{69}$ Future State interventions also aimed to look for ways to intervene in specific high need workplace environments to promote healthy lifestyles. ${ }^{70}$

\subsection{Multiple Causality Model Policy}

This section examines Labour's general approach to chronic disease with specific discussion of three 2005-2006 MCM policies which truly reflected a balance of environmental and behavioural causality.

The 2005 - 2008 Labour Government indicated that it would be developing a general approach to the prevalence of chronic disease. Pete Hodgson, as then Minister of Health, ${ }^{71}$ argued that chronic diseases such as obesity, diabetes, and heart disease accounted for approximately $70 \%$ of health expenditure. ${ }^{72}$ In its Statement of Intent 2006-2009, the MOH argued that nutrition related mortalities ${ }^{73}$ were the number one cause of death and accounted for some $30 \%$ of all deaths. It also argued that another $10 \%$ of total population deaths were related to insufficient physical activity and that without intervention these rates were likely to increase. Part of the MOH's plan for dealing with the problem of chronic disease was to strengthen the HEHA strategy, which they argued would make further gains across a number of sectors. ${ }^{74}$ Labour's generalised MCM approach to chronic disease for this period thus established a fairly balanced relationship between behavioural and environmental approaches.

\footnotetext{
${ }^{69}$ The later phases of HEHA would develop community breastfeeding policies and activity and nutrition plans for older people.

${ }^{70}$ Ministry of Health, Healthy Eating - Healthy Action: Implementation Plan: 2004-2010, 33.

${ }^{71}$ Ministry of Health, Statement of Intent 2006 to 2009 (Wellington: Ministry of Health, May 2006)

${ }^{72}$ P. Hodgson, Implementing the New Zealand Health Strategy 2005 (Wellington: Ministry of Health, December 2005), 4.

${ }^{73}$ These effects included inadequate fruit and vegetable consumption, high blood pressure, high blood cholesterol, and overweight and obesity. See: Ministry of Health, Statement of Intent, 33.

${ }^{74}$ Ibid., 34.
} 
Labour's specific anti-obesity programmes were aimed at reducing what they labelled "obesogenic" environments. This goal was evident in the incoming briefing papers for the Minister of Health, which indicated that Labour would continue their already established "environmental approach" to treating and preventing obesity. ${ }^{75}$ The Ministerial briefing papers, supplied to Pete Hodgson, claimed that the most likely way to achieve population health gains would be from improving a combination of the environmental, social, and behavioural factors in health. ${ }^{76}$ These briefing papers also recommended that, with most primary prevention programmes already in place, the Minister would now be best to focus upon developing broader cross sectorial approaches to health goals such as obesity. ${ }^{77}$

The briefing papers provided the HEHA framework with an example of the sort of cross sectorial environmental policy that the $\mathrm{MOH}$ suggested the Minister pursue. ${ }^{78}$ Hodgson explained how this combination of approaches functioned in the HEHA framework:

The initiative offers DHBs and PHOs an opportunity to work with their communities, alongside other providers and across sectors, to develop collaborative health promotion approaches and interventions to bring about changes to the environment in which high need population groups live, work and play. The changes to the environment are to support individuals, families/whanau and communities to eat healthily, live physically active lives and maintain a healthy weight. ${ }^{79}$

By 2005, Labour already had several specific interventions developed under the HEHA umbrella framework that utilised the MCM approach. These included the Fruit in Schools, the Green Prescription and the Getting there - by Foot, by Cycle programmes. These interventions illustrate the relationship between Labour's use of environmental language and behavioural modification that occurred within individual programmes. In the following chapter I will discuss these interventions further, as they were subsequently modified by the ECM approach to obesity prevention.

The Fruit in Schools programme was released in October 2005. Fruit in Schools was developed in reaction to the findings of the 2002 National Children's Nutrition Survey, which indicated that only two out of every five children ate the recommended amount of fruit each day. ${ }^{80}$ The Fruit in Schools programme targeted 66 primary schools in high need areas. Each school was

\footnotetext{
${ }^{75}$ Ministry of Health, Health and Participation: An Active Agenda. Advice to the Incoming Minister of Health (Wellington: Ministry of Health, October 2005).

${ }^{76}$ Ibid., 27.

${ }^{77}$ Ibid., 27.

${ }^{78}$ Ibid., 28.

${ }^{79}$ Hodgson, Implementing the New Zealand Health Strategy 2005, 22.

${ }^{80}$ Ibid., 22.
} 
provided two pieces of free fruit a day for each child for a period of three years. ${ }^{81}$ The programme aimed to teach children in low decile areas a variety of healthy dietary behaviours through a series lessons related to the consumption of this fruit. The programme combined the provision of fruit with an education campaign, which focused upon teaching children the relevance of nutrition and physical activity to achieving a healthy lifestyle. Through its targeted intervention programme and the controllable environment of the school, Fruit in Schools demonstrated that it had made concrete gains in the health of those particular children.

In 2005, the initial goal of Fruit in Schools was to reform high need children's food behaviours and part of the environment in which they lived. At this stage, it was not the comprehensive policy that it would become later in the decade when it was aimed at making all school environments healthy and making only healthy food choices available to children. However, the perceived success of this initial narrowly targeted Fruit in Schools programme led to the development of several more wide ranging HEHA intervention programmes designed to more comprehensively change the food environments of primary and secondary schools. Moreover, this broad attention to controlling school nutrition stimulated further research ${ }^{82}$ into the effects of fast food and food advertising upon school environments. ${ }^{83}$

In 2005, Pete Hodgson provided the Green Prescription ${ }^{84}$ as another example of the success of "environmental" approaches to obesity. ${ }^{85}$ The Green Prescription was (and still is) a prescription GPs gave patients requiring them to engage in physical activity (usually walking) as a nonmedicinal antidote to health risks and to mitigate the worst effects of some diseases. Hodgson indicated that in 2004/05 there were 14,659 direct Green Prescriptions written as treatments. These 2004/05 figures were significantly higher than the 5,809 prescriptions written in $2002 / 03$ and the 8,161 of 2003/04. Most of these prescriptions were given for weight related problems (59\%). ${ }^{86}$ Hodgson reported that of those people taking a Green Prescription more than half had self identified some form of improvement in health or mental health over the course of the treatment. ${ }^{87}$ The Green Prescription encouraged individuals to exercise instead of taking medication.

\footnotetext{
${ }^{81}$ Ministry of Health, Fruit in Schools, A How to Guide (Wellington: Ministry of Health, April 2006).

${ }^{82}$ Jennifer Utter, David Scahaaf, Cliona Mhurchu and Robert Scragg, "Food Choices Among Students Using the School Food Service in New Zealand," The New Zealand Medical Journal 120, no 1248 (January 26, 2007): 1; Caroline Shaw, "(Non) Regulation of Marketing of Unhealthy Food to Children in New Zealand,” The New Zealand Medical Journal 122, no 1288 (January 23, 2009 ): 76.

${ }^{83}$ School food environments became a central focus of policy interventions and debate for the Environmental Causality Model.

${ }^{84}$ By May 2001, the Green Prescription had been prescribed by 50\% of GPs. See King, Implementing the New Zealand Health Strategy $2001,12$.

${ }^{85}$ Hodgson, Implementing the New Zealand Health Strategy 2005, 22.

${ }^{86}$ Ibid., 23.

${ }^{87}$ Ibid., 22.
} 
The Green Prescription was originally a product of behavioural causality understandings of obesity. One of the benefits to the Government of the Green Prescription is that it cost very little. The health sector did not have to pay or subsidise expensive treatments, as Green Prescription costs were borne by the patient. Moreover, through the Green Prescription the State also asked patients to take more responsibility for their physical health. The Green Prescription had been promoted since 1997 and incorporated into HEHA in Labour's second term in government between 2002 and 2005. The Green Prescription certainly had an environmentally flavoured title but it still primarily required behavioural change and discipline on the part of the patients to be effective. The Green Prescription is, therefore, another example of a programme which utilised the early MCM approach. Later in the 2000s, simply because of its green name, the Green Prescription was eventually associated with Green Party ECM approaches to obesity.

The final example of these combined approaches to obesity is that of a fully cross sectorial "environmental" health policy. This policy was entitled "Getting there - by Foot, by Cycle ${ }^{\text {988 }}$ and originated from the Ministry of Transport (MoT). This policy focused upon developing initiatives to increase walking and cycling participation rates in the major cities. It involved input from the National Land Transport Programme, HEHA, SPARC, the Ministry for the Environment, Police Road Safety, Bikewise initiatives and other walking and biking groups. The policy vision of Getting there - by Foot, by Cycle was to create "[a] New Zealand where people from all sectors of the community walk and cycle for transport and enjoyment." ${ }^{\not 99}$ It attempted to promote both social and physical environmental changes within the nation by encouraging transport options that provided physical exercise.

The MoT saw the Getting there - by Foot, by Cycle policy as both sustainable and environmental. The policy was environmental in that it changed our physical environment through encouraging walk and cycle ways and that it attempted to offer alternatives to car-based transport options. The policy produced environmental health outcomes through carbon emissions reduction from vehicles in combination with the overall effect of improving the health and physical activity rates of walkers and cyclists. Under this environmental transport policy, the State intervened to improve the physical environment. Yet this is another MCM example where policy labelled "environmental" still required behavioural change/s on the part

\footnotetext{
${ }^{88}$ Ministry of Transport, Getting there - by Foot, by Cycle: Strategic Implementation Plan 2006-2009 (Wellington: Ministry of Transport, June 2006).

${ }^{89}$ Ibid., 15.
} 
of individual citizens. This policy was also eventually incorporated into ECM critiques of the built environment's role in creating obesity.

In these three programmes, Labour's policy language, between 2005 and 2006, was increasingly more balanced in its allocation of causality. However, it is also evident that these MCM policies still focused upon behavioural modification for obesity prevention. Each policy encouraged high-risk individuals to learn how to make healthy choices for themselves. In this sense, they were fairly optimistic because they offered some possibility for physical change on the part of the individual, even those in high need groups. This distinction is important because from late 2006 onwards obesity policies would utilise the same environmental language. Instead of focusing on behavioural changes, however, later policies argued that behavioural change was impossible in the face of a free market that subverted any possibility of free choice.

\subsection{The 'Obesity Epidemic' as Fact}

The emergence of the MCM occurred, concurrently, with the release of sufficient amounts of medical and policy research to establish the 'obesity epidemic' as a publically accepted truth. This section demonstrates that by $2003, \mathrm{MOH}$ documentation regularly claimed that an 'obesity epidemic' existed in the population. However, this section also notes that the existence of the 'obesity epidemic' was not as clear cut as was made out. This muddying of clarity about the 'obesity epidemic' leads me, later in this section, to question whether there might be other "political" reasons for the Labour Government to address the 'obesity epidemic.' I explore the form and content of claims about the 'obesity epidemic' to show that Labour's concern with this health problem provided them with the mandate to act as a regulatory body and allowed them to self-justify their methods of health intervention.

By 2003, there were regular examples of $\mathrm{MOH}$ documents proclaiming the dangers of obesity to the general population. The 2003 Food and Nutrition Guidelines for Healthy Adults, for instance, discussed obesity in much stronger terms than seen in previous MOH documents: "Obesity is a major contributor to the global burden of disease and disability. The prevalence of obesity is increasing world-wide and has already reached 'epidemic proportions' in many countries and population groups. Obesity is also a major issue for New Zealand." ${ }^{91}$ In this document this newly discovered obesity prevalence was specifically related to an increasing global obesity

\footnotetext{
${ }^{90}$ Ministry of Health, Food and Nutrition Guidelines for Healthy Adults, 9-10.

${ }^{91}$ Ibid., 49.
} 
problem. This connection to a global obesity problem served to strengthen the urgency and necessity for the Government to actively intervene to address the local 'obesity epidemic.'

The $\mathrm{MOH}$ portrayed the problem of obesity as being spread throughout the population. In late 2003, the MOH released a food and nutrition supplement which stated: "About 30 percent of the projected two- to three-fold increase in the incidence of diabetes will result from the obesity epidemic. ${ }^{92}$ In November 2003, the MOH released the results ${ }^{93}$ of the 2002 National Children's Nutrition Survey. ${ }^{94}$ This survey released additional data that suggested that this 'epidemic'had spread to children as well adults. The report begins by stating: "The results relating to overweight and obesity will not come as a surprise. We all know that overweight and obesity and their consequences constitute a constellation of epidemic diseases of the $21^{\text {st }}$ century." ${ }^{95}$ Obesity was now accepted as a full blown modern 'epidemic' and a significant public health threat. In December 2003, Annette King provided a further example of this language: ${ }^{96}$

Obesity is a public health epidemic. It is a major risk factor for many chronic, debilitating and life threatening diseases. The epidemic has not peaked and is largely due to changing social and physical environments in which people are consuming excess energy through food and drink and not expending adequate energy through physical activity. Obesity is a major public health problem in New Zealand. ${ }^{97}$

Here King treated the 'obesity epidemic' as fact. Established as 'fact,' it thus became imperative for the State to change people's health behaviours. Such behavioural changes were necessary to combat the detrimental effects of 'social and physical' environments which 'promoted' obesity. Interestingly, even this 'obesity epidemic' language follows the trend evident in early MCM models in which behavioural treatments are couched within environmental language.

Once the 'epidemic' was considered to be a fact, the MOH tried to clarify the effects it had on the population. In 2004, the MOH noted that over half the population was overweight. ${ }^{98}$ The

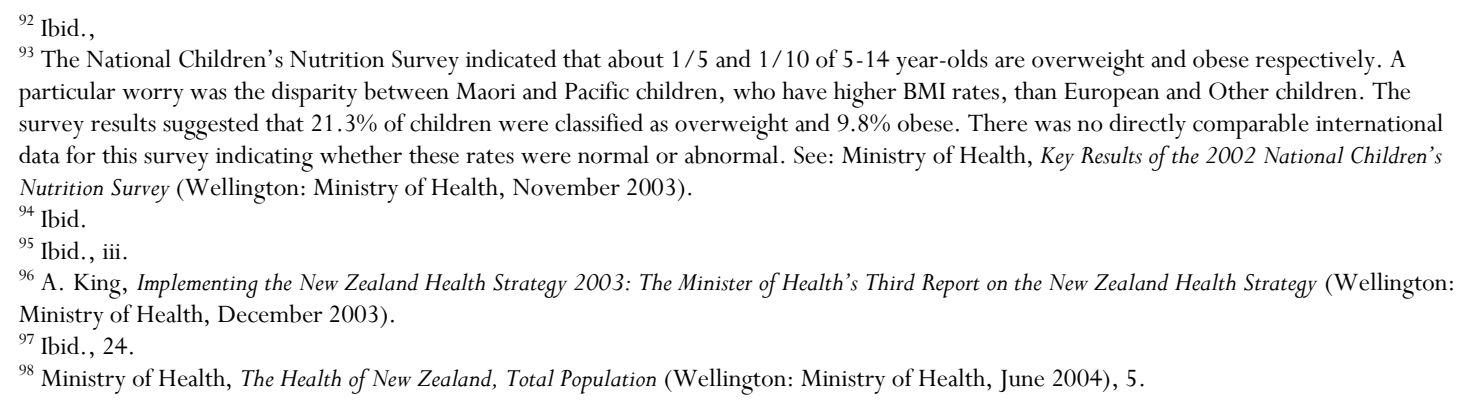


$\mathrm{MOH}$ also defined BMI, physical inactivity, and insufficient fruit and vegetable consumption as health risk behaviours. ${ }^{99}$ Furthermore, the $\mathrm{MOH}$ attributed BMI to be the fourth highest risk factor for mortality rates in the country. The $\mathrm{MOH}$ recorded insufficient physical activity as the fifth highest risk factor, (pre) diabetes as the sixth highest and inadequate fruit and vegetable intake as the eighth highest risk factor. ${ }^{100}$ In sum, the MOH reported that these four risk factors attributed to almost 8000 deaths between 1996 and 1998. It was now apparent that the $\mathrm{MOH}$ considered the 'obesity epidemic' to be a significant contributor to avoidable mortality rates which was a different assumption from several years earlier.

The language proclaiming the danger of the 'obesity epidemic' gave Labour a mandate to increase its interventions and obesity discourse, not least because this health problem was 'reported' as not having peaked. King further reported in her third report on the NZHS2000 that by this stage the Government had released the HEHA Policy and released information on the Children's Nutrition Survey 2002 and provided funding for “5+ A DAY”101 television advertising promoting the consumption of more fruit and vegetables. Moreover, she lists a variety of local initiatives aimed at improving nutrition, ${ }^{102}$ increasing physical activity, ${ }^{103}$ and decreasing the prevalence of obesity. ${ }^{104} \mathrm{~A}$ 'proactive' State was central to the MCM approach which developed a surge of obesity programmes to treat the dangers of this 'epidemic.'

It is important to qualify the general acceptance of increasing obesity prevalence as a health problem, however. As I will show in Chapter Five, in 2009 the National Government completely ignored the dangers of this 'obesity epidemic' and removed obesity as a health target. Moreover, the New Zealand Health Survey 2002/03 ${ }^{105}$ (NZHS2002/03) supplies an even earlier indication that the 'obesity epidemic' was not as prevalent as 'epidemic' claims might indicate. The NZHS2002/03 sought information about the prevalence of health conditions such as chronic diseases and associated risk factors in addition to measures such as BMI and dietary recall information. ${ }^{106}$ Importantly, the NZHS2002/03 results for obesity prevalence

\footnotetext{
${ }^{99}$ Ibid., 7.

${ }^{100}$ Ibid., 7.

${ }^{101}$ King, Implementing the New Zealand Health Strategy 2003, 23.

${ }^{102}$ Ibid., 23.

${ }^{103}$ Ibid., 27

${ }^{104}$ Ibid., 26.

${ }^{105}$ The NZHS2002/03 interviewed over 12,000 people. It achieved statistically significant data for Maori, Pacific Island and Asian participants. Ministry of Health, A Portrait of Health, Key Results of the 2002/03 New Zealand Health Survey, Public Health Occasional Bulletin 21 (Wellington, Ministry of Health, 2004).

${ }^{106}$ Risk factors were described as either biological or behavioural factors (e.g. physical activity) that were causally associated with health outcomes. The NZHS2002/03 found that 2 out of 3 New Zealander ate $3+$ vegetables a day and just over half ate $2+$ items of fruit a day. 3 out of 4 New Zealanders exercised 2.5 hours a week. See: Ministry of Health, Healthy Eating - Healthy Action: Implementation Plan: 2004-2010, 69.
} 
were lower than those found in the NNS97 data. In the NZHS2002/03, 1 in 3 people were overweight, excluding the obese, while 1 in 5 New Zealanders were found to be obese. ${ }^{107}$ Adults living in the lowest socio-economic areas were twice as likely to be obese than those living in the highest socio-economic areas. At no time in the survey were these NZHS2002/03 statistics compared to the NNS97 statistics.

The report made no mention that the obesity and overweight rates from the NZHS2002/03 were in fact lower than those indicated by the previous population surveys. When compared to the NNS97, this survey showed that obesity prevalence in the population had slowed and perhaps even declined. It is not my intention here to dispute the existence of this 'epidemic,' indeed there was still strong evidence for an 'obesity epidemic.' However, these NZHS2002/03 results demonstrate the necessity of questioning the veracity and intent of statements that argued that the 'obesity epidemic' was a 'growing' problem. Moreover, it was evident that claims about the dangers of an 'obesity epidemic' provided Labour with a mandate to act as a regulatory body and justify their interventions as being in the public interest.

\subsection{The Historical Revision of the 'Obesity Epidemic'}

Another curious aspect of the discourse was that the 'obesity epidemic' was revised into being a historical health problem which had affected the population for several decades. In Tracking the Obesity Epidemic: New Zealand 1977 - 2003, ${ }^{108}$ the MOH tracked the 'obesity epidemic' back to 1977. This 'tracking' was achieved through a comparison of the findings of the four nutrition surveys, NDS77, LINZ89, NNS97 and the NZHS2002/03. ${ }^{109}$ This document compared these four surveys to argue that, since 1977, the average BMI of the population has increased. It also demonstrated that most of the increase in population BMI is due to increasing rates of obese classifications (BMI30+) rather than increasing rates of those who are deemed overweight (BMI 25 $\geq 30$ ). Therefore, much of the overall increase in population BMI is found in the increasing extremes of the obese population with BMIs of $40+.{ }^{110}$

\footnotetext{
${ }^{107}$ Ibid., 69.

${ }^{108}$ Ministry of Health, Tracking the Obesity Epidemic: New Zealand 1977 - 2003, Public Health Intelligence Occasional Bulletin No 24 (Wellington: Ministry of Health, December 2004).

109 "Possible explanations for the apparent slowing in the growth rate of the obesity epidemic over the late 1990 s and early $2000 \mathrm{~s}$ included artefact, chance, saturation and genuine public health response (or some combination of these)." See: Ministry of Health, Tracking the Obesity Epidemic, 78.

${ }^{110}$ The comparison only measures the general population and then Maori from 1989.
} 
This document is startling because it rewrites an existence of a population 'obesity epidemic' throughout three decades ${ }^{111}$ between the years 1977 - 2003. The excerpt below summarises the findings of the survey comparison and sets these findings in the context of 'tracking the obesity epidemic':

This overall picture disguises significant differences between age groups, genders and time periods within both the total population and the Maori population. More detailed analysis shows that the 'epidemic' grew relatively slowly in the 1970s and early to mid-1980s (especially among non-Maori and among males), then accelerated rapidly in the late 1980 s to mid 1990 s only to slow once again in the late 1990 s to early 2000 s among Maori, as well as among non Maori females (but not non-Maori males). Yet the epidemic continues to grow, and the apparent slowing in the growth rate of the epidemic among some population subgroups could be due to differences in survey design. ${ }^{112}$

These findings made it clear that the 'obesity epidemic' has existed, albeit in a less pressing manner, since 1977. Interestingly, the survey acknowledges the findings of the NZHS2002/03, which showed a reduction in obesity rates. However, it placed these findings in a wider historical context to suggest that the 'epidemic' had not decreased and that Governmental interventions should not cease.

Tracking the Obesity Epidemic: New Zealand 1977 - 2003 also indicated the direction that future obesity policy and interventions would follow. It recommended both targeted population initiatives and environmental changes to slow the growth in obesity prevalence. It also recommended increased efforts to monitor children's health and obesity rates to protect future generations. It outlined an understanding of obesity causality consistent with later MCM examples. It quotes Swinburn's $1999^{113}$ article to explain the increase in population BMI as being attributable to exposure to an 'obesogenic' environment which promoted sedentary lifestyles and overconsumption of energy dense food and beverages. ${ }^{114}$ It indicated that future obesity interventions be focused on either MCM or ECM.

Tracking the Obesity Epidemic: New Zealand 1977 - 2003 argued that obesity had been a population health problem for almost 30 years. It attempted to provide a long history to what I have shown is a relatively new concern. I have already demonstrated in both this chapter, and in Chapter Two, that despite concerns with nutrition, physical inactivity, and obesity existing

\footnotetext{
${ }^{111}$ Ministry of Health, Tracking the Obesity Epidemic, 1.

${ }^{112}$ Ibid., 1.

${ }^{113}$ Swinburn, Egger and Raza, "Dissecting Obsesogenic Environments."

${ }^{114}$ Ministry of Health, Tracking the Obesity Epidemic, 1.
} 
over the period 1997 - 2003 there was no strong MOH public or political concern with an actual 'epidemic of obesity' until the 2000s. Tracking the Obesity Epidemic proposes the opposite to be true, however, suggesting that the 'obesity epidemic' existed before 1977:

These results confirm that an epidemic of obesity has occurred in New Zealand over the past quarter of a century. In fact, it is clear that the epidemic began even earlier than the 1970s, since by 197742 percent of adult males and 26 percent of adult females were already overweight and 9 percent and 11 percent, respectively were already obese (i.e., 51 percent of males and 37 percent of females were already either overweight or obese). ${ }^{115}$

These findings raise serious questions. ${ }^{116}$ For instance, was the New Zealand population ever normally distributed over the BMI range? Was being overweight normal for the population? Was there a political goal here? Who stood to gain from claiming that an 'epidemic' had been hidden in our population for decades? I contend that an 'obesity epidemic' suited Labour's 'third-way' political differentiation from their opponents. To a certain extent, the 'obesity epidemic' was a political tool used to justify a certain type of centralised State politics. The fact that this revised obesity history was completely ignored five years later, when the National Government refused to treat obesity as a health problem, further reinforces the claim that the 'obesity epidemic' in addition to being a serious health issue was also used as a political tool by Labour.

In the previous section, I argued that the 'obesity epidemic' was accepted as a general truth by 2003. Moreover, reports/surveys such as Tracking the Obesity Epidemic demonstrate that this “truth" was redacted, with a new twist, into New Zealand's medical history. The 'obesity epidemic' had become a historical "truth" despite the fact that neither the NNS77 nor the LINZ89 reports made strong claims or concerns about BMI prevalence at the time they were released. My thesis should have already clearly demonstrated that, at the very least, concerns with the population prevalence of obesity are far more recent social phenomena. At their very worst, concern with the 'obesity epidemic' might be a political tool used to justify certain ideological approaches to health provision.

\footnotetext{
${ }^{115}$ Ibid., 1.

116 This is what I would call retrospective medicalisation. Medicalisation is a process where the human condition becomes defined in medical terms and falls under the authority of the medical establishment, The retrospective use of these population nutrition surveys and the BMI standard has reclassified something which was formally understood as "normal" into an expensive and population threatening epidemic.
} 


\subsection{Conclusion}

This chapter focused upon the obesity discourse emerging under the Labour Government between 2000 and 2005. In doing so it charted the emergence of a second ideological, medical and moral model of obesity discourse. This second model, the MCM, holds that behaviour is the primary cause of obesity, but that there are also other causes: biology and the environment. As we have seen, the MCM emerged after the election of the Labour Government in late 1999. This Labour Government utilised a third-way ideological approach to health provision and was focused on structural health inequality. This inequality was demonstrated by the fact that illness and mortality rates were unevenly distributed throughout the population. This new focus on inequalities in health led to critiques of the BCM model of health provision and required the Government, rather than individuals, to implement a series of policy interventions aimed at treating the widespread 'obesity epidemic' such as HEHA, The Green Prescription, The DHB Toolkit Physical Activity and the Fruit in Schools programme.

The causality focus of the MCM changed over time. Early (2002-2004) MCM discourse focused primarily on behaviour, but by contrast, later discourse balanced consideration of multiple causes. In the early discourse, the environmental causes in question were either undefined, in policy, or the term was used to refer to ethnic or income inequality. However, in 2005, the MCM model changed as obesity came to be considered a general population health problem rather than a specific problem of inequality. As policies such as Fruit in Schools were developed, 'environment' was further defined, but even so, these policies still relied upon behavioural change. The later MCM provided a more wide ranging definition of environmental causality, but it still remained contingent upon how the environment affected behaviour and individual agency. By retaining a focus upon behavioural modification these policies implied that individuals still possessed the agency to make active decisions about their health even while subject to the subversive effects of an obesogenic environment.

The MCM expanded the 1990s behavioural explanation of obesity causality by addressing the affects upon behaviour of other potential causal factors such as biology and the environment. The MCM took its medical basis in the Australasian-based research of Egger and Swinburn who had reacted directly against the limitations of Prentice and Jebb's behavioural model to claim that there were multiple causes of obesity: behaviour, biology, and the environment. Biology and the environment were factors that could then affect the behavioural causes of obesity. MCM policy did not exhibit the BCM preference for citizens to undertake physical 
activity and competition. Equal treatment of nutrition and physical inactivity as causal factors were central to the MCM interpretation of behaviour. The MCM still held that individual behaviour was an important part of disease causality but, that structural inequality also could subvert behaviour into making unhealthy choices a normal occurrence. Thus, the MCM held that agency for health was possible on the part of most individuals but certain population subgroups needed Government assistance to become healthy.

As MCM discourse evolved, over the period 2000-2005, its moral dimensions also changed. At the start of the period MCM discourse was still primarily focused upon behavioural explanations for obesity which we saw in chapter two was associated with an individual morality. Later MCM discourse was more balanced between placing blame for obesity causality on a combination of behaviour and inequality. Labour's focus upon socio-economic and ethnic inequality indicated that some groups fell outside the equal moral playing field assumed by the BCM. Under the MCM certain people could be absolved of blame for their obesity because they belonged to a particular population subgroup which did not have the agency to choose to be healthy. However, in order to opt out of the individualised moral playing field a person had to take on a marginalised 'sub group' status and explain that they were fat because they were poor, or belonged to the Maori or Pacific Island communities. For an individual to acknowledge this marginalised status was to recognise that they were discriminated against by society and buy into Labour's particular ideological approach to politics.

I have shown that, to a certain extent, the 'obesity epidemic' was a political tool used to further the health goals and approach of the Labour Government. By the mid 2000s, the 'obesity epidemic' was considered by Labour to be an established historical and contemporary fact and a mortal danger to the population. This 'epidemic' gave the Government a mandate to generate more targeted obesity policies under the HEHA framework. The 'obesity epidemic' and the proposed MCM solutions to treating this 'epidemic' fitted ideologically together with the third-way politics of Labour. Labour underemphasised evidence that this 'epidemic' was no longer increasing. In addition, the 'epidemic' was rewritten to show that it had existed before 1977, despite the fact that it was not recognised until 1997. We also know now, with the benefit of hindsight, that the very existence of obesity as a population health problem would be disputed by the National Government in 2009. By making this point I am not contesting the existence of the 'obesity epidemic,' rather, I am instead highlighting that the 
'obesity epidemic' was a political football. The dangers of the 'obesity epidemic' were politically convenient for Labour policy because they supported the health approach that they had implemented with the NZHS2000. I will discuss the political nature of these models further in Chapter Five.

The final point arising from this chapter that is important for the discussion of the following chapter is that until 2005, Labour used the term 'environmental' in the context that was distinctively MCM. In Chapter Four, I will show that this use of the term 'environmental' unwittingly provided opportunities for Labour's version of obesity environmentalism to be contested by the ECM position and, ultimately, confused with it. 


\section{Chapter Four: The Environmental Causality Model: Obesity Budgets and the Select Committee}

\subsection{Introduction}

This chapter details the emergence of the third and final model of obesity discourse. This chapter covers a chronological discussion of the obesity discourse produced in the period 2006 - 2008. It discusses how in 2006 obesity was described as the greatest health threat facing New Zealand. ${ }^{1}$ It argues that, by the end of 2008, the Green Party's Environmental Causality Model (ECM) had become the major voice in determining obesity policy. The ECM finds that unhealthy obesogenic environments are the primary cause of obesity. This argument is important because it is the antithesis of the $\mathrm{BCM}$ which holds that individuals have the agency to choose to be healthy in a society based upon economic competition in the free market. The ECM holds that individuals have their agency to make healthy choices subverted by the profit making interests of the free market. Thus the ECM model completely absolves the individual of any moral blame for obesity causality. Instead, the ECM places the moral blame for obesity causality onto the unregulated free market.

The structure of this ECM chapter is chronological. I begin by defining the ECM and demonstrating how it differed from the MCM. I then review the intellectual antecedents of ECM discourse, focusing on the popularisation of 1990s and early 2000s anti-globalisation critiques of the fast food industry and, in particular, the McDonalds Corporation. The medical dimensions of the ECM are then drawn from the 2005 NZMJ.

I then show how political proponents of the ECM eventually replaced Labour's MCM model through the subversion of "environmental” language. Between 2007 and 2008 MCM Labour Coalition obesity policies were reoriented to solely address the environmental causes of obesity. This transition also coincided with two key changes of political leadership in obesity policy. First, Pete Hodgson was replaced as Minister of Health by David Cunliffe who did not show specific interest in obesity policy and left it to the Select Committee level. Second, Green Party MP Sue Kedgley was the chairperson of the Select Committee Inquiry into Obesity and

\footnotetext{
${ }^{1}$ See: Cullen, Budget Speech 2006, 28.
} 
Type 2 Diabetes in New Zealand $d^{2}$ and became the voice for all "environmental" approaches to obesity prevention.

In the final sections of the chapter, I show how the ECM fully emerged as a distinct political position from the recommendations contained in the August 2007, Select Committee Inquiry into Obesity and Type 2 Diabetes in New Zealand report. ${ }^{3}$ This report critiqued the limitations of Labour's approach to obesity prior to 2007 with specific reference to the HEHA framework. It argued that Labour's obesity interventions had not gone far enough in treating the systemic environmental causes of obesity. The Food and Beverage Industry was viewed as being primarily responsible for the obesogenic environment. The report argued that this approach was irresponsible in a social and material environment where it was impossible to make a healthy food choice and exercise properly. The outcome of the Select Committee recommendations had a significant influence on obesity policy in 2007-2008 and redirected older MCM obesity policies to become ECM policies. Thus, the Select Committee obesity solutions focused upon developing healthy environments, especially when it came to children. This chapter notes that one particular subtheme of the obesity debate centres upon children and the question of whether or not children can make healthy choices themselves. ${ }^{4}$

\subsection{The Environmental Causality Model}

The ECM argues that the primary cause of obesity is an unhealthy environment. In this model, the 'environment' is the entire social and material realm within which the population eats, plays, and works. The ECM is critical of free market economics, claiming that the interests of capitalist production subvert the health of the environment through a constant search for economic efficiency (see Chapter Seven). Thus, the free-market dominates the entire environment. When unrestrained, the free-market acts in its own interests rather than in the interests of creating healthy populations. This single causal argument is therefore distinct from the MCM, which views an unhealthy environment as only one of three interrelated causal factors of obesity. ${ }^{5}$

The two key points where the ECM differs from the MCM relate to the free-market and the individual. For the ECM, the free market saturates the food and beverage environment with

\footnotetext{
${ }^{2}$ House of Representatives, Inquiry into Obesity.

${ }^{3}$ Ibid.

${ }^{4}$ This debate will continue in Chapter Five which shows that, in 2009, the National Government unravelled much of the obesity legislation developed between 2003 and 2008.

${ }^{5}$ In the MCM the three casual factors of obesity are behaviour, genetics and the environment.
} 
highly advertised and low cost unhealthy food and beverages. In the face of this saturation, it becomes impossible for the individual to make healthy food choices. Thus, implicit in the ECM is an argument that people do not have any choice but to exist in an unhealthy environment. This unhealthy environment inevitably results in an unhealthy population. Accordingly, this position contests behavioural arguments which presuppose that individuals do have the agency and choice to make decisions about what they eat. The ECM views claims which argue that there should be individual responsibility for disease as a false consciousness. This false consciousness is perpetuated by the capitalist free market, which is the real underlying cause of poor health. The ECM then places the onus for disease causality upon "the market", "globalisation," or specific fast food and/or soft drink companies such as McDonalds or CocaCola Amatil. As a result, the ECM focuses on developing policy responses which attempt to regulate the excesses of the free market.

\subsection{Origins of the Environmental Causality Model}

This section outlines the recent intellectual influences contributing to the ECM as it will later emerge in official New Zealand obesity discourses. I briefly review the emergence of these influences in 1990s radical academic and popular literature, which critiqued the effects of globalisation and the fast food industry upon Western populations. I argue that these radical critiques, especially those focused on the McDonalds Corporation, increasingly influenced more mainstream public opinion about the effects of fast food. It is important to stress that these critiques do not form a direct theoretical or ideological background from which the ECM was formed. Instead, they influenced public opinion in such a way that ECM views gained support. As a consequence certain sections of the population are now more critical of the ways in which companies market and sell food and beverages.

The global antecedents of the ECM developed in the early 1990s from popular practices and a radical academic literature (originally arising out the Marxist tradition), which critiqued the effects of globalisation. Critics in this tradition insisted that the food and beverage advertising industries were profit-focused purveyors of widespread global social and economic evils. Benjamin Barber's Jihad vs McWorld, ${ }^{6}$ originally released in 1992, is an example which argued that the global forces of neo-liberalism are increasingly limiting the possibility for true democracy. For Barber, globalisation forced a monoculture onto populations with only very small, often elite, communities finding ways to resist this influence.

\footnotetext{
${ }^{6}$ B. Barber, Jihad vs. McWorld (New York: New York Times Books, 1995).
} 
One facet of Barber's objection to globalisation is the effect that the standardised products supplied by multinational food and beverage companies have had upon traditional food cultures. Globalisation brought with it a pervasive advertising industry that encourages the uniform consumption of branded high calorie/high sugar foods. He argued that this way of eating food is now so pervasive that it has effectively eradicated many older or traditional forms of dining. Barber points out that some groups are resisting these processes advocating a return to organic or older, often slower, forms of eating. ${ }^{7}$ This process of resistance against the effects of globalisation outlined in McWorld characterises the context in which the ECM has developed.

This resistance against globalisation and its affect on modern social life was further developed in George Ritzer's classic book The McDonaldisation of Society: An Investigation into the Changing Character of Contemporary Social Life (1993). Ritzer's book presents a compelling case for the dystopian effects of globalisation upon populations. He extends Max Weber's analysis of bureaucratisation to suggest that the fast food industry is the new bureaucratic paragon of the steel cage. ${ }^{8}$ This bureaucracy brings with it a Weberian rationalisation of the everyday life, which has a mind-numbing sameness. Ritzer suggests that the structure of the McDonalds Corporation has become the model of social control of individual identity and a dehumanised everyday life. This book, now in its third edition, did much globally (ironically) to popularise negative impacts of globalisation and the business practices of the McDonalds Corporation.

Over the 1990s, the McDonalds Corporation became central to the developing negative perceptions of the fast food industry. This globalisation critique of McDonalds became intertwined with the cause of environmental activists who had been protesting against the fastfood chain since the mid 1980s. In 1997, the McLibel film was released detailing the legal struggle between environmental activists and the McDonalds Corporation. ${ }^{9}$ Over this period the defendants organised world-wide support to gather evidence for their defence, in the process waging an enormous global publicity campaign against McDonalds. McDonalds eventually won the libel section of the case but only after it had been subject to almost two

\footnotetext{
${ }^{7}$ Peter Jones, Peter Shears, David Hillier, Daphne Comfort, Jonathan Lowell, "Return to Traditional Values? A Case Study of Slow Food," British Food Journal 105, no 4 (2003): 298.

${ }^{8}$ G. Ritzer, The McDonaldisation of Society: an investigation into the changing character of contemporary social life (Pine Forge Press, Thousand Oaks, California, 1996).

${ }^{9}$ McLibel focused upon the legality of allegations made by the defendants against the McDonalds Corporation. These allegations included arguments that McDonalds exploits a variety of peoples, sells unhealthy food and is generally bad for the environment. Different disputes in the McLibel court case began in 1990 and carried through to 2005.
} 
decades of negative publicity. Throughout 1990s and early 2000s, the McLibel case stimulated anti-McDonalds sentiment throughout the Western world.

In the mid 2000s, several popular movie-length documentaries further fuelled and popularised anti-fast food sentiment. These documentaries focused specifically upon the deleterious nature of the food itself and food cultures propagated by the fast-food industry. Journalistic research formed the basis for these mid-2000s films which tended to be exposés of the evils of these industries. ${ }^{10}$ These movies included Fast Food Nation (2006), Supersize Me (2004), and the rereleased McLibel (2005), all of which, in various ways, found fault with the fast food industry, its products, and the consumption cultures these companies developed. These movies further served to popularise criticisms of fast-food culture, standardised foods, and food advertising industries.

By the mid-2000s, then, environmental arguments that suggested that globalisation and fast food cultures had normalised unhealthy choices were commonplace. These arguments had begun as radical critiques but were becoming more and more mainstream. As a result, there was increasing public support for ideological arguments propounding an ECM position. From 1999, the success of the Green Party in New Zealand politics can also been seen as part of the growing political representation of this support. Accordingly, in the next section I demonstrate that by 2005/06 this attitude towards globalisation and fast food had become evident in the discourse of medical researchers, politicians and policy makers.

\subsection{The Medical Basis of the Environmental Causality Model}

The ECM was first discussed in the NZMJ in 2005, when Robert Quigley and Carolyn Watts ${ }^{11}$ offered an article that comprehensively assessed the advertising industry and argued that it was the primary cause of obesity. Quigley and Watts also extend their argument about food advertising to make pronouncements about the food environment and individual choice. This section shows how, in this article, they set out the parameters of the ECM.

The primary argument of the ECM is that obesity is caused by the environment rather than explanations based on individual behaviour (BCM) or a combination of factors (MCM).

\footnotetext{
${ }^{10}$ E. Schlosser, Fast Food Nation, The Dark Side of the American Meal (USA: Houghton Mifflin, 2001).

${ }^{11}$ Robert Quigley and Carolyn Watts are the directors of Quigley and Watts Ltd, an independent public health research company centred in Wellington, New Zealand. http://www.quigleyandwatts.co.nz/about us.php
} 
Quigley and Watts argue that the food environment is toxic and they find it no surprise that the population is getting heavier:

[A] walk around any neighbourhood will show that our environment is sick. Our environment is not normal. We should not be surprised that our children are growing fat when their world is saturated with unhealthy messages. Put simply, we need to focus more on the causes of the causes and less on the individual. ${ }^{12}$

They note that existing prevention approaches ignore the 'real' causes of obesity as they place too much emphasis on education and individual behaviour. Quigley and Watts insist that future medical research and Governmental policy should shift attention away from individual behaviour towards examination of the food and advertising environment. They argue that future obesity policy should focus upon changing the environment.

A key argument of the ECM is that capitalism causes obesity through an unrestrained freemarket, food marketing, and the prevalence of unhealthy foods. Quigley and Watts clearly articulate the existence of a relationship between the marketing of unhealthy foods and the causes of obesity: "The marketing of high fat-, salt-, sugar-, and energy dense foods is now firmly in the gaze of parents, the community, and health professionals as a vector (cause) of disease." ${ }^{\prime 13}$ The rhetoric of the ECM is highly emotive and implies that children must be sheltered from the excesses of the free-market. By indicating that marketing is in the gaze of parents they suggest that future obesity prevention programmes will benefit from protecting children.

The specific use of language and policy constructing obesity as a threat to children is characteristic of the ECM position. The ECM argues that children are the people most vulnerable to food marketing. This necessitates policy controlling the environments which children frequent such as schools and children's television advertising, to protect them from becoming fat. ECM policy employs emotive pressure upon parents in the attempt to make them responsible for creating healthy home environments for their children.

This argument that children, and the general population, need protection implies that individual choice is a misnomer and forms a distinctive part of the ECM. This is a key difference from the MCM approach to obesity which argues that individuals can be educated in

\footnotetext{
${ }^{12}$ Robert Quigley and Carolyn Watts, “Challenging Beliefs About the Marketing of Food,” The New Zealand Medical Journal 118, no. 1218 (July 15, 2005): 1 . ${ }^{13}$ Ibid., 1.
} 
order to discern healthy choices from unhealthy choices. Indeed, Quigley and Watts go on to attack the MCM position by stating that educating individuals to make healthy choices just plays into the hands of food marketers who have saturated the food and beverage market in such a way that healthy choices are impossible.

Quigley and Watts argue that the behavioural view, that obesity is caused by poor individual choices, is flawed. They suggest that we live in an environment:

[s]urrounded by the rhetoric of "individual choice", as though this is a panacea for all ills. However whether an individual chooses a healthy diet is much more influenced by the availability, affordability, and accessibility of food than that individual's knowledge about healthy food choices. Choice is important - but we argue that the right to choose a healthy diet has been all but removed from children today. We live in a world where saturation marketing/propaganda of unhealthy food is the norm and environments support unhealthy choices - and yet we continue to be surprised that we are in an obesity epidemic. ${ }^{14}$

Here, Quigley and Watts identify what, for them, is a key question in obesity politics: do individuals actually have a choice about whether or not they get fat? Quigley and Watts answer this question in the negative, taking the position that the language of "choice", "moderation", "personal and parental responsibility" are propaganda tools used by food companies to justify their products. ${ }^{15}$ For them, blaming individual's poor choices hides the true cause of obesity.

Quigley and Watt's ECM article is reliant upon, and appears to have evolved partially out of, the intellectual origins of the MCM model that was developed by Egger and Swinburn. ${ }^{16}$ They use the general framework of Egger and Swinburn's model to develop their own position. ${ }^{17}$ They subvert this model to focus specifically upon the environment as the primary cause of disease. Quigley and Watts argue that healthy choice cannot exist in an obesogenic food environment because it is this environment that is responsible for obesity. This subversion of MCM language and approaches is a key characteristic of the ECM politics and policy positions. As I explore later in this chapter, most of Labour's MCM obesity programmes will be appropriated and subverted by the ECM political approach.

\footnotetext{
${ }^{14}$ Ibid., 1 .

${ }^{15}$ Ibid., 2.

${ }^{16}$ Egger and Swinburn, "An ecological approach to the obesity pandemic."

${ }^{17}$ Egger and Swinburn's model is discussed in Chapter Three.
} 
In Quigley and Watt's article we see medical researchers outlining the key features of the ECM for the New Zealand context. They state that the primary causal factor of obesity is the unhealthy environment in which we live. The environment is unhealthy because the free market has saturated the food choices and food culture so completely that it is impossible for individuals to make healthy food choices. As a result, individual choice and behavioural approaches to obesity treatment are disputed by the ECM approach. Under the ECM approach, effective solutions to obesity will come from policies which regulate the excesses of the free market and/or develop localised or national interventions that attempt to make entire environments healthier.

\subsection{Budget 2006: the Largest Campaign in New Zealand's History to Fight Obesity}

In 2006, the Labour Government expanded and refocused its obesity prevention focus towards children and young people. The emergence of rhetoric that presented obesity as the greatest health threat facing New Zealand was crucial to this refocus. The change in language was the first sign that MCM approaches to obesity prevention were no longer in favour. MCM approaches to obesity would be subverted by ECM policies directly concerned with regulating healthy environments, especially for children. This section documents the emergence of this new focus on children and the reframing of language through the 2006 Budget, the expansion of the Fruit in Schools programme, and the development of the Mission On initiative.

The shift in focus towards children and young people occurred in the 2006 budget which announced an increase in funding for the HEHA implementation plan of some $\$ 76$ million. ${ }^{18}$ Continuing their MCM approach, Labour stated this funding was primarily focused on preventing obesity in children through improving nutrition and physical activity. In his budget speech, Minister of Finance the Hon. Dr Michael Cullen stated:

The greatest public health challenge facing New Zealand is the epidemic of obesity, particularly childhood obesity. The failure to act could mean that the current generation of young New Zealanders could be the first to die younger than its parents. $\$ 76.1$ million over four years will fund the largest campaign in New Zealand's history to fight obesity. The campaign will be built on the Government's world-leading Healthy Eating Healthy Action strategy that has already led to the trialling of exciting innovations since its introduction in 2003.

The campaign will focus on initiatives with schools, primary health care deliverers, social agencies and food industry bodies. ${ }^{19}$

\footnotetext{
${ }^{18}$ M. Cullen, Budget 2006, Executive Summary (Wellington: Treasury, 18th May, 2006), 11.

${ }^{19}$ Cullen, Budget Speech 2006, 28.
} 
To emphasise the critical nature of the risk of this 'obesity epidemic' to children, an emotive approach was used, as evident in Cullen's claim that these children will die younger than their parents. This is the beginning of a shift away from obesity initiatives targeting isolated high need groups towards a more general population focus that indicated all children were in need of obesity interventions and prevention programmes. Indeed, most of the 16 public health initiatives funded by the 2006 Budget were directed to preventing obesity in children.

The expansion of the Fruit in Schools programme was a central initiative of this new funding. Hodgson outlined that a Memorandum of Understanding (MoU) had been developed between the $\mathrm{MOH}$, Ministry of Education, and Sport and Recreation New Zealand. ${ }^{20}$ Fruit in Schools was now seen as the flagship of the MoU because it reflected the new understanding that all children were at high risk. By the end of 2006, 264 schools were participating in the programme. ${ }^{21}$ This change in scope reflected the attitude that all children were at the mercy of the obesogenic environment.

This claim that all children and young people were at risk from the 'obesity epidemic' also led to the 2006 Budget funding of the Mission On programme. The Mission On programme was launched by the Prime Minister, Helen Clark, on the $21^{\text {st }}$ of September 2006. Mission On was another MoU programme and was intended as a three year package aimed at improving the health related lifestyles, behaviours, and environments in which young people participated. ${ }^{22}$ It included a 'social marketing campaign' and 'youth prevention programmes'. Administered by SPARC and aimed at 0-24 year old New Zealanders, Mission On focused upon:

1. Improving health and nutrition within schools and early childhood environments

2. Student Health promotion

3. "Lifestyle" ambassadors

4. Youth branded websites

5. Government walking the talk

6. Television and computer free time

7. Control of advertising

8. Use of radio and television to encourage change

9. Health impact assessments.

10. Expanding the Green Prescription programme ${ }^{23}$

\footnotetext{
${ }^{20}$ Minister of Health, Implementing the New Zealand Health Strategy 2006: The Minister of Health's Sixth Report on Progress on the New Zealand Health Strategy (Wellington: Ministry of Health, December 2006), 14.

${ }^{21}$ Ibid., 14.

${ }^{22}$ Ibid., 26.

${ }^{23}$ Ministry of Health, Progress on Implementing the HEHA Strategy 2007, 14.
} 
Mission On was another 'wide ranging' MCM attempt to reach children and young people through a variety of different environments and sources. Mission On was somewhat controversial because it used the very advertising and media mediums accused of creating obesogenic environment to educate young people about obesity. ${ }^{24}$ This contradiction illustrated the difficulty that these programmes had reaching out to young people who were inculcated into the very obesogenic environment that Mission On sought to reform.

The ECM would use this generalised threat to all young people and children to develop and modify its own programmes removing the availability of unhealthy food choices within schools. From 2006, obesity was portrayed as a palpable threat hanging over all children and young people. This reframing of the threat of obesity to children then necessitated further funding of Government programmes to protect and control the environments in which children spent their time.

\subsection{Soft Drink Advertising: the Transition from the Multiple to Environmental Causality Models}

This section demonstrates that by 2006 Labour was shifting towards developing policies developed from the ECM. This section shows that Labour, under Pete Hodgson, had initiated policies strictly controlling how soft drinks should be sold in schools, an action directly addressing concerns about how the free market contributed to poor health. The concern with soft drinks initiated debate about the extent that advertising could influence the food choices made by consumers.

So far I have demonstrated that Labour's approach to obesity prevention utilised an MCM approach in its policy initiatives. MCM language had ultimately relied upon a notion of an environment in which individuals were able to make healthy food choices for themselves. In 2006, MOH policy concerns implied that the free market might be influencing, perhaps even dictating, the choices made by consumers. ECM policy appeared to be arguing that the free market with its promotion of choice and individual responsibility completely subverted any possibility for individual agency for food choice.

One area in which this subversion of agency occurred was related to the dangers of full-sugar soft drinks. In October 2006, the MOH's Food and Nutrition Report indicated that a

\footnotetext{
${ }^{24}$ Roger Ridley-Smith, “The 'Weighting' List,” The New Zealand Medical Journal 118, no. 1243 (October 13, 2006 ), 1.
} 
'disproportionate' amount of advertising money was being spent on high energy sugary products in comparison to what was spent on marketing fruit and vegetables. The report noted that companies spent $\$ 57,289,000$ on advertising chocolate, soft drinks, and aerated drinks in 2005,9 times the amount spent advertising vegetables and fruit $(\$ 6,215,000) .{ }^{25}$ The unhealthy products that the Government had attempted to convince the population not to eat were receiving \$58 million dollars a year in advertising.

The Labour government acted to protect children from the 'dangers' of soft drinks. In a press release dated, the $11^{\text {th }}$ of December 2006, Hodgson announced that full-sugar fizzy and energy drinks would be removed from sale in secondary schools. ${ }^{26}$ This was part of what Hodgson called a "world leading agreement", entitled the Voluntary Schools Beverage Statement between the New Zealand Government and Coca-Cola Amatil NZ and Frucor Beverages. ${ }^{27}$ Hodgson stated:

I thank Cocacola, Amatil, and Frucor for their leadership on this issue. Today's agreement is a major step forward for the Food Industry Accord and shows once again what can be achieved when we reach for cooperative rather than regulatory solutions. Regulation in this case would have been costly and it's unlikely that we would have been able to move as fast as we're now planning. ${ }^{28}$

This statement was the first indication that Labour were prepared to act within the economy, albeit in the limited environment of schools, to curb the supply of branded foods and beverages that it believed contributed to the excess of calories in people's diets.

Hodgson acknowledged that Labour's action against soft drinks already had a localised precedent in a HEHA initiative organised by the Waitemata DHB. The Waitemata DHB had trialled replacing high energy soft drinks with low sugar alternatives in a secondary school:

The replacement of high energy, high sugar drinks with healthier alternatives in one large secondary high school as part of the Waitemata DHB traffic light beverage project resulted in the removal of $110 \mathrm{~kg}$ of sugar per week from their school supply or almost half a tonne each month ${ }^{29}$

The Voluntary schools beverage statement can be seen as part of the environmental evolution of the HEHA framework and Labour policy. Yet this was not an evolution towards a completely

\footnotetext{
${ }^{25}$ Ministry of Health, Food and Nutrition Monitoring Report 2006, Public Health Intelligence Monitoring Report 9 (Wellington: Ministry of Health, October 2006), xii.

${ }^{26}$ Hodgson, Pete, “Full sugar fizzy drinks out of schools by 2009," Press Release, $11^{\text {th }}$ December 2006.

http://www.beehive.govt.nz/node/28031 last accessed $19^{\text {th }}$ June 2009.

${ }^{27} \mathrm{Ibid}$.

${ }^{28}$ Ibid.

${ }^{29}$ Ibid.
} 
ECM position. The Voluntary schools beverage statement did not prevent companies, such as Coca Cola Amatil, from selling low sugar beverages in schools which meant that they could still retain an advertising presence.

What was most strikingly persuasive about these soft drink schemes was the sheer quantity (weight in kilos) of sugar that was being withdrawn from schools and therefore children's diets. Then Minister of Education, Steve Maharey, stated that this agreement would see the removal of 1.1 million litres of full-sugar beverages from schools over the next three years. The Labour government estimated that "by 2009, around 1,105,000 litres of full sugar fizzy drinks and 118,000 kilos of sugar will have been withdrawn from the country's secondary schools." ${ }^{30}$ However, as NZMJ researchers pointed out, although this scheme removed large amounts of sugar from supply in schools, it did not guarantee that the energy and branded soft drinks were not being substituted in other ways in the environments immediately outside schools. ${ }^{31}$ There were also implied questions about agency in this policy. That Labour believed it necessary to intervene to prevent children having access to full sugar drinks indicated that they believed that children would gravitate towards these high energy drinks before their low energy counterparts. This indicates that Labour acknowledged that advertising was directly affecting the ability of children to make free choices about food consumption.

Labour's enactment of the Voluntary schools beverage statement is an indicator that, by the end of 2006, they were shifting away from the MCM which still granted agency to individuals to make informed healthy choices. A transition was occurring in Labour policy. Although it is impossible to discern where Pete Hodgson would have shifted Labour policy had he remained Minister of Health, what is demonstrable is that the policy initiative behind the Voluntary schools beverage statement was one of the opening clashes in the ideological battleground over how much choice and agency children had regarding the food they consumed.

\subsection{The Select Committee Inquiry into Obesity and Type 2 Diabetes in New}

\section{Zealand}

The Select Committee Inquiry into Obesity and Type 2 Diabetes in New Zealand (Select Committee) used the ECM to critique and reconfigure the already established MCM obesity programmes. The basic findings of the Select Committee are outlined in this section. This section forms the context

\footnotetext{
${ }^{30}$ Ibid.

${ }^{31}$ Anthony Maher, Nick Wilson and Louise Signal, “Advertising and Availability of 'Obesogenic' Foods Around New Zealand Secondary Schools: A Pilot Study,” The New Zealand Medical Journal 118, no. 1218 (July 15, 2005), 2.
} 
for the following section which concentrates specifically upon the ECM anti-free market arguments contained within the 2007 Select Committee report. In this report the Green Party, through the Select Committee Chairperson Sue Kedgley, gained significant space, media, and authority to promote ECM policy responses to the perceived 'obesity epidemic.' In this report the ECM political position emerged to contest the two pre-existing models and obesity ideologies of the MCM and the BCM.

Two key changes of political leadership also assisted the transition from MCM to ECM approaches to obesity. First, Pete Hodgson was replaced as Minister of Health by David Cunliffe, who did not show any specific interest in guiding obesity policy. Second, Green Party MP Sue Kedgley became chairperson of the Select Committee Inquiry into Obesity and Type 2 Diabetes in New Zealand. These changes in leadership assisted the transition. Sue Kedgley and the Green Party became the public voice for all ECM approaches to obesity prevention.

Continuing the earlier position taken by Labour, the Select Committee portrayed obesity as an extremely serious health problem for the whole population. The key findings of the Select Committee also continued the basic theme of Labour's existing policy that children were the most at risk when it came to the 'obesity epidemic.' Thus it found that both obesity and Type 2 Diabetes were 'crucial' health issues, particularly among children, and that these epidemics have the potential to overwhelm the health system. As Chairperson Sue Kedgley argued in the Select Committee report, "Tackling the obesity epidemic in New Zealand is imperative. The issue is so serious and wide-reaching that comprehensive, coordinated action by the Government is needed.”2 The Select Committee report regarded the 'obesity epidemic' as one of the most pressing health threats and that significant Governmental intervention was required to treat and prevent this 'epidemic.'

A central theme of the Select Committee involved criticising the existing MCM approaches implemented by Labour to prevent the 'obesity epidemic.' The Select Committee, without ever being specific, indicated that previous obesity interventions were, at best, mixed in their effectiveness. Of particular concern to the members of the Select Committee was the structure and focus of the current HEHA framework:

There is widespread concern, however, that its scale is not commensurate with the problem, nor is it well implemented; and its impacts have not yet been assessed. The

\footnotetext{
${ }^{32}$ House of Representatives, Inquiry into Obesity, 9.
} 
Food Accord and the Food Industry Group still have a great deal more to deliver on their parts of the strategy. ${ }^{33}$

Arguments that obesity prevalence was still increasing had the effect of discrediting the previously implemented obesity interventions. This had the dual effect of justifying the need for new, widespread solutions, which in turn further undermined the effectiveness of earlier policies. This was accompanied by arguments suggesting that widespread potential solutions would be required. By rejecting the earlier BCM and MCM approaches, the Select Committee made room for the ECM as a favoured solution to the 'epidemic.' We see alarmist language used to describe obesity which then justified further 'drastic' responses. In other words, the way in which the Select Committee report was framed prioritised a shift towards ECM obesity solutions.

Although the Select Committee report focussed on developing ECM solutions, it did not completely discount behavioural or multiple causality explanations for obesity. The Select Committee found that "obesity is caused by an imbalance between energy intake and energy expenditure and that New Zealanders live in an environment where less healthy food choices have become the easy choices." ${ }^{34}$ This statement is consistent with the obesity causality model favoured by the MCM previously pursued by Labour and set out in Egger and Swinburn's ${ }^{35}$ ecological framework. ${ }^{36}$

The Select Committee also acknowledged that physical inactivity was another key environmental barrier to health. However, it was reframed as a barrier emerging from the 'built environment ${ }^{, 37}$ rather than an individual problem. Thus the Select Committee concluded, "Urban planning plays a large role in encouraging or discouraging habitual physical activity, especially cycling or walking to and from work or school and during leisure time. ${ }^{״ 3}$ Built environment $\operatorname{arguments}^{39}$ suggest that the very design of urban areas, workplaces, and schools makes us fat. Designed to facilitate time-saving, ${ }^{40}$ built environments encourage people to take transport options such as trains, buses, and cars rather than travel through physical exercise. Proponents of the built environment argument also targeted those environments that are constructed in

\footnotetext{
${ }^{33}$ Ibid., 11.

${ }^{34}$ Ibid., 3.

${ }^{35}$ Specialist medical and obesity research advice for the Select Committee came from Boyd Swinburn and Jim Mann

${ }^{36}$ Swinburn, Egger and Raza, "Dissecting Obsesogenic Environments," 563.

${ }^{37}$ House of Representatives, Inquiry into Obesity, 24.

${ }^{38}$ Ibid., 24.

${ }^{39}$ Papas, M., Alberg, A., Ewing, R, Helzisour, K., Gary, T., \& Klassen A, “The Built Environment and Obesity,” Epidemiological Reviews (May $28,2007): 8$.

${ }^{40}$ Time saving has the side effect of reducing calorie consumption.
} 
such a way that healthy food options are not easily accessible. Such as high rise buildings which only provide access to food and beverages from vending machines.

Despite allowing for behavioural causality of obesity, the Select Committee report ultimately displaced the priority of behavioural arguments through its suggested solutions to obesity. Its solutions focused upon modifying the environment in which the population develop their eating patterns or behaviours. ${ }^{41}$ The report emphasised that overeating, and the environments which foster overeating, are the most significant cause of obesity. The Select Committee dismissed physical inactivity as a central causal factor for obesity, concluding that "there is too much emphasis on education and the promotion of physical activity as the key preventative interventions. Consumers' knowledge of these measures is already high. ${ }^{\not 2}$ As a result, BCM approaches received less attention from the Select Committee than those policies that prioritised altering the social and commercial environments which determine eating habits. ${ }^{43}$

The ECM position was clearly demonstrated in the objectives created by the Select Committee. These objectives were "to create an environment in New Zealand that encourages and maintains healthy eating and physical activity patterns, especially among children" ${ }^{44}$ and "to develop and implement a coordinated national cross-sectorial response to the prevention and management of obesity and Type 2 Diabetes. ${ }^{45}$ Most of the targets underpinning these objectives were focused upon children ${ }^{46}$ and it was environmental approaches that were regarded as having the greatest potential to reduce the problem. ${ }^{47} \mathrm{~A}$ series of goals were set to achieve between the years 2008, 2010, and 2015. These included arresting the increase of obesity in both children and the general population.

The Select Committee suggested the solution to obesity would come from ongoing systematic Government action and regulation. ${ }^{48}$ They argued that individuals were unlikely to meet their weight loss goals without Governmental intervention. Returning to a rhetoric of urgency, the Select Committee justified the necessity of such strong Government leadership, insisting that

\footnotetext{
${ }^{41}$ House of Representatives, Inquiry into Obesity, 13.

${ }^{42}$ Ibid., 13.

${ }^{43}$ Ibid., 16

${ }^{44}$ Ibid., 3.

${ }^{45}$ Ibid., 3

${ }^{46}$ Ibid., 4.

${ }^{47}$ Ibid., 5.

${ }^{48}$ Ibid., 4 .
} 
there was an urgent need to 'scale up' the public health response to obesity ${ }^{49}$ and Type 2 Diabetes. ${ }^{50}$

The proposed Government regulation required a high level of surveillance of the health of the general population. The Select Committee still required further quantification and measurement of the extent and costs of the problems of obesity and Type 2 Diabetes. ${ }^{51}$ Thus, the Select Committee's recommendations included: regular monitoring and evaluation of all obesity and Type 2 Diabetes policy, the implementation of standardised national surveys of food intake, physical activity and chronic disease, surveillance of the advertising of food marketing and promotion; and measurement of the indirect and direct financial costs of Type 2 Diabetes and obesity. It also recommended that all existing programmes for preventing and managing obesity be evaluated and continued only if they were useful. ${ }^{52}$ This approach was consistent with both MCM and ECM solutions to obesity and required a large public sector to undertake this surveillance. However, this approach was completely inconsistent with BCM approaches to obesity treatment and perhaps this offers one explanation for why National scrapped these obesity solutions in 2009.

The Select Committee Inquiry into Obesity and Type 2 Diabetes in New Zealand represented the MCM fall from influence over the direction of future obesity policy. It recommended that an overall effective strategy was still required to meet the problem of obesity, implying that the existing MCM solutions were ineffective..$^{53}$ This political criticism is likely to have come from both the Green Party and the National Party members of the Select Committee, neither of whom would want to be seen to endorse the established Labour approach to treating obesity. Furthermore, both the Greens (ECM) and National (BCM) had vying ideological solutions to the obesity problem. In this 'divergence' we see evidence that a spectrum of political positions regarding obesity existed in New Zealand. This spectrum is discussed further in the following chapter.

The ECM downplayed the importance of BCM treatments for obesity by arguing that obesity solutions should focus on the environments in which we eat. This was, therefore, a call for further Government intervention and regulation. This position assumed that real change in the

\footnotetext{
${ }^{49}$ Obesity often occurs alongside Type 2 Diabetes. Thus, strategies aimed both illnesses simultaneously were desirable.

${ }^{50}$ House of Representatives, Inquiry into Obesity, 13.

${ }^{51}$ Ibid., 4-5.

${ }^{52}$ Ibid., 6.

${ }^{53}$ Ibid., 3 .
} 
lives of the obese was not going to come from obese individuals but was going to come from the Government changing their environments. 


\subsection{Anti-Free Market ECM Critiques and the Select Committee}

The Food and Beverage Industry was the specific target of ECM criticism. The Select Committee Inquiry into Obesity and Type 2 Diabetes in New Zealand report placed part of the responsibility for obesity causality upon the private sector and, specifically, the food and beverage industry. Accordingly, it sought to hold these industries accountable for causing the obesity problem:

[T] he food and beverage industry is not sufficiently engaged in the prevention of obesity despite having an important role in causing it. The advertising, marketing and promotion industry has the potential to play a key role in the prevention of obesity but has not yet engaged seriously as part of the solution. ${ }^{54}$

The Select Committee suggests that the Food and Beverage Industry gains all the benefits of advertising and marketing high energy foods without bearing any of the individual or treatment costs.

The costs associated with unhealthy food are born by individuals and by society as a whole, and not by the food industry. Furthermore, failure to address obesity and diabetes will place a huge strain on our health system, and have a severe impact on the national economy. ${ }^{55}$

This is a critique of both the effects of a free-market on individuals and BCM individualised approaches to obesity. The overall argument is that either the State or individuals have to bear the social and treatment costs that are a consequence of the Food and Beverage Industry's 'profiteering' from advertising and selling cheap and unhealthy foods. The Select Committee effectively demonised the Food and Beverage Industry as immoral, being representative of the profiteering free market, the effects of advertising, and the increasing prevalence of cheap, unhealthy food.

The Select Committee was also critical of the methods the Food and Beverage Industry used when it did undertake health promotion. The Food and Beverage industry was bound by a voluntary accord where it is encouraged to promote healthy food options. The Select Committee opined that the industry was not meeting its obligations under the accord and was instead behaving in a self-interested and profit driven manner. They accused the Food and Beverage Industry of promoting a $\mathrm{BCM}$ view that it is poor physical activity rates rather than a high calorie diet that is the major factor in obesity:

We understand that the public health evidence indicates that advertising, marketing and promotion help to condition food preferences and choices in children, normalise

\footnotetext{
${ }^{54}$ House of Representatives, Inquiry into Obesity, 12

${ }^{55}$ Ibid., 17.
} 
unhealthy food, and undermine parental authority in this respect. Advertising establishes and reinforces behaviour, and if it did not the food industry would not spend its money on it. ${ }^{56}$

This statement can now be read as an attack on the BCM approach to obesity, as it claims that an industry that self-regulates may ultimately protect the interests of industry rather than public health. The Select Committee argues that relying on the Food and Beverage Industry to self-regulate was a flawed approach. It notes that, at a practical level, it is difficult for the food industry to be impartial when its goal is to sell product. The Select Committee points to the example of the Tobacco Industry as a failure of industry to self-regulate. ${ }^{57}$ For the Select Committee, the solution to the problem of industry self-regulation is to first set specific targets such as limiting television advertising to children and a food traffic light labelling system. The threat remained that if the industry failed to meet or ignored these targets, more direct forms of regulation would follow. ${ }^{58}$ As such, the Select Committee also considered pricing mechanisms to regulate the Food and Beverage Industry; these included specific taxes on some foods and tax relief on others. For the Select Committee, government regulation is the solution to the excesses of the Food and Beverage Industry.

The Select Committee also criticised the Industry Accord because it was limited to advertising and had no restrictions on sponsorship or endorsements. This means a company such as McDonald's could advertise that it is sponsoring sporting icons such as Olympic gold medal winning cyclist Sarah Ulmer. To some extent, this sponsorship arrangement functions as a BCM advertising promotion insofar as it suggests that individuals can achieve a balanced lifestyle that combines eating unhealthy foods with plenty of physical activity.

The overall strategic responses recommended by the Select Committee focused upon mitigating the effects of food advertising and the availability of cheap, unhealthy foods. The Select Committee recommended that a cross-sectorial Ministerial committee chaired by the Prime Minister or the Minister of Health be established to direct strategic responses to obesity. ${ }^{59}$ The Select Committee envisaged that the strategic responses would focus upon "modifying the environmental determinants of eating and activity patterns, especially in children" ${ }^{\circ 0}$ Suggested measures included improving the availability, access, and affordability of healthier foods and

\footnotetext{
${ }^{56}$ Ibid., 17.

${ }^{57}$ Ibid., 19.

${ }^{58}$ Ibid., 20.

${ }^{59}$ Ibid., 5.

${ }^{60}$ Ibid., 13.
} 
decreasing the availability of energy dense foods. Other measures included decreasing the advertising and marketing of energy dense foods and providing more opportunities for physical activity in schools.

The ECM responses, recommended by the Select Committee, would involve Government intervention into the ways in which food was supplied. Select Committee recommendations included food labelling and modification, monitoring of food industry standards, restricting television broadcasts concerning energy dense foods until after 8:30pm at night, and the close regulation and supervision of school food environments. ${ }^{61}$ For these reasons the Select Committee was in favour of the Fruit in Schools programme and recommended rolling it out to even more schools. ${ }^{62}$ The Select Committee identified five 'avenues' of influence over the environment that could be used to determine eating habits:

1. The food and beverage industry

2. Advertising, marketing and promotion

3. Labelling of food and drinks

4. Pricing mechanisms

5. The promotion of breast feeding ${ }^{63}$

Here we see that the first four 'avenues' all involve regulating the food and beverage markets. This would occur through either overt regulation or control of what the Food and Beverage Industry could supply the market, through regulation on what, where, and how unhealthy food products could be marketed. In addition, these overt regulations extended to improving the labelling of products to further explain the contents of foods and pricing mechanisms that attempted to prioritise healthy food over unhealthy food by price. All these interventions would regulate the supply of food goods in the economy. The fifth avenue focused on controlling the environment in which children received nutrition by pursuing policies which focused upon infants receiving breast milk rather than formula-based substitutes. It was apparent from these 'avenues' that all future obesity prevention policy would under this Government be based upon the ECM.

This series of Select Committee responses to obesity represented the full emergence of the ECM. The Select Committee's response to this problem of the Food and Beverage industry was to develop more obesity prevention programmes in which the Government regulated the free

\footnotetext{
${ }^{61}$ Ibid., 5.

${ }^{62}$ Ibid., 11.

${ }^{63}$ Ibid., 16.
} 
market. Specifically, the Select Committee would focus on the environments in which children were most at risk from the Food and Beverage Industry. Given its profit-motive, the Select Committee saw this Industry as adversely affecting the health of the population. Moreover, it argued that the Food and Beverage Industry failed to effectively self regulate and the "health" based messages that do originate from the Food and Beverage Industry were self interested. This critique of the Food and Beverage Industry was also a critique of neo-liberal and BCM understandings of economics, the role of Government and the notion that individuals were free and responsible to make their own health choices. In the following section, I will show how anti-free market ECM policy approaches became more and more prevalent in Labour's policy from 2007.

\subsection{Environmental Causality Model Obesity Policy in 2008}

The ECM policy position enjoyed a period of ascendancy for approximately 12 months between August 2007 and the October 2008 general election where it could enact further obesity interventions. I argue that in 2008 obesity prevention policy continued to focus further upon regulating the environments in which children lived. This ECM focus is evident in the material distributed by the $\mathrm{MOH}$ regarding the roles of parents to protect and nurture the food and nutrition environments of their preschool infants, toddlers, and those in utero. I discuss one particular consequence of these ECM policies which was to place the responsibility for obese children squarely onto parents who were perceived to have failed their child.

In 2008, general approaches to obesity prevention focused on refining HEHA towards the ECM political position. In 2008, the MOH published the HEHA Implementation Strategy Progress Document $^{64}$ as a response to the findings of the Select Committee's Inquiry into Obesity and Type 2 Diabetes in New Zealand. It noted that the Select Committee recommended reviewing and revising the existing HEHA strategy. ${ }^{65}$ The progress document stated that over 75 of the 87 actions in the Implementation Strategy are underway and that these actions complement the HEHA Strategy network. The Implementation Strategy offered examples of new and further developed environmental initiatives to meet the goals of HEHA. These included the Feeding our Futures campaign which featured media advertising to parents and caregivers, giving them 'tips' on

\footnotetext{
${ }^{64}$ Ministry of Health, Healthy Eating - Healthy Action - Oranga Pumau: Progress on Implementing the HEHA Strategy 2008 (Wellington: New Zealand, November 2008).

${ }^{65}$ Ibid., 8 .
} 
how to improve their children's diet. ${ }^{66}$ HEHA was also involved with DHBs in developing Maori and Pacific Island community obesity action projects. ${ }^{67}$

One particularly controversial ECM obesity prevention policy enacted in 2008, however, arose out of the Ministry of Education. The Ministry of Education included a clause in its National Administration Guidelines (NAG) allowing only healthy foods to be sold in schools. On the $1^{\text {st }}$ of June 2008, the New Zealand Schools National Administration Guideline (5) was supplemented by two additional clauses. ${ }^{68}$ The first clause required Boards to promote healthy food and nutrition for all students. The second clause required that all food and beverages options sold on schools' premises must be healthy options. The intended effect of this NAG change was to remove any possibility that children choose unhealthy foods over healthy options.

The NAG Guideline was controversial because it removed the possibility of school children making food choices for themselves. It also directly represented ECM arguments made by the Select Committee ${ }^{69}$ and by medical researchers ${ }^{70}$ that children in schools were at the mercy of Food and Beverage advertising. In 2009, National Education Minister Anne Tolley furthered the controversy surrounding the NAG guidelines by rescinding the second NAG clause (See Chapter Five). ${ }^{71}$

The concern about obesity in children was increased when the MOH released a series of nutrition policies and procedures aimed to protect infants from becoming overweight or obese. These documents described the family diet as creating a child's nutritional environment. ${ }^{72}$ This information campaign ${ }^{73}$ gave guidelines to parents about how to control their children's food and exercise environments in order to prevent them from becoming obese. These documents suggested that there was clear evidence that the nutrition and health of children in their most formative years will directly impact on their quality of health in later life. They directly noted that parents should not restrict their children's consumption through dieting but instead

\footnotetext{
${ }^{66}$ Ibid., 16.

${ }^{67}$ Ibid., 33 .

${ }^{68}$ The NAG guidelines were changed after the 2006 budget.

${ }^{69}$ House of Representatives, Inquiry into Obesity, 13.

${ }^{70}$ Utter, Scahaaf, Mhurchu and Scragg, Food choices Among Students.; Theodore Reremoana, John Thompson, Clare Wall, David Becroft, Elizabeth Robinson, Phillipa Clark, Jan Pryor, Chris Wild and Ed Mitchell, "Dietary Patterns of New Zealand European Preschool Children," The New Zealand Medical Journal 119, no. 1235 (June 2, 2006), 1.

${ }^{71}$ For the current 2009 NAG guidelines see:

http://www.minedu.govt.nz/NZEducation/EducationPolicies/Schools/PolicyAndStrategy/PlanningReportingRelevantLegislationNEGSAn dNAGS/TheNationalAdministrationGuidelinesNAGs.aspx\#NAG5

${ }^{72}$ Ministry of Health, National Nutrition Guidelines for Healthy Infants and Toddlers (Aged 0-2): A background paper (Wellington: Ministry of Health, May 2008), 115

${ }^{73}$ Ibid., 115.
} 
provide a healthy food and physical activity environment for their children. ${ }^{74}$ Childhood obesity was such a concern that the MOH outlined the proper exercise and nutrition for infants. This included a strong focus on breast feeding and engaging even the youngest babies in exercises such as tummy time. ${ }^{75}$

The $\mathrm{MOH}$ also extended the project of preventing obesity in children to those in utero and emphasised the 'responsibilities' of pregnant mothers. ${ }^{76}$ Here we see the Government extending its prevention goals to include the control of the bodies of mothers and the unborn, in order to prevent children from becoming obese. This included monitoring of optimal maternal weight and recommended energy and dietary fat intakes for women in each trimester of their pregnancy. ${ }^{77}$ Further, the $\mathrm{MOH}$ noted that obese women are susceptible to many problems during pregnancy that can result in increased birth weight for infants, in turn increasing the child's chances of becoming obese later in life.$^{78}$ Obese women wanting to become pregnant were, and still are, advised to consider losing weight before becoming pregnant. ${ }^{79}$ It appeared the Government did not want women who were obese reproducing because of the risk that their child would also be obese. ${ }^{80}$

These policies and guidelines wrapped children and infants in a completely protected bubble of healthy food environments. Within these environments children could not manipulated by the insidious marketing techniques of the Food and Beverage Industry. Thus, the Government had comprehensively restricted the possibility for children to make unhealthy food choices.

The Governmental ECM policy placed responsibility for obese children squarely upon parents. Schools were no longer unhealthy environments and children were now protected in both school and home environments from the Food and Beverage Industry. The ramifications of creating 'healthy' schools meant that if a child was obese it was not the School's, or the Government's, responsibility but rather that there was something amiss in the family diet. It was clear that an obese child was the product of irresponsible parents; poor home nutrition environments or obese parents produced obese children. Obese women are particularly

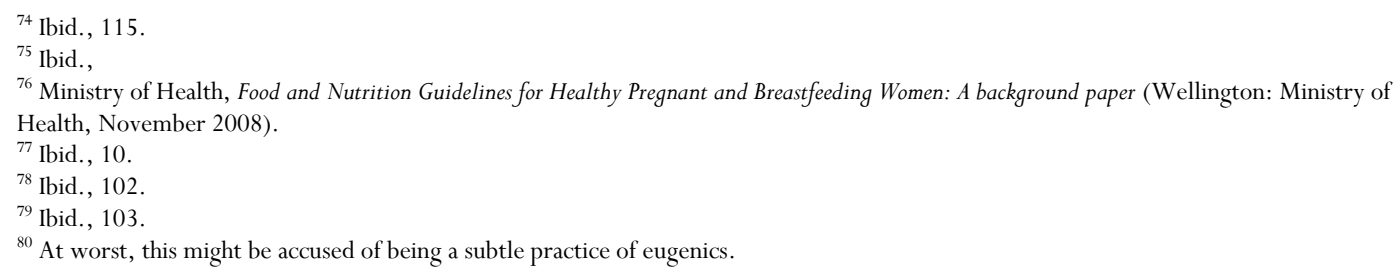


discriminated against by the ECM. The MOH encouraged obese women to lose weight before becoming pregnant to protect their potential children from inheriting the condition. Thus those obese women that did enter pregnancy could be declared irresponsible for combining both their genetic predisposition for obesity and for bringing their children into their unhealthy home environment.

The problem with this emphasis upon parental responsibility was that it did not complement other ECM understandings of the obesogenic environment. This 2008 approach assumed that parents could be held responsible for creating healthy food environments for their children. However, the Select Committee inquiry had argued that the population lived in an obesogenic environment. Thus a paradox existed in ECM discourse where parents were understood to simultaneously have no choice over their food environments but they were required to be actively responsible for home food environments.

This section has demonstrated how the ECM evolved in 2008. ECM policy concentrated on controlling the environments in which children lived. Its goal was to completely protect children from the possibility of making unhealthy food choices. In doing so the responsibility for obese children was shifted from the Government and the Food and Beverage Industry squarely onto the shoulders of parents. Parents were faced with the paradox of having to negotiate the obesogenic environment which subverted their agency while facing the State imperative to supply their children with healthy home environments. When the National party won the election in October 2008 the ECM position shifted into opposition. In Chapter Five we will see that from late 2008, the ECM would be used as the main form of critique of National Government's obesity and nutrition policy.

\subsection{Conclusion}

Emerging in the mid 2000s, the ECM finds the primary cause of obesity in an unhealthy environment. It defines the environment as the entire social and material world. The ECM claims that the entire environment in which we live is dominated by the free-market. When unrestrained the free-market acts in its own interests rather than in the interests of creating healthy populations. Thus, the ECM argues that these external corporate interests dictate our eating habits, which through advertising, supply of high energy foods, and manipulation of the built environment have made the possibility for good health almost impossible. 
The Green Party's ECM position came to dominate obesity discourse in 2008. This shift is surprising because the Labour Party had been responsible for implementing the HEHA initiatives for the previous six years. The Green Party was able to subvert the environmental language used by the Labour MCM policy and make it represent the ECM policy position. For example, Green policy positions appropriated the Green Prescription, Push Play and Fruit in Schools despite the fact that these programmes had been established under other ideological frameworks.

One of the reasons this subversion occurred was because the Select Committee effectively critiqued the Labour Government's existing MCM obesity policy. It appears that in the 2000s, the Labour Government had followed a policy of emphasising the dangers of the 'obesity epidemic' in order to pursue and develop their policies. This policy appears to have backfired in 2007 when the Select Committee used Labour's own claims about the dangers of obesity to condemn Labour's policies for not being effective enough. If the prevalence of obesity was still increasing, they argued, then it provided clear evidence that Labour's MCM policy had failed.

The chapter also showed how the ECM critiqued its opposing models. The chapter then shifts to look at the question of individual agency in making health decisions. It demonstrated that ECM obesity related programmes and policies assumed that individuals did not have the agency to make healthy decisions for themselves. The chapter outlined an argument that the playgrounds of New Zealand's schools were to become the battle ground in which the three obesity models would clash. This argument is continued in Chapter Five. Chapter Five will demonstrate that there would be clashes over the Fruit in Schools programme, the Voluntary Schools Beverage Statement and the NAG (5) Section 2.

So far in this dissertation I have demonstrated that there were three distinct political and medical models of causality at play in obesity discourse by the beginning of 2008. Each model was related to specific types of Governments, time periods, and medical understandings of obesity causality. The BCM is related to the 1990s National governments, New Right economics and behavioural causality. The MCM is related to Labour Governments notions of social inclusion and 'third way' politics which hold that obesity is caused by a combination of behaviour, biology, and, the environment. The ECM is related to Green Party policy which holds that the free-market causes obesity. 
It is now clear that agency and the question of whether all citizens can actively make good healthy decisions for their wellbeing are important themes emerging from this chronology of obesity discourse. Each of the three obesity causality models has a distinct notion of agency, the role of the state, and role of the citizen. The BCM is a proponent of individual responsibility where citizens are free to look after themselves, in a free market, without interference from the State. The BCM views individuals as all having the agency to alter their behaviour. The MCM revises New Right policy through an active State that is concerned with balancing individual freedom and redressing social inequality. The MCM views obesity as being caused by combination of individual behaviour and social inequality. Thus, for the MCM some individuals have the agency to alter their behaviour while other disadvantaged citizens do not. Conversely, the ECM holds that unhealthy environments subvert citizens from achieving any possibility of individual agency. As a result, ECM sees the role of the State as actively protecting its community, especially children, from the excesses of the free-market which it views as the cause of obesity.

The political dynamic in which these models and different notions of agency coexist is the topic of the next chapter. Chapter Five, maps the political spectrum of obesity discourse through a discussion of the 2008 election policy. It also sets out to explain a central question of this dissertation which seeks to find out why the 2009 National Coalition was actively and strangely disinterested in the 'obesity epidemic.' This was a strange disjunction from the 2008 ECM policy, highlighted in this chapter, that claimed that obesity was the greatest health threat facing the nation. 


\section{Chapter Five: The Politics of Obesity Discourse}

\subsection{Introduction}

In February 2009, three months after being elected in to Government, the National Coalition removed obesity as an official Health Target. ${ }^{1}$ This removal was coupled with the cessation of funding for all obesity lobby groups and prevention programmes. HEHA, Mission On, and the Obesity Action Coalition all immediately ceased functioning. As the "biggest health problem facing New Zealand,"2 obesity was suddenly and very strangely omitted from all official government discourse. This obesity policy reversal was at odds with the way in which Labour had treated obesity. In the 2006 budget, obesity prevalence had been such a pressing health concern for the Labour Government that they allocated extra funding to combat the 'epidemic'. Moreover, in 2007, obesity prevalence was considered so serious that a Select Committee Inquiry into Obesity and Type 2 Diabetes in New Zealand ${ }^{3}$ was convened. Consequently, supporters of HEHA related policy viewed the 2009 policy reversal as incomprehensible. ${ }^{4}$ In this chapter, I will argue that this policy reversal illustrates the dynamics of the obesity causality models acting across a political spectrum.

This chapter investigates this recent, confusing, and very radical reversal of obesity policy. I begin by analysing how obesity was treated in the electoral policy of each main political Party contesting the 2008 general election. I claim that the logic behind this policy reversal is inseparable from the three models of obesity discourse outlined in Chapters Two - Four. Each of these three models are found in the obesity policy of the major parties contesting the 2008 general election. I find that the 2008 general election represented a dynamic political spectrum containing all three ideological approaches to obesity, economics, individual agency and the role of the citizen. This analysis will demonstrate that obesity discourse is not neutral and is loaded with political-ideological bias.

I will argue that the National Coalition's reversal of obesity policy resulted from an application of a BCM policy approach. This position is supported by a discussion of National Coalition policy in the areas of education, sport, and soft drinks. I explain that the reversal of obesity

\footnotetext{
${ }^{1}$ J.Key, “Securing a Brighter Future, Social Issues, Our 2010 Priorities.” Published $9^{\text {th }}$ Feb 2010. http://www.national.org.nz/files/2010/2010 SocialIssues.pdf last accessed 10th March 2010

${ }^{2}$ Cullen, Budget Speech 2006, 28.

${ }^{3}$ House of Representatives, Inquiry into Obesity.

${ }^{4}$ Delvina Gorton, Helen Etyles, Cliona Ni Mhurchu and Chris Bullen, "Removal of the Requirement for Schools to Only Sell Healthy Food a Giant Leap Backwards,” New Zealand Medical Journal 122, no. 1290 (February 27, 2009):130.
} 
policy is an application of the BCM view that individuals, rather than the State, should be responsible for insuring against and bearing the cost of illness. This viewpoint also holds that individuals should be free to choose what is best for their own health. Thus, the application of a BCM approach explains the 2009 obesity policy reversal.

\subsubsection{Obesity Policy in the November 2008 General Election}

The November 2008 general election provides a useful and recent example from which to begin discussing the political dynamics of the obesity models. In this section, I apply the obesity causality models developed previously, to 2008 election policies. I show that 2008 election stances regarding of obesity can be mapped along a political spectrum. I present what I call 'a political spectrum of obesity causation models'. The parameters of obesity discourse do not fit the traditional left/right political divide. ${ }^{5}$ Rather, they fit along 'a spectrum' with the limits defined by the ECM and BCM models. Issues-based ${ }^{6}$ obesity agendas and some MCM discourse are located along the spectrum.

I argue that the obesity debate can be understood as 'a political spectrum of obesity causation models' running from the ECM approach of the Green Party at one extreme, to the BCM of the New Right at the other, with MCM discourse being utilised by more centrist political parties. Along the 'spectrum' political definitions of the aetiology of obesity sit between these two diametrically opposed explanations. Table 1 outlines the spectrum. The top of the table represents the Green Party's ECM policy extreme. On descending down the table the Party's electoral health policies are increasingly affected by cost-based models of care eventually ending with the BCM extreme represented by ACT's focus on individual choice.

\footnotetext{
${ }^{5}$ This left-right political division is no longer strongly evident in New Zealand.

6 "Issues-based" policy refers to single health issues such as cancer, obesity, diabetes, or ethnic inequality in health.
} 
Table 1: The Political Spectrum of Obesity Causations Models: November 2008 General Election

\begin{tabular}{|l|l|l|l|}
\hline Party Name & Seats & Seats & Policy Position \\
\hline The New Zealand Green Party & 6 & 9 & Environmental Causality Model \\
Extreme
\end{tabular}

The following sections of election analysis detail the boundaries of the obesity debate by political party in the order provided in Table 1. The obesity-related health policy of the parties which won five or more seats in the 2008 election is discussed. ${ }^{7}$ This order also allows a natural transition from the pre-election ECM obesity policy to BCM policy position of the post-election National Coalition. The spectrum also provides the contextual background for the second part of this chapter which analyses the obesity policy position taken by the National Coalition after the 2008 election.

\subsubsection{ECM Policy - The Green Party}

The Environmental Causality Model (ECM) of the Green Party of Aotearoa New Zealand occupies one extreme of the spectrum. In Chapter Four, we saw that the Greens utilised the ECM to argue that society, by virtue of the way it is constructed, is an environment which produces ill-health. ${ }^{8}$ In their 2008 election policy, the Greens argued against a health policy focused on primary care. Instead, they preferred a policy approach centred upon changing the environmental and social causes of ill-health. Green electoral health policy was intertwined

\footnotetext{
${ }^{7}$ The Progressive Coalition, New Zealand First, and United Future are not discussed because they failed to gain significant representation. ${ }^{8}$ Green Party Front Page (http://www.greens.org.nz/front (accessed Monday 27th October 2008)
} 
with other policies such as food affordability and transport policy. These latter policies were intended to improve the structural and social environments of major cities and, in turn, promote health through physical activity and healthy diets. Green policy is not obesity specific but it is aimed at treating obesity's root causes. Thus, for the Greens, improved population health would only occur by changing the environment and, specifically, the food environment. This is why they promised a substantial education campaign concerning healthy eating, focusing first on children and then on the general population.

Ultimately, the Green Party's environmental position consisted of an argument for the transition to the organic production of food. The development of a healthy organic food environment, they suggest, will improve nutrition, decrease rates of obesity, and increase the overall health of the population. The documents Health Policy ${ }^{9}$ and Preventative Healthcare Strategy ${ }^{10}$ outline the Green ECM health priorities as follows:

To improve the health of New Zealanders we have to improve environmental, economic, and social conditions. The causes of ill health in New Zealand include economic, social and environmental conditions such as air and water pollution, toxins, pesticide contamination, bad diet, poverty, unemployment, poor education, poor quality housing, and poor social cohesiveness. ${ }^{11}$

The Green's eventual goal was and is to develop a holistic interaction or healthy relationship between individuals and the planet. ${ }^{12}$ In Green notions of individual wellness individuals were required to be responsible to pursue environmental health. The Green's Health Policy and Preventative Health Strategy ${ }^{13}$ attempted to offer an integrated approach between an ideological critique and practical policy initiatives. For the Greens, the solution for preventable disease reduction lay with targeting the structural root causes of ill-health in combination with an increase in preventative health care funding. ${ }^{14}$ The Greens argued that both health care and health promotion materials must be publically funded. This policy approach was intended to save the \$3billion spent annually on primary treatments of preventable and chronic diseases.

In summary, the Green Party's ECM policy position represents one extreme of the spectrum. Green policy relates obesity prevalence to larger structural problems surrounding unhealthy

\footnotetext{
${ }^{9}$ Green Party Health Policy

http://www.greens.org.nz/policy/health (accessed 30th October 2008)

${ }^{10}$ Green Party Preventative Health Strategy

http://www.greens.org.nz/sites/default/files/preventativehealth.pdf (accessed 30th October 2008)

${ }^{11}$ Green Party Health Policy

http://www.greens.org.nz/policy/health (accessed 30th October 2008)

${ }^{12}$ Ibid.

${ }^{13}$ Green Party Preventative Health Strategy http://www.greens.org.nz/sites/default/files/preventativehealth.pdf

${ }^{14}$ Green Health Policy http://www.greens.org.nz/policy/health
} 
food, transport and workplace environments. These unhealthy environments have consequences for daily life, one of which is weight gain. Ultimately, for the Greens, effective environmental change and positive health effects will only come from governmental regulation.

\subsubsection{Educating Individuals About Health Risks - The New Zealand Labour Party}

Labour advocated the continuation of its existing ECM/MCM approach to obesity. On the $27^{\text {th }}$ of October 2008, the Minister for Health David Cunliffe and Prime Minister Helen Clark released the Labour Party's election health policy. This election policy did not offer any significant deviation from the health policy they followed between 1999 and 2008. It promised a continuation of policies of the previous nine years. This meant that on the spectrum Labour would offer ECM and/or MCM State-based solutions to obesity treatment and prevalence as well as continuing to retain obesity as an official health target. The Labour Party election policy stated:

Labour will continue to invest in a world-class public health strategy aimed at helping New Zealanders stay well. We will prioritise fighting the disease and disability caused by obesity, tobacco, and alcohol and by the preventable cancers. ${ }^{15}$

Obesity would continue to be at the forefront of Labour's health priorities. Their policy was somewhere between ECM and MCM in its approach. Central to their election policy was continued promotion of a 'combative' approach to the preventable 'lifestyle' diseases caused by obesity, smoking and alcohol. This policy would continue a commitment to populationbased health initiatives focusing on the preventable risks to individuals and communities. It was clear that Labour still considered obesity to be a serious health problem worthy of considerable Government attention.

\subsubsection{Warrant of Fitness Checks - The Maori Party}

The Maori Party's health policy fell in the centre of the spectrum. Their policy tended to be MCM in approach as it was issues-based and directly concerned with the tangata whenua's ${ }^{16}$ experience of health inequality. The Maori Party first gained representation in 2005 and are concerned with the welfare of their people and upholding indigenous values. ${ }^{17}$ They were particularly worried about health because Maori are negatively overrepresented in disease

\footnotetext{
${ }^{15}$ Labour Party Health Policy

(http://www.labour08.co.nz/news/Labour+releases+comprehensive+Health+Policy (accessed Monday 27 $7^{\text {th }}$ of October, 2008).

${ }^{16}$ In New Zealand English tangata whenua means "Maori people in their capacity as the indigenous people of Aotearoa, New Zealand." See The New Zealand Oxford Dictionary ed. Tony Deverson and Graeme Kennedy (Melbourne: Oxford University Press, 2005): 1146.

${ }^{17}$ Maori Party Health Policy

(http://www.maoriparty.org/ ( accessed Monday $27^{\text {th }}$ of October 2008)
} 
prevalence and mortality rates. ${ }^{18}$ Maori are significantly overrepresented in obesity rates, ${ }^{19}$ heart disease rates,${ }^{20}$ and in the prevalence of Type 2 Diabetes. These inequalities are detailed further in Chapter Eight.

The Maori Party possessed two vital perspectives of health which were under emphasised by all their opponents. First, they recognised that their ethnic group and constituency remain significantly overrepresented in illness and mortality rates. Second, the Maori Party highlighted the relationship between socio-economic position and health. Chapters Seven and Eight show that obesity prevalence is correlated with both ethnicity and socio-economic position.

As a response to these two perspectives, the Maori Party promised to instigate free preventative health care for people under six years and those over sixty five, annual wellness checks or 'warrant of fitness' checks for health, including cardiac risk and diabetes for the whole population. ${ }^{21}$ By promising to make health checks free they attempted to overcome certain cost related issues which prevent lower socio-economic groups and Maori gaining access to health care. They targeted extra funding for Type 2 Diabetes and heart disease reduction programmes. They also promised more broadly based health initiatives including working towards the exemption of Goods and Service Tax from foodstuffs to make food more affordable for lower socio-economic groups. These policies were aimed at improving Maori and general population health and, as a consequence, reducing obesity prevalence.

Maori Party policy was MCM due to its concentration on inequality. They sought to impose State restriction of individual freedom of choice through warrant of fitness checks. Moreover, by concentrating on their own inequality they promoted policy which demanded that the State implement ethnically and socio-economically targeted health interventions.

\subsubsection{Healthy People/Healthy Economy - New Zealand National Party}

The National Party election policy favoured BCM modifications to the existing health system. National were not focused on wholesale reform but advocated a centre-right approach to

\footnotetext{
${ }^{18}$ Tony Blakely, Bridget Robson, June Atkinson, Andrew Sporle and Cindy Kiro, "Unlocking the Numerator-Denominator Bias. I: Adjustment Rations by Ethnicity for 1991 - 1994 Mortality Data. The New Zealand Census-Mortality Study,” The New Zealand Medical Journal,115 no. 1146 (February 6, 2002): 39.

${ }^{19}$ Ministry of Health, A Portrait of Health 2002/03, 87.

${ }^{20}$ Kerr, McLachlan, Furness et al, "The burden of modifiable cardiovascular risk factors," 20-32.

${ }^{21}$ The "Warrant of Fitness" term is potentially worrisome as it indicates a certain natural selection based around notions of fitness.
} 
health. On the $27^{\text {th }}$ of September 2008, National released a health discussion paper, with a BCM approach to health. This document was entitled 'Better, Sooner, More Convenient. ${ }^{22}$ It is from this document, along with comments from the Inquiry into Obesity and Type 2 Diabetes in New Zealand, ${ }^{23}$ and two National Party speeches given close to the election that I begin to analyse their obesity policy perspective. In this section, I concentrate on the policy background preceding National's removal of obesity as a health target. I review National's general health policy, their economic policy, their views on individual responsibility, and the role of sport for healthy citizenship. Through this process I demonstrate that many of the 1990s BCM approaches to health were repeated in National's 2008 policy.

Better, Sooner, More Convenient ${ }^{24}$ is focused heavily on issues concerning primary health care, which National argued was under pressure from funding issues and the ageing population. The document is critical of the condition of existing health services, specifically waiting lists, the dominance of a medical bureaucracy, and the problem of a shortfall in the trained medical workforce. Better, Sooner, More Convenient is a critique of the status quo, creating more choice for patients ${ }^{25}$ and a demand for a shift towards more efficiency in health services. These concerns echo the Green and White paper's critique of the welfare health system outlined in Chapter Two. ${ }^{26}$

The BCM necessity for individualised healthy lifestyles is central to Better, Sooner, More Convenient. The National Party framed the relationship between the health of the citizen and the State by stressing that:

People make personal decisions that affect their health and well-being - eating, drinking, smoking or exercising. Although these choices may be shaped by public health messages or cultural experiences, they are still choices that individuals are responsible for. ${ }^{27}$

Although National acknowledge that culture and exposure to a level of education (this appears to be New Right language for social and ethnic inequality) are factors which affect health choices, they also indicate that individuals are ultimately accountable for their health. In Better, Sooner, More Convenient, National unequivocally state that people with chronic disease must be

\footnotetext{
${ }^{22}$ T. Ryall, Better, Sooner, More Convenient Health Discussion Paper (Wellington: The Office of the Leader of the Opposition, 2007).

${ }^{23}$ House of Representatives, Inquiry into Obesity, 35.

${ }^{24}$ Ryall, Better, Sooner, More Convenient, 29.

${ }^{25}$ Ibid., 5.

${ }^{26}$ Upton, Your Health and the Public Health.

${ }^{27}$ Ryall, Better, Sooner, More Convenient, 28.
} 
encouraged to manage their own health. ${ }^{28}$ Better, Sooner, More Convenient's emphasis on individual responsibility had been signalled elsewhere by the National Party. The same focus on individual choice was central to an article Tony Ryall published in the NZMJ, which called for "a new focus on the needs of individual patients, not just populations." ${ }^{29}$ Ryall argued that focusing on individuals rather than communities was necessary to create a healthy population.

For the National Party, the health of the population is tied to the health of the economy. In a pre-election speech to the Public Health Organisations - New Zealand, 'Why a strong economy is good for your health' ${ }^{30}$ Ryall linked the principles of Better, Sooner, More Convenient to the prosperity of the nation: "The link between New Zealanders having better health and increased living standards is clear. By increasing prosperity and opportunities to prosper, a National-led Government will improve the health of New Zealanders." ${ }^{31}$ Ryall also repeated this view in the NZMJ. ${ }^{32}$ This indicated National would favour policies encouraging economic prosperity rather than funding specific health issues like obesity. This health approach was aimed to produce healthy, prosperous individuals who would improve overall living standards, reduce mortality rates, and reduce the costs of primary care.

National's pre-election obesity discourse is slippery because while we know they considered obesity a population health problem it played only a minor role in their health policy. Obesity was briefly addressed under the heading 'Early Detection and Screening' in Better, Sooner, More Convenient. ${ }^{33}$ The report also identified obesity as a key challenge in health promotion and prevention and an area where screening would be important. National argued that one in five New Zealanders is obese and one in three is overweight and that this costs New Zealand $\$ 300$ million dollars a year. Moreover, they argued that the obese and the overweight contribute significant risk for developing chronic diseases. ${ }^{34}$ At least before the 2008 election, then, National, was aware of the high mortality and financial costs associated with obesity prevalence.

\footnotetext{
${ }^{28}$ Ibid., 3.

${ }^{29}$ Tony Ryall, “The National Party's Solutions for New Zealand's Health Care System,” The New Zealand Medical Journal 121 no. 1283 (October 3, 2008): 15-18

${ }^{30}$ Tony Ryall, "Why a Strong Economy is Good For Your Health,” 28 August 2008 Presented to the PHO-NZ Board Meeting Auckland (http:/ / www.national.org.nz/Chapter.aspx?ChapterId $=28442$ (accessed Monday $27^{\text {th }}$ October 2008)

${ }^{31}$ Ibid.

${ }^{32}$ Ryall, "The National Party's Solutions," 15.

${ }^{33}$ Ryall, Better, Sooner, More Convenient, 29.

${ }^{34}$ Ibid., 29.
} 
In 2007, National had commented on the dangers of obesity prevalence ${ }^{35}$ in the report Inquiry into Obesity and Type 2 Diabetes in New Zealand. ${ }^{36}$ National offered the BCM view that obesity and Type 2 Diabetes were serious medical problems which threatened to overwhelm the health system. ${ }^{37}$ However, National were clearly critical of the incumbent ECM approaches, instead favouring individual choice and BCM approaches to prevention:

National is not in favour of food and drink policies in public facilities and workplaces that remove individual choice. The emphasis should be on practical approaches that change attitudes to food and exercise. The necessary changes in diet and exercise habits will not occur through Government pressure. ${ }^{38}$

National's argument was that individuals must change their food and diet preferences themselves. Their view is that Governments should not put any pressure on individuals to change their health: "Interventions that eliminate choice and rely on control will not achieve the required attitudinal changes." ${ }^{39}$ Their argument is that individuals must exercise choice in regards to food consumption and they must learn how to practise being healthy for themselves.

So far it is apparent that, prior to 2009, National were aware of the dangers of obesity prevalence in the population, but preferred BCM responses to treat it. Other National Party primary sources provide further insight into their understanding of obesity. A speech given by Party leader John Key, to a Waitakere electorate lunch, heralded the removal of funding for HEHA and its replacement with sport and physical activity. In 2008: Sport for Young Kiwis: A National Priority ${ }^{40}$ Key broadly criticised the funding for SPARC and HEHA. He was critical of the Labour Party's healthy lifestyle policies, which he viewed as economically inefficient and ineffective. In his critique of Labour's HEHA strategy, Key argued that much of the $\$ 32$ million allocated to the DHBs had been soaked up in administration and that there had been little practical outcome from the initiatives offered by SPARC and HEHA. ${ }^{41} \mathrm{He}$ was also critical of the salaries paid to SPARC employees relative to the output of the organisation. According to Key, one third of the money allocated to SPARC did not leave the head office, ${ }^{42}$

\footnotetext{
${ }^{35}$ National MPs sitting on this Select Committee were Dr Jackie Blue, Dr Jonathan Coleman and former nurse Jo Goodhew. Tony Ryall the current National Minister for Health also sat on this committee. The only MPs who were medical practitioners on the Select Committee were from the National Party.

${ }^{36}$ House of Representatives, Inquiry into Obesity, 35.

${ }^{37}$ Ibid., 35.

${ }^{38}$ Ibid., 35.

${ }^{39}$ Ibid., 35.

${ }^{40}$ John Key '2008: Sport for young Kiwis: a National priority' Waitakere Electorate Lunch, Henderson on the $30^{\text {th }}$ of June 2008 (http://www.national.org.nz/Chapter.aspx?ChapterId=28150 (accessed Monday $27^{\text {th }}$ of October 2008)

${ }^{41}$ Ibid.

42 "47 of the 86 staff have salaries of over $\$ 100,000$ a year." See: Ibid.
} 
and strategy implementation, research, and the website offered little actual change to physical activity rates.

These pre-election sources make it clear that National's approach to obesity prevention would be radically different from that of their predecessor. As Key maintained, programmes such as HEHA and SPARC initiatives would be reassessed by a National Government:

An incoming National Government will have a look at all these programmes, regardless of which portfolio technically funds them, to ensure we get the balance right between funding promotional programmes and telling people to lead healthier lifestyles, and funding actual sports organisations with actual facilities at which sport is actually being played. ${ }^{43}$

National emphasised that the fitness and health of the population needed to be increased by participation in sports activities. The focus on sport renewed the late 1990s BCM focus on physical activity. Moreover, this focus placed the onus of responsibility for health onto individuals who must choose to be active. Key's rationale for the principles of this strategy was:

Most New Zealanders would probably say this is a sporting nation. And though that may be open to debate, what is not debatable is the fact that if New Zealanders can increase participation in sport then we have the capacity to significantly improve their lives. ${ }^{44}$

Taking sport as their example, National stresses the principles of personal responsibility as essential to the prioritisation of physical activity. They argue that increased physical activity will collectively improve the health of individuals, the nation, and, ultimately, the economy. For John Key, this is a logical connection and he states, 'The results, in terms of healthier, fitter people, who are less of a cost on our health system, are obvious. ${ }^{, 45}$ This example suggests that for the National Party fitness and health are ideal traits for citizens. In this preelection rhetoric we see a New Right BCM imperative for social and economic 'fitness' relating the health of individuals to the economy and the nation.

In this section, I reviewed National's general health policy, their economic policy, their views on individual responsibility, and their prioritisation of sport for healthy citizenship. I found that BCM approaches to health, originating from the 1990s, were repeated in National policy. The BCM is evident in National's policy emphasis on individual responsibility, funding primary care, the inefficiency of HEHA and SPARC, the reluctance to regulate food environments, and 
the promotion of sport and physical activity as part of good citizenship. From this review it is no surprise that this pre-election policy emphasis led to the 2009 dropping of obesity as a funded health target. Understood in terms of the BCM, National regarded obesity as an individual rather than State responsibility.

\subsubsection{The Association of Consumers and Taxpayers Party}

The Association of Consumers and Taxpayers Party (ACT) ${ }^{46}$ represent the extreme of New Right ideology and the BCM extreme of the spectrum. ACT policy focused on prioritising individual choice and instituting a programme of reform to create a deregulated State. ACT's philosophy prioritises the individual and their policy focuses on developing individual freedom and personal responsibility. Until 2008, ${ }^{47}$ the ACT Party had operated in opposition to Labour-led Governments. ${ }^{48}$ In 2008, ACT formed part of the new National Coalition and their ideological influence is likely to have contributed to the 2009 approach to obesity. I begin by generally addressing ACT's ideological view of health provision before shifting to analyse how ACT Party leader Rodney Hide employed his personal weight loss narrative as an analogy for his vision of State reform.

The 2008 ACT election policy did not mention the issue of obesity. Indeed, it was difficult to determine any specific ACT Health policy outside general principles and non-definitive statements. Their website ${ }^{49}$ suggested that a series of BCM principles served as the basis for ACT's health policy. These principles include access, competition, equality, an open marketplace, "putting patient's [sic] first", and creating competitive environments for the employment of doctors and nurses. This policy was part of ACT's structural critique of the State, that is, that the current State was economically inefficient and created dependent and lazy citizens. ${ }^{50}$ This placed the individual consumer at the forefront of their policy and emphasised the importance of choice in health care. This constituted a BCM argument for privatisation and health insurance. It focused on individual freedom and personal responsibility and assumed that individuals were able to effectively monitor their own health choices.

\footnotetext{
${ }^{46}$ ACT Party Front Page http://www.act.org.nz/ (accessed Monday $27^{\text {th }}$ of October 2008)

${ }^{47}$ ACT gained 5 seats in the 2008 New Zealand General Election and entered into the National Party Coalition agreement.

${ }^{48}$ In 1996, ACT occasionally offered support to the National - New Zealand First Coalition.

${ }^{49}$ ACT Party Health Policy

http://www.act.org.nz/health-policy (accessed Monday the 27 th $^{\text {, October, 2008) }}$

${ }^{50}$ ACT Party Front Page http://www.act.org.nz/
} 
Despite a lack of ACT policy directly concerned with obesity, Party leader Rodney Hide used his personal testimony regarding his own weight loss as an analogy for his political reform philosophy. His significant weight loss received widespread media attention before the 2008 election. Hide describes this weight loss in terms of a conversion narrative. He claims that in 2005 he was on the verge of losing his health, job, and marriage. As a response, Hide decided to lose weight. ${ }^{51}$ Hide related his personal transformation to the necessity for him to win the Epsom constituency. He explained that before he could gain the respect of his local electorate he had to change the behaviour that was responsible for him being unfit and fat. Hide also equated his personal unhappiness with his weigh. He stressed that after he took responsibility for his weight and behaviour he then became happy and confident. Hide perceived a direct causality between his change in behaviour, weight loss, and his personal success and sense of self worth. Following the BCM preference, Hide credited his transformation to increased physical activity and new found fitness, never mentioning dietary change. This emphasis on physical activity rather than dietary change is characteristic of the BCM approach.

For ACT, the individual benefits from hard work, responsible consumer and consumption choices. This is apparent when Hide discussed the link between his own physical change and ACT's policy to change the nation structurally: "I had talked for years about how we could transform government and the country, now I needed to know if I could do it for myself. I thought that if I could, I would have a better chance for introducing change on a larger scale." 52 Rodney Hide combines his weight loss rhetoric with his political critique of the Labour Government. He argued that the "[Labour] government has grown fat and inefficient while businesses and families are squeezed harder and harder." ${ }^{53}$ In this example, he equates fatness with inefficiency. Given the State was fat and inefficient, he claimed, an imperative existed for State and market reform.

Hide's logic supports the broader critique offered by ACT MP Roger Douglas who argued that the solution to economic recession is to privatise State public services in order "to restore confidence by freeing people from the burden of poor quality infrastructure, health and education systems and unnecessarily high taxes and meddling nanny state regulations.. ${ }^{54}$ For

\footnotetext{
${ }^{51}$ Rodney Hide, My Year of Living Dangerously (Auckland: Random House, 2007), 191.

${ }^{52}$ Ibid., 191.

${ }^{53}$ Ibid., 214

${ }^{54}$ Roger Douglas, ACT's Analysis of New Zealand's Economic Situation.

http://www.act.org.nz/blog/roger-douglas/act-analysis-of-current-new-zealand-economic-situation (Posted 21 ${ }^{\text {st }}$ October 2008, accessed $11^{\text {th }}$ December 2008).
} 
ACT, the current state system hindered the personal and market freedoms of consumers. They employed the analogy that a meddling nanny state is large, unwieldy, and inefficient. For ACT, this obese State was in drastic need of reform so that it could be leaner, more efficient, and, as a consequence, healthier.

ACT's BCM position represented the BCM extreme of the spectrum. ACT's policy demonstrated that BCM understandings of obesity did not fade away in the 1990s. Rather they were integral to New-Right ideology which underpinned a politics that viewed the 'thirdway' State as a fat, inefficient continuation of the Welfare state. This politics views the individual as a rational choosing entity with full responsibility for determining their own health in an unrestricted free-market. After the 2008 election it was the ACT Party along with the Maori Party that went into Coalition with the National Party. It is likely that ACT's extreme BCM view pushed National's milder BCM approach to obesity to towards a more extreme position.

\subsection{The Political Spectrum of Obesity Causation Models}

All 2008 obesity-related discourse is located between two economic and political philosophical extremes represented by Green and ACT policies. This discourse can be mapped upon a 'Political Spectrum of Obesity Causation Models.' The Green party stands for an environmental perspective where the State regulates both general society and the economy to solve the problem of obesity while ACT's New Right position demands State deregulation, an unrestricted free market, and the opening health provision to market-based competition to motivate individuals to be responsible for their own health choices. All of the policies emphasise a form of health 'responsibility' for citizens but the type of political environments in which this should occur remain hotly contested.

This electoral analysis makes it evident that there is no single obesity discourse. Obesity discourse is contested. While the BCM, MCM, and, ECM evolved chronologically all three models are simultaneously at play in contemporary obesity discourse. Thus, obesity discourse evolved over the period 1997 and 2008. The three models of obesity discourse are now spread along the spectrum. Official obesity discourse is never politically neutral. Obesity discourse is always associated with specific notions of causality, treatment, prevention, roles of citizens, and the operations/responsibilities of the State. This means that all health policy and 
treatments for obesity or other lifestyle diseases should be considered with caution because they will inevitably be influenced by one particular political model of causality.

Given that obesity discourse is politically contested, there has been little agreement on a solution to the problem of obesity. However, the debate does have definable political limits. All political parties are, in some way, concerned with the prevalence and cost of obesity treatment in terms of lives and dollars. All parties emphasise the need to reduce obesity prevalence and require individuals to take an increased responsibility for their health. Obesity prevalence is a significant political problem but what is contested is who is responsible for treating this problem and how they should treat it.

Now, it is important to return to consider National Coalition's removal of obesity as a health target. It is, I argue, the National Coalition's BCM ideological view that obesity was an individual behavioural problem rather than a matter of State responsibility which provides the rationale for this shift in obesity policy. This BCM ideology persuasively accounts for the dramatic shift given that National was clearly aware of obesity as a population health problem. Rather than dismissing the 'obesity epidemic' as a Labour-inspired fiction, the National Coalition deployed a BCM approach that cut costs, reduced the role of the State and made citizens wholly responsible for this particular health problem. Thus, I propose that the National Coalition obesity policy employed a BCM approach to obesity prevention and treatment and that their approach was intended to make citizens wholly responsible for any prevention and treatment costs.

\subsubsection{The Removal of Obesity as a Health Target}

The National Coalition, then, saw the funding of obesity prevention programmes as ineffective and instead preferred to focus on providing 'fiscally responsible' primary health care. This shift is part of a larger ideological BCM project which attempted to reduce public sector spending through a cost-based rationale..$^{55}$ The chapter now turns to a discussion of National Coalition obesity examples to show that cost-based rationales and a focus on creating consumer choice were primary drivers of the National Coalition's reversal of obesity policy.

\footnotetext{
${ }^{55}$ Tony Ryall, “Speech Notes from Address to the DHB Chairs in Wellington,” http://www.national.org.nz/Article.aspx?articleId=29009 (accessed $7^{\text {th }}$ December 2009).
} 
The National Coalition reversed Labour's obesity policy in May 2009. Upon becoming Minister of Health, Tony Ryall was briefed on the prevalence of obesity but it was made clear by the MOH that prevalence rates had not grown since $2003 .{ }^{56}$ After this briefing, there is no point between November 2008 and December 2009 where Ryall directly published anything acknowledging obesity as a health problem. Accordingly, when the National Government released its revised list of six Health Target priorities on the $7^{\text {th }}$ May 2009, obesity was no longer a Health Target. The revised Targets included:

Shorter Stays in Emergency Departments

Improved access to elective surgery

Shorter waits for cancer surgery

Increased immunisation

Better help for smokers to quit

Better diabetes and cardiovascular services ${ }^{57}$

Obesity treatment and prevention could have been included under diabetes and cardiovascular services, but there was no explicit mention of obesity. Ryall stated that the new Targets were focused on providing simpler, easier to understand goals for the health sector. Ryall argued that the previous Government's health targets, indicators, and objectives were overcomplicated. National promoted their six health targets as significantly simpler, more cost effective, and concentrated upon primary service delivery. In a later reference to his cost savings, Ryall ironically labelled his approach "leaner healthcare." 58

In addition to being removed as a Health Target, obesity was no longer considered a funding priority. In May 2009, the National Government cut the budgets of the HEHA and the Mission On campaigns established under the Labour Government. Funding for the Obesity Action Coalition lobby group was cut completely and $\$ 5$ million funding was reduced from the Type 2 Diabetes 'Let's Get Checked' budget. The Government presented budgetary concerns as the rationale for scrapping of HEHA. The total cost of the 75 actions contained in the HEHA budget was $\$ 39.83$ million per annum in $2007 / 08 .{ }^{59}$ In addition, there were associated amounts of funding for physical activity and nutrition, not managed by HEHA, which amounted to another $\$ 17.06$ million per annum in $2007 / 08 .{ }^{60}$ These two estimates combined indicated that, by 2008 , the annual cost of obesity actions related to HEHA appeared to be

\footnotetext{
${ }^{56}$ Ministry of Health, Briefing for the Incoming Minister of Health (Wellington, Ministry of Health, November 2008), 10-11.

${ }^{57}$ Tony Ryall, "Address to the Lean Healthcare Summit: The Current and Future Demands on Our Healthcare System and the Need for

Redesign," $11^{\text {th }}$ June 2009. http://www.national.org.nz/Chapter.aspx?chapterId=30171 (accessed $9^{\text {th }}$ December 2009).

${ }^{58}$ Ibid.

${ }^{59}$ Ministry of Health, Progress on Implementing the HEHA Strategy 2008, 6.

${ }^{60}$ Ibid., 6.
} 
some $\$ 57$ million. This funding cut closed all these programmes (except 'Let's Get Checked'). Under the auspices of the BCM, all of this expenditure was regarded as an inefficient and ineffective allocation of budget funding given the $\mathrm{BCM}$ preference for individuals to monitor their own health behaviour/s.

Proponents of both the ECM and MCM positions opposed the National Coalition's lack of obesity policy. Green MP Sue Kedgley, criticised the Government's change in health priorities and removal of funding: “The Government's decision to remove improving nutrition and reducing obesity as health priorities is stupid and short sighted, when poor nutrition is a leading cause of death and disease in New Zealand. ${ }^{\prime 1}$ Kedgley argued that the obesity-related initiatives were intrinsic to stopping the structural determinants of poor health. She suggested that spending money on preventative health was an investment in the health of the nation, the payoffs of which can only be seen in the future. Ruth Dyson, Labour Party Spokesperson for Health, was more restrained in her criticism of the health targets, suggesting that National was focused on cutting financial costs in areas which affect children's and old people's health. ${ }^{62}$

The obesity policy reversal suggests that one difference between the National Coalition, Labour's, and the Green's obesity positions appears is based, largely, on economic point of view. The Greens and Labour saw obesity prevention programmes as an investment in the nation, whereas the National Coalition viewed these programmes as a misallocation of scarce public health funding. While neither side in this debate mentioned the role of the citizen, it appears that the ramifications of this new policy direction will require individuals to be more independently responsible for managing the costs of preventing, understanding, treating, and determining the dangers associated with modern living.

\subsubsection{Healthy Food in Schools - National Administration Guideline Clause Removal}

National's reversal of obesity policy provides additional illustration that a key area of debate between the BCM and ECM is centred upon whether or not individuals could make healthy choices. In 2009, there was intense debate surrounding the removal of a clause which requiring only healthy food options to be sold schools in the New Zealand Ministry of

\footnotetext{
${ }^{61}$ Sue Kedgley, “Government Going Backwards on Obesity,” Green Party Press Release $8^{\text {th }}$ May 2009. http://www.greens.org.nz/node/21094 (accessed 9th December 2009).

${ }^{62}$ Ruth Dyson, “Do reduced health targets signal budget cuts?" Labour Party Press Release $8^{\text {th }}$ May 2009. http://www.scoop.co.nz/stories/PA0905/S00148.htm (accessed 9th December 2009).
} 
Education National Administrative Guidelines. ${ }^{63}$ In the National Administration Guideline (NAG) clause removal the National Coalition favoured 'choice' rather than the restriction of choice when it came to school food provision. I begin by analysing the NAG clause changes and then shift to discuss the debate surrounding notions of choice and agency.

The background to this debate arose in 2008 when the Labour Coalition inserted two ECM clauses in Section 5 of the NAG guidelines. The two original 2008 clauses required each Board of Trustees to:

(ii) promote healthy food and nutrition for all students

(iii) where food and beverages are sold on school premises, make only healthy options available $^{64}$

These ECM clauses removed unhealthy food from school premises, subsequently removing children's agency to make choices about food consumption. This removal of agency was based upon research ${ }^{65}$ that indicated that children's environments were saturated with unhealthy food advertising which made it impossible for them to eat healthy food. This ECM approach to school food environments was completely at odds with National's BCM viewpoint.

It should come as no surprise that the National Coalition amended these NAG clauses. Early in February 2009, the Minister for Education, the Honourable Anne Tolley, released a press statement stating that NAG Section Five Clause Number (iii) had been discontinued. ${ }^{66}$ Tolley stated that the clause created confusion in schools and that its removal will decrease compliance costs. Such cost reduction, she argued, would allow schools to concentrate on their core business, education. ${ }^{67}$ Tolley also used an economic rationale and stressed individual choice to justify this policy change:

I believe boards of trustees should be able to make their own decisions about appropriate food and drink options. After all, they are parents who should be aware of what 'good' and 'bad' foods are. I am confident they will act responsibly. ${ }^{68}$

\footnotetext{
63 "National Administrative Guidelines." New Zealand Ministry of Education

http://www.minedu.govt.nz/NZEducation/EducationPolicies/Schools/PolicyAndStrategy/PlanningReportingRelevantLegislationNEGSAn dNAGS/TheNationalAdministrationGuidelinesNAGs.aspx \#NAG5 (accessed $13^{\text {th }}$ Jan 2010).

${ }^{64}$ Implications of the removal of National Administrative Guideline 5 (iii) on the work of the Education Team at Community and Public Health" Report prepared for Canterbury District Health Board, $18^{\text {th }}$ February 2009. http://www.cdhb.govt.nz/corpbrd/CPHDSACMeetings/2009/01@,February19/Item\%208\%20\%20App $1 \% 20$ Healthy\%20Eating\%20in\%20Schools.pdf (Accessed $13^{\text {th }}$ Jan 2010).

${ }^{65}$ Nick Wilson, George Thomson and Gabrielle Jenkin, "More Evidence For Action on New Zealand's Obesogenic School Environment and Food Pricing," The New Zealand Medical Journal 120 no 1248 (January 26, 2007): 1.

${ }^{66}$ Anne, Tolley, "Schools No Longer Required to be Food Police,” http://www.national.org.nz/Chapter.aspx?chapterId=29288 (accessed

$7^{\text {th }}$ December 2009)

${ }^{67}$ Ibid.

${ }^{68}$ Ibid.
} 
Tolley explained that it is not the State's role to tell people what they should or should not eat. She argues that the State and its institutions, in this case the schools, should not have to bear the cost of educating people about food choices. In her view, it is the role of parents, not State institutions, to take responsibility for how and what children eat.

The clause removal received support from the food industry. Former National MP, Katherine Rich, now CEO of the New Zealand Food and Grocery Council, argued that the NAG removal meant that schools did not need to be 'food police' and could return to hosting events like sausage sizzles again. ${ }^{69}$ Rich argued:

It is important to note that the Education Minister did not abolish National Administration Guideline 5. As Health Minister, Tony Ryall pointed out yesterday the Government retained important wording in that requires schools "to promote healthy food and nutrition for all students. ${ }^{70}$

According to Rich, schools were still required to promote health food and nutrition, but they were no longer constrained by a certain 'ideological' approach to health. She argued that schools were now free to choose to interpret NAG guideline 5. Although Rich rejected an 'ideological' approach to health, her own claims were not free from ideology given her membership in the New Right and her advocacy of a BCM inflected notion of 'freedom of choice.' Again, Rich's comments demonstrate that the recent obesity policy debate centred on the question of whether children should have the agency to choose what they eat.

An ECM analysis of the debate also reinforced that the clause removal was centred upon notions of choice. The Obesity Action Coalition commissioned a public relations company Communiqué to analyse all the media discussion of the NAG clause removal. This analysis ${ }^{71}$ found that the arguments for retaining the NAG guideline were concerned with the increasing rates of Obesity and Type 2 Diabetes. Other arguments for retaining the NAG guideline involved the dangers of giving mixed messages to children regarding healthy eating. In contrast, arguments supporting the NAG guideline exclusion focused on the removal of personal freedoms, nanny state arguments, and the need for parents themselves to instil in their children awareness about healthy food options. Thus, supporters of the clause removal focused

\footnotetext{
${ }^{69}$ Katherine Rich, “No Evidence School Lunches Less Healthy,” Food \& Grocery Council (FGC) Media Release, Wednesday, 13 January 2010 , http://www.scoop.co.nz/stories/GE1001/S00012.htm (accessed 10th March 2010).

${ }^{70}$ Ibid.

${ }^{71}$ Communique found from $82 \mathrm{NZ}$ based metro and provincial newspaper chapters discussing the removal 56 (68\%) were against the removal,

$11(13 \%)$ agreed with the removal and $15(18 \%)$ had a mixed response to the removal.

See: Obesity Action Coalition Media Analysis - March 2009.

http://www.obesityaction.org.nz/docs/OACMediaAnalysisMarch09.pdf.( accessed 9th December 2009).
} 
upon choice and freedom and those who opposed the removal were focused upon creating healthy environments.

ECM supporters found the NAG clause removal incomprehensible. The lobby group Fight against the Obesity Epidemic (FOE) released a press release stating that the clause repeal was "incredible." ${ }^{72}$ The Obesity Action Coalition (OAC) labelled the repeal "[p]eculiar." " Labour Education spokesperson Chris Carter stated that the clause repeal did nothing to alleviate parental concern about what their children were eating or to educate them about the benefits of healthy eating. ${ }^{74}$ Meanwhile, the Green MP Sue Kedgley fumed that National was allowing junk food back into schools: ${ }^{75}$

Poor diet is the leading cause of premature death and disease in New Zealand, the Government knows this only too well - a third of our kids are obese or overweight. Why on earth would it scrap a programme designed to tackle the looming epidemics in obesity-related illness and make sure our kids have healthy habits modelled at school? ${ }^{76}$

Subsequently, Kedgley argued that there will be a detrimental effect for the population's health because of Tolley's decision: "As a result of her decision schools are free to sell whatever high fat, high sugar foods they wish in tuck shops, even if it will contribute to rotten teeth, Type 2 Diabetes, poor behaviour and obesity amongst our children. ${ }^{177}$ Kedgley directly linked the availability of unhealthy foods rather than poor choice as the cause of Type 2 Diabetes and obesity.

Kedgley's critique was repeated in a NZMJ editorial by Utter et al who claimed, "[T]here is no justification for or evidence to support the repeal of the healthy food clause. ${ }^{~}{ }^{78}$ Utter et al argue that the clause repeal sends a message to children that it is okay to eat junk food. Moreover, they noted that the decision to repeal the clause was based on ideological views which emphasised personal responsibility and individual freedom. ${ }^{79}$ They framed their support for retaining the clause by stating:

\footnotetext{
${ }^{72}$ Robyn Toomath, "National Reversal on Healthy Foods in Schools Incredible," Fight against the Obesity Epidemic Press Release $5^{\text {th }}$ February 2009.http:// foe.org.nz/2009/02/18/national-reversal-on-healthy-food-in-schools-incredible/ (accessed $7^{\text {th }}$ December 2009).

${ }^{73}$ Leigh Sturgiss, "Health Group Says Decision to Reintroduce Unhealthy Food at Schools 'Peculiar' Obesity Action," Obesity Action Coalition Press Release $5^{\text {th }}$ February 2009. http://www.obesityaction.org.nz/media/090205Decisionpeculiar.pdf (accessed 9th December 2009.)

${ }^{74}$ Chris Carter, “Education Minister Promotes Child Obesity,” Labour Party Press Release, Saturday $7^{\text {th }}$ February 2009.

http://www.scoop.co.nz/stories/PA0902/S00085.htm (accessed 9th December 2009).

${ }^{75}$ Sue Kedgley, 'National Brings Back Junk Food, say Greens', http://www.greens.org.nz/node/20540 (accessed 7th December 2009). ${ }^{76}$ Ibid.

${ }^{77}$ Sue Kedgley, “Let Them Eat Cake, Drink Cola, and Go Nuts,” http://www.greens.org.nz/node/20594 (accessed 7th December 2009).

${ }^{78}$ Jennifer Utter, Robert Scragg, Teuila Percival and Robert Beaglehole, "School is Back in New Zealand - And So Is The Junk Food,” The New Zealand Medical Journal 122 no. 1290 (February 27, 2009): 5.

${ }^{79}$ Ibid., 5.
} 
The healthy food policy meant that parents could be sure that their children were able to make healthy food choices at school. Children do not always have the maturity and cognitive development to make the healthiest food choices, particularly in a society where they are heavily targeted by the food industry. We cannot expect children and young people to make the healthiest food choices unless we make the healthy choices accessible and cheaper.... By creating school food environments where only healthy foods are available, students have the freedom to make their own personal choices within a range of healthy options. ${ }^{80}$

Here, Utter et al explicitly claim that the food industry directly targets children. Such targeting, they argue, makes unhealthy food choices the default choices for children. Strangely, the authors still utilise the language of freedom and choice in relation to their preferred food environment which restricts the food options to healthy options. A closer look at this ECM language reveals that it restricts choice to only healthy options.

This ECM restriction of choice is evident in another NZMJ example, where Gorton et al argued that education alone does not work for treating public health issues ${ }^{81}$ and that behavioural change will only come through regulation that restricts and dictates food choices. They argue that "the environment must be changed to make healthy choices the easy choices. ${ }^{~} 22$ This is a clear example that certain medical researchers believe that children are not currently capable of making healthy food choices. They argue:

The current rates of childhood overweight (21\%) and obesity (8\%) shows that existing environments are not conducive to healthier choices. Government intervention is justified to protect children and to prevent the high societal costs of nutrition-related disease. This does not make New Zealand a 'nanny state', but simply a caring state. ${ }^{83}$

Here we can see evidence of ECM- and MCM-based arguments that insist that state intervention is necessary to solve the problem of obesity. However, this ECM view of the State is antithetical to the National Coalition's BCM NAG clause removal and its view that its opponents are reliant upon a nanny state.

The NAG guideline removal is important because it further illustrates the ideological nature of obesity debate. Individual choice, agency, and the role of the State are the central contested notions in the debate surrounding the NAG clause removal. These were key notions to the NAG removal and also to the National Coalition's entire rationale for the obesity policy

\footnotetext{
${ }^{80}$ Ibid., 6.

${ }^{81}$ Delvina Gorton, Helen Etyles, Cliona Ni Mhurchu and Chris Bullen, "Removal of the Requirement For Schools to Only Sell Healthy Food a Giant Leap Backwards,” New Zealand Medical Journal 122 no. 1290 (February 27, 2009): 130 -132.

${ }^{82}$ Ibid., 130 .

${ }^{83}$ Ibid., 131.
} 
reversal. The NAG example highlights these two contrasting ideological extremes. The National Coalition favoured BCM policy which gave children choice. Their political opponents found this logic incomprehensible because they believed that health choices and individual agency were impossible in environments dominated by undesirable advertising saturation.

\subsubsection{New Zealand $3^{\text {rd }}$ Most Obese Country in the World}

A further example of the ideological nature of National Coalition's approach to obesity can be found in political reactions to international comparisons of obesity rates. In July 2009, the Organisation for Economic Cooperation and Development (OECD) released a comparative health report ${ }^{84}$ that noted that the 2007 population obesity rate of $26.5 \%$ among adults was the third highest in the OECD (behind only USA and Mexico). Opponents of the National Party used the findings of this report to fault the revised Health Targets.

Foremost amongst those ${ }^{85}$ using the OECD report to critique National's removal of obesity as a health target was Labour Party health spokesperson Ruth Dyson. Dyson used the opportunity of the report to provide a twofold criticism of National's lack of position on obesity. She expressed the opinion that obesity remained one of the largest threats to the health in the nation, insisting that "New Zealand can simply not afford to sit back and let the obesity epidemic continue. The human and financial cost of doing nothing is simply too great." Dyson made the point clearly that, for the Labour Party, obesity remains one of the most pressing health issues for the nation. Her second point is that the financial costs of obesity to the State are going to be significant if the problem is left untreated. Later, Dyson quantified these financial costs by indicating that $\mathrm{MOH}$ figures indicated that the costs of obesity to the health sector will increase to $\$ 1.3$ billion dollars a year by 2016 without Government intervention. ${ }^{87}$

The National Coalition was silent in response to the OECD report and the ECM allegation that they were ignoring the problem of obesity prevalence. The criticisms that obesity cost the State were simply irrelevant to the BCM approach which intended to devolve the costs of

\footnotetext{
${ }^{84}$ OECD Health Data, How Does New Zealand Compare? Released $1^{\text {st }}$ July 2009 http: //www.oecd.org/dataoecd/43/22/40905041.pdf (accessed 9th December 2009).

${ }^{85}$ Sue Kedgley, "Report Highlights Government Stupidity on Obesity," Green Party Press release, Monday, 13 July 2009

http://www.scoop.co.nz/stories/PA0907/S00151.htm (accessed 9th December 2009).

${ }^{86}$ Ruth Dyson, “National fails to understand importance of obesity," Labour Party Press Release, $14^{\text {th }}$ July 2009 , http://www.scoop.co.nz/stories/PA0907/S00162.htm (accessed $9^{\text {th }}$ December 2009).

${ }^{87}$ Ruth Dyson, “Obesity strains health services,” Labour Party press release $20^{\text {th }}$ July 2009. http://www.scoop.co.nz/stories/PA0907/S00209.htm (accessed 9th December 2009).
} 
obesity from the State to individuals themselves. Dyson's comments highlight the difference in the way National and the Labour Coalitions view obesity. For Labour obesity is a pressing population health concern which the State must address and the findings of the OECD report simply reinforce this belief. For National, the OECD findings are irrelevant because obesity prevention and treatment are considered an individual's problem and not an issue of State concern.

\subsubsection{Physical Activity: The Emphasis on Sport}

Sport, competition, and the encouragement of physical activity are an ideological priority of the National Coalition. It is now clear that the National Coalition understands obesity prevention to be an individual's responsibility rather than a State obligation. Following the BCM approach, National actively funded and promoted 'Sport' instead of focusing on obesity interventions. As I discussed in Chapter Two, the BCM frames 'Sport' as a grass roots activity that produces beneficial results for individuals, communities, and the nation. 'Sport' replaces earlier BCM notions of physical activity as an important part of healthy citizenship. Given such views, National shifted significant amounts of funding from obesity campaigns to 'Sport.' In the 2009 budget, $\$ 82$ million dollars of funding, distributed over four years, was allocated to promote schools sports and sports organisations:

Prime Minister John Key announced the boost to school sport funding yesterday, saying money cut from "social marketing" campaigns such as the multimillion-dollar Push Play and Mission On campaigns which combined healthy eating and physical activity messages was better used on school sports teams and equipment. ${ }^{88}$

Key's statement indicated that the Government was aware that there are problems surrounding exercise rates. His point of view is that there are more effective places for public money to be spent than on obesity related 'Social Marketing' programmes. Key preferred funding preventative physical activity programs aimed at future generations through funding children's sport:

Mr Key said it [National] recognised that sport had "undeniable benefits" in terms of physical fitness, teamwork and leadership. Getting more Kiwi kids involved at school level can lead to a lifetime of involvement in organised sport. ${ }^{89}$

Key argues that programmes directed at promoting 'Sport' have broad public appeal and that encouraging the young to be sporting was more likely to gain widespread support than policies

\footnotetext{
${ }^{88}$ Tracy Watkins. “\$82m Funding Boost for School Sports,” http://www.stuff.co.nz/national/education/2742110/82m-funding-boost-forschool-sports. (last accessed 7th December 2009).$$
{ }^{89} \text { Ibid. }
$$ 
which 'waste money.' Moreover, increasing funding to already existing sports organisations pursues policy which shifts public sector services into the private and volunteer sector.

Criticism has been made of this focus upon 'Sport.' FOE spokesperson Robyn Toomath commented that the physical activity funding of sport was indeed good for improving the lifestyles of some children. ${ }^{90}$ However, she made a distinction between encouraging sport and that of encouraging increases in the physical activity rates. She also suggested that stripping population-wide programs such as HEHA of funding to provide funding for children's sport was unlikely to have the same health benefits that HEHA might have produced. She was highly critical of the overall effect of the combination of policies such as increasing sports in schools in combination with the repeal of the NAG clause. Toomath suggested that this funding for 'Sport' benefits children unequally. For Toomath, both the NAG removal and the funding of sport ignore the root cause of obesity: the obesogenic environment.

In reply to the criticism that sport was an uneven allocation of funding the Hon Murray McCully, Minister for Sport and Recreation, argued that claims that the Kiwisport programme was unequally distributed were based on "selective and shonky number crunching." ${ }^{91}$ He stated that secondary school funding for sports is being increased from an existing budget of 5.3 million to 20 million between 2009 and 2010. McCully stated: "Every child in the country will have access to increased resources for organised sport under the new policy" ${ }^{92}$ Thus, we see that access to 'Sport' has been made available to all those who choose to participate in these programmes. McCully's comments echo those he made while serving as a National Minister for Sport and Recreation in the late 1990s. At that time, he argued that physical activity contributed to the social and economic wellbeing of the country. ${ }^{93}$ The key difference between the 1990s approach and the 2009 approach was a semantic shift from 'physical activity' which had encouraged participation to a language of 'sport' which encouraged competition.

The competitive nature of sport requires further discussion because competition is an essential part of BCM ideology. John Key argued that funding 'Sport' for children could develop future

\footnotetext{
${ }^{90}$ Robyn Toomath, “New Zealand: More Sport Won't Stop the Obesity Epidemic,” Fight Against the Obesity Epidemic Press Release 12 August 2009, http://foe.org.nz/2009/08/12/nz-more-sport-won\%e2\%80\%99t-stop-the-obesity-epidemic/ (accessed $9^{\text {th }}$ December 2009). ${ }^{91}$ Murray McCully, "Kiwisport Provides More Funding For All School Kids," National Party Press Release $17^{\text {th }}$ August 2009. http: / / www.national.org.nz/Chapter.aspx?chapterId=30609 (accessed $9^{\text {th }}$ December 2009).

${ }^{92}$ Ibid.

${ }^{93}$ McCully and Creech, Physical Activity.
} 
sports stars who would produce effective marketing opportunities for the entire nation. ${ }^{94}$ For example, Key stated in relation to cricket that "Sport is an important part of international relations and ... cricket is great for building strong bilateral relations with countries and attracting tourists and offshore interests to New Zealand." ${ }^{95}$ Key sees a beneficial relationship between successful professional elite 'Sports' and the improvement of the nation. It follows that Kiwisport must be considered a programme which assists in our competition on a world stage. Thus, under the BCM view the competition offered by sport has outcomes for both individuals and the nation.

In summary, the BCM focus on sport benefits those who participate. However, those who choose not to take part will be held responsible for the consequences. The economic rationale for this BCM focus on sport is twofold. First, it is an investment in the health of those who participation as physical activity acts as a form of insurance against ill-health and reduces the future cost of treating illness for primary services. Second, it is investment intended to develop future generations of athletes. In no way does this policy help those people who are already obese. This focus on sport also indicates the priorities of BCM funding. National is prepared to focus upon and fund those who are prepared to get physically active rather than those who suffer as a result of physical inactivity.

\subsubsection{Recent Obesity Politics: The Voluntary Schools Beverage Statement}

The chapter has so far explained National's obesity policy reversal as an application of BCM ideology to the health sector and the propensity for BCM approaches to be tempered by cost efficiency. One recent development in National Coalition health policy has been their support of the Voluntary Schools Beverage Statement. This statement prohibits the sale of full sugar soft drinks in schools. This statement is interesting because it does not easily fit within the BCM as it restricts individual choice and limits the free-market. Here, I argue that at times the National Government employs MCM policy when it could be justified as cost effective.

Labour developed the Voluntary Schools Beverage Statement in 2006 and the National Government Ministers of Health and Education, Tony Ryall and Anne Tolley, confirmed that they would complete the agreement to stop the direct sale of full sugar drinks in primary, intermediate,

\footnotetext{
94 “PM Joins 50th Test Celebrations,” New Zealand Cricket Press Release Monday the $7^{\text {th }}$ of December 2009.

http://www.blackcaps.co.nz/news/international/1/pm--joins-50th-test-celebrations/6158/chapter.aspx (accessed $9^{\text {th }}$ December 2009).

${ }^{95}$ Ibid.
} 
and secondary schools as of the $11^{\text {th }}$ of December 2009. ${ }^{96}$ Under this policy schools could still provide non-sugar drinks from Coca-Cola and Frucor and their company vehicles could still display full branding when distributing orders. ${ }^{97}$ The Voluntary Schools Beverage Statement, released by Cocacola Amatil and Frucor, has the following vision:

The Government vision is an environment and society where individuals, families and whanau and communities are supported to eat well, live physically active lives and attain and maintain a healthy body weight. [AND] ... obesity is a major risk to public health and to working collaboratively to tackle it. Doing all that is possible to encourage all sectors of the food industry to create commercially successful products and services that will make a contribution to the health of New Zealanders. ${ }^{98}$

The Food and Beverage Industry are continuing the ECM/MCM policy initiated by Labour in 2006. However, it is this industry that uses the obesity and environmental language not the National Coalition. This Voluntary Statement is interesting because it acknowledges that certain food industries do contribute to an unhealthy environment and are under pressure to create healthy products. However, this voluntary agreement still allowed consumers (children) the freedom to continue purchasing products from these companies within school grounds.

Opponents of this agreement suggested that the agreement did not go far enough as soft drinks and their associated advertising were not completely removed from schools. This meant that Schools were still environments that promoted the consumption of branded soft drink beverages. ${ }^{99}$

A closer analysis of the Voluntary Schools Beverage Statement shows that the National Coalition Government appeared to have supported the statement to avoid discussion of the imposition of 'Fat and Sugar taxes.' Katherine Rich, Chief Executive of the New Zealand Food and Grocery Council and chief lobbyist for the FMCG (Fast-Moving Consumer Goods Industry), released a press release which supported the Voluntary Statement, stating: ${ }^{100}$

The announcement by Coca-Cola and Frucor this morning is timely because it neatly rebuts food activists' impractical calls this week that punitive and unworkable sugar taxes were the only answer... The Minister of Health Tony Ryall was absolutely right to rule out fat and sugar taxes, saying New Zealand families are already struggling and don't need this extra burden. ${ }^{101}$

\footnotetext{
96 “Companies Remove Full Sugar Drinks From Schools," http://www.infonews.co.nz/news.cfm?id=45831 (accessed $8^{\text {th }}$ March 2010).

${ }^{97}$ Ibid.

${ }^{98}$ Ibid.

${ }^{99}$ Sue Kedgley, “Coca Cola and Pepsi Move Just Fizzy PR Spin,” Green Party Press Release $11^{\text {th }}$ December 2009.

http://www.greens.org.nz/press-releases/coca-cola-and-pepsi-move-just-fizzy-pr-spin (accessed 10 $0^{\text {th }}$ March 2010).

${ }^{100}$ Katherine Rich, “Govt, Companies, Removing Fizzy From schools,” Food \& Grocery Council (FGC) Media Release, $11^{\text {th }}$ December 2009.

http://www.scoop.co.nz/stories/ED0912/S00027.htm (accessed March 10th 2010).

${ }^{101}$ Ibid.
} 
National appears to be following a MCM approach with this policy. Why? Perhaps as a response to the threatened ECM food tax policies being developed. The MCM approach seems to be a policy compromise caught between the BCM and ECM approaches. For BCM practitioners, MCM programmes that incentivise healthy behaviours are justifiable and can be co-opted if they can be independently funded and can show that they offer some future benefit.

The National Coalition also continued a MCM approach to obesity prevention in late October 2009, when Tony Ryall announced that the Fruit in Schools programme would continue. ${ }^{102}$ This policy still continues the economic priorities of the BCM model, though, as schools were still expected to fully fund the costs of the fruit themselves. Similar to the rationale provided with funding sport, a self sufficient Fruit in Schools program is a cost-effective method for the Government to invest in the future health of the nation.

\subsection{National Coalition Obesity Policy Reversal}

The 2009 obesity policy reversal was ideological. The chapter showed, through a number of examples, that National used cost based and choice rationales to justify this policy reversal and made obesity an individual's rather than the State's problem. National did not need to discuss the 'costs of obesity' or 'obesity as a population epidemic' because obesity was no longer a State problem. Indeed, any use of this language would have implied State responsibility. The employment of obesity 'epidemic' language implies that there is a problem to treat or prevent. The absence of discourse effectively removes the whole problem. Consequently, National's lack of acknowledgement of the OECD report can be understood as ideological. To address the OECD report would have been to recognise a problem for which the State would be responsible.

Thus, the simple explanation for the obesity policy reversal is that the National Coalition understood obesity prevention and treatment to be an individual problem rather than a State problem. National was still aware that obesity rates were high, but when it did act in this area the party encouraged individuals to 'choose' to become healthy through self-discipline in food choice and through participation in sport. However, moral consequences resulted from this devolution of responsibility for obesity onto individuals. Individuals, rather than the State,

\footnotetext{
${ }^{102}$ Tony Ryall, "Fruit in Schools Future Confirmed," National Party Press Release $26^{\text {th }}$ October 2009 http://www.national.org.nz/Chapter.aspx?chapterId=31211 (accessed $9^{\text {th }}$ December 2009).
} 
were now responsible for the maintenance of their own health. Following this logic, obese individuals were a product of their own lack of self-discipline and poor choices. This BCM explanation blames the obese for their illness rather than the explanations offered by the ECM and MCM which at least place some of the blame on the environment and give responsibility to the State to prevent and treat the problem. These moral ramifications of individual responsibility and opposing notions of collective responsibility are discussed in Chapter Six.

\subsection{Conclusion}

This chapter brought the three obesity causality models together in an analysis of the obesity policy of the major political parties contesting the 2008 General Election. As is evident in my analysis of the electoral policies of political parties, obesity discourse is never neutral and always contains a political bias leaning towards one particular obesity causality model. All three obesity causality models, outlined in the previous chapters, are currently operative in contemporary politics. Indeed they can be mapped along 'a political spectrum of obesity causation models.'The ECM of the Green party forms one limit of the spectrum while the $\mathrm{BCM}$ of the ACT party forms the opposing limit. MCM and other issues-based viewpoints fall in the middle of the spectrum.

The opposing limits of the spectrum act in such a way that ideological views of particular social problems can effectively talk past each other. Understood in this light, the second half of the chapter demonstrated that 'scientific facts', such as the existence of the 'obesity epidemic,' become contested by ideological notions of State governance. Tracking the political dimensions of obesity discourse and causality models makes it possible to outline a rationale for the National Coalition's removal of obesity as a health target and their cessation of funding for obesity prevention. The National's Coalition's BCM viewpoint is that individuals, not the State, are tasked with the responsibility for obesity prevention.

This analysis answers one important sub-question of this dissertation research which sought to explain why the National Government reversed Labour's obesity policy in 2009. Throughout this chapter, I argued that the BCM policy with its focus upon cost and choice rationales explains the removal of National Coalition support for obesity as a population problem. The reason for National's removal of obesity as a Health Target and the cessation of funding for obesity prevention programmes is thus ideological. The National Coalition is focused on providing 'leaner' health care that reduces the size and cost to the Public sector. This 
preference for a smaller state sector is clearly aligned with the economic rationale of the $\mathrm{BCM}$, which emphasises individual responsibility and strives to create or deregulate environments to enable choice and individual agency. BCM proponents consider that State based obesity prevention programmes take away individual choice and are an inefficient use of funding. It is then a combination these BCM rationales that explains the National Coalition's reversal of obesity policy and their apparent lack of concern about what Labour had argued was: "the greatest public health challenge facing New Zealand." ${ }^{103}$

This now concludes my chronological discussion of obesity discourse. In Chapters Two to Five, I have specifically outlined the medical and political dimensions and limits of obesity discourse. I traced a general history of the emergence and evolution of obesity discourse in one Western nation by tracking three distinct models of obesity causality and policy. I have shown that these models all still co-exist in today's political climate along 'a political spectrum of obesity causation models'. I have also explained why the National Coalition removed obesity as a health priority. This analysis shows that the 'obesity epidemic' is to some extent a political football which has been used by political parties to suit their own ideological agendas without consideration of the socio-economic, ethnic, and moral ramifications. Thus I argue that the National Coalition's policy reversal serves to illustrate the dynamics of the obesity causality models across this spectrum.

My remaining chapters are thematic and address three particular issues arising out this chronological analysis of obesity research. I now focus upon the moral dimensions of obesity discourse and the obesity models. In Chapter Six, I explicitly focus upon the moral dimensions of obesity discourse. I argue that the moral dimensions of obesity discourse can be further understood through religious notions of individual and communal morality. Religious systems and language theorise notions of sin and badness in ways in which modern culture does not. I argue that religion provides further conceptual tools to consider how modern obesity discourse moralises and scapegoats the obese. This will compel some exploration of the medical and policy language used to describe the obese.

\footnotetext{
${ }^{103}$ Cullen, Budget Speech 2006, 28.
} 
Part Two: The Moral Dimensions of Obesity Discourse 


\section{Chapter Six: The Moral Dimensions of Obesity Discourse}

\subsection{Introduction}

This chapter outlines the moral dimensions of the ECM and the BCM and then critiques them. It finds that obesity discourse, in whatever form, is particularly concerned with allocating moral responsibility for the causes of obesity. In the process of discussing the moral dimensions of the ECM and $\mathrm{BCM}$, a general critique of obesity discourse emerges which finds that the obesity models scapegoat different things for causing obesity. All three obesity models allocate blame for the cause of obesity to a specific set of factors, for example, individual behaviour, an obesogenic environment, or a combination of the two. Thus, this analysis of the moral dimensions of obesity discourse will show some of the limitations of the existing models and points to the additional considerations of economics and ethnicity which are often subordinated in the blaming process.

I begin by showing how communal and individual models of sin and moral politics illustrate the moral dimensions of the obesity causality models. I am particularly interested in understanding how these models diagnose, classify, systematise, and expurgate sin. I analyse the ECM and MCM moral models through George Lakoff's ${ }^{1}$ liberal moral politics and Gary Anderson's ${ }^{2}$ investigation of the metaphors for sin used by ancient Hebrew communities. I then explore the moral dimensions of ECM and MCM discourse by analysing the ways in which the term 'burden' operates as a descriptor for the generalised effects of obesity on the nation. I analyse the BCM through the individualised moral models offered by George Lakoff' s ${ }^{3}$ conservative moral politics and Max Weber's Protestant Ethic. ${ }^{4}$ I then explain how individualised and communalised notions of society can coexist and create compromised middle grounds. This middle ground is used to outline how, using the work of Rene Girard, ${ }^{5}$ the process of scapegoating is a common theme in the obesity models. Finally, I turn to an example which illustrates the conflicting moral dimensions of obesity discourse. I analyse the example on two levels. First, I outline the conflicting ideological views arising out of the example. Second, I explore the ironies and limitations of this example. I conclude the chapter

\footnotetext{
${ }^{1}$ G. Lakoff, Moral Politics: How Liberal and Conservatives Think, Second Edition (Chicago, University of Chicago Press, 2002).

${ }^{2}$ G. Anderson, Sin: A History (New Haven: Yale University Press, 2009).

${ }^{3}$ Lakoff, Moral Politics.

${ }^{4}$ M. Weber, The Protestant Ethic and the Spirit of Capitalism (London: Routledge, 1992,).

${ }^{5}$ R. Girard, Violence and the Sacred (Baltimore: John Hopkins University Press, 1977)
} 
by arguing that the moral dimensions of the obesity models are primarily concerned with allocating responsibility and blame for the causes of obesity.

This chapter represents a change of approach to the subject matter. The previous chapters have been chronological whereas this chapter and those following are thematic. This chapter applies religious studies theories to the case material. Such a shift from chronological to thematic approach is necessary because modern culture does not offer such a systematised account of those people that society constructs as pariahs. In contrast, religious cultures and systems offer us contexts and explicit models which systematise blame and guilt. Thus, religious analyses and notions of sin offer useful analogies to consider the problem of blaming and scapegoating in obesity discourse. I am not arguing that obesity language and the models of obesity causality contain a direct and/or modernised reinvention of the Christian traditions of sin. Rather, having established obesity discourse as moralised and politically divided, it is my intention here to argue that Religious Studies methodology can provide lenses that allow us to reconsider the moral dimensions of obesity discourse.

\subsection{ECM - Communal Morality}

In Chapter Four, I claimed that the ECM blamed unhealthy environments for causing obesity. For the ECM obesity is a problem borne by States and communities rather than individuals. Here, I extend this argument to include a moral dimension. I compare ECM discourse to George Lakoff's ${ }^{6}$ liberal moral politics and Gary Anderson's ${ }^{7}$ investigation of ancient Hebrew metaphors for sin. These comparisons demonstrate how communalised notions of morality explain classify, systematise, and expurgate sin. I argue these comparative methods are useful for understanding the moral dimensions of the ECM. ${ }^{8}$

One important dimension of ECM discourse is its focus upon the protection of children. This view of the State has sometimes been called 'paternalism' in obesity discourse. ${ }^{9}$ In his analysis of American moral politics, George Lakoff outlines a liberal position ${ }^{10}$ which is similar, but not identical, to the ECM view. ${ }^{11}$ Lakoff focuses on the moral metaphors that liberals use to

\footnotetext{
${ }^{6}$ Lakoff, Moral Politics.

${ }^{7}$ Anderson, Sin, A History.

${ }^{8}$ The MCM also holds this view, but for comparative clarity I confine my discussion to the ECM.

${ }^{9}$ Cass Sunstein and Richard Thaler, "Libertarian Paternalism is not an Oxymoron," The University of Chicago Law Review 30, no 4 (Fall 2003): 1159-1202

${ }^{10}$ Lakoff, Moral Politics, 31.

${ }^{11}$ American liberalism is a more generalised and inclusive political approach than the ECM. The ECM is confined to the New Zealand Green Party and certain Labour Party policies released in the period 2006-2008.
} 
describe their ideological values in particular, arguing that ${ }^{12}$ the liberal moral view is more focused on communities than individuals. ${ }^{13}$ Both Lakoff's view of liberal morality and the ECM understand the State as being communally responsible for protecting and nurturing society, like a parent would their child. ${ }^{14}$

Both the liberal/ECM world views are concerned with developing nurturing environments, such as healthy schools, in which children can develop safely and in good health. Both these world views understand a fulfilling life to be one where the individual is nurtured and nurtures others within a community. This view employs the principle of empathy ${ }^{15}$ where individuals are committed to family and the community. Lakoff argues that this type of politics is based upon the golden rule ${ }^{16}$ and is intended to develop both a social consciousness and social responsibility in the child. This helps to explain why ECM policy concentrated its policy upon school children. Policies such as the NAG guidelines and Fruit in Schools were intended to develop a generation for whom eating only healthy food was normal in the hope that they would pass on these values to their own children.

Lakoff conceptualises the role of the liberal State as a nurturant ${ }^{17}$ parent who has a protective relationship with their child or its dependents. This model relies upon the notion/assumption that children develop best when encouraged to have positive social relationships with others. Thus, ECM policy is focused on interagency work where the functions of Government all work together for the betterment of society, as in cross sectoral obesity intervention programmes $^{18}$ and umbrella strategies such as HEHA. ${ }^{19}$ In these programmes, ECM policy assumes communal responsibility in order to intervene to protect the population, especially children, from the dangers of unrestricted environments. This responsibility is evident in the two objectives of the Select Committee Inquiry into Obesity and Type 2 Diabetes:

1 - To create an Environment in New Zealand that encourages and maintains healthy eating and physical activity patterns, especially among children.

2 - To Develop and implement a coordinated national cross sectoral response to the prevention and management of obesity and type 2 Diabetes. ${ }^{20}$

\footnotetext{
${ }^{12}$ Liberal metaphors include: social forces, social responsibility, human rights, equal rights, care, health, nutrition, basic human dignity, oppression, diversity, deprivation, alienation, big corporations, corporate welfare, ecology, eco-system, bio-diversity and pollution. See Ibid., 31.

${ }^{13}$ Ibid., 21.

${ }^{14}$ Ibid., 108

${ }^{15}$ Ibid., 115

${ }^{16}$ Ibid., 255.

${ }^{17}$ Nurturant and nurturance are Lakoff's terms. See: Ibid., 108

${ }^{18}$ Ministry of Health, Progress on Implementing the HEHA Strategy 2007.

${ }^{19}$ Ministry of Health, Healthy Action - Healthy Eating Oranga Pumau - Oranga Kai: Towards an Integrated Approach to Physical Activity, Nutrition and Healthy Weight for New Zealand, Submission Booklet (Wellington: Ministry of Health, February 2002).

${ }^{20}$ House of Representatives, Inquiry into Obesity, 3.
} 
These two objectives assume the State has an active 'cross sectoral' role to create an environment which prevents obesity. This responsibility is necessitated by the implication of the first objective that children currently do not live in a healthy eating and physical activity environment.

The moral dimensions of ECM discourse become clearer from this comparison with Lakoff's work. For liberals, moral strength comes from empathy developed from parental nurturance rather than from self discipline or competition. ${ }^{21}$ Anything perceived as destructive to this nurturance is understood to be immoral or evil. ${ }^{22}$ Immoral metaphors include social irresponsibility, selfishness, narrow mindedness, and things that compromise safety. ${ }^{23}$ This liberal view tends to want retribution from those who hurt children. Lakoff argues that harm to children often comes from polluters and manufacturers of products such as the food and cigarette industries. ${ }^{24}$ This comparison fits with the ECM's focus on combating those people, industries, or lack of legislation that it believes make children's school and home environments obesogenic. The parent and State is responsible for supporting and protecting the child from the evils in the world. For example, in the ECM parents are required to create healthy food environments in the home ${ }^{25}$ while the State must ensure that schools are healthy food environments. ${ }^{26}$ Ensuring the health of the child is a moral imperative of the ECM. Thus, obesity is understood as a real danger to children and a threat which must be expelled from the community.

Lakoff does not explain how liberal moralities remove danger from the community. To further explain how this process occurs I now turn to an ancient example of communalised morality which was concerned with the removal of the physical weight of sin. An example of communal morality and its method for removal of sin can be found in Gary Anderson's exegetical book Sin: A History. ${ }^{27}$ Anderson draws on Lakoff's notion of moral metaphor to show that the metaphors describing sin changed from being communal in classical Hebrew texts to individualised notions of sin after the destruction of the First Temple. ${ }^{28}$ In the classical texts,

\footnotetext{
${ }^{21}$ Lakoff, Moral Politics, 110.

${ }^{22}$ Ibid., 134

${ }^{23}$ Ibid., 132

${ }^{24}$ Ibid., 133.

${ }^{25}$ Ministry of Health, National Nutrition Guidelines for Healthy Infants and Toddlers, 115.

${ }^{26}$ Ministry of Health, Implementing the HEHA Strategy 2008.

${ }^{27}$ Anderson, Sin, A History.

${ }^{28}$ Ibid., 5 .
} 
Anderson finds a set of metaphors which describe sin as a burden and a communal problem. ${ }^{29}$ Anderson's argument is that these metaphors provided the conceptual framework in which those groups of people physically reacted to the problem of sin. Anderson argues that burden metaphor was the dominant metaphor for sin in the early books of the Hebrew Bible, especially in Leviticus. ${ }^{30}$ He explains how this tradition viewed the sinner: "The sinner is depicted as a person who bears the full weight of the burden created by his offence; so for example, 'he who blasphemes against God shall bear the weight of his sin' (Lev 24:15)."31 I will argue later in the chapter that this use of the burden metaphor by communal models of sin parallels the way ECM and MCM discourse employed burden metaphor to describe how obesity affects the nation.

The removal of sin was an important part of maintaining the integrity of the community. Anderson argues that the classical Hebrew conceptualisation of sin as a heavy burden affected the entire community and sin removal was viewed as a shared responsibility. ${ }^{32}$ The community held the role that the State has today under the ECM and MCM. The removal of sin was ritualistic and occurred through the process of the scapegoat. The scapegoat beast "has one simple task: to carry the burden of Israel's sins. ${ }^{\circledR 3}$ The ritual places Israel's sins upon the animal and casts it out into the wilderness returning the sin to its source. ${ }^{34}$ The scapegoat had the responsibility of removing the weight of sin from the entire community. Later in the chapter, I will expand this notion of scapegoating to argue that all three obesity models scapegoat, albeit in different ways.

Communalised moralities hold a shared responsibility to address the dangers which threaten their society. For the ECM, the State, acting as a parent, has the socially responsibility to nurture the good health of the community. ECM discourse is directly concerned with the health of children and it actively attempts to create healthy environments such as HEHA, Fruit in Schools, and the NAG Guidelines. The ECM views obesity and its causes (big corporations, deprivation, and commercial self-interest) as morally harmful to the health, happiness, and wellbeing of the community. The conflict over soft drinks, illustrated in Chapter Five, is an

\footnotetext{
${ }^{29}$ Ibid., 25.

${ }^{30}$ Anderson investigated the classical Hebrew Bible to find the metaphors associated with sin. He found that the Hebrew verb nasa awon "to bear" was associated with notions of sin some 108 instances whereas the association of sin with the verb "forgive" occurred only 17 times. See: Ibid., 16.

${ }^{31}$ Ibid., 20

${ }^{32}$ Ibid., 26.

${ }^{33}$ Ibid., 22

${ }^{34}$ The wilderness is perceived as the domain of the demonic and the scapegoat bears the sins back to their source. See Leviticus 1-6 and Anderson, Sin: A History, 23.
} 
example of ECM morality ${ }^{35}$ clashing with and condemning the interests of the Food and Beverage Industry. ${ }^{36}$ Soft drinks, for the ECM, are detrimental to everybody, which makes them a communal moral problem against which the State is obliged to protect the population especially children. Thus, ECM morality focuses upon protecting the community from the evils that often stem from the free market. Obesity, in this ECM view, is a communal moral problem caused by a nexus of self-interested commercial groups, all of which hurt society through 'unethical' profit making. Anderson's work gave us hints into how communalised moralities label and remove threats and dangers from a society. In this next section I look how MCM and ECM discourse describes obesity as a communal burden.

\subsection{Obesity Burden Language}

Obesity discourse produced between 2000 and 2008 regularly used burden language to describe obesity as a communal problem. ${ }^{37}$ Burden language implies that the moral responsibility for obesity is spread evenly through a society where, in reality, obesity prevalence is significantly higher in particular marginalised economic and ethnic communities. In this way the burden language I discuss here communalises the problem of the 'obesity epidemic' by moralising against the obese as a generic danger to society. However, this moralising occurs in the full knowledge that it is marginalised communities who disproportionately contribute to the prevalence of obesity within the nation.

Earlier we saw in the work of Gary Anderson that burden was a metaphor used to describe the effects of sin on a community. Anderson explains that this burden was understood as a moral problem for the whole community. Here, in these examples we find that the metaphor of burden was utilised by the Labour Coalition to describe the imposed effects and costs of 'obesity epidemic' upon the population.

The obesity burden should be understood in two ways: first, that the disease is a burden on the sufferer and second, that the sufferers of obesity are a burden on the health system. These understandings of burden are then interpreted by the moral views of the obesity models. For the ECM, the obese individual and the State bear the financial and mortality burden of an unhealthy environment. At times, BCM discourse also uses burden metaphor. When the BCM

\footnotetext{
35 "Companies Remove Full Sugar Drinks From Schools."

${ }^{36}$ Katherine Rich, "Govt, Companies, Removing Fizzy From Schools."

${ }^{37}$ These discourses were produced between $2000-2008$.
} 
does use this metaphor the obese person is described as both a burden to themselves and a selfish burden upon the State system.

ECM and MCM health policy and medical discourse also draw on the burden trope to describe the aggregate mortality effects of obesity upon the state, economy, and the health system. Each of these three applications of the trope describes obesity as a general communal burden which affects the State. The first form in which the burden trope appears is via a generalised use of the term burden. This discourse claims that health policy ${ }^{38}$ and the health system ${ }^{39}$ will increasingly have to deal with a generic obesity burden as overall population BMI rates increase. This type of language assumes that sedentary lifestyles ${ }^{40}$ are increasing, that the 'obesity epidemic' is a fact, ${ }^{41}$ and that new strategies are necessary to "moderate the downstream burden of disease in the long term." ${ }^{42}$ The rising concern with burden focuses upon the inevitable increase in obesity-related morbidities from cardiovascular disease, Type 2 Diabetes, and other obesity-related chronic diseases. Such a population-wide rise in obesity-related morbidity will then result in premature death, will lower individuals' quality of life, and will increase the economic burden for the cost of care for both the health system and the taxpayer. $^{43}$

A second form of generalised burden language in obesity discourse is economic in nature. The economic burden is both individual and communal. An economic burden is portrayed in obesity discourse as being imposed by the increasing prevalence of obesity both locally ${ }^{44}$ and globally. ${ }^{45}$ The NZMJ describes the effects of this economic form of obesity burden as follows: The financial burden of obesity and physical inactivity is substantial. It is estimated that obesity health care expenditure in New Zealand is $\$ 303$ million per annum. Further estimates indicate a saving of NZ\$2 5 million per year could result from a 5\% increase in physical activity levels and that $\$ 160$ million each year could be saved if all New Zealanders were to become physically active to levels that afford health benefits. ${ }^{46}$

\footnotetext{
${ }^{38}$ Ministry of Health, Tracking the Obesity Epidemic, xii.

${ }^{39}$ Elizabeth Duncan, Grant Schofeild, Scott Duncan, Gregory Kolt and Elaine Rush, "Ethnicity and Body Fatness in New Zealanders,” The New Zealand Medical Journal 117 no. 1195 (June 4, 2004): 1.

${ }^{40}$ Rosalina Richards, Anthony Reader and Helen Darling, "Interest and Participation in Selected Sports Among New Zealand Adolescents," The New Zealand Medical Journal 117 no. 1195 (June 4, 2004): 1.

${ }^{41}$ Norman Sharpe and Gerard Wilkins, "Quality and Equity in Cardiovascular Health in New Zealand: The Need For Agreed Achievable

Standards of Care, Cohesive Planning, and Action,” The New Zealand Medical Journal 117 no. 1197 (July 9, 2004): 4.

${ }^{42}$ Ibid., 4.

${ }^{43}$ Duncan, Schofeild, Duncan, Kolt and Rush, "Ethnicity and body fatness in New Zealanders," 1.

${ }^{44}$ A conservative estimate of the economic burden of obesity in New Zealand has been calculated at BZ \$134million (1991) or 2.5\% of the total health care costs based on the cost of treating the most significant obesity related co-morbidities. See: Simon Thornely and John Windsor, "The Role of Surgery in the Management of Obesity," The New Zealand Medical Journal no 1122, 113 (24 ${ }^{\text {th }}$ (November 1998): 445.

${ }^{45}$ Thompson David and Anne Wolf, "The Medical-Care Cost Burden of Obesity," Obesity Reviews 2 (2001): 189.

${ }^{46}$ Maea Hohepa, Grant Schofeild and Gregory Kolt, "Adolescent Obesity and Physical Inactivity,” The New Zealand Medical Journal 117 , no. 1207 (December 17, 2004): 2.
} 
The general implication of economic burden discussions is that it is the obese who, through a lack of exercise and financial responsibility, create a substantial financial burden for the health system, ${ }^{47}$ community, ${ }^{48}$ national economy, ${ }^{49}$ or the tax-payer. ${ }^{50}$ This form of burden language is used by all three obesity models. This increasing burden of obesity also means that a 'growth industry' in medicine needs to be developed and funded to offer various forms of laparoscopic and/or bariatric surgery. ${ }^{51}$ The suggested solutions to this burden are national exercise campaigns ${ }^{52}$ or further research into ways that the community could be induced to exercise. ${ }^{53}$ All fat people are encouraged to exercise as a way to alleviate the financial burden which they have placed upon the State.

In addition to these forms of the burden trope, burden language appears in a third systematised and aggregated form in MCM and ECM decision-making criteria. The term burden is used to describe the general effects of illness in the Global Burden of Disease framework (GBD Framework). The GBD Framework was integral to the development of ECM and MCM policy in the 2000s. In this example, the burden is completely communalised as the GBD framework measures the effects of a particular disease over very large populations, nationally and globally. The framework was developed for population health planning purposes to differentiate between the total financial costs of various diseases within and among nations. The GBD Framework allows researchers and policy makers to make global assessments about the relative dangers to nations from one particular disease or risk factor in comparison to another. ${ }^{54}$ For the purposes of the moral analysis of communal models, this framework allows for nations to compare various external health risks to a society and develop moral priorities to respond to potential dangers.

The GBD Framework was initially developed in 1992 after it was commissioned by the World Bank. ${ }^{55}$ It was then utilised and standardised by the WHO. ${ }^{56}$ The Labour Government's

\footnotetext{
${ }^{47}$ Utter, Scragg, Percival and Beaglehole, "School is back", 5.

${ }^{48}$ The Medical Research Council, Adequacy of Medical Statistics, 19.

${ }^{49}$ Utter, Scragg, Percival and Beaglehole, "School is back", 5.

${ }^{50}$ Nick Wilson, Carolyn Watts, Louise Signal and George Thomson, “Acting Upstream to Control the Obesity Epidemic in New Zealand," The New Zealand Medical Journal 117 no. 1207 (March 31, 2006): 3.

${ }^{51}$ Iain Martin, "Bariatric Surgery: Folly or the Future?” The New Zealand Medical Journal 117 no. 1207 (December 17, 2004 ): 1.

${ }^{52}$ Grant Schofield, “Push Play: Whats Under the Umbrella?” The New Zealand Medical Journal 116 no. 1179 (August 8, 2003 ): 1.

${ }^{53}$ Medical Research Council, Adequacy of Medical Statistics, 19.

${ }^{54}$ Using the GBD Framework researchers made claims such as “...the global burden of Non Communicable Disease was incontestable by the mid 2000s..." See: Amelia Waxman, "Why a Global Strategy on Diet, Physical Activity and Health? The Growing Burden of NonCommunicable Diseases," Public Health Nutrition 7, no. 3 (2005): 381.

${ }^{55}$ Alan Lopez, Colin Mathers, Majid Ezzati, Dean Jamison and Christopher Murray, "Measuring the Global Burden of Disease and Risk Factors, 1990 - 2001," in ed. Allan Lopez, Colin Mathers, Majid Ezzati, Dean Jamison and Christopher Murray, Global Burden of Diseases and Risk Factors (New York: Oxford University Press, April 2006), 1.

${ }^{56}$ World Health Organisation, “Global Burden of Disease," http://www.who.int/healthinfo/global_burden_disease/en/, last accessed 21 February 2011.
} 
initial $^{57}$ development of obesity discourse drew upon GBD framework decision making criteria. ${ }^{58}$ The New Zealand Health Strategy $2000^{59}$ and a series of documents released in the early $2000 \mathrm{~s}^{60}$ all utilised the GBD framework. The GBD criteria were used to determine the thirteen health objectives, including obesity, for the NZHS2000. ${ }^{61}$ The MOH used the GBD framework decision making criteria to describe obesity as a generalised burden and a danger to the health of the nation. ${ }^{62}$ In 2003, then Director General of Health, Karen Poutasi explained the GBD understanding of this population level relationship between obesity and mortality rates:

[N]utrition plays a role in about 11,000 deaths a year in New Zealand (two in every five deaths), of which approximately 8000-9000 reflect diet and 2000-3000 reflect physical inactivity. With over 4500 premature deaths in 1997 attributable to high cholesterol, the report highlights the health impact of prolonged high intake of saturated fat. This report also finds substantial burdens from obesity and overweight (due in part to decreasing levels of physical activity), high blood pressure and lack of fruit and vegetable intake. ${ }^{63}$

Here the moral dangers of obesity are portrayed in the form of deaths due to physical inactivity and poor nutrition. Thousands of New Zealanders form a burden upon the nation each year due to physical inactivity and poor diet. Other obesity dangers identified by GBD criteria allowed researchers to make the following claims in the NZMJ:

Estimations of the burden of disease attributable to excess weight indicate that high BMI has been estimated to account for approximately $7 \%$ of all disability-adjusted life years (an integrated measure of population health incorporating both fatal and non fatal outcomes), which places high BMI close behind tobacco (12\%), high blood pressure (11\%), alcohol (9\%), and high cholesterol (8\%) as a leading cause of loss of healthy life in these regions. ${ }^{64}$

\footnotetext{
${ }^{57}$ The GBD framework was first applied in 1999.

${ }^{58}$ Obesity was considered a risk factor for incurring DALYS in: Ministry of Health, Our Health Our Future: Hauora Pakari, Koiora Roa, The Health of New Zealanders 1999 (Wellington: Ministry of Health, December 1999).

${ }^{59}$ Ministry of Health, Priorities for Maori and Pacific Health: Evidence from Epidemiology, Public Health Intelligence Occasional Bulletin No 3. (Wellington: May 2001), 2.; Ministry of Health, Evidence-based Health Objectives for the New Zealand Health Strategy, Public Health Intelligence, Occasional Bulletin Number 2 (Wellington: Ministry of Health, March 2001).

${ }^{60}$ In 2001, the Ministry of Health released its report entitled "Burden of Disease and Injury in New Zealand". The political goal of this document was to outline the details of the ethnic "Health gap" which the Ministry of Health had identified. In March 2002 the Labour Government released a series of documents modelling and forecasting the prevalence of Diabetes through the population. All these documents refer DALYS and to the burden and mortality burden of Type 2 Diabetes. See: Ministry of Health, The Burden of Disease and Injury in New Zealand, Public Health Intelligence, Occasional Bulletin No 1 (Wellington: Ministry of Health, January 2001.), 22.; Ministry of Health, Diabetes in New Zealand: Models and Forecasts 1996 - 2011 (Wellington: Ministry of Health, March 2002); Ministry of Health, Modelling Diabetes: The Mortality burden, Public Health Intelligence, Occasional Bulletin No. 8 (Wellington: Ministry of Health, March 2002); Ministry of Health, Modelling Diabetes: A Summary, Public Health Intelligence Occasional Bulletin No 11 (Wellington, Ministry of Health, March 2002).

${ }^{61}$ Ministry of Health, Evidence-based Health Objectives.

${ }^{62}$ Ministry of Health and the University of Auckland, Nutrition and the Burden of Disease: New Zealand 1997-2011 (Wellington: Ministry of Health, August 2003).

${ }^{63}$ Ibid., iii.

${ }^{64}$ Cliona Ni Mhurchu, Derrick Bennett, Ray Lin, Maree Hackett, Andrew Jull, Anthony Rodgers, “Obesity and Health-Related Quality of Life: Results From a Weight Loss Trial, “The New Zealand Medical Journal 117 no. 1207 (December 17, 2004): 1.
} 
The problem with the GBD framework and all three forms of burden language is that they tend to aggregate obesity as a social or health problem that bypasses the existence of different obesity rates in particular population groups. Anderson's work on communal sin and the forms of burden language suggest that the community is affected equally by obesity. However, in New Zealand the burden of obesity falls unevenly onto specific economic and ethnic communities. Some obesity discourse does recognise that this obesity burden is unequally located in the population. These sources acknowledge that "more deprived groups experience a greater burden of the disease." ${ }^{65}$ At times, this inequality is described by researchers in alarmist terms which state that the growing prevalence of 'overweight and obesity' is responsible for increasing the burden of ethnic and socio-economic inequalities in health through the risks that obesity has for producing mortality. ${ }^{66}$ All the inequality discourse is unified in stating that it is these disadvantaged sections of the population which disproportionately contribute to the rising rates, and therefore costs,${ }^{67}$ of obesity. This distinction is important because most burden language does not acknowledge this inequality and it blames all of the obese for incurring a burden upon the State.

One consequence of the relationship between obesity prevalence and inequality is that there are definable scapegoats who bear the burden of population-wide concerns with obesity. Burden language is often evident in discussions of ethnic inequality and obesity. ${ }^{68}$ This language makes claims such as "Maori carry the greater burden of chronic disease. ${ }^{{ }^{69}}$ Maori, collectively, experience higher risks for disease ${ }^{70}$ and higher mortality rates than Europeans ${ }^{71}$ and that 23$27 \%$ of the burden of mortality amongst Maori was due to high BMI compared to $11 \%$ among non-Maori. ${ }^{72}$ The difference between the two ethnic groupings is described in this research as an excess mortality burden. ${ }^{73}$ Fewer documents acknowledge that this 'burden' is shared by Pacific Island peoples. ${ }^{74}$ This discourse is carefully worded to state that the Maori community

\footnotetext{
${ }^{65}$ Tania Riddell, 'Heart Failure Hospitalisations and Deaths in New Zealand: Patterns by Deprivation and Ethnicity," The New Zealand Medical Journal 118 no. 1208 (Jan 28, 2005): 6.

${ }^{66}$ Tony Blakely, Diana Sarfati and Caroline Shaw, "What Proportion of Cancer is Due to Obesity?" The New Zealand Medical Journal 122 no. 1290 (February 27, 2009): 9.

${ }^{67}$ This link is not stressed by obesity inequality researchers.

${ }^{68}$ Tony Blakely, Cindy Kiro, and Alaistair Woodward, "Unlocking the Numerator-Denominator Bias.II: Adjustments to Mortality Rates by Ethnicity and Deprivation During 1991 - 1994. The New Zealand Census Mortality Study,” The New Zealand Medical Journal 115 no. 1146 (February 6, 2002): 45.

${ }^{69}$ Allan Pelkowitz and Sue Crengle, "The Orewa Speech,” The New Zealand Medical Journal 117 no. 1205 (November 5, 2004 ): 2.

${ }^{70}$ Cindy Towns, Nathan Watkins, Arapera Salter, Patricia Boyd and Lianne Parkin, “The Orewa Speech: Another Threat to Maori health?” The New Zealand Medical Journal 117 no. 1205 (November 5, 2004): 4.

${ }^{71}$ Blakely, Kiro, and Woodward, "Unlocking the Numerator-Denominator Bias.II," 45.

${ }^{72}$ Carlene Lawes, Niki Stefanogiannis, Martin Tobias, Natalie Paki Paki, Cliona Ni Mhurchu, Maria Turley, Stephan Vander Hoorn and Anthony Rodgers, "Ethnic Disparities in Nutrition-Related Mortality in New Zealand: 1997 - 2011, The New Zealand Medical Journal 119 no. 1240 (August 18, 2006): 8.

${ }^{73}$ Blakely, Kiro, and Woodward, "Unlocking the Numerator-Denominator bias.II," 45.

${ }^{74}$ Colin Bell, B Swinburn, D Simmons, W Wang and B Gatland, "Heart Disease and Diabetes Risk Factors in Pacific Islands Communities and Associations with Measures of Body Fat,” The New Zealand Medical Journal, 114 no. 1131 (May 11, 2001):208.
} 
is disproportionately affected by the burden of obesity. The finding that Maori are disproportionally affected by the obesity burden is never correlated with arguments that the obese incur an avoidable burden of cost on the financial system. This is because it could quickly be rewritten to blame both Maori and lower socio-economic groups for disproportionately contributing to the cost burden of obesity related illnesses. These burden language examples further illustrate the moral dimensions of obesity discourse as they show that obesity discourse views specific groups as embodying the obesity burden. I return to these problems of ethnicity and socio-economics in a discussion of scapegoating later in the chapter.

In summary, obesity burden language very rarely describes the obese as sinners; ${ }^{75}$ it is more subtle in its moralisation. For the ECM and MCM, the term "burden" functions as a metaphorical referent to describe obesity's negative effects on the community. The metaphor dictates the ECM/MCM physical, medical, and policy responses to this societal problem. It is quite clear that obesity, like sin, is a burden that must be borne by nations and communities. Such notions, however, demonstrate a fundamental inconsistency. In all examples this burden is a moral problem for the community and the State, a conceptualisation that obscures the fact that this burden is disproportionately located in specific ethnic groups, economic groups, or in systematic inequality. Moreover, there is a clear imperative in ECM and MCM burden language to find ways in which this physical weight can be expurgated from the community. BCM discourse does not often employ burden language and when it does it is used to indicate the unnecessary health costs that Welfare states have to bear. More generally, BCM approaches do not use the term burden because it implies a form of Governmental responsibility for bearing the cost of treatment. This is one reason that obesity burden language disappeared in the National Coalition's removal of obesity policy. This is because the New Right possesses different metaphors for, and methods of, 'accounting' for sin.

\subsection{BCM - Individual Morality}

The BCM employs an individual morality rather than the communal morality of the ECM. Under the BCM the blame for sin, immorality, or illness is placed upon the individual. As I made clear in Chapter Two, BCM morality locates obesity causality in behaviour, especially Gluttony and Sloth. ${ }^{76}$ This morality is far more overt and easier to understand than the ECM because it directly applies sin language to the actions and inactions of the obese. However, we

\footnotetext{
${ }^{75}$ Prentice and Jebb, “Gluttony or Sloth?" 
still know very little about how this BCM morality functions. In order to gain further insight into individualised morality I now compare the BCM to two similar individualised moral systems, namely, those detailed in George Lakoff's discussion of conservative morality ${ }^{77}$ and Max Weber's discussion of the Protestant Ethic. ${ }^{78}$ The purpose of these comparisons is to demonstrate how individual morality is constructed around notions of self-discipline and economic success. Further, I will show how individualised forms scapegoat those individuals who are deemed morally weak, self-indulgent, or lazy.

In Chapter Two, I explained that BCM morality concentrated upon the behaviours of eating and exercise. The BCM holds that obesity is caused by individuals eating too much (gluttony), exercising too little (sloth), or a combination of these two behaviours. In contrast, virtuous behaviour allows individuals to directly influence their own health. The resultant physical health of the virtuous body signifies personal responsibility and social grace. Physical fitness and healthy food choices are positive lifestyle characteristics of the New Right citizen. For the $\mathrm{BCM}$, personal health discipline is a moral duty for citizens ${ }^{79}$ and this duty implies that citizens who do not practice such discipline lack personal responsibility. As a consequence, the BCM views chronic disease, such as obesity, to be self-induced due to a lack of healthy behaviours, self-indulgence, and failure of individual responsibility. Thus, individual obese bodies represent their physical transgression of the BCM rules of healthy conduct and become the embodied location of political and medical discourses concerned with their lack of social grace and personal responsibility.

BCM policy tends to preference self-discipline and restraint as indicative of moral strength. The language of moral strength is detailed by George Lakoff in his analysis of the language of conservative American moral politics. ${ }^{80}$ Lakoff finds that conservative morality has a strict authoritarian notion of the parent, whereas liberals conceive of the parent as nurturant. ${ }^{81}$ Conservative parents raise their children to be self-disciplined through a strict schema of reward and punishment that is enforced by a disciplinarian parent. Lakoff argues that this type of disciplinary family arrangement replicates a form of politics, like New Right politics, where the State strictly holds its citizens responsible for their own actions. Therefore, individual discipline is an essential sign of individual development in both the BCM and conservative

\footnotetext{
${ }^{77}$ Lakoff, Moral Politics, 32.

${ }^{78}$ Weber, The Protestant Ethic

${ }^{79}$ McCully and Creech, Physical Activity.

${ }^{80}$ Lakoff, Moral Politics, 31.

${ }^{81}$ Nuturant and nutrance are Lakoff's terms.
} 
morality. BCM policy rewards those who are disciplined enough insure against ill-health and are unsympathetic towards those who fail to do so.

Individualised conservative moral politics and the BCM both employ a series of moral metaphors ${ }^{82}$ which portray moral strength as virtue and individual weakness as immoral. The conservative view and the $\mathrm{BCM}$ both emphasise personal responsibility and require individuals to be disciplined rather than self indulgent. In the conservative worldview, the strong and selfdisciplined individuals have the moral authority and responsibility to enforce weaker people's compliance through punishment and reward. Lakoff is particularly interested in how conservative morality locates virtue in an individual's strength of will:

Much of the metaphor of moral strength is concerned with internal evils where the issue of self control arises. What has to be strengthened is one's will. One must develop willpower in order to exercise control over the body, which is seen as the seat of passion and desires... "temptations that threaten to overcome one's self control....the opposite of self-control is "self indulgence," a concept that only makes sense only if one accepts the metaphor of moral strength. Self-indulgence is seen in this metaphor as a vice, while frugality and self denial are virtues. ${ }^{83}$

In light of this analysis, it is evident that BCM obesity discourse such as the House of Commons Report $^{84}$ and the Prentice and Jebb ${ }^{85}$ article draw upon the deadly sin metaphor to indicate that the behavioural causes of obesity are a product of self-indulgent moral weaknesses in the obese. Indeed, Lakoff refers directly to the schema of the Seven Deadly Sins ${ }^{86}$ as archetypal internal evils against which conservative virtue and morality are constructed. The Conservative worldview sees the world as a place in which there is good and evil. In religious terms, which I explore shortly, a form of Protestant ascetic self-discipline is encouraged in order to protect the individual from the consequences of the internal evils of self-indulgence. ${ }^{87}$ This analysis of the moral values of political conservatives helps to explain why the BCM views obesity as an individual problem produced by weaknesses or the self-indulgent behaviours of gluttony and sloth.

Individual moral virtue, in the $\mathrm{BCM}$ and the conservative worldview, comes in the form of the disciplined success which results from competition. In the conservative moral view, the

\footnotetext{
${ }^{82}$ Lakoff, Moral Politics, 30.

${ }^{83}$ Ibid., 72-3.

${ }^{84}$ House of Commons, Health Committee Report.

${ }^{85}$ Prentice and Jebb, "Gluttony or Sloth?"

${ }^{86}$ Lakoff, Moral Politics, 73.

${ }^{87}$ Conservative metaphors include: "character, virtue, discipline, tough it out, strong, self-reliance, individual responsibility, authority, competition, hard work, enterprise, property rights, reward, freedom, intrusion, interference, meddling, punishment, traditional, dependency, self-indulgent, corrupt, deviant and lifestyle.” See: Ibid., 251.
} 
parent's task is to school the child in the world through encouraging them into competition with others to develop strength of individual will. This explains why BCM policy encourages competition through sports such as Kiwi sport and Pushplay and stresses the importance of physical activity to citizenship. ${ }^{88}$ The BCM teaches children to compete within these physical activity programmes in order to become strong and disciplined enough to successfully negotiate the evils of the world. The BCM also creates food environments where the selfdisciplined show virtue by resisting the unhealthy evils propagated by the Food and Beverage Industry the $N A G$ guideline removal. ${ }^{89}$ Good children are those who succeed in the face of these gambits and resultantly develop self-discipline and the moral authority to govern and replicate their society. Conservative morality is consequently highly resentful of authorities, such as active States, which attempt to interfere with this process of raising children. ${ }^{90}$ Conservative morality, like the BCM, considers these active ECM and MCM States as meddling nanny states.

One final aspect to consider in Lakoff's analysis is his argument that the as a consequence of their self-indulgence morally weak - in our case the obese - are not worthy of respect. ${ }^{91}$ Lakoff explains that this is why conservatives are not interested in issues of inequality in society. ${ }^{92}$ This helps to explain why the New Right are not overly concerned with inequality because they understand social disadvantage to be a product of poor choices and moral weakness on the part of individuals. Furthermore, in the conservative moral schema, an individual's moral weakness is a metaphor for the weaknesses of opposing political approaches. ${ }^{93}$ This demonstrates why the $\mathrm{BCM}$ at times scapegoats the obese and suggests they are a product of their own poor choice.

Because the obese are viewed as a product of their morally irresponsible choices, the BCM State is not prepared to tolerate or financially subsidise their health costs. Chapter Five's discussion of the 2009 National Coalition demonstrated that the State had no interest in paying for obesity prevention or treatment. Wellington Gastric Surgeon Richard Stubbs provides an example of the BCM logic behind this position when he explains why public funding of bariatric surgery would be politically controversial: "Paying for public hospital surgery so the supposedly greedy, slothful and unmotivated can climb onto operating tables instead of into

\footnotetext{
${ }^{88}$ McCully and Creech, Physical Activity.

${ }^{89}$ A. Tolley, "Schools no Longer Required to be Food Police."

${ }^{90}$ Lakoff, Moral Politics, 79.

${ }^{91}$ Ibid., 73.

${ }^{92}$ Ibid., 93.

${ }^{93}$ Ibid., 93.
} 
running shoes isn't going to go down well with the $50 \%$ of tax payers who aren't overweight.." ${ }^{94}$ Stubbs indicates that publically funded obesity-related operations for the selfindulgent would be incredibly unpopular with the public. Ironically, bariatric surgery is easily accessible to the wealthy. For example, it was reported that "The Capital and Coast District Health Board deputy chairman, who paid $\$ 20,000$ for his gastric bypass in 2003, describes it as the best investment he has made - and one that saved the taxpayer thousands. ${ }^{95}$ The BCM logic of this statement shows that this man took responsibility for his obesity by using private payments to pay for his sins and in doing so he saved the taxpayer. For the poor it is not an option to pay $\$ 20,000$ for surgery and therefore they cannot be good citizens by saving the taxpayer's funds. The BCM solution for the obese is that they either pay for the treatment on their $\mathrm{own}^{96}$ or they develop some self-discipline and moral strength by working off their sin through physical activity.

Max Weber's book The Protestant Ethic and the Spirit of Capitalism ${ }^{97}$ also illuminates the moral associations between individualised notions of work, virtue, and economic success. Weber's work is useful because it links Protestant religious values to the moral values of modern capitalism and individualism. Here, I seek to show Protestant views of capitalism parallel BCM discourse through the association of the behaviours of industry, frugality, and efficiency with individual moral virtue and success. This discussion of the Protestant Ethic then allows us to consider the behaviours gluttony and sloth that cause obesity to be conceived within BCM discourse as both immoral and antithetic to capitalist endeavour.

Diligence and the refusal to indulge the impulses of body were intrinsic to the disciplines required by the followers of the Protestant Ethic. Like the BCM, Weber's Protestant Ethic links individualised systematic practices of ascetic virtue to the activity of capitalist acquisition. Weber describes the behavioural virtues of the capitalist individual: "Honesty is useful, because it assures credit; so are punctuality, industry, frugality and that is the reason that they are virtues. ${ }^{98}$ These virtues are repeated by Lakoff in his examples of the conservative metaphors associated with moral strength. ${ }^{99}$ For Weber, the highest capitalist virtue is diligence in one's calling. He quotes Proverbs XXII 29: "Seeist thou a man diligent in his business? He shall stand

\footnotetext{
${ }_{95}^{94}$ Jenny Chamberlain, “Getting Heavy with Fat,” North and South Magazine (Auckland: May 2004): 36.

${ }^{95}$ Ruth Hill, "Obesity: A Heavy Burden"

http://www.stuff.co.nz/dominion-post/local/2906245/Obesity-A-heavy-burden last accessed $28^{\text {th }}$ September 2009

${ }^{96}$ Ibid.

${ }^{97}$ Weber, The Protestant Ethic.

${ }^{98}$ Ibid., 52.

${ }^{99}$ Lakoff, Moral Politics, 71.
} 
before Kings."100 The virtues associated with work also produced capitalist value. Thus, the virtues were the individual behaviours which contributed to capitalist endeavour and individual success. The BCM never quite states what makes a 'good' citizen but physical activity and competition are virtues of the thin and healthy. Under the Weber's ethic, virtuous people worked systematically and diligently, consequently, they were rewarded socially and material for their efforts. Weber's Ethic and the BCM create stereotypes where material success is inextricably intertwined with notions of work, diligence, and physical activity.

In the Christian tradition, notions of virtue were constructed dualistically in opposition to a series of vices or sins. In the Protestant Ethic, the "lack" of virtue the BCM associates with obesity causality - that is, indulging one's appetite and being lazy - demonstrates that obesity is antithetical to the moral values of the capitalist endeavour. Thus, a moral division existed between the virtuous and prosperous elite and the sinful self-indulgent poor. Weber found that the elect, with their consciousness of the importance of divine grace, wealth and industry, were not particularly sympathetic to their unsuccessful neighbours:

This consciousness of divine grace of the elect and holy was accompanied by the attitude toward the sin of one's neighbour, not of sympathetic understanding based on consciousness of one's own weakness but of hatred and contempt for him as an enemy of God bearing the signs of eternal damnation. ${ }^{101}$

The Protestant Ethic allowed for a righteous religious moralisation against the poor. Thus, those who did not display the signs of election were contemptible because they obviously did not work hard enough and their behaviour resulted in their lack of prosperity. This type of righteous discrimination proclaiming the obese as immoral and failing to uphold capitalist values is documented in discussions of fat and class. ${ }^{102}$ I will return to this notion of the elect righteously scapegoating the obese later in this chapter.

Importantly for my discussion of the moral dimensions of the BCM, we have now seen two similar forms of individualised morality in which the morally strong overtly scapegoat the weak. This helps to explain why BCM elites can dictate economic policy to the lower classes and moralise against individuals who do not exhibit the values of capitalist acquisition. When this BCM morality is compared to ECM morality it helps us understand why BCM proponents are not particularly interested in obesity as a State problem. Obesity is an individual's

\footnotetext{
${ }^{100}$ Weber, The Protestant Ethic, 53.

${ }^{101}$ Ibid., 122.

${ }^{102}$ Bordo, Unbearable Weight, 197.
} 
responsibility and those who fail in that responsibility will reap the consequences. This lack of interest in the weak explains why BCM policy approaches are not interested in the social inequality dimensions of obesity prevalence. The distinction between the ECM and the BCM can now be framed and understood as dependent upon distinct understandings of what is considered moral. In the BCM individual self-discipline is considered moral, whereas the ECM finds morality in the exercise of empathy that manifests as social responsibility to the whole community.

\subsection{Coexisting Individual and Communal Moralities}

I argued that individualised and communalised moralities operate within the BCM and ECM extremes of the 'political spectrum of obesity causation models.' These positions can be understood as ideological and moral extremes between which moral middle grounds exist. The MCM is an example of a moral position caught in the middle of these two extreme moralities. However, these extremes should not always be thought of as minority positions or opposing views because they actually coexist alongside each other. This coexistence was evident in Chapter Five where we saw that in 2009 the dominant discourses were the ECM and BCM.

The problem of how to account for two different sets of moralities coexisting is described by Lakoff as a worldview problem. ${ }^{103}$ Lakoff points out that conservatives and liberals do not speak the same language and actually talk past each other as ${ }^{104}$ their languages are tied to very different conceptual, moral, and ideological views of the world. ${ }^{105}$ This explanation illustrates the very problem we find in obesity discourse. All three models are ostensibly concerned with the problem of obesity but, as I have shown in Chapters Two - Five, each causality model has a different conceptual, moral, and ideological view of the world. They all talk about 'obesity' but have radically different notions about its causality, prevention, and treatment. These three models all entail various sets of ideological metaphors and moral categories utilised by different groups for their own political goals.

Anderson's ${ }^{106}$ and Lakoff's work shows that different sets of conceptual metaphors for describing evil or immorality coexist alongside each other. ${ }^{107}$ What is common among all these

\footnotetext{
${ }^{103}$ Lakoff, Moral Politics, 24

${ }^{104}$ Ibid., 29.

${ }^{105}$ Ibid., 29

${ }^{106}$ Anderson, Sin: A History.
} 
moral traditions is that they are all concerned with sin, its causes, who or what is responsible for this sin, and how one can remove it. This has been particularly evident in the morality associated with BCM whereas for the ECM and MCM the practice of moral discrimination against the obese is more subtle.

\subsection{Scapegoating the Obese}

Blame and a moral imperative to hold something or someone responsible for causing obesity has been a constant theme of this chapter. In the work of Anderson, scapegoats take on the responsibility for sin to expel it from a society. Here, I apply the notion of scapegoating to the moral dimensions of the obesity models. Scapegoating should be loosely understood as a process where a person bears the blame for the sins of others. I claim that the two extreme obesity models both overtly scapegoat the obese and covertly scapegoat specific class and ethnic groups.

The allocation of blame or responsibility for obesity causality can be interpreted as scapegoating. Scapegoating is a process where blame is placed on an entity which is not the real cause of the problem. Following this definition, both the ECM and BCM could be interpreted by proponents of the opposing model as engaging in scapegoating. Thus, proponents of the BCM would view those who hold ECM views as scapegoating the freemarket for what they clearly see is a problem related to individual behaviour. Conversely, proponents of the ECM would view individual behavioural arguments as scapegoating obese individuals for what they understand to be an environmental problem. As a result, in the process of allocating blame for obesity, causal responsibility is placed onto a scapegoat which represents the causal explanation of that particular ideological model. In each case, the scapegoat is not fully understood by everyone to be responsible for obesity prevalence. Thus, the process of scapegoating involves placing the blame for evil, immorality, or, impurity upon a victim who only symbolises the fears of a society. ${ }^{108}$ Each obesity model scapegoats, but each model blames different things.

The BCM has two targets for its scapegoating. First, it directly scapegoats obese individuals. Second, it scapegoats the Welfare or Nanny State as fat, inefficient, and a facilitator of moral weakness within the population. ${ }^{109}$ The first target is of particular interest. The BCM is the most overt in its blaming of obese individuals as morally weak and self-indulgent. For the BCM,

\footnotetext{
${ }^{107}$ Lakoff, Moral Politics.

${ }^{108}$ Girard, Violence and the Sacred, 269.

${ }^{109}$ Hide, My Year of Living Dangerously, 191.
} 
obese people are effectively damned and the morally strong may consider any punishment or misfortune that might befall them to be just retribution for moral weakness. The BCM righteously and unsympathetically condemns the obese as self-indulgent gluttons and sloths. Under the BCM view, the obese body physically signifies its lack of moral strength and this body can be permissibly discriminated against or scapegoated because this body visibly contradicts the ideological and moral values of BCM ideology. Punishment of the obese occurs through lack of employment opportunities, ${ }^{110}$ social exclusion, ${ }^{111}$ reduced sexual attractiveness, ${ }^{112}$ and the inevitable financial costs ${ }^{113}$ which will be incurred when obesity affects the individual's health.

The ECM, like the BCM, also has two targets for its scapegoating. However, the ECM scapegoats in a more subtle manner than the BCM. First, it targets the obesogenic environment. Second, it targets a generalised 'burden' of obesity. First, the ambiguity of the term 'unhealthy environment' can encompass many different things. However, when pushed, the ECM scapegoats specific industries ${ }^{114}$ such as the Food and Beverage Industry for causing obesity. The second target is the 'burden' of obesity which I discussed in 6.2. In burden language the obese are perceived to be inflicting a harm or unbearable cost upon a society. In the ECM and MCM, the obese population, rather than individuals, is scapegoated as imposing structural ills upon society. The ECM and MCM target the obese as a large financial burden harming the society. ${ }^{115}$

Both these extremes scapegoat very different things for causing obesity. The disjunction between the scapegoats of these two models suggests that at the bottom of the 'obesity debate' is a fundamental lack of consensus. If both extremes of the debate are misassigning blame for causality it indicates that there exists significant scientific and political uncertainty over the causes of obesity. An explanation of the 'true causes' of obesity appears to be still up for grabs. One consequence of this uncertainty is that the poles at each end of the spectrum are blaming something or someone for causing obesity based upon only partial explanations. The BCM's blaming of individuals for obesity overlooks the environmental determinates of obesity while the ECM blaming the environment for obesity neglects to take into account the role individual

\footnotetext{
${ }^{110}$ Stephen Morris, “The Impact of Obesity on Employment," Labour Economics 14 no. 3 (2007): 413.

${ }^{111}$ Rebecca Puhl and Kelly D. Brownell, “Bias, Discrimination, and Obesity,” Obesity Research 9 no. 12 (2001): 790.

${ }^{112}$ Michelle Pearce, Juli Boergers, and Mitchell J. Prinstein, "Adolescent Obesity, Overt and Relational Peer Victimisaton, and Romantic Relationships," Obesity Research 10 (5 May 2002): 386

${ }^{113}$ Louis, Aronne, "Classification of Obesity and Assessment of Obesity-Related Health Risks," Obesity Research 10 (2 December 2002): 105S.

${ }^{114}$ Utter, Scragg, Percival and Beaglehole, "School is Back," 5.

${ }^{115}$ Expanded upon in Chapter Seven
} 
self-discipline has in preventing obesity. Thus, I argue that due to the contested nature of obesity discourse it is clear that neither the environment nor individuals are fully or solely to blame for causing obesity and indicates that more nuanced causal explanations require consideration.

In search for a more nuanced explanation of causality I now turn to a stricter definition of scapegoating. If we can understand why a society scapegoats people then perhaps we can develop more functional explanations of obesity causality. An explanation of scapegoating in religious contexts can be found in Rene Girard's Violence and the Sacred. ${ }^{116}$ Girard argues that scapegoating functions as a social mechanism to eliminate violence and impurity from a community. In this process the destructive desires and fears of the community are placed onto a sacrificial victim who is either killed or expelled from the community. The removal of the scapegoat acts to purify and renew the community. ${ }^{117}$ The scapegoat is a representative substitute for all the violence of the community who unanimously participate in the practice. ${ }^{118}$ It is important that the ritual victim come from both inside and outside ${ }^{119}$ the community because that unifies the group in its sacrifice. In modern societies, the purpose of ritual sacrifice of a scapegoat is to ensure the integrity of the community. ${ }^{120}$ In these religious contexts the scapegoat requires purification and bears a mark of difference. Girard gives examples of modern scapegoat victims being drawn from marginalised groups such as beggars, cripples, ${ }^{121}$ and prisoners. ${ }^{122}$

As scapegoats, the obese are marked as different and marginalised. This mark might be the obese body itself or the cost of obesity prevalence to society. The financial and mortality burden of obesity and/or the poor behaviour of obese people are targets of scapegoating for various dominant political and medical powers. In both cases the rhetoric implies that the removal of these bodies or costs will make a better and purer society. However, when we dig around the demographics of these scapegoats we find that all these political/medical discriminations omit the fact that the majority of New Zealand's obese victims are drawn from marginalised groups including the most economically deprived people, Maori, and Pacific

\footnotetext{
${ }^{116}$ Girard, Violence and the Sacred.

${ }^{117}$ Ibid., 31.

${ }^{118}$ Ibid., 115.

${ }^{119}$ Ibid., 92.

${ }^{120}$ Ibid., 280.

${ }^{121}$ Ibid., 254.

${ }^{122}$ Ibid., 276.
} 
Island peoples. ${ }^{123}$ The generalised moralisations of obesity as a population problem or an individual problem hide the demographic locatedness of obesity prevalence. Explanations of the relationship between ethnicity and socio-economic position need to be added to the ECM and BCM causal explanations both of which omit these factors.

In this section I began by arguing that proponents of the ECM and BCM can accuse those holding opposing views of engaging in scapegoating. The BCM scapegoats obese individuals and the Welfare State. In contrast, the ECM scapegoats the unhealthy environment and the collective burden of obesity prevalence. The fact that both models scapegoat very different things for obesity causality lead me to argue that these models offer only a partial explanation and an explanation of the 'true causes' of obesity remains contentious. By following a stricter definition of scapegoating we find that scapegoats tend to come from marginalised communities. This led me to argue that the generalised scapegoating of the obese by the BCM and ECM tends to omit the fact obesity prevalence is highest in marginalised social groups which include deprived people, Maori, and Pacific Island peoples. These groups constitute an additional set of unseen scapegoats who bear the brunt of the generalised moralisations of the obesity models. As such, an exploration of class and ethnicity forms the content of Chapters Seven and Eight.

\subsection{Moralising against the Obese: "It's Your Fault If You're A Fatty"}

In this section, I outline a case study which encapsulates many of the contradictions of the obesity models which arose from the discussion of scapegoating. Here, I discuss a conspicuous example of a BCM obesity researcher, intentionally or not, letting slip the politically correct veneer that characterises most medical and policy discourse. In May 2009, Professor John Birkbeck, who had been head researcher for the NDS77 and LINZ89 national nutrition surveys, retired from his professorship in human nutrition at Massey University. Upon his retirement he caused considerable public controversy by advocating a BCM position which argued for overt moral discrimination against the obese.

The Birkbeck controversy arose from a newspaper article entitled “It's Your Fault if You're a Fatty.” ${ }^{124}$ In this article Birkbeck blamed fatness solely on individual behaviour. He assumed

\footnotetext{
${ }^{123}$ Ministry of Health, A Focus on the Health of Maori and Pacific Children Key Findings of the 2006/07 New Zealand Health Survey (Wellington: Ministry of Health, December 2009), 55.

${ }^{124}$ Geraldine Johns \& Anna Leask, “Expert: It's Your Fault if You're a Fatty,” New Zealand Herald Online, 31 May 2009 http: / / www.nzherald.co.nz/nz/news/article.cfm?c id=1\&objectid $=10575537$ last accessed $7^{\text {th }}$ October 2010.
} 
that bodies are efficient and are able to easily convert calorific inputs into outputs and described this BCM view as basic thermodynamics. ${ }^{125}$ However, Birkbeck then employed the controversial analogy of Nazi concentration camps to further emphasise his BCM view: "You do not see fat people in concentration camps. Why? Because they get hardly anything to eat and they have to do a lot of work." ${ }^{126}$ In a later interview, he explained that his analogy of emaciated concentration camp bodies was intended to demonstrate how a lack of calorific input verified his thermodynamic argument. ${ }^{127}$ Birkbeck's blaming the obese for their fatness was not a particularly unusual argument, but it was his analogy which was controversial. The analogy implied that fat people should be forcibly put into camps, have their diet restricted, and be made to work off their accumulated calorific intake. The horror of the analogy was that Birkbeck's language implied that this was just and necessary punishment for the immoral sins committed by obese individuals. When this analogy is pushed to its extreme it legitimates a form of inhumane torture. Enforced starvation and labour are tortures from which there is no salvation or normalised return to society. The only escape from concentration camps came through death or external liberation, both of which are bleak prospects for the obese.

Birkbeck's comments elicited strong reactions from across the obesity political spectrum. All of these reactions were concerned with the allocation of blame and finding specific scapegoats for causality. Maree Burns, coordinator of the Auckland-based Eating Difficulties Education Network, accused him of perpetuating a societal discrimination against the obese. ${ }^{128}$ Leigh Sturgiss, of the now defunct Obesity Action Coalition, claimed that he missed the point that obesity "should be blamed on environment rather than the individual." ${ }^{129}$ For Sturgiss it is the environment which should be blamed. In his 'Kiwi Blog' David Farrar, a lifetime member of the Young National Party, supported Birkbeck's BCM position but not his hyperbole. ${ }^{130}$ Farrar also took the opportunity to critique Leigh Sturgiss' comments: “Thank God we have stopped taxpayer funding to this group [the $\mathrm{OAC}$ ]. As someone overweight myself, I find it outrageous to have Leigh Sturgiss saying it is society's fault - rather than my own...it is nothing to do with society or the environment - and everything to do with personal choices." ${ }^{131}$ Farrar argued that his personal fatness should be blamed upon his own personal choices. When these three responses to Birkbeck's comment are all taken together they show how blame language occurs

\footnotetext{
${ }^{125}$ Close Up News, June 10, 2009, http://tvnz.co.nz/close-up/being-fat-your-own-fault-2778376/video last accessed 31 st January 2011

${ }^{126}$ Johns and Leask, "Expert: It's Your Fault."

${ }^{127}$ Close Up News, June 10, 2009.

${ }^{128}$ Johns and Leask, "Expert: It's your fault."

${ }^{129}$ Ibid.

${ }^{130}$ David Farrar, “Obesity”, http://www.kiwiblog.co.nz/2009/05/obesity.html last accessed 31st January 2011.

131 Ibid.
} 
all along the political spectrum of obesity discourse. Each response, while overtly concerned about the moral ramifications of Birkbeck's overtly discriminatory language, was similarly intent upon blaming and scapegoating something or someone for the problem of obesity.

Further illustration of the moral dimensions of this debate emerged when John Birkbeck was subsequently interviewed on prime time television by Mark Sainsbury's Closeup programme. In this debate, Birkbeck argued that overt discrimination against the obese was necessary. Birkbeck and Sainsbury were joined by Dr Cat Pausé, Fat Studies Scholar, from Massey University's Palmerston North Campus. Pausé holds the intellectual position that "Fat Studies creates paradigms for the development of fat acceptance and celebration within mass culture." ${ }^{132}$ Sainsbury's interview attempted to bring together these two scholars. A sympathetic analysis of the debate would explain that the discussion centred around two primary areas of contention. The first was whether or not thermodynamic understandings of calories and obesity causality were reliable. The second was whether or not discrimination against the obese should be publically permissible. A cynical synopsis of the debate would argue that these two scholars talked past each other.

Birkbeck's argument for the necessity of moral discrimination was predicated on his assumption that "at the crux of the matter" ${ }^{133}$ there is something wrong with being fat. He stated that there is overwhelming evidence to demand that people simply must accept that being fat is a health hazard because when one is obese or overfat then one's risk of developing chronic disease or life threatening disease is much higher. He claimed this has the effect of causing health problems for the individual as well as incurring economic costs for the family and the health system. For Birkbeck "Over-fatness" was a self-inflicted burden on the taxpayer. ${ }^{134}$ Thus, for Birkbeck one individual's lack of self control and resulting fatness affects all of us. ${ }^{135}$ He claims that by being politically correct we are covering the problem because we are too worried about offending people. ${ }^{136}$ His solution is to create a climate where people must accept that being overfat is not a good thing and people must be motivated to prevent obesity." ${ }^{137}$ Birkbeck effectively made the argument that moral discrimination against the obese should function as a motivating tool to coerce fat people into becoming 'healthy' or 'normal.'

\footnotetext{
${ }^{132}$ Cat Pausé Homepage, http://www.massey.ac.nz/massey/learning/colleges/college-education/about/staff/adhe/en/Pausé -caitlin.cfm last accessed 31st January 2011.

${ }^{133}$ Close Up News, June 10, 2009,

${ }^{134}$ Johns and Leask, "Expert: It's your fault."

${ }^{135}$ Close Up News, June 10, 2009

${ }^{136}$ Ibid.

${ }^{137}$ Ibid.
} 
Pausé argued against the assumption that obesity is caused by individual behaviour and Birkbeck's view that weight loss strategies are effective. She claimed that the thermodynamics position is very simplistic model of fat gain. Her position is that individuals have different energy expenditure levels and that determining the amounts of energy people expend is highly problematic. She further criticised the thermodynamic position by stating that, at present, there is no reliable weight loss or dieting system that allows individuals to reliably keep weight off and that there are a lot of risk factors for poor health which creates a false situation where one factor is being blamed for a much more complicated problem. ${ }^{138}$

Pausé claims that the current climate of discrimination against the obese is the last allowable discrimination. ${ }^{139}$ For Pausé the concentration camp analogy simply furthers already existing fat phobia, fat discrimination, and fat hatred. She indicates that Birkbeck's language and use of analogy when combined with his considerable authority indicates he is making a very serious argument for this overt discrimination to be a legitimate discourse. Pausé's language includes the terms problem and blame as referents to obesity which inadvertently demonstrates how even Fat Studies scholars cannot easily escape the moral dimensions of obesity language. Fat Scholars view the problem of obesity to be an oppressive society that does not accept people's right to bodily fatness or extend to the obese the human right of freedom from discrimination. This position claims that the obese should have equal rights to freedom of expression.

When one scratches the surface of the Closeup debate some deep ironies are revealed.

Birkbeck's BCM position and concentration camp analogy is ironic because it implies that only a closely regulated, violent, and unethical environment of starvation and enforced labour is required to force fat people to become thin. The concentration camp analogy is the complete inverse of an obesogenic environment. The concentration camp is an environment which completely abnegates individual responsibility through enforced bureaucratic brutality. This irony helps to further illustrate my argument that the extreme obesity models are only partial explanations for causality because they oversimplify the treatments and causes of obesity. Birkbeck's BCM argument contradicts itself because it requires individuals to be placed into a rigidly controlled State-run environment - the concentration camp - to force people to become thin. 
Pausé's position also contains one particularly interesting irony. She firmly argues against the position that individual behaviour is the primary determinant of obesity. She places the blame for obesity into a complicated nexus of causality effectively absolves the obese individual for any form of responsibility for health. This appears to be an argument for ECM causality. However, it is also a call for a form of radical individualism. Fat Studies scholars ${ }^{140}$ want to be free autonomous individuals who are able celebrate the fat body rather than hate it. This position holds that individuals should not be moralised against for their choices, instead they should be free to celebrate and embrace these choices and bodies. This is, in fact, an argument based upon the celebration of individual choice and freedom. Here we find that arguments which place obesity causality on a combination of environmental factors begin to fall down again because they cannot be easily reconciled with notions of radical individualism. ${ }^{141}$ Moreover, these arguments do not account for the locatedness of obesity prevalence in specific population subgroups.

A key irony of the ECM can be illustrated through a reading of the work of Michel Foucault. ${ }^{142}$ Foucault is useful for demonstrating how ECM and MCM State policies scapegoat obesity for the betterment of the whole. One of Foucault's concerns is the correction of deviance which here I employ as a synonym for obese individuals. In Discipline and Punish Foucault shows how State correction of deviance occurs through regulated environments such as schools, hospitals, workplaces, and prisons. ${ }^{143}$ The function of these institutions is then diffused out into the general society. State correction is the enforced implementation of discipline upon deviant individuals who are coerced towards becoming normal participants in a society. ${ }^{144}$ Foucault described the goal of institutionalised discipline as:

[U]seful pedagogy [that] would revive for the lazy individual a liking for work, force him back into a system of interests in which labour would be more advantageous than laziness, form around him a small miniature, simplified, coercive society in which the maxim, 'he who wants to live must work,' would clearly be revealed ${ }^{145}$

Foucault's words about a small simplified coercive society echo the sentiment expressed by Birkbeck's camp analogy. The goal of the disciplinary process Foucault describes - and we must positively assume the same for Birkbeck's claim - is to reincorporate the individual as a

\footnotetext{
${ }^{140}$ Murray, “(Un/Be)coming out,” 153.

${ }^{141}$ For Fat Studies scholars to support a MCM or ECM politics would be to support an ideological approach to governance which actively discriminates against their intellection position. MCM and ECM Governments are intent upon regulating away individual choice, freedom of expression and institute environments which punish and scapegoat the obese.

${ }^{142}$ M. Foucault, Discipline and Punish: The Birth of the Prison (London: Penguin Books, 1991).

${ }^{143}$ Ibid., 179.

${ }^{144}$ Ibid., 183.

${ }^{145}$ Ibid., 122.
} 
functioning economic member of a society. The medical establishment's drive to push the population towards normal BMI ranges can be understood as an example of this type of correction. Correction occurs through environments which coerce individuals to act in a certain manner. Correction is coercive and essentially violent because it forces individuals to undergo regimens against their will for the good of society. ${ }^{146}$ This forces us to reconsider the obesity related correction programmes developed by Labour such as HEHA, Pushplay, the Green Prescription, and the regulation of school food environments. Labour ECM and MCM policy pursued a type of regulation of the social environment which was intended to correct the immoral burden of obesity prevalence in the population. The ECM may not directly scapegoat the obese but it is focused upon developing coercive and controlled food and exercise environments.

This section surveyed an example of overt moral discrimination against the obese. A variety of moral dimensions surfaced in the controversy arising from Birkbeck's concentration camp analogy. The most overt discrimination was Birkbeck's argument that at the crux of the matter there was something wrong with being fat. ${ }^{147}$ From his thermodynamic premise he advocates social discrimination against the obese on economic and health grounds. Birkbeck's basic assumption that there is something wrong with being fat is only contested by Fat Studies scholars. All sides of the obesity causality spectrum appear to accept his argument, and the proponents of each model are intent upon blaming something or someone for the problem of obesity. However, when we look more closely Birkbeck's argument we find that his analogy requires complete environmental restriction of the obese to enforce his BCM view. This requirement shows how BCM arguments for self-discipline are not universal arguments because they require the implementation of disciplinary institutions.

The Birkbeck controversy also brings to the fore the fact that each model scapegoats different causes of obesity. It also demonstrates that serious ironies exist within the BCM and ECM positions. The failings of both the ECM and BCM were apparent in this controversy as advocates of each obesity model ended up surreptitiously invoking aspects of their opposing model to explain their potential solutions to obesity. These ironies suggest that both models are inadequate explanations for obesity causality when the causality situation is far more complex than these views are prepared to accept. These ironies, in combination with the fact

\footnotetext{
${ }^{146}$ Ibid., 170.

${ }^{147}$ Close Up News, June 10, 2009.
} 
that the obesity models scapegoat certain causes at the expense of others, leads one to ask what other causal explanations might be omitted by these models? In the scapegoating section, I noted that the covert scapegoats of obesity discourse were specific economic and ethnic groups. Here, Birkbeck wants to scapegoat the obese for their self inflicted illness but he omits to note that if the State were to instigate these camps would predominately be filled with the poor, Maori, and Pacific Islanders.

\subsection{Conclusion}

This chapter outlined the moral dimensions of the obesity models. These moral dimensions indicated that obesity discourse, in whatever form, is concerned with allocating responsibility and blame for the causes of obesity. The chapter began by comparing the ECM to communal forms of morality drawn from Lakoff's liberal moral politics and Anderson's analysis of classical Hebrew understandings of sin. I showed that communal moral systems, including the ECM, are fiercely protective of the collective and tend to seek retribution against those things perceived to threaten the integrity of the community. ECM discourse is directly concerned with the health of children for whom it actively attempts to create healthy environments, for example, through the HEHA, Fruit in Schools and the NAG Guidelines. Thus, obesity and its causes (big corporations, deprivation and commercial self-interest) are all viewed as morally harmful to the health, happiness and wellbeing of the community. For the ECM, the State, acting as a parent, has the moral responsibility to nurture and protect the health of the community.

One particular aspect of communalised morality given further attention was the ECM and MCM's use of burden metaphor. Three forms of burden language were shown to exist all of which aggregated obesity as a generalised communal problem affecting society. This language portrayed obesity as both a financial and mortality burden borne by the State. However, this approach omitted to consider that obesity is unevenly distributed throughout the population. This omission indicated that an investigation of the moral dimensions of obesity discourse might reveal unexplored dimensions of the obesity debate which were not directly addressed by the obesity models.

The discussion shifted to address the individualised morality of the BCM. The BCM was compared to Lakoff's analysis of conservative moral politics and Weber's discussion of the Protestant Ethic. This discussion showed how individualised forms of morality attempt to 
create societies in which disciplined individuals succeed materially, socially, and physiologically. Individual moral virtue, strength, and health are active projects achieved by an individual through a systematic application of the principles of restraint and work. This explains why BCM policy encourages competition through sports, such as Kiwi sport and Pushplay, and highlighted the importance of physical activity to citizenship. ${ }^{148}$ Conversely, the conspicuous absence of individual virtue in an obese individual is regarded as immoral by the $\mathrm{BCM}$. Thus, for the BCM, obese individuals physically represent their lack of virtue because they are visibly subject to the immoral behaviours of gluttony and sloth. Moreover, this perceived immorality, on the part of the obese, allowed successful proponents of the BCM to righteously scapegoat them as products of their own self-indulgence.

The chapter then explored the concept of scapegoating. It found that both the ECM and BCM scapegoat very different things for causing obesity. The BCM scapegoats individuals and the nanny state, whereas, the ECM scapegoats the obesogenic environment and generalised notions of an obesity burden. From this analysis, I argued that both these models misassign blame for causality with their scapegoating. These contesting scapegoats highlight the fact that there remains significant scientific and political uncertainty over the causes of obesity. The contested nature of obesity scapegoating indicates that neither the environment nor individuals are fully or solely to blame for causing obesity. Further investigation of the function of the scapegoating process then showed that both the ECM and BCM ignore the fact that the obese are mostly prevalent in demographically marginalised population groups. I concluded by arguing that further discussion of these unseen scapegoats, decoupled from ideology, will be one simple, important and necessary step to progress the obesity causality debate.

The final section addressed the 'concentration camp controversy.' This example encapsulated many of the moral dimensions of the obesity debate. In this controversy we saw eminent nutritionist John Birkbeck use BCM logic to argue that fat people should be put in concentration camps to be forced to diet and work off their fat. He claimed that fat people should be publically discriminated against in order to make them less of a burden upon the tax payer. This is a classic example of how the obese are scapegoated by proponents of the BCM. A closer investigation of the responses to this controversy demonstrated the failings of both the ECM and BCM as advocates of each obesity model ended up surreptitiously invoking aspects of their opposing model to explain their potential solutions to obesity.

\footnotetext{
${ }^{148}$ McCully and Creech, Physical Activity.
} 
This chapter represented a change of approach to my subject matter. It applied several religious studies theories to the case material. Religious studies lenses extend models of sin and morality which offer useful analogies for the problem of blame in obesity discourse. What began as a religious studies investigation into the application of the sins of gluttony and sloth to obesity discourse has now resulted in a survey and critique of a moral political spectrum of obesity. Gluttony and sloth represent the moral failings of obese individuals for the BCM. Burden language is utilised by the ECM and MCM to explain obesity as an imposed communalised threat to the community. Scapegoating is a process used by all dimensions of the obesity debate to allocate blame and responsibility for the causes of obesity. A critique of the obesity models emerged from the process of applying religious studies models to the moral dimensions of obesity discourse. It was found that the moral dimensions of the obesity models scapegoat different things for causing obesity. Moreover, the obesity models tend to generalise their scapegoats in such a way that they neglect to mention that New Zealand's obesity prevalence is found predominately amongst the poor, Maori, and Pacific Islanders. I now turn to address these factors in Chapters Seven and Eight. 


\section{Chapter Seven: Obesity Economics, Morals, and, Income Inequality}

The global emergence of obesity and diabetes is as much an economic issue as it is a health issue. ${ }^{1}$

\subsection{Introduction}

This chapter will demonstrate that the economics of obesity are divided along similar ideological and moral lines to those of the obesity models. The first part of the discussion shows that the emergence of economic cost burden of obesity literature contributed to the 'political spectrum of obesity causation model's' moralisations against the obese. In the second half, I show how income inequality is correlated with obesity prevalence and I argue that this relationship is omitted by the mono-causal models of obesity causality.

The first section outlines how a cost of obesity literature developed in the mid 1990s. This literature calculated the total cost burden of obesity to nations. I argue that this literature contributed to generalised and moralised understandings that obesity was a burden upon the taxpayer and health systems. I then show how this cost of obesity literature operated in New Zealand and how this economic burden of obesity can be envisaged as direct costs and indirect costs to the State, employer, and family. This will lead me to claim that this economic literature helped fuel the generalised moral imperative, inherent in political spectrum of obesity, to allocate blame and responsibility.

The chapter shows how $19^{\text {th }}$ century notions of economic efficiency were tied to scientific understandings of the calorie. This association linked the virtues of capitalism, economic success, self-discipline, and responsibility with diet and the health of the body. The discussion then addresses the $20^{\text {th }}$ century relationship between class and body shape and the counter position offered by the Marxist critique of capitalism and medicine. The final sections of the chapter highlight the association between socio-economic position and health inequality. In the discussion of inequality, I demonstrate that lower socio-economic status is correlated with higher prevalence of disease, mortality, and obesity. I argue that BCM ideology does not acknowledge inequality and thus obese individuals are unjustly scapegoated through

\footnotetext{
${ }^{1}$ Derek Yach, Stuckler David and Kelly Brownell, "Epidemiological and Economic Consequences of the Global Epidemic of Obesity and Diabetes," Nature Medicine 12 no.1 (January 2006): 63.
} 
accusations that they embody the behavioural sins of gluttony and sloth. Finally, I explore the implications of this critique of the BCM.

\subsection{The Economic Burden of Obesity}

In this section, I focus upon the literature concerned with the economics of the obesity burden. In the previous chapter, we saw that the MCM and ECM used the obesity burden as an aggregated metaphor for the costs of treating obesity-related illness. Now, however, I demonstrate that from 1997 a supplementary literature estimating the financial burden of obesity to nations emerged to complement the growing awareness of the dangers of an 'obesity epidemic.' I argue that this literature contributed an economic dimension underpinning the various ideological moralisations of the models existing along the spectrum.

Financial estimates of the cost of obesity to nations are only very recent. Before 1997, little academic literature was devoted to analysing such costs. In 1997, Hughes and McGuire ${ }^{2}$ conducted a research review of the economic analyses of obesity and found nine studies worldwide. However, by 1998, it was evident that the calculations estimating the worldwide cost of obesity were going to be enormous. ${ }^{3}$ A 1998 US study found that American health costs attributable to obesity were $\$ 99.2$ billion dollars in $1995 .^{4}$ In 1998 , Kortt et $\mathrm{al}^{5}$ identified and reviewed fourteen published cost-of-illness studies concerned with the costs of obesity. They found that obesity-related costs represented 2\%-7\% of health expenditure for the reviewed nations. Kortt et al argued that these percentages represented an overwhelming financial cost burden for health care systems. ${ }^{6}$ Thus, by the time the 'obesity epidemic' emerged in 1997 it was budgeting problem for Governments as well as a health risk.

This cost of obesity literature commonly used the term burden to describe this financial problem. Thompson and Wolf's 2001 review of the "medical-care cost burden of obesity"7 found: "that obesity exacts an immense economic toll in various countries through the world a toll that is borne by national health systems, health insurers and employers alike" ${ }^{8}$ This review indicates that the burden is spread across a variety of organisations that must 'bear' the

\footnotetext{
${ }^{2}$ David Hughes and Alastair McGuire, “A Review of the Economic Analysis of Obesity,” British Medical Bulletin 53 no.2 (1997): 253.

${ }^{3}$ Anne Wolf and Graham Colditz, "Current Estimates of the Economic Cost of Obesity in the United States," Journal of Obesity Research 6 no. 2 (March 6, 1998): 173-175.

${ }^{4}$ Ibid., 173.

${ }^{5}$ Michael Kortt, Paul Langley, and Emily Cox, “A Review of Cost-of-Illness Studies on Obesity,” Journal of Clinical Therapeutics 20:4 (1998): 772 .

${ }^{6}$ Ibid., 772.

${ }^{7}$ Thompson and Wolf, "The Medical-Care Cost Burden of Obesity."

${ }^{8}$ Ibid., 195.
} 
economic costs of obesity. Here the obese are seen as contributing direct costs to their society. The use of language such as 'toll' and 'borne' implies that these obesity costs are unfairly imposed upon society. In the mid 2000s, economic critiques of 'cost of obesity' literature argued for a shift from calculating the costs of obesity to conducting economic evaluations of potential solutions: ${ }^{9}$

More important than putting a dollar value on the burden alone is what can be done about the burden and what dollar values can be put on the costs and benefits associated with such treatment and prevention options. ${ }^{10}[\mathrm{Sic}]$

Even this fresh methodological approach was still specifically concerned with solving the burden of cost imposed by obesity

This concept of the economic burden of obesity to nations was firmly entrenched by the end of the 2000s. In 2008 Barret et al in their review of the existing economic analyses of obesity identified 29 papers published between 1997 and 2007 which discussed the direct costs of obesity. ${ }^{11}$ A 2010 research paper surveying the worldwide literature discussing the economics of obesity produced between 1990 and June 2009 yielded 32 articles suitable for review. ${ }^{12}$ Both papers discussed and summarised the costs of obesity in terms of an "economic burden" and in terms of direct and indirect costs. The 2010 review concluded that:

$[\mathrm{T}]$ here is a general consensus and acceptance in the literature that obesity places a significant financial burden on the health system. In our review, obesity was estimated to account for between $0.7 \%$ and $2.8 \%$ of a country's total health care expenditures. ${ }^{13}$

Thus, by the end of the 2000s the 'obesity burden' was understood to be a significant cost to the health care budget of a nation. The highest estimates found that the costs of obesity can reach up to $10 \%$ of health spending. ${ }^{14}$

The findings from this cost-based 'burden of obesity' literature contribute a financial angle to the systematic moralisation against the obese systematically portraying the obese as an avoidable financial burden to national health systems. Obesity literatures use of burden language implies that the obese have irresponsibly failed their obligations to their own health,

\footnotetext{
${ }^{9}$ Larissa Roux \& Cam Donaldson, “Economics and Obesity: Costing the Problem or Evaluating Solutions?” Obesity Research 12:2 (2004): 173. ${ }^{10}$ Ibid., 173.

${ }^{11}$ Amy Barrett, Ann Colosia, Kristina Boye and Olatoye Oyelowo, "Burden of Obesity: 10-Year Review of the Literature on Costs in Nine Countries." Seminar provided at the $13^{\text {th }}$ Annual Meeting of the International Society for Pharmoeconomics and Outcomes research, May 3-7 2008 Toronto.

${ }^{12}$ D. Withrow, \& David Alter, "The Economic Burden of Obesity Worldwide: A Systematic Review of the Direct Costs of Obesity," Obesity Reviews, International Association for the Study of Obesity, (2010): 1.

${ }^{13}$ Ibid., 8 .

${ }^{14}$ Eldo Frezza and Mitchell Wachtel, “The Economic Impact of Obesity,” Surgical Endoscopy 23 no.4 (April 2009): 677.
} 
their employer(s), their insurance company, and the national health sector that will have to eventually bear the financial costs. Nation States are now forced to address the problem of how they should account for these obesity costs. Indeed, this economic logic makes obesity a moral accountability problem for all the ideological approaches to causality; all the moral politics of the spectrum are undergirded by this demand to allocate the costs of the 'obesity burden' to a particular cause.

\subsection{New Zealand Economics of Obesity}

In this section, I demonstrate how costs of obesity estimates were applied in New Zealand. Here, I argue that the need to define accountability for the costs of obesity filtered into health policy decision making in this nation in a process that made these costs become a political health problem.

The earliest local example I can find of costs being attached to the causes of obesity comes from the 1987 Hilary Commission, which attached cost-based rationales to exercise and physical inactivity. The Cost of Doing Nothing ${ }^{15}$ provided a strong economic rationale to reduce the costs associated with cardiovascular disease. It stated that if another $10 \%$ of the population became physically fit then $\$ 24.75$ million dollars a year could be saved in coronary heart disease costs. ${ }^{16}$ Even as early as 1987 there were vast financial costs being attached to physical inactivity/sloth.

In 1997, Swinburn et al provided what they described as a comprehensive estimate of the annual total direct costs of obesity for the nation. ${ }^{17}$ They estimated a single year's health care costs of obesity (1991) by concentrating on six conditions they regarded as contributing to the health costs of obesity. These included Type 2 Diabetes, coronary heart disease, hypertension, gallstones, colon cancer, and post menopausal breast cancer. Their research also calculated inpatient costs, outpatient costs, general practitioner costs, pharmaceutical costs, laboratory costs, and ambulance costs for these conditions. ${ }^{18}$ These total costs were then divided by the proportion of the population that was designated obese (14\% as an average of men and women found by the LINZ and Auckland Heart health surveys). They estimated in 1991 that the contributable cost of obesity to health care costs was NZ \$135 million dollars per annum for a

\footnotetext{
${ }^{15}$ Russell, Worsley, and Wilson, The Cost of Doing Nothing.

${ }^{16}$ Ibid.

${ }^{17}$ Boyd Swinburn, Toni Ashton, Julie Gillespie, Brian Cox, A Menon, David Simmons and John Birkbeck, "Health Care Costs of Obesity in New Zealand,” International Journal of Obesity 21(1997): 894.

${ }^{18}$ Ibid., 894.
} 
population which was estimated at 3.4 million people. They noted that their estimate did not include the indirect costs of obesity, which would be substantial.

Swinburn et al's research encumbered more than just the health sector with the financial burden of obesity. The costs of obesity in Swinburn et al's research are directly allocated to four different areas: the State, the employer, the family, and the obese individual him or herself. Obesity costs burden the State both through the primary health services required to provide treatment and the loss of State revenue when the obese person cannot work. Obesity also affects employers who have to either replace or do without their obese employee. Families and obese individuals lose their income and lose years of life. In their discussion, Swinburn et al outline the way in which they conceive the structure of the obesity costs:

Obesity and its consequences carry many costs. These include the direct costs of health care, the indirect costs of loss of production, the costs of attempting to lose weight and the human costs of suffering shortened lives. ${ }^{19}$

The primary form of analysis, direct cost, is concerned with the financial costs borne by the State through the provision of primary health care services to treat the medical consequences of obesity. Indirect costs are the lack of economic production in the economy. The economic burden of obesity is understood here as having a variety of direct and indirect negative financial consequences for the whole society. We begin to see how burden language moralises against the obese. Following Swinburn et al's logic, one person's obesity ends up incurring costs for at least four other groups within society.

The exact cost burden of obesity to New Zealand is difficult to find. Several different estimates for the cost of obesity were used in the early 2000s. At times, Labour used Swinburn's original estimate. In 2003, Annette King used the figure of $\$ 135$ million dollars ${ }^{20}$ when she announced the HEHA programme. ${ }^{21}$ In 2004, the cost of obesity was valued in the NZMJ at $\$ 303$ million dollars each year. ${ }^{22}$ In 2007, the Select Committee identified obesity costs as an estimated \$247.1 million dollars per year in 2000/01 dollars. ${ }^{23}$ The Select Committee argued that there was an urgent need for the direct and indirect costs of obesity to be recalculated. ${ }^{24}$ Swinburn's work is

\footnotetext{
${ }^{19}$ Ibid., 894.

${ }^{20}$ HEHA's reliance upon Swinburn et al's research is curious because this research calculated the cost of obesity before the NNS97 obesity prevalence statistics were released. Moreover, the costs of obesity were calculated in 1990/1991 dollar amounts. This meant that, at best, by the 2000s Swinburn et al's research provided a very conservative benchmark of the direct costs of obesity.

${ }^{21}$ Annette King, "King Launches Strategy to Tackle Obesity, Improve Nutrition and Increase Physical Activity," http://www.beehive.govt.nz/node/16181 (last accessed October 4, 2010).

${ }^{22}$ Duncan, Schofeild, Duncan, Kolt and Rush, "Ethnicity and Body Fatness in New Zealanders," 1.

${ }^{23}$ House of Representatives, Inquiry into Obesity, 10.

${ }^{24}$ Ibid., 10.
} 
now out of date and there has been there has been no subsequent comprehensive study of the costs of obesity. In 2009, Labour Party MP Ruth Dyson argued that the costs of obesity to the health sector will increase to $\$ 1.3$ billion dollars a year by $2016 .{ }^{25}$ If and when up-to-date research is released with recalculations of these costs, they will be dramatically higher than Swinburn et al's figures and will reinvigorate calls for further action to prevent obesity. It is likely that a future national estimate of these direct and indirect costs would instigate further coercion of individuals to exercise and eat better as a moral duty to the health sector.

New Zealand health policy has been driven to some extent by estimates of the cost of obesity. In these examples, the costs are all understood as either avoidable or preventable. ${ }^{26}$ Swinburn's direct and indirect cost methodology shows exactly how the financial burden of obesity is spread across individuals, employers, and the State. This methodology clearly shows the economic impact of obesity upon others. This literature implies that the view that the obese have failed their obligations to their own health, their employer, and their national health sector. This 'cost of obesity' logic creates a political imperative for Governments to allocate economic responsibility. The cost rationale explains why each obesity model is concerned with finding either someone or something to blame.

\subsection{Capitalism and Nutritional Efficiency}

I now reconsider economic explanations of obesity as an individual moral problem. In the $19^{\text {th }}$ century notions of economic efficiency were linked to diet. This linking saw motions of calorific efficiency and economic efficiency conflated to create a dietary morality concentrated upon the counting of calories. This dietary morality viewed excess calorific intake as economically wasteful. After World War II, when Western populations were surrounding by excess calories this morality developed into a form of dietary asceticism for economic elites. The individual behaviours which produced thinness also happened to be those essential for capitalist success. Thus, through dietary success one portrayed one's mastery of capitalist virtue and conversely those individuals whose dietary failings were visible easily portrayed their failure to master capitalist virtue. In this way, economic notions of individual success and class were tied to a morality of the individual's diet. Importantly for our discussion of health inequality, these existing arguments link capitalist notions of virtue to diet in a way that permitted the successful to scapegoat those people designated as financial and dietary failures.

\footnotetext{
${ }^{25}$ Ruth Dyson, "Obesity strains health services"

${ }^{26}$ House of Representatives, Inquiry into Obesity, 11.
} 
Consequently, capitalist notions of individual virtue quietly condemned lower-socioeconomic groups as immoral.

Bryan Turner, seminal sociologist of the body and religion, has argued that in the $18^{\text {th }}$ century an 'elective affinity' between the spirit of capitalism and efficient dietary management arose in Protestant nations. ${ }^{27}$ He noted that early writing on diet had its origin in religious notions of self-control. By the $19^{\text {th }}$ century, however, this religious notion of personal morality had been replaced with a secularised morality concerned with calories and proteins. He argues that the counting of calories and proteins constituted a new $19^{\text {th }}$ century understanding of personal discipline and morality. In the search for personal discipline and health, calories and proteins could be counted with economic efficiency. ${ }^{28}$ However, Turner omits to say that this moral view was ideological. It was linked to specific capitalist notions of virtue and morality. These $19^{\text {th }}$ century Western notions set the ground for the designation of those who failed their dietary responsibility as scapegoats.

Hillel Schwartz, in his classic history of the origins of modern American obesity, outlines the conceptual development of the notion of efficiency and the calorie as a means of nutritional exchange. Schwartz argues that the origins of efficiency occurred from the late $19^{\text {th }}$ century when body fat became conceptualised as a bank account of stored energy in the body in the work of physiologist Claude Bernard. ${ }^{29}$ Fat, therefore, could be seen as a representing wealth or a store of capital. Schwartz goes on to note that the body and nutrition underwent significant analysis in the Great War, when mobilisation for the war effort required a systematic and efficient ordering of bodies and nutrition. ${ }^{30}$ In the allocation of resources for the war effort, excess was seen to be inefficient as it represented an unnecessary consumption of food at another's expense. Schwartz argues that by the end of the Great War "Fatness was as selfish as it was uneconomical." ${ }^{31}$ Schwartz provides evidence to suggest that, by the beginning of the $20^{\text {th }}$ century in America, fatness was understood as being economically inefficient and, in some quarters, a crime against the State and one's fellow citizens. This goes some way to explain why for the BCM economic efficiency is tied to dietary morality.

\footnotetext{
${ }^{27}$ Bryan Turner, "The Discourse of Diet." in The Body, Social Process and Cultural Theory, ed. Mike Featherstone, Mike Hepworth and Bryan S Turner (London: Sage Publications, 1991), 164.

${ }^{28}$ Ibid., 167.

${ }^{29}$ Schwartz, Never Satisfied, 217.

${ }^{30}$ Ibid., 142-143.

${ }^{31}$ Ibid., 142.
} 
Schwartz also traces the emergence of the notion of a calorie in both the work of American nutritionists and economists. ${ }^{32}$ Understandings of calories and calorific content of food were first developed in 1890 by chemist William Atwater. Atwater understood a calorie to be "the amount of heat required to raise the temperature of one gram of water by one degree centigrade. ${ }^{33}$ Calories are burned to produce energy. Food was then understood to be an input of a certain amount of energy, in the form of calories, into the body which could then be stored or burnt to produce energy. Schwartz ${ }^{34}$ then describes how in 1906, controversial Yale University economist Irving Fisher drew a parallel between this notion of burning calories and the notion of market equilibrium. ${ }^{35}$ The body, its energy reserves, and food were seen to be engaged in a process which could move towards an equilibrium point where energy consumed could be matched by the amount of energy burnt. Here we can see the origins of Birkbeck's thermodynamic argument. For Fisher, the efficient body, like an efficient market, was always a physical possibility in this equation.

James Whorton argues that in America by the 1900s, subsequent to this work on the calorie, ideas of efficiency had a new morality. Waste and/or excess represented a failure of moral responsibility. ${ }^{36}$ Inefficiency represented an individualised form of self-indulgence and a squandering of resources. ${ }^{37}$ In these examples the term efficiency linked ideas of economic and dietary efficiency.

Obesity researchers commonly argue that changes in economic methods of production have changed ideal body types for the wealthy. ${ }^{38}$ In pre-modern societies (some of which still exist today in places such as Nigeria ${ }^{39}$ ) wealth was represented physically by the large bodies of those who had plenty to eat given that in these societies only the very wealthy had enough to eat. Production-based industrial economies also suffered from a lack of food. It is only after World War II, in combination with the rise of the leisure classes, ${ }^{40}$ the advent of sedentary lifestyles and consumption-based economies that food environments were represented by an excess of

\footnotetext{
${ }^{32}$ Ibid., 134

${ }^{33}$ Ibid., 134 .

${ }^{34}$ Ibid., 134

${ }^{35}$ Irving Fisher, “A New Method For Indicating Food Values," American Journal of Physiology 15 (1906): 417.

${ }^{36} \mathrm{~J}$. Whorton, Crusaders for Fitness. The History of American Health Reformers (Philadelphia: Princeton University Press, 1982 ), 166.

${ }^{37}$ Ibid., 166.

${ }^{38}$ Janet Polivy \& David Garner, “Causes and Consequences of the Current Preference for Thin Female Physiques," in Physical Appearance, Stigma and Social Behaviour, ed. Edward Higgins, Peter Herman \& Marc Zanna, The Ontario Symposium, Volume Three (New York: Lawerance Erlbaum Associates, 1986), 91.

${ }^{39}$ Rebecca Popenoe, “Ideal," in Fat: The Anthropology of an Obsession, ed. Don Kulick \& Anne Meneley (New York: Penguin Books, 2005$), 9$.

${ }^{40}$ T. Veblen, The Theory of the Leisure Class: An Economic Study of Institutions (New York: Random House, 1922).
} 
food or, to be more specific, an excess of calories. ${ }^{41}$ Thus, this change in economic system led to a change in class structure for obesity. ${ }^{42}$ As a result of this class change, the wealthy began to eschew being fat, as this no longer provided health benefits, instead favouring slimmer bodies which now provided extra health benefits, were harder to achieve, and symbolised their capitalist virtue.

The preference for lean bodies brought with it a dietary morality that associated economic wastefulness with calorific inefficiency. Susan Bordo argues that one of the consequences of this changing class and bodily morality was a reassertion, by some, of a connection between obesity and idleness or sloth:

where associations of fat and lower class status exist, they are usually mediated by moral qualities - fat being perceived as indicative of laziness, lack of discipline, unwillingness to conform and the absence of "managerial" abilities that according to the dominant ideology, confer upward mobility. ${ }^{43}$

Bordo points to meritocracy arguments produced by neo-liberals that follow the logic that the thin are simply thin because they are disciplined and choose to actively eat healthy and to exercise. This argument suggests that individuals can make a choice about whether they will be fat or not. Thus, the poor were fat because they were lazy and refused to work hard. Given that these are necessary habits for successful participation in the capitalist economy, individuals who are disciplined and hard working also tend to be the people who enjoy economic and social success. This is one of the reasons why the wealthy, especially wealthy women, became thinner and thinner through the $20^{\text {th }}$ century. Conversely, it was the working class and other disenfranchised social groups which became increasingly overweight in the latter half of the $20^{\text {th }}$ century due to the fact that the cheapest manufactured foods were also the unhealthiest.

This section has demonstrated that from the $18^{\text {th }}$ century onwards notions of individual moral success were tied into notions of capitalist virtue. Specifically, this linking occurred around understandings of calorific efficiency and diet. This association also influenced notions of individual success in the $20^{\text {th }}$ century. $20^{\text {th }}$ century successful capitalist bodies would ideally be thin and industriously efficient. The BCM draws upon this form of economic moral logic in its behavioural and individual responsibility approach to obesity causality. In doing so, the BCM equates bodily health with capitalist virtue.

\footnotetext{
${ }^{41}$ M. Cohen, Health and the Rise of Civilisation (New Haven: Yale University Press, 1989), 71

${ }^{42}$ Polivy \& Garner, "Causes and Consequences," 91.

${ }^{43}$ Bordo, Unbearable Weight, 197.
} 


\subsection{Obesity, Class, and Critiques of Capitalism}

Classical understandings of economics have pitted liberal capitalist arguments against the Marxist view. In the previous section, we considered the development of liberal notions of the body as an independent individual project living in a meritocracy based upon a calorifically level playing field. Here, I highlight the association between class and body shape. I then provide an overview of Marxist understandings of the relationship between health and class. The Marxist argument sets out to explain that notions of health based upon individual merit are flawed because of class based structural divisions in Western societies. I consider this argument briefly here given that this overview is crucial to understanding the health inequality I discuss later in the chapter. Additionally, the Marxist understanding of health helps us to further understand the MCM and the ECM.

For almost two centuries the unequal relationship between the working class and the wealthy has been a central theme of Marxist theory. In his discussion of Marxist sociology of health, Kevin White argues that this view perceives the capitalist economic system itself as systematically producing higher mortality rates in the working class. He argues that the way the disease is treated will reflect the capitalist organisation of that society. ${ }^{44}$ This organisation commodifies the needs of the sick turning them into an object of financial exchange for the benefit of the wealthy. White goes onto explain that the profession of medicine plays

[A] central role in obscuring the way in which capitalism produces disease and death. By explaining to individuals that their diseases and illnesses are purely biological, or the outcome of freely chosen lifestyles, doctors perform the ideological function of obscuring the real causes of disease: the capitalist structure of the economic system. ${ }^{45}$

In White's reading, medicine prioritises the interests of elites and obscures their material interest in order to maintain the status quo. Thus, arguments about inequality tend to be overlooked because they reveal the unequal class structure of society. One result of class inequality is Marxists understand illnesses such as obesity to be produced by the material conditions in which we live. Those people living in poorer circumstances are more likely to become obese than those living in wealthier circumstances. ${ }^{46}$ The Marxist view is that the material conditions which cause obesity are obscured by rhetoric, such as the BCM, which

\footnotetext{
${ }^{44}$ Kevin White, "Theories About Health and Society," in Health and Society in Aotearoa, New Zealand, ed. Peter Davis and Kevin Dew (Auckland: Oxford University Press, 1999), 20.

${ }^{45}$ Ibid., 21.

${ }^{46}$ Kate Pickett, Shona Kelly, Eric Brunner, Tim Lobstein and Richard Wilkinson, "Wider Income Gaps, Wider Waistbands? An Ecological Study of Obesity and Income Inequality," Journal for Epidemiology and Community Health no. 59 (2005): 670.
} 
argues that obesity is a lifestyle disease resulting from people freely making poor health choices. This argument concerning the obscuring of material conditions is central to the MCM and ECM.

Marxist understandings of health are also central to certain public health approaches to disease. Marxist medical sociologists have argued that the primary reason for increased longevity occurring in industrialised nations since 1900 has not been due to improved medical care or increasing the promotion of health behaviours but has resulted from the changes to the material conditions of everyday life. ${ }^{47}$ It was the development of understandings of sanitation and public health that produced the increases in health in the $19^{\text {th }}$ and $20^{\text {th }}$ centuries. Marxists find that the qualitative experience of different health environments is associated with varying socio-economic positions. Thus, the poor and disadvantaged live in far less healthy environments than do more economically privileged people. In this view, disease causality, health status, and obesity prevalence are ultimately determined by the material environment in which one lives, not one's choices. As a result, those who ignore arguments about class tend to point to individual behavioural explanations of disease causation leaving them free to blame individuals for their illnesses rather than the material conditions in which people live:

The dominant class supports a conception of illness as an individual phenomenon and denies the salience of social structures in the production of ill-health.... From a Marxist perspective contemporary capitalist health-care organisation systematically neglects the environmental, occupational, and social production of disease. ${ }^{48}$

The Marxist tradition has contributed to environmental understandings of disease and provides insight into why some public health researchers promote ECM or MCM understandings of obesity causality. These obesity models need to be understood as drawing upon a Marxist tradition that emphasises that the material conditions (environment) of a society help to produce disease. The distinction between the two models is that the ECM locates responsibility solely on the environment and ignores the fact that behaviour is another important causal factor of obesity. In contrast, the MCM compromises and locates causality in a combination of factors.

\footnotetext{
${ }^{47}$ Dennis Raphael, “Social Determinants of Health: Present Status, Unanswered Questions, and Future Directions," International Journal of Health Services 36 no.4 (2006): 655.

${ }^{48}$ White, "Theories About Health and Society," 23.
} 
Marxist approaches underpin regulatory approaches to Government and public health such as those we have seen in the ECM and MCM. Mello et al argued that the greatest ally for proponents of public health is the law: ${ }^{49}$

The public health law approach posits that the law can be used to create conditions that allow people to lead healthier lives and the Government has both the power and the duty to regulate private behaviour in order to promote public health. ${ }^{50}$

Mello et al also make the argument that successful experiences of State level public health intervention for tobacco and alcohol provide impetus for further interventions when it comes to the supply of foodstuffs to the population. ${ }^{51}$ The authors are also aware that anti-obesity laws encounter resistance because they are considered to be 'paternalistic' interventions into lifestyle choices and enfeeble the notion of personal responsibility. ${ }^{52}$ The difficulty for public health law advocates lies with providing 'proof' that the food industry actually causes harm. ${ }^{53}$ Thus, public health understandings of obesity tend to be aligned with ECM policy.

This section has outlined the basic Marxist critique of capitalist and BCM notions of health and individual responsibility. It has shown that Marxists dispute the notion that it is laziness which produces poor health and economic position. Instead, they argue that the structure of capitalism produces disease and death in a way that privileges the wealthy to the detriment of the lower classes. Thus, the bodies of the wealthy are likely to have better health than the poor. Variations of this critique of capitalism are still central to the ECM, which places blame for obesity squarely on unrestrained markets. For example, Wilson et $\mathrm{al}^{54}$ argue in the NZMJ that "Market forces have led to the cheapest foods being the most obesogenic, undermining public health efforts to address obesity. ${ }^{" 55}$ The Marxist stance also contributes to the MCM to the extent that the MCM maintains that a combination of behavioural and environmental factors causes obesity. Moreover, as we will see the Marxist understanding of health was central to the Helen Clark Labour Government's focus upon health inequalities in the early 2000s.

\subsection{The Relationship Between Income and Health Inequality}

\footnotetext{
${ }^{49}$ Michelle Mello, David Studdert, \& Troyen Brennan, “Obesity - The New Frontier of Public Health Law,” The New England Journal of Medicine 354 no. 24 (June 15, 2006): 2601.

${ }^{50}$ Ibid., 2601.

${ }^{51}$ Ibid., 2601

${ }^{52}$ Ibid., 2602.

${ }^{53}$ Ibid., 2602.

${ }^{54}$ Nick Wilson, Richard Edwards and Osman Mansoor, "Economics Can Be Good For Health: Need For Rational Policy Without The Influence of Vested Interests," The New Zealand Medical Journal 120 no. 1263 (October 12, 2007):1.

${ }^{55}$ Ibid., 2.
} 
In this section, I explain the relationship between obesity prevalence and income inequality. I show that arguments that income inequality is correlated with healthy inequality were central components of early 2000s health research and policy. These arguments suggest that disease prevalence and higher mortality rates are all related to social and economic inequality. One outcome of these studies was the finding that income inequality is related to obesity prevalence.

A strict definition of inequalities is difficult to find in $\mathrm{MOH}$ publications and Labour Party policy and statements in the 2000s. ${ }^{56}$ In the NZMJ, Philippa Howden Chapman et al define the way in which social inequality produces health inequality: "Inequalities in the distribution of material resources, income, education, employment, and housing generate health inequalities. ${ }^{57}$ Howden et al note that countries which minimise economic inequalities are more likely to have healthy people. They found that the New Zealand Census $1996^{58}$ demonstrated widespread social inequality and explained the relationship between income and health inequality as follows:

These health inequalities do not just occur among individuals. People living in more deprived areas are more likely to have poor health and live shorter lives. At a regional level in New Zealand, income inequality (over and above household income) is adversely associated with both mortality and hospitalisation rates... The most pronounced social indicator of social inequality in New Zealand over the last two decades is the growth in income inequality. ${ }^{59}$

Howden Chapman et al commented further:

$[\mathrm{H}]$ ealth status is distributed as a gradient up the social hierarchy and applies to almost all causes of death - from cancer, cardiovascular disease and Alzheimer's dementia, to injuries. Individual health related behaviours such as smoking only partially explain the strong graduated relationship, and such behaviours are themselves socio-economically patterned. ${ }^{60}$

Here we see support for the Marxist health position in claims that health status is related to class. As a consequence, Howden et al note that health solutions which focus solely upon BCM explanations miss the point that most disease prevalence has a graduated relationship with incomes. This argument is central to this thesis and I will return to it at the end of this section.

\footnotetext{
${ }^{56}$ See: Ministry of Health, Reducing Inequalities in Health (Wellington: Ministry of Health, September 2002).

${ }^{57}$ Phillipa Howden-Chapman, Tony Blakely, Alison Blaiklock and Cindy Kiro, “Closing The Gaps,” The New Zealand Medical Journal 113 no.1114 (July 28, 2000): 301 .

${ }^{58}$ The New Zealand Census of Population and Dwellings, 1996: National Summary, Statistics New Zealand (Wellington, October, 1997).

${ }^{59}$ Howden-Chapman, Blakely, Blaiklock and Kiro, "Closing The Gaps," 301.

${ }^{60}$ Ibid., 301.
} 
Mortality rates are also correlated with income status. The material consequences of health and economic inequalities can be found in the differences in lifespan (mortality rates) between highest and lowest socio-economic group. ${ }^{61}$ In 2001, the MOH released information correlating income disparity with average life span. This research measured the difference in years of life between the richest and poorest people. It found that the wealthiest males live nine years longer than males in the lowest deprivation deciles and for females the difference was seven years between the two extremes. ${ }^{62}$ In 2002, Blakely et al released their Census Mortality study which provided an extensive study of the mortality reporting of the entire population. ${ }^{63}$ They found that their "results demonstrate strong socio-economic mortality gradients among adults for a range of socio-economic factors and a range of causes of death." ${ }^{64}$ Thus, by the early 2000s it was clearly established that income inequality was correlated with both disease prevalence and higher mortality rates.

In 2000, the Labour Government argued that health inequalities had arisen as a product of the economic reforms previous Governments. Labour claimed that "New Zealand household income inequality [had] increased sharply in the late 1980s and early 1990s." ${ }^{, 65}$ Labour accused this inequality of having ripped the heart out of the claim that New Zealand was a classless society. ${ }^{66}$ Labour argued that income inequality had impacted heavily upon lower socioeconomic groups and often includes Maori and Pacific Island peoples. ${ }^{67}$

In the period 2000-2004, the Labour Coalition focused its policy on addressing social, income, and health inequalities. Labour's approach employed the MCM, balancing causal explanations between behaviour, environment, and genetics. This provided a mandate to the Government to take a State-based interventionist approach to health care in the early 2000 s. ${ }^{68}$ Labour developed an intervention framework aimed at improving health and reducing inequalities, which Sarah Hill outlines as follows:

\footnotetext{
${ }^{61}$ Charlotte Paul, "Socio-Economic Factors and Death Rates," The New Zealand Medical Journal 115 no.1149 (March 8, 2002$)$ : 91 - 92.

${ }^{62}$ Ministry of Health, Life Expectancy and Small Area Deprivation in New Zealand, Public Health Intelligence Occasional Bulletin No 6 (Wellington: Ministry of Health, September 2001), 11.

${ }^{63}$ Ministry of Health, New Zealand Census Mortality Study: Socioeconomic Inequalities and Adult Mortality 1991 - 94 (Wellington: Ministry of Health, June 2002), iii.

${ }^{64}$ Tony Blakely, Alistair Woodward, Neil Pearce, Clare Salmond, Cindy Kiro, and Peter Davis, "Socio-Economic Factors and Mortality Among 25 - 64 year Olds Followed From 1991 to 1994: The New Zealand Census-Mortality Study," The New Zealand Medical Journal 115 no.1149 (March 8, 2002): 96

${ }^{65}$ Brian Easton, “Does Poverty Affect Health?” in “Understanding Health Inequalities in Aotearoa New Zealand,” ed. Kevin Dew and Anna Matheson (Dunedin: Otago University Press, 2008), 99.

${ }^{66} \mathrm{~K}$. Sinclair, A History of New Zealand (Auckland: Penguin Books, 2000), 328.

${ }^{67}$ Helen Clark, "Prime Minister's Post-Budget Speech To Parliament," http://www.beehive.govt.nz/node/7715 (last accessed March 11, 2010)

${ }^{68}$ Ministry of Health, Doing Better for New Zealanders: Better Health, Better Participation, Reduced Inequalities (Wellington: Ministry of Health, August 2002).
} 
This framework illustrates the way in which health inequalities reflect the unequal distribution of those resources that are the basic foundations for good health (structural determinants). Inequalities in these underlying factors are then played out along various pathways (intermediate pathways) - including biological, behavioural, and environmental experiences - and in the interaction with health services. ${ }^{69}$

These differing inequalities led to the MOH implementing in 2002/03 a health inequalities awareness programme for the health sector staff in the $\mathrm{MOH}$ and DHBs. ${ }^{70}$ In 2000 , the $\mathrm{MOH}$ addressed the MCM solutions for reducing income and health inequalities when they set up a National Health Committee (NHC) to address this problem. The NHC argued that intervention was required: "Improvements in the health status of the New Zealand population as a whole will not be achieved without reducing these inequalities." ${ }^{71}$ The NHC suggested that the way in which these inequalities could be reduced was through policies that changed the economic and social factors which caused this poor health. Other researchers have argued that primary health care could be improved by developing policies in non-health areas such as housing $^{72}$, education, transport, and employment that would then act downstream to reduce health inequality. ${ }^{73}$

The negative side of this social, income, and health inequality is generally referred to as 'social deprivation' by the independent Atlas of Social Deprivation NZDEP 2006 (NZDEP2006). NZDep2006 measures this inequality by implementing a "hybrid" Marxist Weberian approach to understanding social deprivation. ${ }^{74}$ It is Marxist in that it reflects the material conditions that define a group's geographic, economic and ethnic relations to society. This contrasts to a Weberian interest in the income and characteristics of individuals themselves. The Atlas states:

The social and structural relations between groups in any particular society have a broadly defined material basis that is determined by a group's access to productivity in relationship to the economy. This relationship is characterised by the group's effective control of resources. Exercise of this control exploits, dominates, alienates, and excludes other less advantaged groups. ${ }^{75}$

NZDep2006 argues here that certain ideological preferences of dominant groups will obscure the material inequalities within a society. Thus, the wealthy can then scapegoat the poor for

\footnotetext{
${ }^{69}$ Sarah Hill, "Socio-Economic Inequalities in Health," in Understanding Health Inequalities in Aotearoa New Zealand, ed. Kevin Dew and Anna Matheson (Dunedin: Otago University Press, 2008), 34.

${ }^{70}$ Ministry of Health, Tackling Inequalities: Moving Theory To Action, A Final Report on Health Inequalities Awareness Workshops For The Health Sector (Wellington: Ministry of Health, June 2004).

${ }^{71}$ National Health Committee, Improving Health For New Zealanders, 10.

${ }^{72}$ Lawrence Murphy, “To the Market and Back: Housing Policy and State Housing in New Zealand,” Geojournal 59 (2003): 125.

${ }^{73}$ National Health Committee, Improving Health For New Zealanders, 10.

${ }^{74}$ Paul White, Jinny Gunston, Clare Salmond, June Atkinson, \& Peter Crampton, Atlas of Socio-economic Deprivation in New Zealand NZDep2006, Public Health Intelligence Occasional Bulletin No.50 (Wellington: Ministry of Health, June 2008).

${ }^{75}$ Ibid., 6 .
} 
immoral choices without regard to the material environment's negation of choice. In 2006, the NZDep2006 argued that social deprivation takes place in different ways, distinguishing between social and material deprivation. Accordingly, those experiencing inequality may experience a single form of deprivation or multiple deprivations. ${ }^{76}$

Earlier versions of the NZDep had confirmed the relationship existing between obesity prevalence and social deprivation. In females, there was a strong relationship between obesity and NZDep96 quartile. Females living in NZDep96 quartile I areas had the lowest level of obesity (13.1 percent), compared with quartile IV areas (25.4 percent). ${ }^{77}$ In NZDep2001, obesity was clearly related to deprivation quintile as can be seen below:

\section{Figure 1: Obesity in adults, by NZDep2001 quintile and sex (age- standardised $)^{78}$}

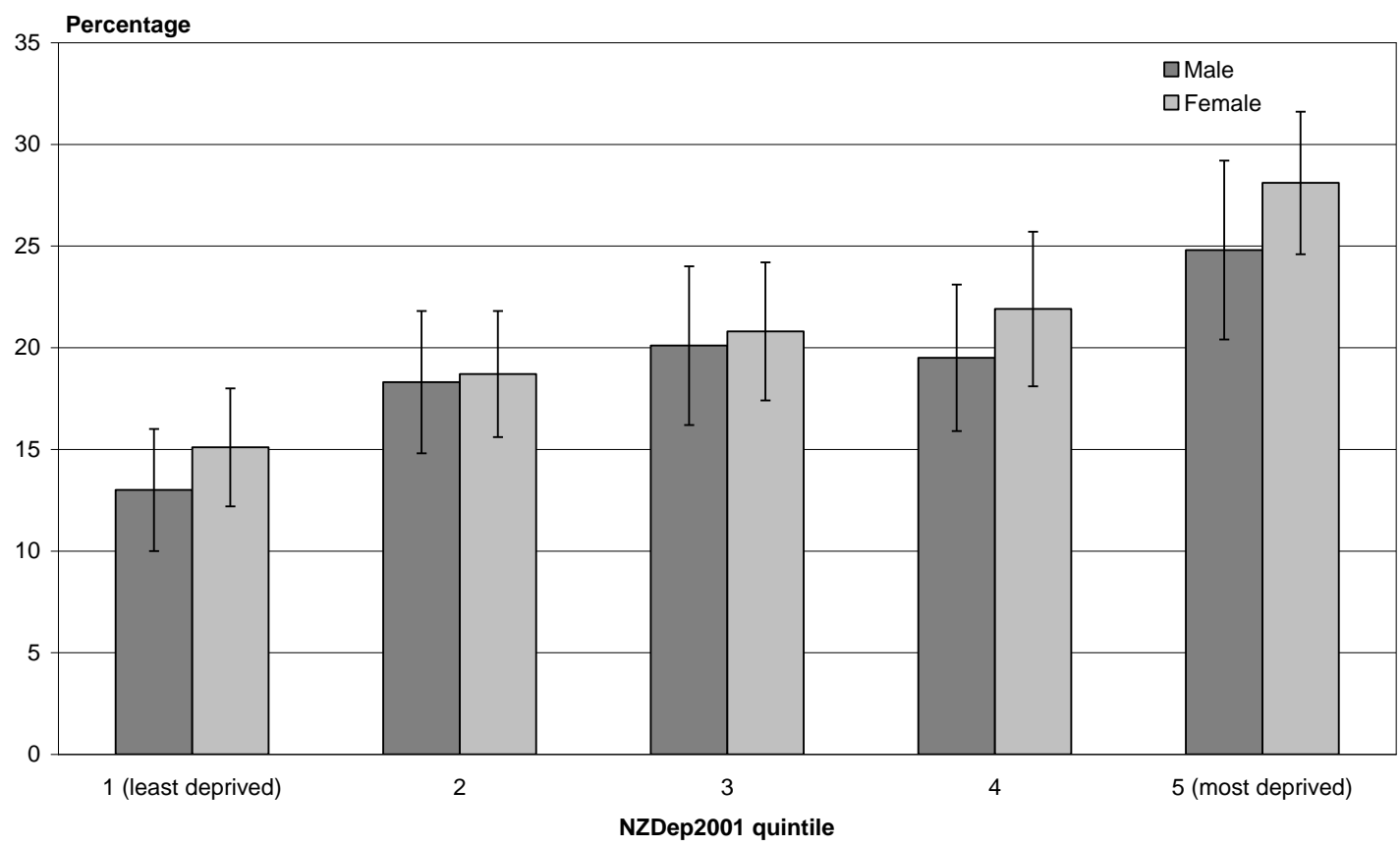

This research confirmed the Marxist view of the relationship between income and health inequality. This confirmation included evidence confirming that obesity rates shared the same gradient. This relationship is confirmed elsewhere: "In general, all socioeconomic status (SES) measures showed higher mean BMI levels and waist-to- hip ratios, higher odds of smoking, and

\footnotetext{
${ }^{76}$ Ibid., 5.

${ }^{77}$ Ministry of Health, 1997 National Nutrition Survey, 164

${ }^{78}$ Ministry of Health, A Portrait of Health 2002/03, 86.
} 
lower stature in the lower SES strata compared to the highest SES Stratum." ${ }^{\text {79 }}$ Metcalf et al ${ }^{80}$ clearly relate obesity prevalence to socio-economic status confirming that people in lower socio-economic positions suffer from increased rates of obesity and overweight than those in higher socio-economic groups. Simply put, poor people were more likely to be fat than rich people. This finding is consistent with meta-analyses of the relationship between obesity and income throughout the developed world. ${ }^{81}$

An unscientific example of the relationship between deprivation and obesity can found between the prices of Coke and milk. In my local supermarket Coke 1.5 litre bottles can sell for as little as \$NZ1.29 each whereas 1 litre of milk sells at approximately $\$$ NZ1.85. ${ }^{82}$ The Sunday Star Times recently found that the single most purchased item in most supermarkets is the 1.5 litre bottle of Coke; the third most purchased item is the 2.25 litre bottle of Coke and the eighth most purchased item is the 1.5litre bottle of Sprite Lemonade which is another Coke product. ${ }^{83}$ In many cases, unhealthy foodstuffs are cheaper than their healthy alternatives. These types of examples reinforce ECM arguments that it is unrestricted freemarkets, where unhealthy choices are the cheapest, which are creating environments which make people obese.

Obesity may be a disease of affluent countries, but it is not a disease of the affluent. We have seen in this section that social deprivation and income inequality are correlated with higher disease prevalence, mortality and obesity rates. Lower socio-economic group have a much higher risk of illness. Behavioural and choice-based arguments ignore the structural economic determinants and distribution of disease, mortality, and obesity prevalence. Therefore, moral arguments implying that gluttony and sloth cause obesity must be tempered by the recognition that society is not equal and obesity prevalence is unevenly distributed.

\subsection{Income and Health Inequality Today}

In this chapter I have argued that the correlation of obesity prevalence with socio-deprivation contests BCM explanations of obesity causality. However, those who employ the term 'health inequality' hold an ideological position arising out of the Marxist critique of capitalism. Thus, MCM and ECM viewpoints favour 'inequalities' approaches. The MCM-focused Labour

\footnotetext{
${ }^{79}$ Patricia Metcalf, Robert Scragg and Peter Davis. "Relationship of Different Measures of Socioeconomic Status With Cardiovascular Disease Risk Factors and Lifestyle in a New Zealand Workforce Survey,” The New Zealand Medical Journal 120 no.1248 (January 26, 2007$)$ : 1. 
Coalition foregrounded a politics of inequality between 2000 and $2004 .{ }^{84}$ However, for reasons I discuss in the following chapter, ${ }^{85}$ from 2004 our Governments have not prioritised inequalities language.

Different ideological viewpoints understand obesity prevention programmes as a cost or an investment. Those who hold that obesity is a state problem hold that obesity prevention programmes are an investment in reducing the future health care costs to the country. Whereas, those people who view obesity as an individual programme view these programmes as a cost. Thus, whether obesity programmes are considered a cost or investment is purely down to the ideological obesity causality model to which someone subscribes.

Despite the ideological politics surrounding the term inequality, the correlation between obesity prevalence and social deprivation highlights the fact that the problem of health and income inequality is still salient today. Inequality, like obesity, has not gone away despite the fact that it is not a specific ideological focus of the John Key National Coalition Government. Indeed, when the National Coalition was elected, medical commentators attempted to remind medical practitioners of the continuing existence of 'health inequalities.' In the NZMJ, National Heart Foundation Director Norman Sharpe stated:

As a new government is elected, it is timely to question the actual substance of our national commitment to the reduction and eventual removal of health inequalities in New Zealand. At a time of unusual global and national economic stress, it is crucial to confirm that quality and equity in healthcare are prerequisites for true economic wellbeing in the long-term. Environmental change and increased investment in health promotion and preventive care are vital, acknowledging the need for the careful balance needed between this investment and the ever increasing demand for clinical care. $^{86}$

Sharpe took pains to remind the newly elected Government that long term economic prosperity is contingent upon redressing inequalities. He argues that the removal of these inequalities will only come through environmental change and increasing the role of the State in terms of health promotion and preventative care. The National Heart Foundation attempted to persuade a neo-liberal and economic efficiency focused BCM Government to follow the

\footnotetext{
${ }^{84}$ See: "Helen Clark, Prime Minister's Post-Budget Speech To Parliament,"

Ministry of Health, Doing Better for New Zealanders: Better Health, Better Participation, Reduced Inequalities (Wellington: Ministry of Health, August 2002); Hill, "Socio-Economic Inequalities In Health,” 34; Ministry of Health, Tackling Inequalities; National Health Committee, Improving Health For New Zealanders, 10; Murphy, "To the Market and Back," 125

${ }^{85}$ In Chapter Eight, the cessation of MCM inequality politics is discussed in relation to the Orewa Speech.

${ }^{86}$ Norman Sharpe, "Reducing Health Inequalities: A Foremost Priority," The New Zealand Medical Journal 121 no.1285 (November 7, 2008 ): 1.
} 
language and goals of an ECM economic view of health and wellbeing. It is no surprise that these two groups have had little success in talking to each other.

A further example of the political and economic ideological divisions between the BCM and the ECM can be seen in the Green Party's current critique of the National Coalition. In 2010, current Green Party Co-Leader Metira Turei drew upon research suggesting that inequality rates had begun to grow again from 2006. ${ }^{87}$ Subsequently, much of Turei's political lobbying has been heavily focused upon using the problem of inequality to denigrate the policies of the incumbent John Key National Government. Thus, the problem of income and health inequality is still disputed by the BCM and ECM approaches to health.

The relationship between income inequality and obesity prevalence is a fact. However, it is also a fact recognised only by certain political viewpoints. It is important to foreground this disparity because this factual correlation between income inequality and obesity prevalence provides a substantial critique of the current BCM policy approach of the National Coalition. However, the argument that the ECM negates choice is equally important. ECM policy still benefits the wealthy over the poor because it is easier to change the environments of the rich than that of the poor. The point of these critiques is to demonstrate how mono-causal ideological explanations of obesity omit its material distribution. In the meantime, the obese remain unfairly scapegoated by these ideologies.

\subsection{Conclusion}

This chapter demonstrated that a global literature calculating the financial cost of obesity to nations emerged between 1997 and 2011. I argued that this literature contributed a financial dimension to systematic moralisation against the obese as it emphasised that obesity was a significant, imposed, and avoidable health cost borne by the State. This 'cost of obesity' literature was also replicated in New Zealand when Swinburn et $\mathrm{al}^{88}$ calculated a conservative estimate of the financial cost of obesity to the nation. One side effect of this analysis was that it portrayed the obese as negative contributors to our society. The obese are portrayed as having failed in their economic obligations to their State, employer, and family, all of whom, this literature argued, must bear the costs associated with obesity. Thus, this 'cost of obesity' literature overtly moralised against the obese for imposing these costs upon others. This

\footnotetext{
${ }^{87}$ Metira Turei, “Inequality in Aotearoa: A Brief History of Inequality,"

http://blog.greens.org.nz/2010/04/06/inequality-in-aotearoa-a-brief-history-of-inequality/ (accessed October $\left.7^{\text {th }}, 2010\right)$.

${ }^{88}$ Swinburn, Ashton, Gillespie, Cox, Menon, Simmons and Birkbeck, "Health Care Costs of Obesity in New Zealand," 894.
} 
literature also provided Governments with compelling financial reasons to be concerned about obesity and helped fuel obesity as a topic of political concern. One further consequence of this argument was that it aided the findings of the NNS97 create 'the political spectrum of obesity causation models' and its demand to allocate responsibility for these costs.

The chapter then outlined the ideological differences existing in the economics of obesity. ${ }^{89} \mathrm{I}$ showed that notions of economic efficiency were related to the development of scientific understandings of the calorie. This calorific understanding of the body led to understandings of the obese body being economically inefficient and self-indulgent because it consumed more than was optimally required. This led some commentators to argue that a morality, which I associate with the BCM, was linked with capitalist virtue and notions of the body. Moreover, this morality was tied to notions of dietary discipline and responsibility. The linking of the body to capitalist notions of success associated the thin body with the upper class. In contrast, fat working class bodies signified their lack of economic success and this was blamed upon the behaviours of idleness and sloth.

The Marxist critique of this association was that capitalist society systemically produces higher mortality and disease rates amongst the working class. This position contests the BCM argument that individuals become obese through poor choices given that lower socioeconomic groups live in material conditions which systemically disadvantage them. Poor housing, education, and low-paid jobs are all factors which additionally contribute to illness. Thus, for Marxists, the BCM creates a false consciousness that perpetuates the moral and economic values of the wealthy when it blames behaviour and individual choice for obesity.

This Marxist position highlights the correlation between health inequality, social deprivation, and the prevalence of obesity. It shows that, across the board, lower socio-economic groups have higher disease prevalence and higher mortality rates than higher socio-economic groups. As a consequence, New Zealand's lower socio-economic groups have much higher prevalence of obesity than is found in higher socio-economic groups. The BCM omits this correlation between class, inequality, and obesity prevalence. Accordingly, I argue that BCM moral arguments which associate gluttony and sloth with obesity causality need to be tempered by

\footnotetext{
${ }^{89}$ I did not discuss the contested economic notions of choice and obesity. For a New Zealand specific example of this problem see: Eric Crampton, "Taxes An Invasive Way of Guiding Choices," (Christchurch: The Press, Monday December 17, 2007), B5; Wilson, Edwards and Mansoor, Economics Can Be Good For Health, 2; Eric Crampton, “Economics Can Be Good For Health, But It Needn't Be So Dismal,” The New Zealand Medical Journal 120 no.1263 (October 12, 2007): 2; Richard Edwards, Nick Wilson and Osman Mansoor, “Taxes For Health: The Argument Is More About Health Than Economics," The New Zealand Medical Journal 120 no.1264 (October 26, 2007$): 1$.
} 
the recognition that our society is not equal. BCM language unjustly moralises against the obese without recognition of the unequal distribution of disease.

The current National Coalition Government is not overly concerned with this relationship between health and income inequality, as is evident in its BCM focus. However, the fact that the $\mathrm{BCM}$ omits mention of inequality does not mean that health inequality does not exist within society. Moreover, the Marxist critique suggests that the current BCM approach of devolving responsibility for obesity onto individuals will likely further perpetuate this systemic health inequality. It is possible that this current BCM approach might fuel a larger inequality problem, which subsequent ECM and MCM governments could then use to pursue their own ideological agendas. Another significant danger exists here, too, as it is likely that the ideological nature of obesity discourse will endlessly shuttle the obese to and fro between these two opposing systems of governance without ever directly addressing the ideological perpetuation of this health problem. As such, the political nature of obesity discourse and its mono-causal explanations creates the conditions to prevent an actual solution to the very problem it sets out to address. Caught between these obesity models, the obese have become the scapegoats of larger ideological societal divisions. Consequently, the obese they have to bear the emotional, mortal, health, and economic costs of their bodies.

This correlation between income inequality and obesity prevalence still requires additional analysis. In the following chapter, I turn to another complicating factor, that of ethnicity. Ethnicity is correlated with both income inequality and obesity prevalence. Thus, as I will explore in Chapter Eight, Maori and Pacific Island peoples have much higher population prevalence of obesity and poverty than Europeans or Asian New Zealanders. 


\section{Chapter Eight: Ethnic Inequality and Obesity}

Unfortunately New Zealand has had faster growth in inequality than any other country in the developed world. That is shameful. In our country that inequality has had a unique and unfortunate dimension. There has been a growing disparity between the life chances of Maori and other New Zealanders, and Pacific peoples and other New Zealanders. It is simply not tolerable to this government to see tangata whenua consigned permanently to the status of disadvantaged citizens in their own land. It is not acceptable. ${ }^{1}$

Helen Clark 2000

We are one country with many peoples, not simply a society of Pakeha and Maori where the minority has a birthright to the upper hand, as the Labour Government seems to believe. ${ }^{2}$

Don Brash 2004

\subsection{Introduction}

This chapter explores the relationship between ethnic inequality and health status. Ethnicity is an additional variable in the relationship between health status and inequality. I argue that by failing to acknowledge the ethnic dimensions of obesity prevalence the BCM and ECM are flawed explanatory models for obesity causality. These models incorrectly moralise against single obesity causes and effectively neglect to mention that entire ethnic groups constitute the obesity burden or are those accused of the behavioural sins of gluttony and sloth. In tracking the ethnic dimensions of obesity prevalence, I demonstrate that more nuanced causal explanations are required for effective discussion of obesity.

In this chapter, I review the empirical evidence that demonstrates the existence of a relationship between ethnic inequality and health disparity. I show that Maori, Pacific Island, and Asian populations all deviate from the health norms imposed by Euro-centric models of health. Specifically, I concentrate upon the relationship between ethnicity and the Body Mass Index (BMI). I find that the obesity models neglect to mention that the majority of obesity prevalence is found in specific non-European ethnic groups. In the conclusion, I argue that the ramifications of ethnic dimensions of obesity necessitate that the 'political spectrum of obesity causation models' is ideologically limited and must be reconsidered.

\footnotetext{
${ }^{1}$ Helen Clark, "Prime Minister's Post-Budget Speech To Parliament, $16^{\text {th }}$ June 2000."

${ }^{2}$ Don Brash, "Orewa Speech - Nationhood, 27th January, 2004.”

http: / / www.national.org.nz/speech_article.aspx?ArticleID=1614 (accessed 11 th November, 2010).
} 


\subsection{Two Forms of Inequality}

A key theme of this chapter is the ideological tension between those who promote health interventions at a general population level and those who argue for ethnic specific interventions for obesity treatment. This chapter opened with a quote from Prime Minister Helen Clark's Closing the Gaps ${ }^{3}$ budget speech which claimed that two forms of social inequality existed: economic inequality and ethnic inequality. Helen Clark's and Don Brash's quotes illustrate this conflict because they clash over whether the State should specifically preference Maori. Simply, there is friction between those who want a society to be based upon equality and those who argue that society is not equal and specific groups within the population need to be treated differently to rectify this inequality. Inequality politics was a focus of the MCM Labour Government between 2000 and 2004. The Labour Government's inequality politics was originally oriented toward Maori but this policy approach would be later reframed away from an ethnic specific policy. ${ }^{4}$ In this section, I outline the arguments which claim that specific ethnic groups experience certain types of systemic discrimination ${ }^{5}$ and that in determining health status ethnicity should be treated as a separate variable from income.

In my research, political statements promoting inequality inevitably hold a political bias towards interventionist governments such as the MCM Labour Government. For example, one recent explanation of inequality comes from Public Health researcher Sarah Hill, who argues that there are two specific factors at play in ethnic inequality. The first factor is socioeconomic position and the second is that ethnic inequality is also a product of the social effects of colonisation and an Anglo-centric institutional racism or discrimination. ${ }^{6}$ Hill's view is that a mediating influence, such as an active State, is required to acknowledge and rebalance this inequality.

Hill goes on to indicate that the experience of ethnic socio-economic inequality is a global problem for minority ethnic groups. Hill's view is that Maori and Pacific Islands people experience the effects of socio-economic inequality because they are underrepresented in the distribution of material resources in the nation. This under-representation is either due to the effects of colonisation (Maori) or immigration (Pacific Islanders). Under Labour, the $\mathrm{MOH}$

\footnotetext{
${ }^{3}$ Helen Clark, "Prime Minister's Post-Budget Speech To Parliament, $16^{\text {th }}$ June 2000."

${ }^{4}$ Louise Humpage and Augie Fleras, "Intersecting Discourses: Closing the Gaps, Social Justice and the Treaty of Waitangi,” Social Policy Journal of New Zealand no.16 (July 2001): 50.

${ }^{5}$ Discrimination is often referred to as racism.

${ }^{6}$ Hill, "Socio-economic inequalities in health," 36.
} 
took this critique seriously, publishing Monitoring Ethnic Inequalities in Health in 2001 in an effort to explain the two forms of inequality:

Few would disagree that the socioeconomic location of the Maori ethnic group today is largely a consequence of the experience of colonisation (with its associated alienation of land and economic collapse). By contrast, that of the Pacific ethnic group largely reflects the experience of international migration (with its associated employment in low-skilled manufacturing 'sunset' industries). However, maintenance of these socioeconomic locations today may be at least partly the result of more recent - and ongoing - experience of discrimination by Maori and Pacific Island peoples, at both institutional and personal levels. ${ }^{7}$

In this bulletin, the MOH echoes Hill's argument that socio-economic position and discrimination cause poor health among Maori and Pacific Island peoples. The MOH too suggests that discrimination is one additional factor affecting ethnic equality:

[E]thnicity is both a marker of socioeconomic location (structural dimension) and an aspect of one's identity (cultural dimension). The report proposes that underlying both structural and - to a lesser extent - cultural dimensions of ethnicity are discrimination (institutional and personal racism). Discrimination also has a direct impact on health, acting through psychological pathways. These three dimensions of ethnicity - structure, identity and the direct experience of discrimination - are thought to interact with each other and with age, gender and social class to generate the observed health inequalities. ${ }^{8}$

The MOH argues that ethnic differences in health status were caused by a social and material environment which systematically discriminated against and economically disadvantaged certain ethnic, gender, and class groups. Monitoring Ethnic Inequalities in Health thus made arguments for State-based strategies to rectify ethnic health inequality: "Clearly, policies to redress ethnic health inequalities will need to include strategies aimed at both redistribution (socio-economic disadvantage) and recognition (cultural devaluation and the personal experiences of racism)." The report ultimately argues that the solution to systemic disadvantage is the State-organised redistribution of wealth and the recognition that the political institutions and social and economic structures are Anglo-centric.

In Chapter Six, I argued that the obesity models scapegoat and misassign blame for obesity causality without looking to the ethnic and income locatedness of obesity. As this chapter develops, the inadequacy of the obesity models to address the various ethnic dimensions of

\footnotetext{
${ }^{7}$ Ministry of Health, Monitoring Ethnic Inequalities in Health, Public Health Intelligence Occasional Bulletin no 4 (Wellington: Ministry of Health, June 2001), 30.

${ }^{8}$ Ibid., 1 .

${ }^{9}$ Ibid., 31.
} 
obesity prevalence will be illustrated. The discrimination experienced by ethnic groups in health demonstrates the real problem of omitting ethnicity from obesity discourse.

\subsection{Inequality by Ethnic Group}

Despite the politically biased nature of inequality discourse, significant empirical evidence exists demonstrating that ethnic inequality is a separate variable from income inequality when it comes to health inequality. The findings of the New Zealand Census Mortality Studies (NZCMS) and the New Zealand Social Deprivation Index (NZ Dep2006), for instance, point to the existence of significant ethnic inequality in both socio-economic status and mortality rates. Both these reports demonstrate that ethnicity is an additional factor for determining inequality.

The NZCMS supplies strong evidence for ethnic disparities in health status. The NZCMS found that death certificate recordings of ethnicity did not always match the ethnicity identification made by the deceased in the Census. This problem is defined as the "numeratordenominator bias." ${ }^{10}$ The NZCMS found that all mortality data produced before 2001 had under-reported the rates of Maori and Pacific Island mortality. The NZCMS authors stated:

It is clear that during the early 1990s there were large numerator-denominator biases between census and mortality data that caused both Maori and Pacific mortality rates to be severely underestimated even using census sole ethnicity as the denominator. The extent of this under estimation disguised the true extent of the ethnic disparities in mortality. These estimates were particularly severe for Pacific people, and young Maori and Maori living in central and southern regions. The results from this study should be used to adjust ethnic specific mortality rates for the early 1990 s. $^{11}$

The NZCMS research revealed that the method of recording mortality had obscured real differences in mortality rates amongst ethnic groups. Accordingly, when the NZCMS research team adjusted the mortality rates for the numerator-denominator bias between1991-1994, they found that ${ }^{12}$ mortality rates for Maori between the ages 0-74 were significantly higher than previously estimated. ${ }^{13}$ The authors determined that: "both ethnicity and SES [SocioEconomic Status] are important determinants of mortality (and more generally health) in New Zealand, and SES 'explains' some (perhaps the majority) of ethnic inequalities." ${ }^{14}$ The NZCMS work resulted in several $\mathrm{MOH}$ publications ${ }^{15}$ and NZMJ articles providing mortality data

\footnotetext{
${ }^{10}$ Blakely, Robson, Atkinson, Sporle and Kiro, “Unlocking the Numerator-Denominator Bias. I,” 39.

${ }^{11}$ Ibid., 42.

${ }^{12}$ Blakely, Kiro, and Woodward, "Unlocking the Numerator-Denominator Bias. II. 43.

${ }^{13}$ Ibid., 48 .

${ }^{14}$ Ibid., 47.

${ }^{15}$ Ministry of Health, Decades of Disparity: Ethnic Mortality Trends in New Zealand 1980 - 1999, Public Health Intelligence, Occasional Bulletin no.16, (Wellington: Ministry of Health, July 2003).
} 
adjusted for the numerator-denominator bias. ${ }^{16}$ Moreover, while European mortality rates had been slowly decreasing over the past two decades, NZCMS research found Maori and Pacific Island mortality rates had not declined. This NZCMS result found significant and increasing disparities in health status, indicating that Maori and Pacific Islanders had lower health status than Europeans. ${ }^{17}$ Coupled with the consistent underreporting of ethnicity on death certificates, these disparities suggested that the health system had been oblivious of the real state of mortality inequality experienced by Maori and Pacific Island people.

An additional indicator of ethnic inequality is supplied by measures of social deprivation by ethnic group. This discussion shows that ethnic groups are unevenly distributed when it comes to deprivation measures. In 2006, the NZ Dep2006, measuring ethnic group deprivation, was released. In addition to having higher mortality rates than Europeans, Figure $8^{18}$ shows that Maori and Pacific Islanders are the most socially deprived ethnic groups in the country.

Figure 8 , demonstrates that deprivation is distributed unequally by ethnic group and that the nation's most deprived peoples tend to be Pacific Islanders and Maori. ${ }^{19}$ In the NZ Dep2006 graph, the entire population is divided into 10 deciles of deprivation. The rankings 1-10 are distributed with 1 being the least deprived and 10 being the most deprived. This graph then correlates these 10 deciles with ethnicity. NZDep2006 shows that $35.7 \%$ of Pacific Island peoples and $24.1 \%$ of Maori lived in the lowest deprivation decile. Moreover, for both these ethnic groups, more than $60 \%$ of their entire population live in the lowest three deciles of deprivation. These findings indicate that significant disparities exist between ethnic groups in the nation.

Taken together, the results of the NZCMS and the NZDep2006 provide strong evidence for the existence of ethnic inequality in socio-economic status and mortality status for Maori and Pacific Island peoples. The measures of socio-economic status and mortality status both correlate with health inequality, indicating that these population groups experience lower health status than European and Asian populations. Thus, despite inequality discourse having an ideological dimension, there is sufficient evidence to demonstrate the existence of real ethnic inequalities in health status.

\footnotetext{
${ }^{16}$ Tony Blakely, Shilpi Ajwani, Bridget Robson, Martin Tobias, Martin Bonne, "Decades of Disparity: Widening Ethnic Mortality Gaps From 1980 to 1999," The New Zealand Medical Journal 117 no. 1199 (August 6, 2004).

${ }^{17}$ Ibid., 16.

${ }^{18}$ White, Gunston, Salmond, Atkinson, and Crampton, "NZDep2006,” 22.

${ }^{19}$ For the NZDep2006 methodology see: Ibid, 7.
} 
Figure 8: NZDep2006 profile of New Zealand

ethnic groups

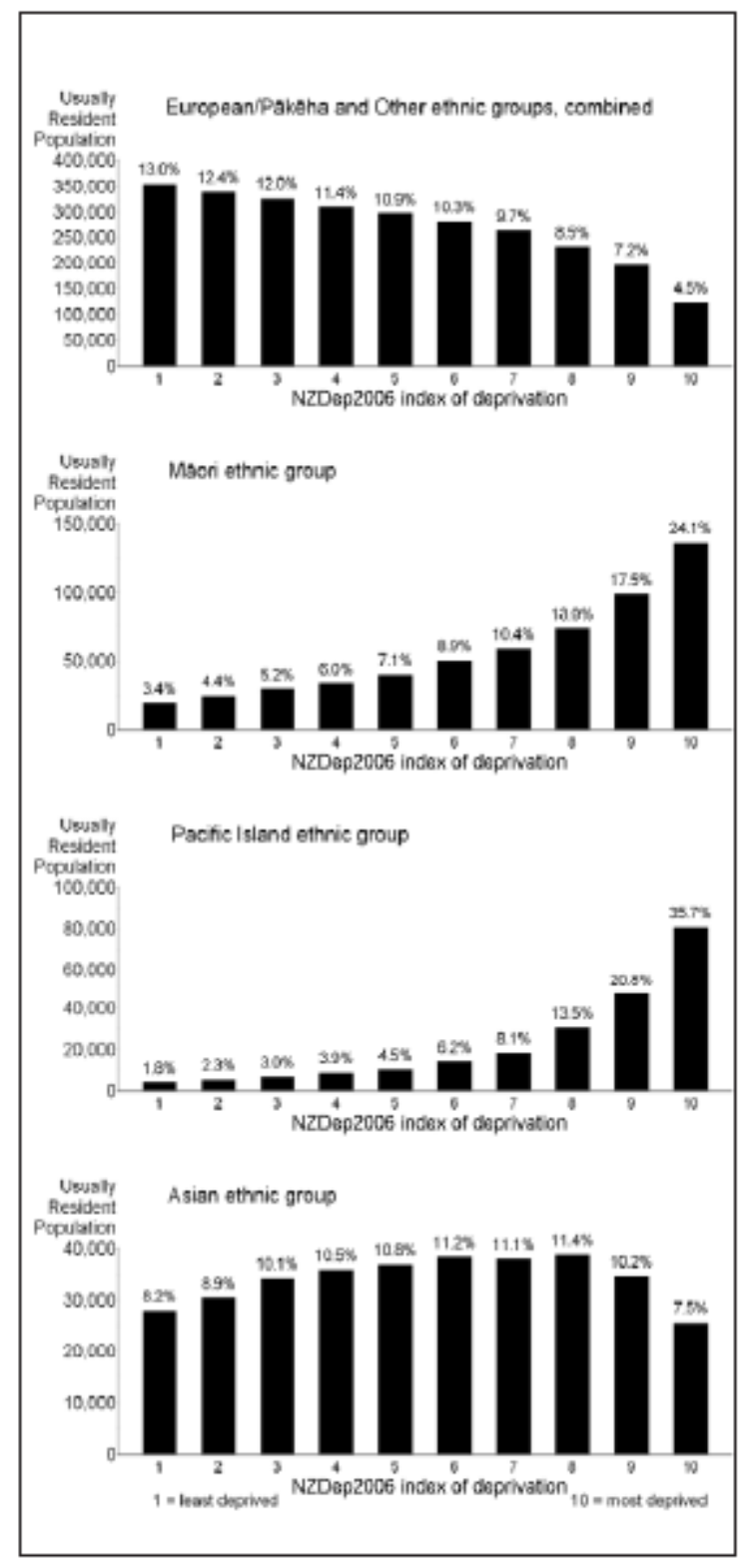

Source: Census of Population and Dwelings 2008.

\subsection{Ethnic Contestations of BMI}

The question of whether ethnic groups have specific biological differences and/or propensities for obesity is contentious. By the late 1990s, evidence existed that ethnicity was potentially an independent variable when it came to health inequality and disease prevalence. These arguments produced research which claimed that ethnic specific BMI measurements were the only effective measure of BMI. As a result, the NNS97 and NZHS02/03 used ethnic specific BMI ranges. 
Measuring BMI by ethnic group is a difficult process. For example, at times Pacific Health is equated with Maori Health. Moreover, often Maori statistics are compared to the non-Maori population as a whole rather than to specific ethnic groups. The result of this form of comparison is that it neglects the fact that non-Maori averages hide evidence which indicates that other ethnic groups (such as Pacific Island peoples) may actually experience similar or even worse health disparity than Maori. This obfuscation is sometimes accidental or simply statistically convenient, but at other times it indicates the privileging of a bi-cultural understanding of inequality over a multi-cultural understanding of inequality. This bi-cultural preference of medical research into Maori, rather than Asian or Pacific Island groups, emerged in the mid 2000s and so far has not been rectified.

Until 1998, the BMI of Maori and Pacific Islanders was measured using the same classification range as Europeans. ${ }^{20}$ In 1998, then Medical Director of the New Zealand Heart Foundation, Boyd Swinburn, released several articles arguing that Pacific Island Peoples and Maori had a higher bone density than European and Asian peoples. ${ }^{21}$ He concluded that Pacific Island peoples and Maori should have their BMI ranges adjusted from the BMI ranges used by the remainder of the population (European and Asian peoples). Swinburn argued that Pacific and Maori ethnic groups should be regarded as overweight if they have a BMI of 26-31.99 and obese if they have a BMI of $\leq 32$. The statistical effect of these adjusted ranges increased the weight to height ratio at which members of these ethnic groups were recorded as being obese or overweight. These new ethnically adjusted BMI ranges for Maori and Pacific Islanders were utilised by the NNS97 and the NZHS02/03 nutrition surveys, can be seen in Table $1 .^{22}$

\footnotetext{
${ }^{20}$ World Health Organisation, "Obesity: Preventing and Managing the Global Epidemic."

${ }^{21}$ Boyd Swinburn, Ley SJ, Carmichael HE, Plank LD. "Body Size and Composition in Polynesians," International Journal of Obesity 23 (1999). Boyd Swinburn, "Using the Body Mass Index: Weight Then Weigh Up,” New Zealand Medical Journal 111 (1998), 1178.

Boyd Swinburn, Craig P L, Daniel R, Dent D P D, and Strauss B J. "Body Composition Differences Between Polynesians and Caucasians Assessed by Bioelectrical Impedance," International Journal of Obesity, 20 (1996): 889.

${ }^{22}$ Ministry of Health, Body Size Technical Report, (Wellington: Ministry of Health, June 10, 2008), 12.
} 
Table 1: Classifications of overweight and obesity according to BMI $\left(\mathrm{kg} / \mathrm{m}^{2}\right)^{23}$

\begin{tabular}{|l|l|l|}
\hline Classification & $\begin{array}{l}\text { European, Asian and } \\
\text { Other }\end{array}$ & Maori and Pacific \\
\hline Overweight & $25.0-29.9$ & $26.0-31.9$ \\
Obese & $\geq 30.0$ & $\geq 32.0$ \\
Overweight or obese & $\geq 25.0$ & $\geq 26.0$ \\
\hline
\end{tabular}

The NNS97 results utilised Swinburn et al' ${ }^{24}$ adjusted BMI measurements. The results of the NNS97 provided definitive information regarding the nutritional status of Maori and indicative measures for Pacific Island peoples for the first time. ${ }^{25}$ The NNS97 ethnicity BMI measurements found:

NZ Maori (males 27.0 percent, females 27.9 percent) and Pacific people (26.2 percent, 47.2 percent) were more likely to be classified as more obese than NZ European \& Others (12.6 percent, 16.7 percent). However, Pacific males were more likely to be classified as overweight (59.2 percent) than NZ European \& Others (41.0 percent) and NZ Maori (30.0 percent). NZ Maori males (30.0 percent) were less likely to be classified as overweight than NZ European \& Others (41.0 percent). ${ }^{26}$

In the NNS97, even using the adjusted rates, obesity and overweight prevalence for the Pacific Island and Maori populations were higher than the population average. $35 \%$ of the general population were classified as overweight and $17 \%$ were classified as obese ${ }^{27}$ Indeed, the use of Swinburn's adjusted BMI ranges instead of the WHO standardised BMI ranges prevented these NNS97 statistics being even higher again. Even with these adjusted BMI measures, the NNS97 demonstrated that obesity prevalence was unevenly located by ethnic group.

The New Zealand Health Survey 2002/2003 (NZHS02/03) also utilised Swinburn's adjusted BMI methodology. The ethnic group results of the NZHS02/03 for overweight and obesity prevalence can be seen in the figures in Figure 1. For the first time, the NZHS02/03 also

\footnotetext{
${ }^{23}$ Ministry of Health, A Portrait of Health 2002/03, 84.

${ }^{24}$ Swinburn, Ley, Carmichael, Plank. "Body Size and Composition."

Swinburn, "Using the Body Mass Index"

Swinburn, Craig, Daniel, Dent, and Strauss. "Body Composition Differences.”

${ }^{25}$ Tuariki Delamere, "Foreword" in Ministry of Health, New Zealand Food: New Zealand People: Key results of the 1997 National Nutrition Survey, (Wellington: Ministry of Health, 1999), ii.

${ }^{26}$ Ministry of Health, 1997 National Nutrition Survey, 164-5.

${ }^{27}$ Ibid., 164.
} 
included an ethnic category for Asian peoples. It also suggested that lower BMI cut-offs should be used for Asian peoples. However, the proposed cut-offs were not widely accepted and Asian peoples continued to be measured using the general range. ${ }^{28}$ The NZHS02/03 results show marked ethnic differences in obesity prevalence. In the general population 19\% of men and 21\% of women are considered to be obese. Maori and Pacific Island people recorded a prevalence of obesity significantly higher than the population average. Pacific Island peoples have the highest rates of obesity with $38 \%$ of men and $48 \%$ of women measured as being obese. Maori men had an obesity prevalence of $29 \%$ and Maori women 27\%. In comparison, the Asian population recorded an obesity prevalence of $4 \%$ for men and $6 \%$ for women. These three ethnic groups all showed radically different prevalence of obesity to the European population and the general population measures.

NZHS02/03

Figure 2: Overweight in adults, by ethnic group and sex (age-standardised) ${ }^{29}$

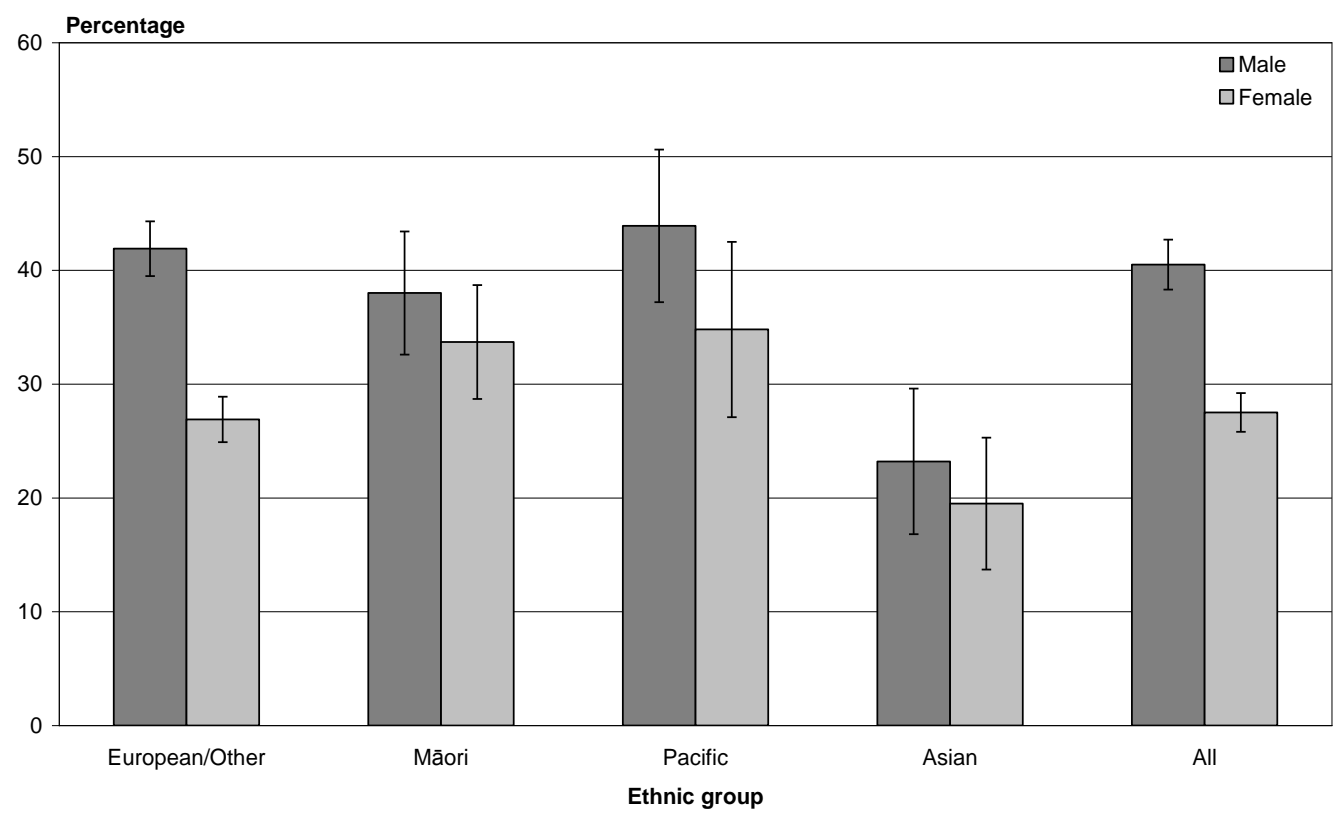

${ }^{28}$ Ministry of Health, A Portrait of Health 2002/03, 84.

${ }^{29}$ Ibid., 85. 
NZHS02/03 Figure 3: Obesity in adults, by ethnic group and sex (age-standardised) ${ }^{30}$

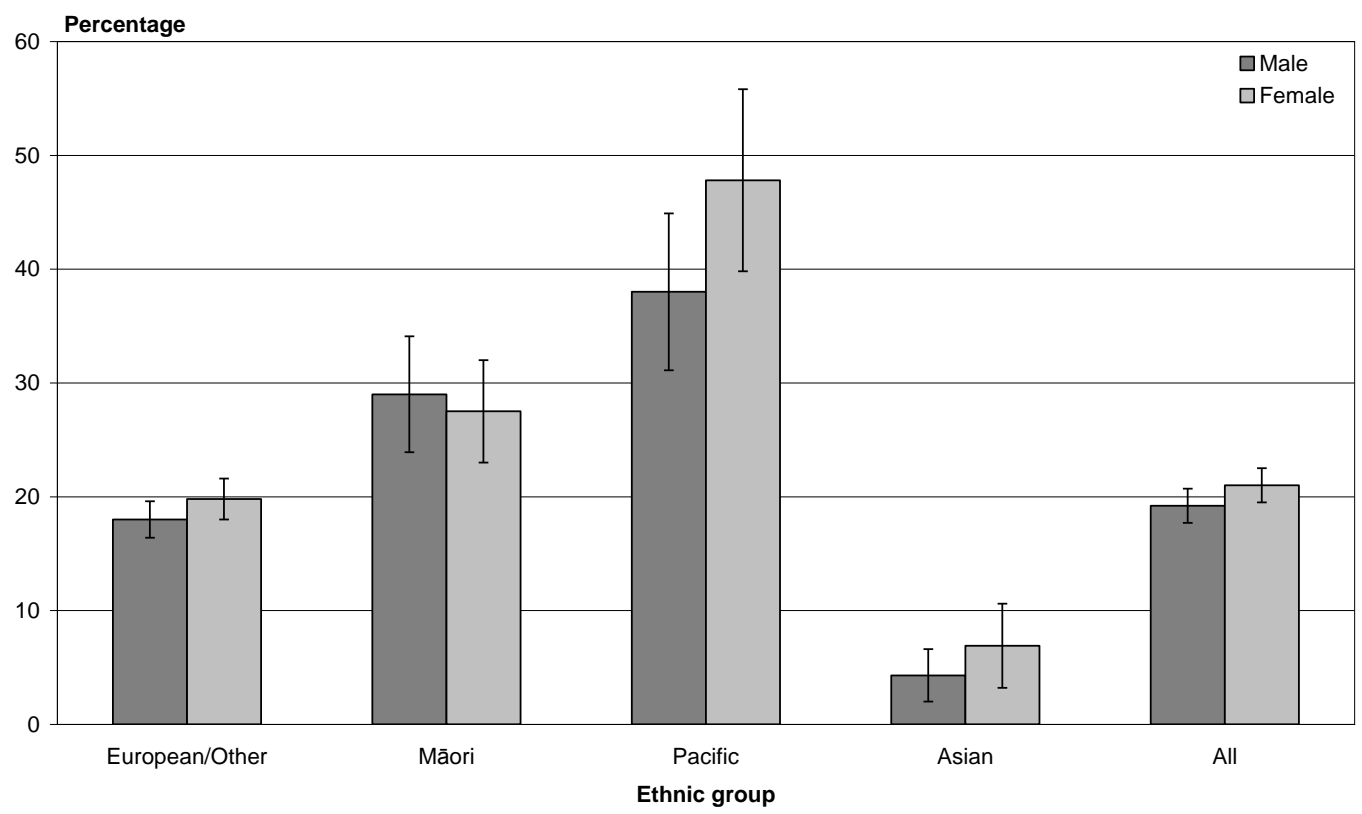

I argue that any form of obesity discourse that does not account for this uneven distribution must be treated with scepticism. This section demonstrated that Maori and Pacific Island peoples experience significantly higher rates of obesity than other ethnic groups. The NZHS02/03 indicated that the Asian population has a much lower incidence of obesity and overweight than the rest of the population. Taken together, these measures demonstrate that obesity is not equally distributed among the population. It also indicates that ethnicity may be an additional variable to income inequality for obesity prevalence. The use of Swinburn's adjusted BMI measures also indicated that Pacific Island and Maori people were considered as being biologically different from other ethnic groups, although this claim remains contentious.

\subsection{The Removal of Ethnic BMI Ranges in the NZHS06/07}

Today, ethnic differences in BMI still remain a controversial concept. ${ }^{31}$ The ethnic specific BMI ranges used in the NNS97 and NZHS02/03 were not used in the NZHS06/07. ${ }^{32}$ It has been recognised by the $\mathrm{MOH}^{33}$ that a number of problems exist preventing reliable ethnic specific measures of BMI. These include the need for international compliance and comparison and the problem of individuals identifying with more than one ethnic group. This section

\footnotetext{
${ }^{30}$ Ibid., 87.

${ }^{31}$ World Health Organisation, "Obesity: Preventing and Managing the Global Epidemic."

${ }^{32}$ Ministry of Health, Body Size Technical Report, 12.

${ }^{33}$ Ibid., 12.
} 
demonstrates that consensus on ethnic specific BMI is highly problematic. This logic resulted in population BMI ranges employing using generalised 'European' population measurements.

The NZHS06/07 stated a preference for moving back towards the international population standardised BMI range. ${ }^{34}$ The $\mathrm{MOH}$ rationalised this move by explaining the importance of complying with WHO standards released in 2004:

Although the WHO BMI cut-off points were developed primarily using data from populations of European origin, the health risks associated with increasing BMI are continuous and graded and begin at a BMI below 25 in all population groups.

Therefore, the most recent WHO Expert Consultation recommended that principal BMI cut-off points should be retained as the international classification for all adults. ${ }^{35}$

Two extra rationales were utilised by the MOH for returning to these standardised BMI ranges. The first was that there are no ethnic cut-off points for children and therefore BMI cannot be measured accurately between these groups without the standardised measure. ${ }^{36}$ The second rationale was that the increasing identification of individuals with multiple ethnic groups was complicating the use of ethnic specific BMI measures.

The effect of this change in BMI range was to increase the reported rates of Maori and Pacific Island overweight and obesity. However, this change made no difference to the overall population rate of obesity, which remained constant. However Maori and Pacific Island rates were higher: "Using the new anthropometric definitions, the unadjusted prevalence of obesity in 2006/07 was 42 percent for Maori adults and 64 percent for Pacific adults, compared to 26.5 percent for the total adult population." ${ }^{37}$ The return to standardised measures of obesity prevalence reaffirms my argument that generalised moral arguments about obesity prevalence fail to take into account that specific ethnic groups have very high average BMI.

In changing the measures used, the MOH acknowledged that Maori and Pacific Island peoples may indeed have a lower proportion of body fat at any BMI level. However, the standardised BMI ranges still identify an increased risk of health conditions associated with that BMI range rather than percentages of body fat to lean muscle per se. ${ }^{38}$ This indicates that ethnic specific BMI ranges are necessary but more research is required to develop valid, accurate, and

\footnotetext{
${ }^{34}$ Ibid., 12.

${ }^{35}$ Ibid., 12.

${ }^{36}$ Ibid., 13.

${ }^{37}$ Ibid., 16.

${ }^{38}$ Ibid., 16.
} 
systematically comparable measures of ethnic variation in BMI. Recent research indicates that there exist distinct differences in Body Fat (BF) percentages among adolescents from various ethnic groups. ${ }^{39}$ A large Auckland-based study suggests that the adoption of the 30+ BMI obesity classifications in non Western populations "may mask the true prevalence of obesity and the associated disease risk." ${ }^{40}$ Rush et al's research into BMI and BF percentages of European, Maori, Pacific, and Asian Indian peoples indicates that there is a wide disparity in measurements of BMI and BF between these populations. For example, Asian Indians have the highest percentage BF and the lowest BMI of all the surveyed ethnic groups. They also found that at a BMI of 30 Pacific Island Men had a BF percentage of 25\% while Asian Men at BMI 30 had a BF percentage of 37\%. ${ }^{41}$ Moreover, they also found that in both men and women the percentage of total fat as abdominal fat, regarded as one of the more dangerous forms of fat, was significantly higher in the Maori, Pacific Island, and Asian populations than it was in the European population. ${ }^{42}$

Obesity prevalence has ethnic dimensions but despite a decade of research, periods of heavy funding, and widespread public and media concern with the 'obesity epidemic,' it appears that there has been little progress in addressing this problem. Arguments claiming that certain ethnic groups are biologically different from others are contentious. It is clear that the shift back to a generalised measure of BMI masks the ethnic specific experiences of obesity. Moreover, BMI and BF are not easily correlated. The distinction between the two measures is particularly important for a population such as the Asian Indian peoples who, while having low BMI, might actually have high BF percentages. In this way, generalised BMI measurements also miss potential health problems within communities which are regarded as not having a BMI problem. This indicates that obesity prevalence cannot be discussed effectively as a generalised population level problem. One alternative, albeit complicated, is to investigate the health status of each of these ethnic groups separately. Accordingly, I will now shift to discuss the specific experiences of nutritional health and related diseases for the Maori, Pacific, and Asian populations in relation to BMI.

\footnotetext{
${ }^{39}$ John Sluyter, David Schaaf, Robert K. R. Scragg, Lindsay D. Plank, "Body Mass Index and Percent Body Fat in a New Zealand Multi-Ethnic Adolescent Population,” International Journal of Pediatric Obesity (March 17, 2010): 1.

${ }^{40}$ Elaine Rush, Ismael Frietas and Lindsay Plank, "Body Size, Body Composition, and Fat Distribution: Comparative Analysis of European, Maori, Pacific Island and Asian Indian adults,” British Journal of Nutrition, 102, (2009):632.

${ }^{41}$ Ibid., 637

${ }^{42}$ Ibid., 638
} 


\subsection{Maori Health and BMI}

Maori experience a lower health status and have a higher prevalence of obesity than Europeans. This difference is often attributed to the history of European colonisation. ${ }^{43}$ Maori understand this disparity to have arisen from generalised health provision and policy which by treating all patients like Europeans tacitly enforced a policy of ethnic assimilation. ${ }^{44}$ In regards to health status, in the 1980s and the 1990s the number of health disparities between Maori and Non Maori increased significantly. ${ }^{45}$ This disparity has been fairly extensively research through "a number of key health indicators: life expectancy, cancer mortality, and cardiovascular rates. The difference in life expectancy between Maori and non-Maori grew to 10 years. ${ }^{96}$ This disparity has also occurred through racial discrimination and deprivation. ${ }^{47}$ NZCMS data show that the gap between Maori and non-Maori cardiovascular mortality rates continues to widen. ${ }^{48}$ Consequently, on almost every indicator of health status Maori find themselves at a disadvantage to the general and European populations.

Explanations for Maori health inequality are beginning to suggest that this inequality arises from ethnicity or culture rather than income inequality. Sporle, Pearce, and Davis argue that:

Maori mortality remains higher than that of non-Maori even when the mortality rates are adjusted for social class. This indicates that the higher Maori mortality is more than just a result of Maori being under being overrepresented in the lower social classes as suggested by a recent critic of Maori focused social policies. ${ }^{49}$

This evidence supplements arguments which associate poor health solely with lower socioeconomic status. Recently, my colleagues and I found that Maori are less buffered than Europeans in terms of wellbeing against large scale hardship arising from events such as the global recession of 2007-2010. ${ }^{50}$ Maori are more adversely affected by hardship based upon ethnic identification in addition to being affected by the classic problem of income inequality.

\footnotetext{
${ }^{43}$ For an outline of the historical theories of the causes of poor health in the Maori People see: D. Dow, Maori Health and Government Policy $1840-1940$ (Wellington: Victoria University Press, 1999), 214.

${ }^{44}$ M.Durie, Nga Kahui Pou Launching Maori futures (Wellington: Huia Publishing, 2003), 1.

See also: M. Durie, Mauri Ora: The Dynamics of Maori Health (Melbourne: Oxford University Press, 2001).

${ }^{45}$ Bridget Robson, "What is Driving the Disparities?" in Understanding Health Inequalities in Aotearoa New Zealand, ed. Kevin Dew and Anna

Matheson (Dunedin: Otago University Press, 2008), 20.

${ }^{46}$ Ibid., 20.

${ }^{47}$ Ricci Harris, Martin Tobias, Mona Jeffreys, Kiri Waldegrave, Saffron Karlsen and James Nazroo, "Effects of Self-Reported Racial Discrimination and Deprivation on Maori health and Inequalities in New Zealand: Cross Sectional Study," The Lancet, 367 (June 2006 ): 2005.

${ }^{48}$ Phil Hider, "Improving Maori Health Outcomes With Decision Support,” The New Zealand Medical Journal 120 no. 1250 (March 2, 2007 ):1.

${ }^{49}$ Andrew Sporle, Neil Pearce and Peter Davis, "Social Class Mortality Differences in Maori and Non-Maori Men Aged 15-64 During the Last Two Decades," The New Zealand Medical Journal 115 no. 1150 (March 22, 2002): 130.

${ }^{50}$ Chris Sibley, Nikki Harre, William Hoverd, and Carla Houkamau, “The Gap in Subjective Wellbeing of Maori and New Zealand Europeans Widened from 2005 - 2009,” Journal for Social Indicators Research $\left(8^{\text {th }}\right.$ October 2010).
} 
In addition, Maori health inequality is replicated in obesity rates. Late 1990s obesity research tentatively supported the argument that Maori ethnicity was an additional factor for obesity prevalence. ${ }^{51}$ Non representative sampling of Maori from the 1990s indicated that they had higher rates of obesity and overweight than non-Maori over the period 1977-2003..$^{52}$ Later representative research in the NZMJ noted that "Maori, compared to European and Others have approximately double the prevalence of obesity and this is reflected in the increased incidence of diabetes, ischaemic heart disease and stroke reported for this group. ${ }^{53}$ Thus, since the outset of the 'obesity epidemic' in 1997, the NNS97 had shown that the Maori population had higher rates of obesity than non-Maori. ${ }^{54}$

The exact relationship between Maori obesity prevalence and socio-economic status remains problematic. The results of a recent study of obesity in Maori children challenge some of the existing assumptions about health and inequality. The NZHS06/07 measured obesity in Maori children at ages 2-4. It found that Maori children have the same prevalence of obesity as the general population. However, as they get older these children begin to develop significantly higher rates of obesity compared to the general population. ${ }^{55}$ When the NZHSO6/07 measured obese Maori children with obese non-Maori children by social deprivation quintile, it found that there was no significant difference in the prevalence of obesity for Maori. Here we see (Figure 41: from the NZHS06/07) evidence that Maori obesity is not related to social deprivation. Indeed, even the least deprived Maori tended to be bigger than their non-Maori counterparts. ${ }^{56}$ This evidence is supplement by $\mathrm{MOH}$ research which indicates that Maori Males tend to be larger in higher economic brackets. ${ }^{57}$

Figure 41 demonstrates that Maori children in all population deciles except the lowest decile have significantly higher rates of obesity than non-Maori. These results provide compelling data to support the argument that socio-economic position does not fully explain health disparity for Maori. It shows that other cultural and ethnic-specific factors must be considered in future research. This data also demonstrates that obesity discourse ignores the fact that Maori, across the deprivation deciles, have a higher average BMI than non-Maori. Thus, when

\footnotetext{
${ }^{51}$ Boyd Swinburn, Lisa Walter, Heather Ricketts, Gary Whitlock, Bonnie Law, Robyn Norton, Rod Jackson and Stephen MacMahon, "The Determinants of Fat Intake in a Multi-Ethnic New Zealand Population,” International Journal of Epidemiology 27 (1998).

${ }^{52}$ Ministry of Health, Tracking the Obesity Epidemic, 55.

${ }^{53}$ Wilson, Wilson, and Russell, "Obesity and body fat distribution in the New Zealand population."

${ }^{54}$ Ministry of Health, 1997 National Nutrition Survey, 164.

${ }_{55}$ Ministry of Health, A Focus on the Health of Maori and Pacific Children, 54

${ }^{56}$ Ibid., 55.

${ }^{57}$ Ministry of Health, Embodying Social Rank: How body fat varies with social status, gender and ethnicity in New Zealand, Public Health Intelligence Occasional Bulletin No. 34, (Wellington: Ministry of Health, October 2006), 26.
} 
obesity discourses engage in scapegoating, the fact that Maori are more obese than non-Maori is obscured. This misassignation of blame indicates there is an additional ethnic dimension that needs to be factored into causal explanations. Moreover, those individuals who argue that obesity is a general population health problem or 'epidemic' are quietly circumventing political correctness and omitting to mention that the majority of the people that they are talking about are poor, Maori, and as I discuss shortly, Pacific Island people.

Figure 41: Obesity, Maori and non-Maori children aged 2-14 years, by NZDep2006 quintile (age standardised) ${ }^{58}$

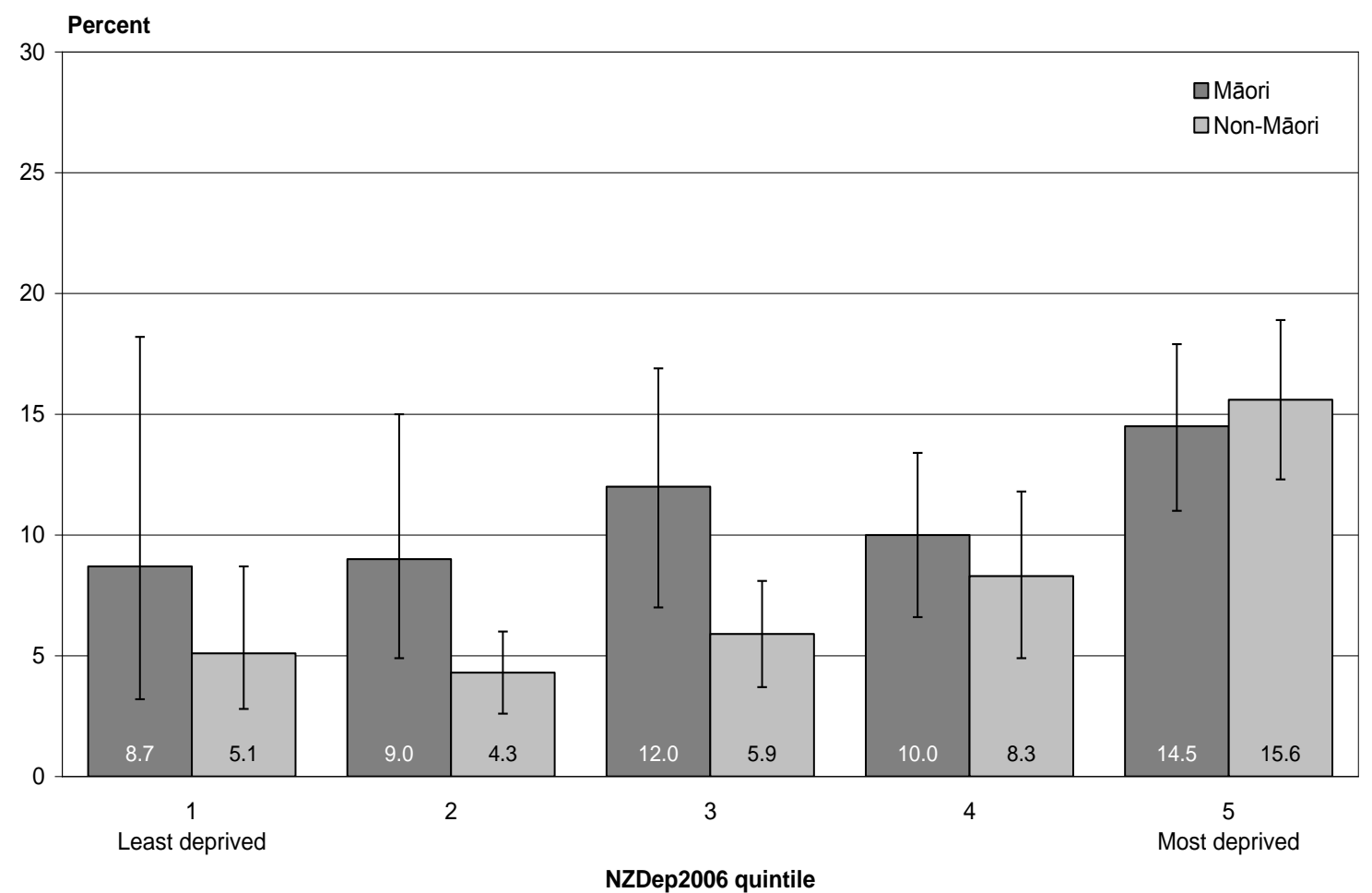

\subsection{Pacific Island Health and BMI}

The Pacific Island population has the highest prevalence of obesity of any ethnic group in the country. ${ }^{59}$ Despite this fact there has been very little Pacific Island specific research or health policy ${ }^{60}$ undertaken. Pacific Island health inequality has its roots in the food colonisation of the Pacific, a problem that has been exacerbated in NZ. In this section I explore this problem and the ways in which generalised obesity moralisations overwrite the data that demonstrates that specific ethnic groups experience high rates of health inequality and obesity prevalence.

\footnotetext{
${ }^{58}$ Ministry of Health, A Focus on the Health of Maori and Pacific Children, 55.

${ }^{59}$ Ministry of Health, A Portrait of Health 2002/03, 84.

${ }^{60}$ As part of Labour's focus on inequality the MOH released the Pacific Health Action Plan in February 2002 (PHAP2002) See: Annette King, Pacific Health Action Plan (Wellington: Ministry of Health, February, 2002).
} 
The high prevalence of Pacific Island obesity has its roots in the food colonisation and culture of the Pacific Islands. In 2000, the obesity rates of many Pacific Islands exceeded most developed nations including the United States and Australia. ${ }^{61}$ In 2003, the WHO reported that at least ten Pacific Island countries had rates of overweight and obesity numbering over $50 \%$ of the population. ${ }^{62}$ Rates of overweight and obesity combined as high as $75 \%$ have been reported in Nauru, Samoa, American Samoa, Cook Islands, Tonga, and French Polynesia. ${ }^{63}$ The WHO stated that "Even after accounting for variation in frame size, the level of obesity in many Pacific Islands is double that in most developed countries." ${ }^{64}$

Cultural expectations affect this prevalence. Traditionally, "Big” body size has been culturally desirable in the Pacific as it indicates status and health. ${ }^{65}$ The ruling classes traditionally placed high value on fatty foods. ${ }^{66}$ Resource exploitation and the two world wars have reshaped Pacific culture, however, placing emphasis on urbanisation and creating a situation of food dependence $^{67}$ or what is understood as "Dietary Colonialism." These events changed the cultural preferences for foods. In 2000, the WHO estimated that imported foods made up 30$90 \%$ of all foods consumed in the Pacific. ${ }^{68}$ This food inequality was combined with a decrease in Pacific Island physical activity rates as Pacific Island peoples moved away from labouring lifestyles. Additionally, obesity often coexists with under nutrition and undernourished children are more susceptible to developing non-communicable diseases such as obesity in later life. ${ }^{69}$

Pacific Island migration to New Zealand has brought with it the issue of body size and poverty. ${ }^{70}$ In 2001, the NZMJ acknowledged that Pacific Islanders are some of the most

\footnotetext{
${ }^{61}$ Jimaima Tanidau Schultz, Workshop on Obesity Prevention and Control Strategies in the Pacific. Convened by: World Health Organisation Regional Office for the Western Pacific and Co-Sponsored By Secretariat of the Pacific Community, International Association for the Study of Obesity/International Task force on Obesity, Food and Agriculture Organisation of the United Nations and International Life Sciences. (Apia: Samoa, 26-29 ${ }^{\text {th }}$ September 2000): 5.

${ }^{62}$ World Health Organisation, Diet, Food Supply and Obesity in the Pacific (Manila: World Health Organisation Regional Office for the Western Pacific, 2003), 3 .

${ }^{63}$ Ibid., 3.

${ }^{64}$ Ibid., 8 .

${ }^{65}$ Tanidau Schultz, Workshop on Obesity Prevention, 5.

${ }^{66}$ See: I. De Garine and N. Pollock, Social Aspects of Obesity (Amsterdam: Gordon and Breach Science Publishers, 1995).

${ }^{67}$ Food dependence is a term describing situations where consumers depend on others to produce their foods. See: World Health Organisation, Diet, Food Supply and Obesity in the Pacific, 37.

${ }^{68}$ World Health Organisation, Obesity in the Pacific: too big to ignore (Manila: World Health Organization, Regional Office for the Western Pacific, 2002), 10.

${ }^{69}$ Tanidau Schultz, Workshop on Obesity Prevention, 5.

${ }^{70}$ Nick Wilson, Osman Mansoor and George Thomson, “Key Arguments for Increasing New Zealand's Health Development Assistance in the Pacific," The New Zealand Medical Journal 117 no.1191 (April 2, 2004): 1.
} 
marginalised and poorest people in the nation and this directly affects their health status. ${ }^{71}$ On average, Pacific peoples have higher mortality rates and lower health status than any other ethnic group. ${ }^{72}$ In 2001, Colin Bell et al explained the relationship between Pacific Islanders and diabetes risk factors with particular reference to obesity. ${ }^{73}$ They noted that despite the known relationship between Pacific Islanders and obesity prevalence there were only two nonrepresentative studies specifically measuring Pacific Island BMI in this country. These surveys were the NNS97 which sampled 273 Pacific Islanders and a work force survey which measured Pacific Islanders in Tokoroa and Auckland. Bell et al argued that taken together these two studies confirmed that

Pacific populations in New Zealand carry a heavy burden of coronary heart disease (CHD) and diabetes. Several CHD risk factors are more prevalent amongst Pacific people than they are among European New Zealanders. They have higher mean blood pressures and a higher prevalence of hypertension, microbuminuria is more prevalent, physical activity levels are lower and smoking rates are higher. Also, Pacific people consume larger quantities of food than Europeans and their diets contain more meat and less fruit and vegetables. Moreover, Pacific Populations are among the most obese populations in the world and obesity is a strong independent risk factor for both CHD and Type 2 Diabetes. ${ }^{74}$

Even without a proper representative study of Pacific Island health, Bell et al argued that it appeared that the prevalence of obesity in the domestic population was even higher than the homogenous populations in the Islands. ${ }^{75}$ This research demonstrates that Pacific people experience significant health problems and these problems required extensive research.

Representative data measuring BMI for Pacific Island peoples was not available until 2005 when the results of the NZHS02/03 were released. The NZHS2002/03 used the adjusted BMI ranges for Pacific Islanders developed by Swinburn et al. ${ }^{76}$ The results of the NZHSO2/03 found that Pacific Islanders had twice the prevalence of obesity of the rest of the population. ${ }^{77}$ The NZHS2002/03 found that 82 percent of Pacific male adults and 79\% of Pacific female adults have higher combined rates of overweight and obesity compared to their total population counterparts (60 percent and 47 percent respectively).$^{78}$ These results confirmed that Pacific Island peoples were the most obese ethnic group in the nation. The Pacific Island

\footnotetext{
${ }^{71}$ Sitaleki Finau, "Marching From the Margin: A Health Vision for Pacificans of Aotearoa," The New Zealand Medical Journal 114 no.1134, (June 22, 2001):296

${ }^{73}$ Andrew Bell, Boyd Swinburn, David Simmons, W Wang and B Gatland, "Heart Disease and Diabetes Risk Factors in Pacific Islands Communities and Associations With Measures of Body Fat," The New Zealand Medical Journal 114 no.1131 (May 11, 2001 ): 208. 
population, with or without adjusted BMI ranges, experiences a significantly higher rate of obesity prevalence than the European and general population. This finding has been reconfirmed in studies of Pacific Island children. ${ }^{79}$

Recent studies of Pacific Island health have aimed to assess awareness of nutritional health and the benefits of physical activity. ${ }^{80}$ The Pacific Islands Family (PIF) study at Middlemore hospital found that $55-60 \%$ of Pacific children were overweight and attributed this to a lack of physical activity. ${ }^{81}$ The PIF study argued that "Obesity is predominantly the result of an "energy gap," the excess of energy intake over energy expenditure. These energy gaps can be relatively small (e.g. - 20-30 cal/day), and therefore could be easily reduced by small increases in physical activity (PA)." ${ }^{\$ 2}$ The solution to the energy gap problem is behavioural and focused upon encouraging Pacific Island people to eat less and exercise more. It is interesting to observe that Pacific Island families in this project are being brought back to basic behavioural causality principles. It is outside the scope of this project and my expertise to comment on medical practice, but one has to wonder why? Is it simply that health needs to be taught from BCM principles? Or does it demonstrate that hospitals are unable to implement the large structural changes required for implementing inequality or ECM solutions and thus garner more positive results from applying $\mathrm{BCM}$ principles which place the cost of treatment on the patient?

This chapter argues that obesity discourse ignores the ethnic locatedness of obesity. It also neglects the specific problems that each ethnic group has with BMI. Generalised obesity discourse neglects to mention that Pacific Island peoples are the most obese ethnic group in the nation. An example of this problem is found in the latest MOH document on Pacific Health. ${ }^{83}$ In this document, Pacific Island obesity rates are not actually mentioned as a health problem. Instead, BCM principles are used as explanatory factors for obesity. Obesity is considered a behavioural risk factor for causing other diseases along with other problems such as alcohol, smoking, and drugs ${ }^{84}$ Here the extent of Pacific Island obesity prevalence is muted and reoriented to align with the $\mathrm{BCM}$ priorities of the National Coalition. In doing so obesity is

\footnotetext{
${ }^{79}$ Melody Oliver, Philip Schluter, Janis Paterson, Gregory S Kolt and Grant Schofield, "Pacific Islands Families: Child and Parental Physical Activity and Body Size - Design and Methodology,” The New Zealand Medical Journal 122 no.1298 (July 3, 2009). 
made an individual health problem and the fact that it is whole ethnic groups that are obese is not mentioned. Moreover, the report implies that Pacific Islanders are obese because of behavioural problems rather than a combination of factors.

\subsection{Asian Health and BMI}

So far we have seen how generalised obesity discourse hides the fact that the Maori and Pacific Island populations have higher rates of obesity than other groups. Now I turn to the ways in which the Asian population contest standardised BMI measurements in a very different manner from the aforementioned groups. Using standardised BMI ranges, the Asian population has the least overweight or obese prevalence of any ethnic group. Given that the Asian population has lower BMIs than the European, Maori, and Pacific Island populations, it is often assumed that they do not have obesity-related problems. However, this is not the case as the Asian population has a very high rate of obesity related illnesses, especially Type 2 Diabetes.

As with Pacific Island health, there has been relatively little research into Asian health. By 2006, the $\mathrm{MOH}$ had published only three reports on Asian health. ${ }^{85}$ Explanations for this vacuum of Asian-focused health research and health policy tend to favour arguments that the population has been regarded as "invisible." ${ }^{\prime 6}$ As a consequence, Asian health status has been subsumed in surveys of European health or "Other" health categories, which has been the case with BMI. This omission may be due to the fact that Asian populations exhibit similar mortality rates to the European population ${ }^{87}$ and are not adversely affected by income inequality.

Analyses of Asian health are important because of the fast growth of this population. In 2006, the Asian population consisted of some $9.5 \%$ of the population and is estimated to be $15 \%$ by $2020{ }^{88}$ It is estimated that $34 \%$ of the Auckland DHB population will be Asian by $2016 .{ }^{89}$ However, the Asian category definition is extremely broad and encompasses an enormously diverse number of peoples. This presents problems for meaningful analysis because the ethnic category is geographically defined and refers to all the countries east of Afghanistan stretching to Japan and south to Indonesia and Malaysia. Currently, the MOH divides the Asian population into three broad and amorphous subgroups, Indian Asian, Chinese Asian and Other

\footnotetext{
${ }^{85}$ Kumanan Rasanathan, Shanthi Ameratunga and Samson Tse, "Asian Health in New Zealand - progress and challenges," The New Zealand Medical Journal 119 no.1244 (October 27th, 2006): 1.

${ }^{86}$ Max Abbott and Wilson Young, "Asian Health Chart Book 2006: Foundation For a New Health Agenda in New Zealand?" The New Zealand Medical Journal 119 no.1244 (October 27th, 2006): 2.

${ }^{87}$ Ibid., 5.

${ }^{88}$ Rasanathan, Ameratunga and Tse, "Asian Health in New Zealand," 1.

${ }^{89}$ Ibid., 1 .
} 
Asian. ${ }^{90}$ These sub-categories are still extremely broad. Abbott and Young argued that "Substantial heterogeneity can be obscured when data are averaged." Despite this averaging, Asian BMI prevalence is still lower than the population average.

Early 2000s investigations into the health of the Asian population found that there were high rates of obesity related disease in this ethnic category, despite the population having a low average BMI. In 2002, the MOH facilitated the establishment of an Asian Public Health Project Team to oversee an initial health assessment of Asian peoples. ${ }^{92}$ The first MOH report specifically dedicated to Asian health was released in February 2003. ${ }^{93}$ The MOH report found that Indians have a higher prevalence of obesity than Europeans and that Chinese and Asian Other populations did less than 150 minutes of exercise a week. Indians and Other Asians eat less vegetables and fruit than Europeans. ${ }^{94}$ Despite this fact, that the average BMI of the Asian population tends to have the lowest ethnic group average BMI, this community is affected by high rates of Type 2 Diabetes and low physical activity rates. ${ }^{95}$ As the Asian population has developed past the first generation the incidence of Type 2 Diabetes has increased. ${ }^{96}$ This process is described as the dissipation of "the healthy migrant effect." population is exhibiting many of the health problems associated with obesity without high rates of obesity prevalence.

Analysis of the Asian population BMI becomes more problematic when one considers the recommendations from the $\mathrm{WHO}^{98}$ to adjust BMI measurements for Asian peoples:

On the basis of the available data in Asia, the WHO expert consultation concluded that Asians generally have a higher percentage of body fat than white people of the same sex, age and BMI. Also, the proportion of Asian people with risk factors for Type 2 Diabetes and cardiovascular disease is substantial even below the existing WHO BMI cut-off point of $25 \mathrm{~kg} / \mathrm{m}^{2}$. Thus, current WHO cut-off points do not provide an adequate basis for taking action on risks related to overweight and obesity in many populations in Asia. ${ }^{99}$

\footnotetext{
${ }^{90}$ Ministry of Health, Asian Health Chart Book 2006, Public Health Intelligence Monitoring Report No 4 (Wellington: Ministry of Health, July 2006), XIX.

${ }_{91}$ Rasanathan, Ameratunga and Tse, “Asian Health in New Zealand,” 1.

${ }_{92}^{92}$ Ministry of Health, Asian Public Health Project Report (Wellington: Ministry of Health, February 2003), 5.

${ }^{93}$ Ibid.

${ }^{94}$ Ministry of Health, Asian Health Chart Book 2006, XIX

${ }_{95}^{95}$ Ministry of Health, A Portrait of Health 2002/03, 87.

${ }^{96}$ David Simmons and Trish Harry, "Prevalence of Known Diabetes in Different Ethnic Groups in Inner Urban South Auckland," The New Zealand Medical Journal 112 no.1094 (24 August, 1999): 318.

${ }^{97}$ The healthy migrant effect is discussed by: Rasanathan, Ameratunga and Tse, “Asian Health in New Zealand," 1.

${ }^{98}$ World Health Organisation, "Appropriate Body-Mass Index For Asian Populations and its Implications for Policy and Intervention Strategies.” Lancet (Jan 10, 2004):163.

${ }^{99}$ Ibid., 161.
} 
The WHO report stated that these findings are consistent with studies of Hong Kong Chinese, Singaporean Chinese, Malays, Indians, Indonesians, and Japanese that demonstrate that these populations have a high BF\% at a low BMI. ${ }^{100}$ Moreover, even at a low BMI, Asian populations have increased incidence of cardiovascular disease and diabetes. To compensate for Asian peoples having a higher BF\% at a lower BMI it was recommended [passive] that different BMI cut-offs from other ethnic groups be used to calculate overweight and obesity. Overweight is determined for BMIs of 23-24.9 and Obesity is defined for Asians with a BMI greater than 25. ${ }^{101}$ This research suggests that even with the broadest categorisation of ethnicity Asian populations might be biologically different from other ethnic groups.

The MOH has claimed that if Asian specific ethnic specific BMI determinants were utilised in this country then the Indian and the Other Asian category would have higher rates of obesity than the European population. ${ }^{102}$ More recent research has also confirmed that our Asian population has a higher BF\% at a lower BMI range than European, Maori, or Pacific Island peoples. ${ }^{103}$ This partially explains why, even with low BMI, the Asian population has a high prevalence of Type 2 Diabetes. As early as 1999, the findings of the South Auckland Diabetes study demonstrated that there was a high incidence of diabetes in Asian populations ${ }^{104}$ and is particularly high in the Indian population. In 2006, the Indian population had a self-reported rate of Type 2 Diabetes three times higher than the population average. ${ }^{105}$ Indian Asians are also more likely to get tested for Type 2 Diabetes than the remainder of the population. ${ }^{106}$ Part of the explanation for this increased percentage of diabetes prevalence is that physical activity rates in Asian populations are lower than other ethnic groups. ${ }^{107}$ Robert Scragg and Alokandanda Maitra observed that Asians were significantly less active than Europeans and Maori. Asians had similar activity levels to the Pacific Island population. ${ }^{108}$ Thus, sections of the Asian population have high rates of obesity-related illness despite having a low BMI average compared to the standard range.

\footnotetext{
${ }^{100}$ Ibid., 160.

${ }^{101}$ Ibid., 160.

${ }^{102}$ Ministry of Health, Asian Health Chart Book 2006, 88.

${ }^{103}$ Rush, Frietas and Plank, "Body Size, Body Composition," 632.

${ }^{104}$ Simmons and Harry, "Prevalence of Known Diabetes in Different Ethnic Groups."

${ }^{105}$ Ministry of Health, Asian Health Chart Book 2006, xvii.

${ }^{106}$ Ibid., xviii

${ }^{107}$ Rasanathan Kuman, Ameratunda, Shanthi, Janet Chen et al, A Health Profile of Young Asian New Zealanders Who Attended Secondary School: Findings from Youth 2000 (Auckland: University of Auckland, April 2006), VII.

${ }^{108}$ Robert Scragg and Alokandanda Maitra, Asian Health in Aotearoa: An Analysis of the 2002/03 New Zealand Health Survey (Auckland: The Asian Network Inc, 12 August 2005), 13.
} 
This section provides additional evidence to suggest that ethnic groups experience obesity in markedly different ways. The Asian population is an example of low BMI. The Asian population is a diverse group of peoples who collectively have the lowest average BMI of the four ethnic categories monitored. The invisibility of the Asian population and their apparent good health obscures the fact that Asian peoples experience high rates of Type 2 Diabetes. Because the Asian population does not experience significant disadvantage from income inequality this leaves ethnicity as a factor to explain these levels of BF and Type 2 Diabetes. This finding supplies a contrasting dimension to my argument that generalised moralisations about obesity contain an element of veiled racism because they omit to mention the ethnic specific experiences of disease prevalence.

\subsection{The Orewa Speech: Equal Access to Health}

So far I have argued that ethnicity needs to be addressed as a separate variable for determining health status. I have also claimed that ECM and BCM policy has omitted the specific challenges and complexities of ethnicity. This section explains how the Labour Government's focus upon ethnic inequality was challenged and irrevocably altered by a 2004 speech entitled Nationhood ${ }^{109}$ given by Dr Don Brash, then National Party Leader. This speech damned Labour's funding prioritisation for dealing with ethnic inequality. Brash argued for a funding principle based upon need and a general equality of access to health care. In particular, this call for equal treatment of all citizens regardless of ethnicity, disputed Labour's political prioritisation of Maori, which had been based upon arguments that this ethnic group systemically experienced inequality.

Brash's Nationhood address to the Orewa Rotary club is now commonly called the Orewa Speech. In his address Brash argued: "In both education and healthcare, government funding is now influenced not just by need - as it should be - but also by the ethnicity of the recipient." ${ }^{110} \mathrm{He}$ was specifically critical of claims which prioritised Maori instead preferring policy focused upon what he called 'one equal rule for all.' He declared that a funding focus which prioritised the needs of Maori was racially divisive and that a National Government would remove funding based specifically on a recipient's ethnicity. ${ }^{111}$ Brash's claim was that the population

\footnotetext{
${ }^{109}$ Don Brash, "Orewa Speech - Nationhood."

${ }^{110}$ Ibid.

${ }^{111}$ Anna Matheson and Kevin Dew, "Health, Justice and Politics," in Understanding Health Inequalities in Aotearoa New Zealand ed. Kevin Dew and Anna Matheson (Dunedin: Otago University Press, 2008), 11.
} 
should be understood as being all New Zealanders first and foremost and then recognised its diverse cultural heritage and ethnic ancestry.

The Orewa Speech did not contest the existence of economic inequality. Rather, it questioned the prioritisation of ethnicity. Brash disputed Labour's argument that ethnicity was an additional factor when it came to social inequality. He claimed that "Maori-ness explains very little about how well one does in life. Ethnicity does not determine one's destiny."112 This ideological position contested the political position of the Labour Party at the time. The Orewa Speech did not address the findings of the Social Deprivation Index and the Census Mortality Studies.

The Orewa Speech contested the view that ethnic inequality is a social problem. Anna Matheson and Kevin Dew outline the broad debates that the Orewa Speech opened:

This political manoeuvring also touched on one of the more substantive debates around understanding inequalities - individual versus social causes of inequality. The National party rhetoric of 'all New Zealanders' gave the impression of collectivity while individual need gave the impression of equity. ${ }^{113}$

Brash's position is that inequality is related purely to individual income disparity rather than to whole ethnic groups. This is why Brash's opponents criticised him for missing the point that Maori are systemically disadvantaged in terms of health status. Brash had argued that social deprivation should be the sole determinant of need whereas, as we have seen, that strong counter arguments exist that claim need should be determined by both deprivation and ethnic group. This latter position was taken by Allan Pelkowitz and Sue Crengle ${ }^{114}$ who responded to the Orewa Speech by stating:

While the level of additional funding for ethnicity can continue to be vigorously debated, the principle that ethnicity is a valid independent factor for health must be accepted, and must generate positive discriminatory policy until disparity is shown to have been corrected. The issue is vital not only for Maori but also for the physical, social, and economic health of the whole of this country. ${ }^{115}$

Pelkowitz and Crengle maintain that ethnicity is a valid independent factor for health before claiming that this factor must be acknowledged before the country can become healthy. ${ }^{116}$ Other scholars in the NZMJ, such as Cindy Towns et al, provided more extreme critiques

\footnotetext{
${ }^{112}$ Don Brash, "Orewa Speech - Nationhood."

${ }^{113}$ Matheson and Dew, Health, Justice and Politics, 11.

${ }^{114}$ Pelkowitz and Crengle, "The Orewa Speech."

115 Ibid., 2.

${ }^{116}$ Ibid., 2.
} 
framing the Orewa Speech itself as another systemic threat to Maori health. ${ }^{117}$ Towns et al argued that Maori were already systemically disadvantaged and that there was sufficient epidemiological evidence to support this position. ${ }^{118}$ Moreover, they argued that the Government had a Treaty of Waitangi contractual obligation to guarantee Maori health. Towns et al claimed that together these two epidemiological and legal arguments combined to create an ethical obligation to specifically address and fund Maori health issues, an obligation aligned with the central tenets of medicine to alleviate suffering and improve quality and length of life. ${ }^{119}$

The Orewa Speech offers a further example of the polarised ideological views of disease causality. The Orewa Speech also shows how particular ideological views and policy models can be critiqued and overturned. The position characterised by the Left at that time was that illness was unequally spread throughout society. This argument stated that both income and ethnicity were independent variables associated with experiences of low health status and high mortality rates. Brash's counter-position was that illness was experienced by individuals. From this position, Brash argued that income inequality was correlated with experiences of low health status and high mortality but not ethnicity.

Since the Orewa Speech, the ethnic dimensions of health have been avoided by all political parties except the Maori party. The attack on Labour's Closing the Gaps policy was supported by wider tensions, difficulties, and policy directions surrounding ethnicity and health. Michael Belgrave writes:

In contrast, where ethnic group outcomes became a priority during the brief flowering of the Clark government's 'Closing the Gaps' policy the objective of removing barriers between Maori and non-Maori soon became politically untenable. By 2000 the issue of separate funding for Maori had become politically problematic, interwoven with public perceptions of Maori sovereignty claims and Maori separatism. Even before 2004, when Don Brash's Orewa Rotary speech attacked Treaty of Waitangi-based social policy as 'privileging' Maori, the government had substantially withdrawn from the approach in its public rhetoric, particularly in health. The issue of poor Maori and Pacific health status became subsumed under the more inclusive rubric of population-based health care. ${ }^{120}$

Thus, from 2004 onwards there was much less emphasis upon ethnic inequality in health policy. It still existed but policy approaches which singled out certain ethnic groups such as

\footnotetext{
${ }^{117}$ Towns, Watkins, Salter, Boyd and Parkin, "The Orewa Speech.”

${ }^{118}$ Ibid.

${ }^{119}$ Ibid.

${ }^{120}$ Belgrave, “A Historical Perspective,” 79-80.
} 
Maori for interventions were politically untenable. Social policies aimed at improving the health of New Zealanders, especially those in at risk groups would be treated by generalised policy approaches. The 2004 Working for Families ${ }^{121}$ tax legislation change is one social balancing policy aimed at a general reduction of both these forms of inequality. ${ }^{122}$ The HEHA framework is another example of this type of generalised policy.

\subsection{Ethnic Mobility and Identification}

I have argued that, despite the challenge of the Orewa Speech, ethnicity is a variable omitted by $\mathrm{BCM}$ and ECM discourse and that ethnicity disrupts classical understandings of disease causality. I have shown how there has been dramatic rise in obesity rates and Type 2 Diabetes in non-Western populations. In this final section, I address why ethnic self-identification complicates solutions for addressing ethnic inequalities in health.

Despite growing evidence of an association between ethnicity and health inequality, ${ }^{123}$ there is still no conclusive explanation of how ethnicity affects health status. We know that particular ethnic groups have different experiences of obesity and nutrition and outside the very recent (in last 12 years) investigations in the health of the Maori population, there is very little definitive research providing ethnic specific information for the Asian and Pacific Island ethnic groups. ${ }^{124}$ For example, the accuracy of ethnicity data in hospital records has been investigated several times with each investigation demonstrating inadequacies, especially for Maori. ${ }^{125}$ Commonly, the Asian population is simply ignored and/or conflated with the European population. There are other cases where measurements of Pacific Island health problems are simply inferred from study of Maori populations. ${ }^{126}$ These are global problems; the WHO has identified that longitudinal study of homogenous Pacific Island and Asian populations is desperately required to understand the problems associated with the correlations between ethnicity and health status. ${ }^{127}$

\footnotetext{
${ }^{121}$ Taxation Act 2004. (Working for Families)

${ }^{122}$ Tony Blakely, "Social Injustice is Killing People On a Grand Scale," The New Zealand Medical Journal 121 no.1281 (September 5, 2008 ): 8.

${ }^{123}$ Pamela Smart, Roger Marshall, Tord Kjellstrom and Lorna Dyall, "Reporting Comparisons Between Maori and Non-Maori Populations," The New Zealand Medical Journal 115 no.1151 (April 12, 2002): 169.

${ }^{124}$ Ibid., 169.

${ }^{125}$ Judith Swann, Steven Lillis and David Simmons, "Investigating the Accuracy of Ethnicity Data in New Zealand Hospital Records: Still

Room For Improvement," The New Zealand Medical Journal 119 no. 1239 (August 4, 2006): 1.

${ }^{126}$ Ministry of Health, Monitoring Ethnic Inequalities in Health.

${ }^{127}$ World Health Organisation, “Appropriate body-mass index for Asian populations," 162.
} 
The need to define ethnicity produces an additional complicating factor for investigations into ethnic inequality. The current official (Statistics New Zealand) definition of an ethnic group is a social group whose members:

- share a sense of common origin

- claim a common and distinctive history and destiny

- possess one or more dimensions of collective cultural individuality

- feel a sense of unique collective solidarity ${ }^{128}$

There is no definitional criterion from which an individual claims membership to an ethnic group through genetics or biology. Instead, an individual self-identifies his or her membership with an ethnic group and there is no other reliable method for measuring ethnicity. ${ }^{129}$

The reliance upon such self-identification produces several ambiguities. For instance, individuals apply their own personal subjective criteria when identifying their ethnicity. Subjective self identification problems occur when respondents record different ethnicity in differing contexts. Professor Chris Cunningham of Massey University noted: "that not all Maori respondents identify as Maori in every situation." ${ }^{130}$ Moreover, as well as omitting ethnicity another phenomenon associated with ethnic mobility is the adoption of several ethnicities. ${ }^{131}$ As a result, any record of ethnicity needs to be understood as elastic and potentially open for manipulation.

Indeed, ethnic mobility over time is another ambiguity that makes comparison with earlier data sets difficult. ${ }^{132}$ Ethnic mobility is the label given to the process whereby the population is becoming increasingly heterogeneous. Significant numbers are identifying with more than one ethnic group. This makes ethnic specific study of health responses problematic and is one of the reasons that ethnic specific BMI cut-offs have come under question. ${ }^{133}$ We have seen already that individuals who identify with several ethnic groups have produced several problems for recording ethnicity in hospitals. ${ }^{134}$ From their investigation into discrepancies in reported ethnicity in hospitals, Swann, Lillis, and Simmons concluded:

These findings have significant policy implications. With such discrepancies in ethnicity reporting among non-European groups in the major national outcome

\footnotetext{
${ }^{128}$ Ministry of Health, Monitoring Ethnic Inequalities in Health, 2.

${ }^{129}$ Hohepa, Schofeild and Kolt, "Adolescent obesity and physical inactivity," 3.

${ }^{130}$ Chris Cunningham, "Diversity and Equity for Maori," in Understanding Health Inequalities in Aotearoa New Zealand, ed. Kevin Dew and Anna Matheson (Dunedin: Otago University Press, 2008), 61.

${ }^{131}$ Ibid., 61 .

${ }^{132}$ Ibid., 60

${ }^{133}$ Hohepa, Schofeild and Kolt, "Adolescent obesity and physical inactivity," 3.

${ }^{134}$ Ibid., 3-4.
} 
dataset (besides death certificates), it is difficult for the impact of policies focussing on the inter-ethnic health disparities to be interpreted. ${ }^{135}$

As a consequence, determining any actual measurement of ethnic disparity is extremely difficult so non-ethnic specific general population data are preferred for discussing health problems.

The ethnic dimensions of health are problematic. There are two extreme responses to this problem which could be taken: either we treat the general population as equals or we acknowledge that each ethnic group is fundamentally different and requires specific consideration. A New Right political position demands an equal society and a decentralised state where there is no reason to treat ethnic groups separately. This returns us to the solution offered by Don Brash's Orewa Speech and the problem of ethnic self-identification:

The short cut of referring to Maori as one group and Pakeha as another is enormously misleading. There is no homogenous, distinct Maori population - we have been a melting pot since the $19^{\text {th }}$ century - although there is, of course, a highly distinctive Maori culture, which many people see as central to their identity. Our definition of ethnicity is now a matter of subjective self-definition: if you are part Maori and want to identify as Maori you may do so... What we are seeing is the emergence of a population in New Zealand of multi-ethnic heritage - a distinct South Seas race of New Zealanders - where more and more of us will have a diverse ancestry. ${ }^{136}$

Brash's argument that all citizens be treated equally by the institutions of Government is fuelled by his claim that definitions of ethnicity are a matter of "subjective self-definition." This stance conflicts with evidence that ethnic groups' experience disease differently and require ethnic specific treatment. The danger of Brash's position is that explanations for illness in an equal society fall back upon BCM rationales. This BCM line of reasoning could imply that entire ethnic groups are more slothful and gluttonous than others. Moreover, there is sufficient evidence to show that arguments for equality ignore the fact that various ethnic groups experience disease differently. However, defining ethnicity remains a matter of individual identification while ethnicity mobility complicates this identification. This leaves us with the conundrum that ethnicity cannot be ignored, but neither can it be neatly quantified or classified.

\footnotetext{
${ }^{135}$ Ibid., 5.

${ }^{136}$ Don Brash, "Orewa Speech - Nationhood."
} 
Proponents of the ECM tend to subsume ethnic inequality into more generalised policies aimed at controlling obesogenic environments. ECM arguments are predicated on the view that the whole population lives in an obesogenic environment and neglect to mention that specific ethnic and income groups live in material environments which are more obesogenic than those in which wealthy Europeans live. Generalised ECM arguments fail to mention that ethnic groups experience obesity prevalence differently. This omission occurs as ECM discourse misassigns the blame for obesity solely onto environments without considering that there might be specific ethnic, cultural, or behavioural factors involved in obesity prevalence. Specifically, by blaming obesity on obesogenic environments, the ECM ignores evidence suggesting that certain ethnic groups have low physical activity rates and unhealthy eating habits.

Thus, I argue that ECM and BCM explanations of obesity causality ignore the problems relating to ethnicity and obesity prevalence. They both prioritise single causal explanations of obesity. They misassign the blame for obesity onto these single causal explanations: environment or behaviour. Despite definitional problems, sufficient evidence exists in measures of health, mortality, and social deprivation to indicate that ethnic groups do not experience obesity in an equal manner. This discussion of ethnicity illustrates that more nuanced causal explanations of obesity are required.

\subsection{Conclusion}

In this chapter, I argued that generalised measures of obesity hide the ethnic specificity of obesity prevalence and that the 'political spectrum of obesity causation models' overlooks the role that ethnicity plays in obesity prevalence. To be more precise, I am not claiming that ethnicity is a cause of obesity. I am claiming that obesity prevalence is related to ethnic group and that BMI measurements do not properly address potential ethnic variation which is evident when each ethnic group is examined in isolation. This conclusion begins as a summary and then extends its analysis to briefly assess the ramifications of these findings under six points. 1. I found that ethnic inequality, for Maori and Pacific Islanders, is an additional variable for determining obesity prevalence. 2. I found that the two extreme obesity causality models fail to mention ethnicity. Thus, when moralised discourse is used to discriminate against the obese it should now be understood as potentially racist due to the high prevalence of non-European obese. 3. I found that this omission has occurred because ethnicity became a political hot potato in 2004. 4. I argue that by neglecting to mention the ethnic aspects of obesity these 
models inflict harm upon non European groups. 5. I consider that there might be resistance to BMI occurring amongst certain ethnic groups. 6. Finally, in preparation for Chapter Nine, I apply the ethnic dimensions of obesity to critique the 'political spectrum of obesity causation models' and argue that, for the future, more nuanced and informed understandings of obesity discourse are necessary.

1. Maori and Pacific Islands peoples still have high rates of obesity after accounting for income inequality. Even when accounting for social deprivation Maori and Pacific Island peoples still have higher average BMI across all socio-deprivation levels. In contrast, the Asian population does not suffer from the negative outcomes of income inequality and is the least obese ethnic group in the nation. Despite these advantages this ethnic group experiences high rates of obesity related diseases such as Type 2 Diabetes and high rates of physical inactivity.

2. I find each of the models of obesity causality neglects to mention ethnic specific experiences of obesity. The ECM argues that people are powerlessly subject to an obesogenic environment which causes ill-health and concentrates upon protecting children and creating healthy environments. I argue that the ECM misassigns the blame for obesity solely onto environments without considering the specific ethnic, cultural, or behavioural factors involved in obesity prevalence. I find that the ECM doesn't account for inequality. I argue that the solution of treating obesogenic environments benefits the wealthy and Europeans before it assists the poor or ethnic specific groups. The ECM does not take into account the possibility that certain ethnic groups might live in more obesogenic environments than others or might collectively practice poor health behaviours than others. Sue Kedgley's generalised ECM interventions only benefit people whose children can afford to buy unhealthy food and do not benefit children who cannot afford to buy food and struggle to attend school.

I find that BCM explanations are limited by an ideological viewpoint which refuses to acknowledge inequality or be tempered by non-behavioural considerations such as the correlation between ethnicity, income, and health status. The BCM argues that the population should be treated equally and behaviour is the sole determinate of obesity. Thus, for the BCM ethnicity is not considered to influence individual obesity rates. I believe that BCM explanations of obesity prevalence were politically strengthened by Don Brash's Orewa Speech ${ }^{137}$ and the definitional problems arising from ethnic self-identification and ethnic mobility. Each 
of these problems can contest arguments that ethnic groups should have their health concerns addressed separately. These definitional problems were used by the $\mathrm{MOH}$ to explain the discontinuation of ethnic adjusted BMI rates in the NZHS06/07.

Applying a BCM view to the generalised BMI ranges could result in entire ethnic groups getting stereotyped as moral, normal or immoral. Against the 'normal' European population the Asian population with its low average BMI could be understood as a moral ethnic group, whereas the Maori and Pacific Island ethnic groups become a moral problem for the BCM. Thus, the BCM viewpoint could be accused of being racist because it can easily imply that entire ethnic groups are obese because they suffer from gluttony and sloth. I think it is important to point out that if I am a Pacific Island New Zealander I will, on average, be obese. A language which blames obesity purely on behaviour or the environment sweeps this fact under the carpet.

3. The chapter explained why ethnicity has been omitted from the ECM and BCM from 2004. Ethnic inequality was a strong MCM policy concern of the Labour Party between 2000 and 2004. The MCM did take ethnicity into account but, after the Orewa Speech, this policy approach became a political hot potato. The political demise of the MCM pushed political considerations of ethnic inequality into more generalised social policy addressed by proponents of the ECM and BCM. The blaming of obesity causes on either the environment or behaviour fails to acknowledge that the obese are primarily Maori and Pacific Islanders. One reason that these models scapegoat and misassign blame for obesity causality is that the ECM and BCM are now tentative about addressing the ethnic dimensions of obesity prevalence

4. Harm is inflicted upon the community by the "political spectrum of obesity causation models" avoidance of the ethnic dimensions of obesity. 'The spectrum's' generalised approaches to obesity fail to acknowledge that people suffering from the negative aspects of inequality are the most likely to die early or suffer from illness. All of 'the spectrum's' generalised approaches to obesity benefit the privileged before they treat those suffering from inequality such that this form of inequality is likely to be continued. I am concerned that by neglecting to openly discuss the ethnic dimensions of disease we, as a nation, will not develop the political language necessary for addressing the health needs of our diverse population. 
5. Another possibility to consider is that Maori and Pacific Island peoples might be physically resisting the dominant European medical and policy discourse with their bodies. I cannot recall this possibility being considered in any form of obesity discourse except the radical fat studies literature where resistance tends not to have an ethnic dimension. ${ }^{138}$ It is possible that resistance has occurred because entire ethnic groups have been consistently told that they are obese and that they must change their eating traditions and cultural preferences. Resistance might occur when an ethnic group is forced for 'their own good' to follow the medical guidelines of a dominant ethnic group. Resistance might also occur when a dominant ethnic groups does not heed the perspectives or priorities of other ethnic groups. Certainly we know that Maori can find visits to GPs difficult. ${ }^{139}$ It is outside the bounds of this current study to pursue this line of reasoning further but this possibility must to be considered in future studies of obesity discourse.

6. I find that the 'political spectrum of obesity causation models' has closed down the possibility for robust political discussions of ethnicity because it incorrectly assigns blame for obesity causality. More nuanced causal explanations of obesity are required in the future. A broader understanding of obesity discourse will need to be developed that acknowledges that ethnicity is a key issue. This broader understanding is necessary because the ECM and BCM are limited by their ideological views. Currently the obese are being torn, election by election, between two policy positions which do not fully address all the dimensions of obesity prevalence. Obesity prevalence is far more complicated than is evident in most BCM and ECM discourse. Ethnicity must be brought back into political consideration because of our increasing ethnic diversity and the ethnic dimensions of obesity. The current BMI ranges were designed to measure European populations and their application to an ethnically diverse population is highly problematic. ${ }^{140}$ In Chapter Nine I outline a model of the 'Moral Politics of Official Obesity Discourse' which addresses the need for more nuanced understandings of obesity discourse.

\footnotetext{
${ }^{138}$ Cooper, "Fat Studies," 1020.

${ }^{139}$ Timothy McCreanor \& Raymond Nairn, “Tauiwi General Practitioners' Talk About Maori Health: Interpretative Repertoires,” The New Zealand Medical Journal 115 no.1167 (December 13, 2002): 1.

${ }^{140}$ This approach would require significant funding and bureaucracy and would potentially contest bi-culturalism.
} 


\section{Chapter Nine: The Moral Politics of Official Obesity Discourse}

\subsection{Introduction}

This chapter summarises the thesis findings and then outlines a 'Model of the Moral Politics of Official Obesity Discourse.' This study of 'official obesity discourse' has come a long way from my original question of why the sins of gluttony and sloth were evoked in obesity policy. My research located the answer to this initial question in behavioural understandings of obesity and New Right politics. This answer then developed into a project tracing the emergence of official obesity discourse between 1997 and 2009. This history showed that, prior to 1996, obesity was not a significant health concern in this country but, by 2006, the 'obesity epidemic' was described by the Labour Government as the "greatest health threat facing New Zealand." Three years later, in 2009, the National Government had scrapped Mission On and the HEHA framework and obesity was no longer a national health target or priority. Did all New Zealanders become safe from the risks of obesity overnight or was an alternative explanation required? The answer to the question of whether or not New Zealand really is in the grip of an inexorable 'obesity epidemic' is ideological.

\subsection{The Research Question}

Chapter One outlined how my research began as an investigation dedicated to understanding why the deadly sins of gluttony and sloth were being ascribed to obesity. My potted history of the Seven Deadly sins showed that the doctrine of these sins fell out of systematic usage in the $16^{\text {th }}$ century. My review of the religion and body literature indicated the importance of avoiding reliance upon historical versions of Christianity as a framework for understanding modern obesity discourse. Thus, tracing a history of Christian sin and/or ideas of the body into 'official obesity discourse' is a mistake because this discourse must be studied within its own context. However, it was apparent that some scholars were doing precisely that - trying to explain the moral dimensions of obesity discourse by reference to Christian notions of sin. My approach showed that this explanation was inadequate and I sought instead to study the moral dimensions of official obesity discourse within its own political context. I therefore turned to investigating the ideological and moral dimensions of this discourse.

\footnotetext{
${ }^{1}$ Cullen, Budget Speech 2006, 28.
} 
Studies have often approached obesity from the perspective of a single academic discipline. Through such an approach, obesity is understood as a problem of medicine, personal responsibility, risk analysis, biology, biochemistry, genetics, evolution, cost analyses, behaviour, or a lack of education. It was apparent that a broader interdisciplinary perspective was required to elucidate the moral dimensions of obesity discourse. 'Official obesity discourse' needs to be studied in comparison to other contrasting examples of the same discourse. During the study, I found that the balkanisation of these academic disciplines had hidden and masked several forms of moralisation, each attached to certain ideological views. This led me to divide the thesis discussion into two parts. Part One provided a chronological history of official obesity discourse, structured around the three ideological models of obesity causality, and how these three models interact. Part Two outlined the moral dimensions of these models and demonstrated how they each neglect to address the economic and ethnic inequalities which exist in obesity prevalent groups.

\subsection{The Ideological Dimensions of Obesity Discourse}

Part One provided a history of New Zealand 'official obesity discourse' produced between the years 1997 and 2009. This is the first history of the 'obesity epidemic' pertaining to New Zealand and one of the first studies of this kind to be produced worldwide. Part One argued that there were three obesity causality models at play in the research period. I discussed these three obesity causality models chronologically in Chapters Two (pre 2000), Three (2000-2005) and Four (2006-2008). In Chapter Five, I illustrated that each of these obesity models was still evident in the health policy of the political parties contesting the 2008 general election. I argued that these models were spread across a 'Political Spectrum of Obesity Causation Models.' I then applied this 'spectrum' to explain why the National Government elected in 2008 had no obesity policy and ceased to address the 'obesity epidemic.'

In Chapter Two, I outlined the emergence of the Behavioural Causality Model (BCM) and of 'official obesity discourse.' This history showed that concerns about obesity arose out of investigations into mortality from cardiovascular disease. Chapter Two also outlined the ideological arena into which the 'obesity epidemic' would emerge in 1997. It showed how the mid-1990s New Right reform of the health sector temporarily privatised health and relabelled patients as consumers of health products. This New Right ideology focused on developing a deregulated society in which individuals were assumed to all be equal and free to choose to 
spend their money as they wished. This was the ideology that underpinned the BCM. It encouraged citizens to insure themselves against poor health by maintaining a healthy lifestyle.

The BCM understands obesity to be caused by poor choices and the failure of individual responsibility. Consequently, under the BCM, the terms 'gluttony' and 'sloth' are understood to refer to the undisciplined behaviours and choices which cause obesity. The BCM has been heavily critiqued by the other causality models discussed in this thesis. Despite this criticism, the $\mathrm{BCM}$ remains an extremely powerful causal explanation because it focuses on two variables of obesity causality that individuals can manipulate: gluttony and sloth. Crucially, unlike other models, the BCM holds that individuals retain full agency to control these behaviours through personal discipline. BCM ideology always allows for the possibility of individual conversion, redemption, and salvation from obesity, and holds that an obese individual who undertakes a disciplined regimen can, and will eventually, reverse their physical condition.

Chapter Three outlined the second obesity causality model. The Multiple Causality Model (MCM) emerged as an ideological response to the BCM. The MCM was part of the Labour Government's 'third way' response to the New Right ideology of the National Government, which had promoted the BCM. The MCM found that attention to the behavioural causes of obesity needed to be complemented by consideration of other factors. The MCM held that obesity has multiple causes, including behaviour, genetics, and the wider environmental or structural determinants of disease. The MCM acknowledged the existence of socio-economic and ethnic inequality and found that certain population groups fell outside the equal moral playing field assumed by the BCM. Under the MCM, certain people could be absolved of blame for their obesity because they belonged to a particular population subgroup that lacked the agency to choose to be healthy. However, in order to be excluded from the individualised moral playing field, a person had to take on a marginalised 'subgroup' status. According to the MCM, they were fat because they were poor or belonged to a specific ethnic group.

The MCM was in its political ascendancy between 2000 and 2005. The MCM required an active state to intervene to protect what it regarded as the disenfranchised because it viewed society as unequal. Thus, as the 'obesity epidemic' was firmly entrenched as a Governmental health priority under the MCM, obesity intervention programmes were developed, such as 
HEHA. ${ }^{2}$ The relative emphasis given to different causal factors under the MCM evolved between 2000 and 2005. Early MCM discourse focused primarily on behaviour, while at best vaguely gesturing towards the structural determinants of obesity. However, by 2005 these environmental determinants were understood as a central causal factor. The growing authority of the environmental explanations began to shift understandings of obesity causality towards the ECM.

Chapter Four described how Labour's policy evolved from MCM to Environmental Causality Model (ECM) understandings of obesity from 2006 to 2008. The ECM holds that the cause of obesity is an unhealthy or obesogenic environment, caused by an unregulated free market. The ECM holds that the agency of individuals to make healthy food choices is completely subverted when they live in obesogenic environments. As a result, the ECM requires the State to intervene in order to regulate and protect the population from what it perceives as the excesses of the free market. The ECM viewpoint is illustrated in Chris Slane ${ }^{3}$ cartoon below, which commented on the 'Fruit in Schools program.' Slane's cartoon depicts the free-market as a fattening threat to children, one which conflicts economically and ideologically with the 'protectionist old-fashioned nanny state.'

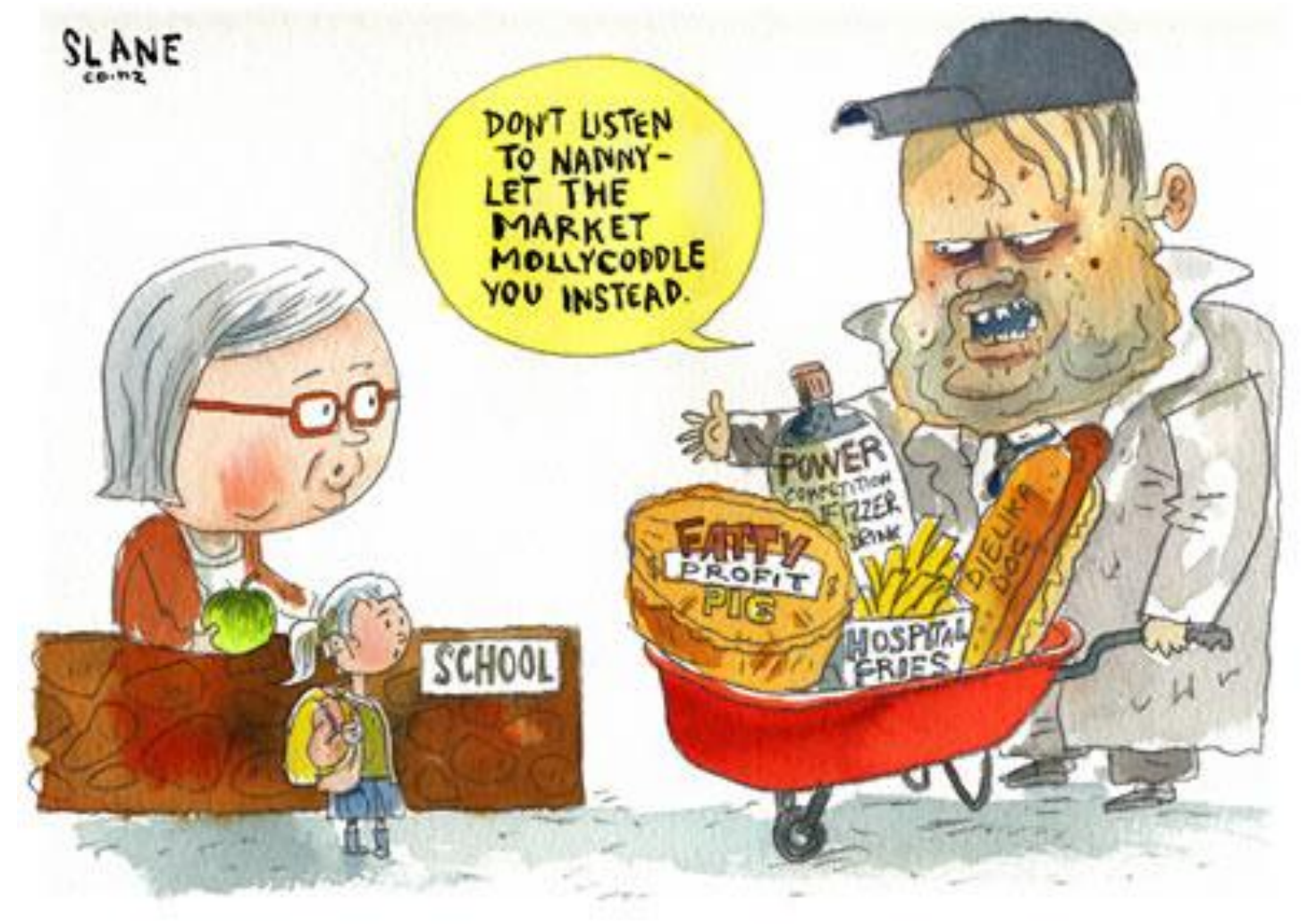

${ }^{2}$ Ministry of Health, Towards an Integrated Approach to Physical Activity, Nutrition and Healthy Weight.

${ }^{3}$ Thanks to Chris Slane for permission to reproduce this cartoon. The reproduction rights are attributable to www.slane.co.nz 
In Chapter Five, I examined an important juncture in recent obesity politics: the November 2008 general election and the subsequent change of Government. The review of election policy demonstrated that each of the obesity models outlined in Chapters Two-Four were still functioning in contemporary politics, and could be mapped along a 'Spectrum of Obesity Causation Models.' Along this 'spectrum', the ECM formed one extreme and the BCM the other extreme, with the MCM falling somewhere in between. I argued that obesity discourse had evolved and diversified over the period 1997 to 2009 and that those at the opposing limits of the spectrum talk past each other.

The second half of Chapter Five shifted to explaining why, in 2009, the National Government reversed Labour's obesity policy. Referring to the spectrum, I argued that 'scientific facts', such as the existence of the 'obesity epidemic,' can be contested by ideological notions of State governance. This analysis revealed that National's utter disinterest in the 'obesity epidemic' and their complete removal of funding for obesity policy and programmes was ideological and a renewed application of the BCM. This is because it is the National's Coalition's BCM view that individuals, not the State, are tasked with the responsibility for obesity prevention.

In summary, Part One of the dissertation mapped the previously undocumented history of New Zealand's official obesity discourse in the period 1997 to 2009. This particular history has the advantage of being exhaustive as I can comfortably assert that I reviewed the majority of the publically available 'official obesity discourse' produced in the research period. Additionally, these four chapters demonstrated that obesity discourse was not ideologically neutral nor was it a unitary discourse but it was ideologically divided. My research indicated that three contesting ideological models existed in 'official obesity discourse', each of which contained notions of obesity causality, individual agency, morality, and the role of State.

The most important finding I want the reader to take from Part One is that all official obesity discourse produced by medical researchers, policy makers, and politicians contains ideological assumptions and bias. Obesity discourse is not neutral; it is ideologically divided. Policy makers do not produce and implement objective health promotion materials, as they are constrained by the Government's or certain expert's particular ideological view.

I hope that my research into the ideological nature of obesity discourse will encourage other researchers to question the ideological dimensions of 'official obesity discourse.' We now 
know that obesity discourse is ideological and the New Right/Neo-Liberal dimensions of obesity (BCM) have been already acknowledged. What is not documented is the existence of other equally strong and important ideological viewpoints within 'official obesity discourse.' In my case study, the BCM is contested by two other ideological models of obesity causality: the MCM and the ECM. These models can be mapped across a 'political spectrum of obesity causation models.' It is my hope that other researchers might use these obesity models and my 'spectrum' to begin to critically analyse obesity discourse within their own research.

\subsection{A Brief Comment about Agency in Obesity Discourse}

I want to address briefly the issue of agency, as it is central to the 'official obesity debate.' In the late 2000s, discussion of agency centred upon questions of whether children could make healthy food choices for themselves. One of the key questions in obesity politics concerns the degree to which individuals have a choice about whether or not they get fat. The obesity models are divided in their answer to this question. The ECM implies that individuals do not have a choice, whereas the BCM and MCM allow individuals some form of agency.

I have not pursued this question further because it breaks down in the face of the problem of social inequality. In New Zealand, poor health, the prevalence of obesity, and Type 2 Diabetes rates are related to socio-economic status, gender, and ethnicity. Discussions of agency assume that people can choose to be healthy or not, whereas a more nuanced model of causality is required. I find that questions about agency merely repeat the ideological agendas represented by the positions outlined in 'the spectrum' and neglect the moral and inequality dimensions of obesity discourse outlined in Part Two of the thesis.

\subsection{The Moral Dimensions of Obesity Discourse}

Part Two of the dissertation explored the moral dimensions of the models that emerged from the case study. The chapters constituting Part Two were thematic and addressed the moral, economic, and ethnic dimensions of the obesity models discussed in Part One, thus offering a critical analysis of the obesity causality models to show their biases and limitations. In this sense, Part Two paints a fuller picture of several dimensions of obesity discourse which are typically neglected, glossed over, or poorly communicated by the obesity causality models. The goal of Part Two was to show that in light of this fuller picture, we must develop a more nuanced and informed model of the ideological and moral dimensions of 'official obesity discourse.' 
Part Two began with Chapter Six which shifted from the chronological discussion of 'official obesity discourse' towards a thematic critique. As such, Chapter Six employed several lenses derived from Religious Studies to provide a fuller analysis of the moral dimensions of obesity discourse and open the way for the inequality critiques of the obesity models.

Chapter Six argued that there were two primary types of morality at play in obesity discourse: communal and individual morality. I found that the ECM and MCM utilise a communal morality. Communal moralities understand obesity as a burden which is borne by the State. Communal moral systems are fiercely protective of children and attempt to create protected environments in which children can be nurtured. Communal moral systems tend to attack and/or seek retribution from entities that might potentially harm children. Consequently, the ECM promotes policies such as the NAG guidelines to protect children and is highly suspicious of food and beverage advertising that could potentially influence children to make unhealthy food choices.

In contrast, the BCM is concerned with individual morality and creating societies which favour self-disciplined citizens. For the BCM, individual moral virtue, strength, and health are active life projects achieved through systematic application of the principles of work and restraint. Proponents of individualised moralities prioritise moral strength and tend to be ambivalent at best towards those people considered weak or immoral. As a result, for the BCM, the bodies of obese individuals signify or visibly manifest their lack of virtue because those very bodies have been produced by the immoral behaviours of gluttony and sloth.

I argued that the moral dimensions of the obesity models lead directly to a process of scapegoating. Here, a 'scapegoat' is any entity onto which blame and responsibility for obesity causality is arbitrarily projected. The scapegoat is then sacrificed in order to purify the community of the danger represented by obesity. I asserted that both the ECM and BCM misassign moral blame to some degree by employing mono-causal explanations of obesity which blame either behaviour or the environment as the sole cause. In this blaming process, both models neglected to acknowledge the explanation given by the other. In addition in this blaming process, both of these causality models neglect to acknowledge that obesity prevalence is highest in low income groups and specific ethnic groups. These facts combine with the moralisation of the problem of obesity, to scapegoat these groups. These groups are 
loaded with an unfair portion of the blame for problems that are in fact products of complex factors not entirely within their control. In sum, each of these models: 1 . obscures the fact that the causes of obesity are complicated; 2. proffers insufficient explanations of causality; 3. fails to adequately address the problem of correlation between obesity, income inequality and ethnicity; and 4. scapegoats various forces and groups by combining simplistic explanations with moralising and blame.

The next two chapters addressed what I take to be the most significant scapegoats in the moralisation of obesity, socioeconomic and ethnic groups.

Chapter Seven addressed the economic dimensions of the obesity models. The chapter began with an overview of the worldwide literature calculating the financial burden of obesity to nations. This literature adds a financial dimension to the moralising 'burden' language outlined in Chapter Six. I argued that this 'cost of obesity' analysis portrayed the obese as negative contributors to society. The obese have increasingly been an object of political and moral discourse because they are portrayed, across the board, as a cost to nations, economies, health systems, employers, families, and employers. This financial rationale explains why all models, right across the 'spectrum', are specifically concerned with allocating responsibility for obesity.

Chapter Seven then discussed the ideological differences which existed in 'official obesity discourse.' I argued that proponents of the BCM associate economic efficiency with the nutritional intake and expenditure of the body. For the BCM, the body should function at a point of efficient equilibrium where outputs equal nutritional inputs. As a consequence, the $\mathrm{BCM}$ views the obese body as inefficient. In contrast, the Marxist critique of economics argues that obesity is caused through people living in material conditions which systematically disadvantage them.

This Marxist critique reoriented the chapter towards discussing the correlation between social deprivation and obesity prevalence. I discussed how 'inequalities' arguments were ideological, and associated with the MCM policy of Labour in the years 2000-2005. However, despite the fact that those who promote inequalities arguments are politically motivated, there is sufficient evidence that New Zealand's lower socio-economic groups have higher instances of mortality, disease, and obesity than higher income groups. One characteristic of the 'obese' which is neglected by the ECM is that they tend to be poor. This means that these two politically 
dominant models of obesity, the BCM and ECM, with their generalised mono-causal explanations, obscure the fact that obesity is related to inequality.

Chapter Eight built upon the previous chapter by addressing the ethnic dimensions of obesity prevalence. I argued that generalised measures of obesity, such as BMI, hide the ethnic specificity of obesity prevalence and that the models at both ends of the 'political spectrum of obesity causation models' overlook the relationship between ethnic identification and obesity prevalence. I claimed that the majority of 'official obesity discourse' does not explore the possibility that two forms of inequality - that is, ethnic and income inequality - might be major factors in producing and distributing obesity in this country

Chapter Eight showed that significant variation existed in the average BMI measurements of the four ethnic groups measured in the 2000s. The Maori and Pacific Islands populations had significantly higher average BMI than the population average and Europeans. Maori were on average heavier than non-Maori across all deprivation deciles. In contrast, the Asian population had a lower average BMI compared to the general population and Europeans and yet still had high rates of cardiovascular diseases, physical inactivity, and Type 2 Diabetes. These results demonstrated that generalised discussions of obesity and the obesity models neglect an important ethnic dimension of obesity prevalence.

Chapter Eight then explained why the ECM and BCM did not address ethnicity and the harm inflicted by this omission. The MCM policy had addressed the relationship between obesity and ethnicity, but by 2004, this had become a political hot potato. Political tension contributed to the ECM and BCM's failure to address ethnicity directly. The harm which arises out of the 'spectrum's' avoidance of ethnicity is that the people who are most likely to suffer or die early from obesity related illnesses are being ignored.

I concluded Chapter Eight with the argument that the 'political spectrum of obesity causation models' had closed down the possibility for robust political discussions of ethnicity and inequality because it incorrectly assigns blame for obesity causality. I claimed that my analysis illustrated that more nuanced causal explanations of obesity will be required in the future. A broader understanding of obesity discourse will need to be developed that acknowledges that ethnicity and social deprivation are key issues. In the following section, I point in the direction of an analytical model of official obesity discourse that could redress these oversights. 
This completes my summary of the findings of Part Two. Part Two began by reformulating the moral dimensions of obesity discourse. The moral dimensions allowed for a critical analysis of the moral arguments of the obesity models and of the scapegoating dynamics at work in them. Part Two shows that the moralisation of 'official obesity discourse', in combination with inadequate, monocausal explanatory models, is particularly harmful to those on low incomes and those in Maori and Pacific Island populations.

\subsection{Modelling the Moral Politics of Official Obesity Discourse}

In Part Two of this dissertation, I argued that a more nuanced model is required to overcome the shortcomings of 'official obesity discourse.' I suggested also that the politicised nature of this discourse might be preventing effective communication and progress in treating obesity. To clarify, I do not want to make a naïve claim that obesity discourse must be decoupled from particular moral or ideological views for progress to be made in treating and accepting obesity within the population. Instead, I want to clarify my views on 'official obesity discourse' and then offer five lessons from this study, which I hope can reframe our understanding of obesity discourse. In particular, I will argue that it is crucial that we move towards a 'Model of the Moral Politics of Official Obesity Discourse' that includes all the ideological and moral views of official obesity discourse and the criticisms of these views.

As background to what follows, I must first clarify my own views on certain issues. I hold that the notion of the 'obesity epidemic' is an ideological tool used to justify certain approaches to health provision. Nonetheless, I believe that obesity is indeed a health problem insofar as it increases one's risk of developing other illnesses. I believe also that through the force of the 'cost of obesity' literature alone, obesity will continue to be seen as a financial and moral problem for Governments. Of course, it is true that current ideological approaches diverge over who or what is responsible for these costs. However, the limits of the current debate are set by a common conviction that obesity is a real cost that must somehow be met. Thus, while I believe the 'epidemic' is in part an ideological construct, it rests upon a real problem.

Whether or not it is given the name 'epidemic', that problem is likely to remain important for policy in the foreseeable future.

It is also important to acknowledge that the obese are discriminated against in a manner no longer acceptable in any other part of society. Moreover, as should have been clear from my 
arguments about scapegoating, I find that this discrimination is underpinned by flawed ideological models of causality. I hold that this discrimination should be challenged and overcome, but it also seems that this is unlikely to occur in the near future. Finally, as will be clear from Chapters 7 and 8 , I believe that obesity prevalence is unevenly distributed by class and ethnicity and that these two factors provide powerful tools that could be used to challenge discrimination.

Against this background, the most important lessons of my dissertation are:

First, I would hope that anyone who reads this dissertation would, in the future, pause and consider the language, assumptions, and value judgements that they themselves use to frame their thinking about obesity or fatness. Simply acknowledging the existence of discrimination is a beginning.

Second, I hope that readers of this dissertation can use the discussion of models of obesity causation and the other themes developed within this thesis for future interpretation and classification of 'official obesity discourse.' The BCM, with its links to the New Right and Neo-Liberalism, is applicable on a global scale, while elements of the ECM and MCM will also be informative for the study of other nations. Moreover, I hope that readers will acknowledge the importance of addressing economic inequality and the treatment of indigenous peoples and non-European peoples in other studies of 'official obesity discourse.'

Third, I hope that my history of obesity discourse, the political spectrum of obesity causation models, and the critique I have offered of them will help New Zealand readers to understand and interpret the ideological and moral dimensions and limits of obesity discourse in this country. I hope that this analysis might be particularly helpful to those who were confused about the rationale behind the current National Government's lack of concern about obesity. I hold that National's apparent lack of obesity discourse is in fact a return to a BCM-based, ideological approach, concentrated on making individuals responsible for meeting the costs and consequences of their obesity.

Fourth, I would urge that any future discussion of the moral dimensions of obesity discourse should not interpret it as directly linked to Christian understandings of the body and morality. I found little evidence to suggest that a Christian theology, moral discourse, or ideas of sin are 
evident in official obesity discourse outside of some ideas presented by proponents of the BCM. It is possible that some proponents of the BCM tacitly employ Protestant notions of work to their obesity discourse but I cannot conclusively demonstrate this argument. I would recommend that those who wish to pursue the theory I held going into the thesis, that there is a type of implicit Protestantism at play in contemporary body morality, should investigate popular culture for this effect. Perhaps such an effect might be found in certain areas of the United States because of high proportions of religious affiliation. Even after these suggestions, I suspect the increasing diversity and multi-ethnic nature of Western societies will make this sort of search increasingly problematic as empirical evidence for such an argument is likely to only come from Protestant dominated communities and discourses.

In response to this finding, I ultimately rooted my analysis in Religious Studies while demonstrating that moral systems must be addressed in terms of the context and language from which they arise. It is still possible that one can use lenses and analogies from Religious Studies, as I do in Chapter Six, to provide insight or comparison into the context of the case study but we must also recognise that such frameworks have limited usefulness for understanding obesity discourse.

Fifth, I suggest that we need to reframe our conceptual thinking around a 'Model of the Moral Politics of Official Obesity Discourse.' I have shown that the terms used to discuss 'the obesity problem' are often ambiguous and contain certain economic, political, and moral assumptions and agendas. These terms also a priori assume that the health problem of obesity is also a social, moral, and economic problem. I have also outlined how 'official obesity discourse' neglects to address the inequality dimensions of obesity prevalence. One way that we can think about the limits of 'official obesity discourse' is through the 'political spectrum of obesity models.' This 'spectrum' models the current ideological divisions and is useful for thinking about how this discourse currently constitutes itself without any critical reflection. However, Part Two argued that this model needs to be supplemented by the hitherto neglected nuances and limits of 'official obesity discourse,' which is why I offer a 'Model of the Moral Politics of Official Obesity Discourse' here. 
Future research will be able to draw upon this model to incorporate all the various dimensions and limitations of this discourse. To clarify, this 'Model of the Moral Politics of Official Obesity Discourse' should consider:

1. That all official obesity discourse is ideological. There exist three different ideological models of obesity discourse which can be mapped along a 'spectrum' with the ECM at one extreme and the BCM at the other.

2. That obesity creates a burden of costs that must be allocated.

3. That the causes of obesity remain disputed with the models blaming obesogenic environments, individual behaviour, or a combination of the two.

4. There exist disputed notions over whether states or individuals should be responsible for the costs of obesity.

5. There exist contested views of whether individuals have the agency to change their bodies.

6. That ideological obesity models, to date, neglect to address the moral, ethnic, and economic dimensions of obesity and this neglect inflicts harm upon the obese.

7. The moral dimensions of obesity discourse are divided between individual and communal interpretative models, where the individual moral model is far more overt in its discrimination, while the communal model discriminates through correction and coercion.

8. That obesity prevalence is related to social deprivation.

9. That obesity prevalence affects various ethnic groups in different ways.

10. That blinkered approaches to obesity perpetuate obesity prevalence and prevent real progress in addressing obesity prevalence and discrimination.

When one includes all these dimensions of official obesity discourse, one should be able to produce more nuanced research. I hope that by using this 'inclusive model of official obesity discourse', it will be possible to set aside the ideological dimensions of this discourse to some extent. This thesis shows the difficulties of considering the problem of obesity as a whole without influence from powerful ideological, economic, and scientific discourses. Yet this model is inclusive enough to recognise the widespread concerns associated with obesity and the global growth in obesity rates, while also addressing criticisms of the 'obesity epidemic' and some of the views of Fat scholars. 
Thus, this model's purpose is to acknowledge that obesity is a global concern, whilst weakening the domination of the debate by ideological, economic, and scientific agendas. This model allows us to consider 'official obesity discourse,' in its entirety, as a contested sphere in which the obese are unnecessarily discriminated against. This model opens the possibility for future discourse that acknowledges and addresses these limitations and problems.

\subsection{Future Research Directions}

This dissertation contributes a series of future research directions over a number of disciplines.

In New Zealand, this study and history of 'official obesity discourse' would, if pursued further, benefit from qualitative interviews with the main personalities who have contributed to and constituted this discourse. These people include, but are not limited to, Robyn Toomath, Boyd Swinburn, Nick Wilson, John Birkbeck, Cat Pausé, Annette King, Pete Hodgson, Simon Upton, Bill Birch, David Cunliffe, Sue Kedgley, Tony Ryall, Andrew Prentice, Susan Jebb, and Carolyn Watts. Questioning these people about their contributions to the discourse would provide additional insights into the history, nature, and workings of the discourse as a whole. My study could also be supplemented by investigations into different population groups, discussions with bariatric surgeons, studies of how GPs treat the obese, gender comparisons, age comparisons, ethnic comparisons, and class comparisons, all of which would add further dimensions and challenges to our readings of 'obesity discourse.'

My research methods and causality models could be applied by a wide range of researchers to draw out their specific research interests. The three causality models of obesity discourse developed in this thesis should be applicable and evident in most countries around the world. The BCM explains the type of causality model which was applied in the House of Commons Report. ${ }^{4}$ In Australia, Townend' ${ }^{5}$ work demonstrated that there are similar ideological dynamics at play in 'official obesity discourse.' Her research suggested that the BCM was one strong view at play in Australian obesity discourse. Her work also suggested that there was a conflation of the MCM and ECM also evident in Australian discourse.

\footnotetext{
${ }^{4}$ House of Commons, Health Committee Report.

${ }^{5}$ Townend, "The Moralizing of Obesity," 175.
} 
The dynamic 'Model of the Moral Politics of Official Obesity Discourse' will be applicable to the study of official obesity discourse in many other Western Countries. The 'Model of the Moral Politics of Official Obesity Discourse' can be applied as a working tool which other researchers can use to identify and investigate the various overt and covert ideological, moral, economic, and ethnic dimensions of official obesity discourse. It is vital, however, that researchers cautiously consider ethnicity within their own context.

Ethnicity and its relationship with obesity prevalence is a crucial area of future research as the world's populations are becoming increasingly multi-cultural. My research shows that the ethnic dimensions of obesity remain poorly understood and there needs to be intensive empirical and qualitative research into the relationship between ethnicity and body mass. It is likely that future research will need to balance national and ethnic specific studies with the contextual problem of the global immigration of peoples. Ethnic studies will also need to address the complications of ethnic mobility and acknowledge that many children today have parents with radically different ethnic backgrounds.

In respect to those interested in a radical approach aimed at dismantling obesity discrimination, my findings indicate that the greatest gain in this area would result from a systematic analysis of the financial dimensions of obesity discourse. Such an analysis would challenge the assumptions of 'cost of obesity' literature, which is the central pillar that girds the systemic ideological and moral discrimination against the obese.

Religious Studies scholars can use this study as a contribution to the puzzle encapsulating the use of Christian language and morality within popular culture. Future studies in this area can draw upon my work, and my methodological difficulties, to delineate their own research agendas in this field. I suggest that future research could investigate the possibility that the moral language and systems of Christianity are still being revised and relied on as nontheological schemas used by people who struggle to find clear language to talk about fears of death, illness, and discrimination. 


\section{Bibliography}

\section{Publications}

Alighieri, Dante. Dante's Inferno: The Vision of Hell. London: Cassell and Company, 1892.

Anderson, Gary. Sin: A History. New Haven: Yale University Press, 2009.

Aronne, Louis. "Classification of Obesity and Assessment of Obesity-Related Health Risks," Obesity Research 10 (2002): 105S-115S.

Ashton, Toni. The Economics of Health Promotion. Auckland: Premier Print, 1992.

Ayers, John, Richard Hofstetter, Veronica Irvin, Yoonju Song, Hae Ryun Park, Hee-Yong Paik and Melbourne Hovell. "Can Religion Help Prevent Obesity? Religious Messages and the Prevalence of Being Overweight or Obese Among Korean Women in California.” Journal for the Scientific Study of Religion 4, no.3 (2010): 536-549.

Banks, John. "Forward." In Life in New Zealand Summary Report. N. C. Wilson, D.G. Russell, J.M. Paulin et al. Dunedin: University of Otago, 1990.

Barber, Benjamin. Jihad vs McWorld. New York: New York Times Books, 1995.

Barrett, Amy, Ann Colosia, Kristina Boye and Olatoye Oyelowo, "Burden of Obesity: 10-Year Review of the Literature on Costs in Nine Countries." $13^{\text {th }}$ Annual Meeting of the International Society for Pharmoeconomics and Outcomes research Seminar. Toronto: International Society for Pharmoeconomics and Outcomes, 2008.

Beaglehole, Robert, and Ruth Bonita. “Cardiovascular Disease.” In Social Dimensions of Health and Disease: New Zealand Perspectives, eds. John Spicer, Andrew Trlin, and Jo Ann Walton, 55 82. Palmerston North: Dunmore Press, 1994.

Belgrave, Michael. "A Historical Perspective on the Politics of Health Care.” In Understanding Health Inequalities in Aotearoa New Zealand, eds. Kevin Dew and Anna Matheson 69-84.

Dunedin: Otago University Press, 2008.

Bell, Rudolph. Holy Anorexia. Chicago: The University of Chicago Press, 1985.

Birkbeck, John. New Zealanders and their Diet: A Report to the National Heart Foundation of New Zealand on the National Diet Survey 1977, 2nd Edition. Dunedin: Otago University Press, 1983.

Birkbeck, J. A. “Obesity, Socioeconomic Variables and Eating Habits in New Zealand.” Journal of Biosocial Science 13 (1981): 299-307.

Bloomfield, Morton. The Seven Deadly Sins: An Introduction to the History of a Religious Concept with Special Reference to English Literature. Michigan: Michigan State University Press, 1967.

Bordo, Susan. Unbearable Weight: Feminism, Western Culture, and the Body. California: University of California Press, 1993. 
Bossy, John, "Moral Arithmetic: Seven Sins into Ten Commandments." In Conscience and Casuistry in Early Modern Europe, ed. Edmund Lietes, 214 -234. Cambridge: Cambridge University Press, 1988.

Bowie, Robert, and Ian Shirley. "Political and Economic Perspectives on Recent Health Policy." In Social Dimensions of Health and Disease: New Zealand Perspectives (eds) John Spicer, Andrew Trlin, Jo Ann Walton, 298- 322. Palmerston North: Dunmore Press, 1994.

Brown, Peter. The Body and Society: Men, Women, and Sexual Renunciation in Early Christianity. New York: Columbia University Press, 1988.

Brown, Tim. "Towards an Understanding of Local Protest: Hospital Closure and Community Resistance.” Social and Cultural Geography 4, no. 4 (2003): 489-506.

Campos, Paul. The Obesity Myth, Why America's Obsession With Weight is Hazardous to Your Health. New York: Gotham Books, 2004.

Cassian, John. The Conferences. New York: The Newman Press, 1997.

Chamberlain, Jenny. "Getting Heavy with Fat." North and South Magazine (May 2004): 34-45.

Chapian, Marie and Neva Coyle. Free to Be Slim: A Christian Approach to Losing Weight.

Minneapolis: Bethany House Publishers, 1989.

Chaucer, Geoffrey. The Canterbury Tales. London: Arnold, 1980.

Clark Jr, Charles. "Combating Sloth as Well as Gluttony: The Role of Physical Fitness in Mortality among Men with Type 2 Diabetes.” Annals of Internal Medicine 132, no. 8 (2000): $669-670$.

Cline, Krista and Kenneth Ferraro. "Does Religion Increase the Prevalence and Incidence of Obesity in Adulthood?" Journal for the Scientific Study of Religion 45, no. 2 (2006): 269-281.

Coakley, Sarah. Religion and the Body. Cambridge: Cambridge University Press, 1997.

Cohen, Mark. Health and the Rise of Civilisation. New Haven: Yale University Press, 1989.

Coney, Sandra. The Unfortunate Experiment: the Full Story Behind the Inquiry into Cervical Cancer Treatment. Auckland: Penguin Books, 1988.

Cooper, Charlotte. "Maybe it Should be Called Fat American Studies." In The Fat Studies Reader, eds. Esther Rothblum and Sondra Solway, 327-333. New York: New York University Press, 2009.

Cooper, Charlotte. "Fat Studies: Mapping the Field.” Sociology Compass 4, no. 12 (2010) 10201034.

Crampton, E. “Taxes an Invasive Way of Guiding Choices.” The Press, December 17, 2007.

Cullen, Michael. Budget Speech 2006. Wellington: The Treasury, 18th May 2006. 
Cullen, Michael. Budget 2006, Executive Summary. Wellington: The Treasury, 2006.

Cullen, Michael. Budget Policy Statement 2000. Wellington: The Treasury, 8 March 2000.

Cunnigham, Chris. "Diversity and Equity for Maori." In Understanding Health Inequalities in Aotearoa New Zealand, eds Kevin Dew and Anna Matheson, 55 - 66. Dunedin: Otago University Press, 2008.

Daley, Caroline. Leisure and Pleasure: Reshaping and Revealing the New Zealand Body 1900-1960. Auckland: Auckland University Press, 2003.

Dairy Advisory Bureau. Fat in your Food. Wellington: Dairy Advisory Bureau, 1992.

De Garine, Igor, and Pollock, Nancy. Social Aspects of Obesity. Amsterdam: Gordon and Breach Science Publishers, 1995.

Dixon, Jane and Dorothy Broom. The Seven Deadly Sins of Obesity: How the Modern World is Making Us Fat. Sydney: University of New South Wales Press, 2007.

Dow, Derek A. Maori Health and Government Policy 1840 - 1940. Wellington: Victoria University Press, 1999.

Durie, Mason. Nga Kahui Pou: Launching Maori Futures. Wellington: Huia Publishing, 2003.

Durie, Mason. Mauri Ora: The Dynamics of Maori Health. Melbourne: Oxford University Press, 2001.

Durie, Mason. Whaiora: Maori Health Development 2nd Edition. Auckland, Oxford University Press, 1998.

Eagleton, Terry. An Introduction to Ideology. London: Verso Press, 1991.

Easton, Brian. “Does Poverty Affect Health?" In Understanding Health Inequalities in Aotearoa New Zealand. eds. Kevin Dew and Anna Matheson. Dunedin: Otago University Press, 2008.

Easton, Brian. The Commercialisation of New Zealand. Auckland: Auckland University Press, 1997.

Egger, Garry and Boyd Swinburn. "An Ecological Approach to the Obesity Pandemic.” British Medical Journal 315 (1997): 477-480.

Ellis, Lee and David Biglione. "Religiosity and Obesity: are Overweight People More Religious?" Personality and Individual Differences 28 (2000): 1119-1123.

Evans, Bethan. "Gluttony or Sloth: Critical Geographies of Bodies and Morality in (Anti) Obesity Policy.” Area 38, no. 3 (2006): 259-267.

Henrie, Farlie. The Seven Deadly Sins Today. Washington: New Republic Books, 1978. 
Ferraro, Kenneth. "Firm Believers? Religion, Body Weight, and Well Being." Review of Religious Research 39, no. 3 (1998): 224-244.

First International Conference for Health Promotion. Ottawa Charter for Health Promotion. Ottawa: First International Conference for Health Promotion, 1986.

Fisher, Irving. “A New Method for Indicating Food Values.” American Journal of Physiology 15 (1906): 417-432.

Foucault, Michel. Power: Essential Works of Foucault 1954-1984, Volume 3. London: Penguin Books, 2000.

Foucault, Michel. The Birth of the Clinic: An Archaeology of Medical Perception. London: Routledge, 1997.

Foucault, Michel. Discipline and Punish: The Birth of the Prison. London: Penguin Books, 1991.

Fox, Matthew. Sins of the Spirit, Blessings of the Flesh: Lessons for Transforming Evil in Soul and Society. New York, Three Rivers Press, 1999.

Frezza, Eldo and Mitchell Wachtel. "The Economic Impact of Obesity.” Surgical Endoscopy 23, no. 4 (2009): 677-679.

Gard, Michael. The End of the Obesity Epidemic. New York: Routledge, 2011.

Gard, Michael and Jan Wright. The Obesity Epidemic: Science Morality and Ideology. New York: Routledge, 2005.

Gibbs, Alan, Dorothy Fraser, and John Scott. Unshackling the Hospitals. Wellington: Hospital and Related Services Taskforce, 1988.

Girard, Rene. Violence and the Sacred. Baltimore: John Hopkins University Press, 1977.

Griffith, Marie. Flesh and Spirit in American Christianity: Born Again Bodies. California: University of California Press, 2004.

Grimshaw, Michael. "I Can't Believe My Eyes!!! The Religious Aesthetics of Sport as Postmodern Salvific Moments." Implicit Religion, 3, no. 2 (2000): 87-99.

Hall, Anne. "Anorexia Nervosa, Bulimia and Obesity." In Are We Really What We Eat? Food Choice as a Basis for Better Health, ed. J. A. Birkbeck, 96-104. Auckland: Dairy Advisory Bureau, 1987.

Haren, Michael. Sin and Society in Fourteenth-Century England: A Study of the Memoriale Presbiterorum. Oxford: Clarendon Press, 2000.

Harjunen, Hannelle. Women and Fat: Approaches to the Social Study of Fatness. Jyvaskyla: University of Jyvaskyla, 2009. 
Harjunen, Hannelle. "The Construction of an Acceptable Female Body in Finnish Schools.” In Gendered and Sexualised Violence in Educational Environments, eds. Vappu Sunari, JennyKangasvuo and Mervi Heikkinen. 78-91 Oulu: Oulo University Press, 2003.

Harris, Ricci, Martin Tobias, Mona Jeffreys, Kiri Waldegrave, Saffron Karlsen and James Nazroo. "Effects of Self-reported Racial Discrimination and Deprivation on Maori Health and Inequalities in New Zealand: Cross Sectional Study.” The Lancet, 367 (2006): 2005-2009.

Hide, Rodney. My Year of Living Dangerously. Auckland: Random House, 2007.

Hill, Sarah. "Socio-economic Inequalities in Health." In Understanding Health Inequalities in Aotearoa New Zealand, eds Kevin Dew and Anna Matheson, 33-54. Dunedin: Otago University Press, 2008.

Hopper, Ngaire. "Pilot Study Provides a Glimpse of Kiwi Diet, Health.” Evening Post, December 19, 1989.

House of Commons. Health Committee Report on Obesity: Third Report of the Session 2004-04 Vol 1. London: The Stationary Office Ltd, 2004.

House of Representatives. Inquiry into Obesity and Type 2 Diabetes in New Zealand: Report of the Health Committee Chairperson Sue Kedgley. Wellington: House of Representatives, 2007.

Hoverd, William James. "Deadly Sin, Gluttony, Obesity and Health policy." In Medicine, Religion and the Body, eds Elizabeth Burns Coleman and Kevin White, 205-230. Leiden: Brill, 2010.

Hoverd, William James, and Chris Sibley. "Immoral Bodies: The Implicit Association between Moral Discourse and the Body.” Journal for the Scientific Study of Religion 46, no. 3 (2007): 391 403.

Hoverd, William James. Working Out My Salvation: The Contemporary Gymnasium and the Promise of 'Self' Transformation. Aachen: Meyer and Meyer Sport, 2005.

Hughes, David, and Alastair McGuire. "A Review of the Economic Analysis of Obesity." British Medical Bulletin 53, no. 2 (1997): 253-263.

Humpage, Louise, and Augie Fleras. "Intersecting Discourses: Closing the Gaps, Social Justice and the Treaty of Waitangi." Social Policy Journal of New Zealand 16 (2001): 37-54.

Hunter, Francis. God's Answer to Fat...Loose it! Houston: Hunter Ministries, 1976.

James, Phillip, Rachel Leach, Eleni Kalamara \& Maryam Shayegi. "The Worldwide Obesity Epidemic.” Obesity Research 9 (2001): S228-S233.

Janieswski, Dolores, and Paul Morris. New Rights New Zealand: Myths, Moralities and Markets. Auckland: Auckland University Press, 2005. 
Jones, Peter, Peter Shears, David Hillier, Daphne Comfort and Jonathan Lowell. "Return to Traditional Values? A Case Study of Slow Food.” British Food Journal 105, no. $4 / 5$ (2003): 297-304.

Jutel, Annemarie. "Doctors Orders: Diagnosis, Medical Authority, and the Exploitation of the Fat Body." In Biopolitics and the Obesity Epidemic: Governing Bodies, (eds) J. Wright and V. Harwood, 60-77. New York: Routledge, 2009.

Jutel, Annemarie. "Weighing Health: The Moral Burden of Obesity.” Social Semiotics 15, no. 2 (2005): 113-125.

Karcher, Helmut et al. "Hospital Closures.” British Medical Journal 309 (1994): 973-977.

Katzmarzyk, Peter. “The Canadian Obesity Epidemic 1985-1998.” Canadian Medical Association Journal 166, no. 8 (2002): 1039-1040.

Kim, Karen, and Jeffery Sobal. "Religion, Social Support, Fat Intake and Physical Activity.” Public Health Nutrition 7, no. 6 (2004): 773-781.

Kim, Karen, Jeffery Sobal and E. Wethington. "Religion and Body Weight." International Journal of Obesity 27 (2003): 469-477.

Kortt, Michael, Paul Langley, and Emily Cox. "A Review of Cost-of-Illness Studies on Obesity." Journal of Clinical Therapeutics 20, no. 4 (1998): 772-778.

Ladd, Tony, and James Mathieson. Muscular Christianity, Evangelical Protestants and the Development of American Sport. Grand Rapids: Baker Book House, 1999.

Lakoff, George. Moral Politics: How Liberal and Conservatives Think Second Edition. Chicago: University of Chicago Press, 2002.

Lalonde, Marc. A New Perspective on the Health of Canadians: A Working Document. Ottawa: Ministry of Supply and Services, 1974.

Lebesco, Kathleen. Revolting Bodies? The Struggle to Redefine Fat Identity. Boston: University of Massachusetts Press, 2004.

Lelwica, Michelle. Starving for Salvation: The Spiritual Dimensions of Eating Problems Among American Girls and Women. New York: Oxford University Press, 1999.

Lopez, Alan, Colin Mathers, Majid Ezzati, Dean Jamison and Christopher Murray. "Measuring the Global Burden of Disease and Risk Factors, 1990 - 2001." In Global Burden of Diseases and Risk Factors, eds Allan Lopez, Colin Mathers, Majid Ezzati, Dean Jamison and Christopher Murray 1-12. New York: Oxford University Press, 2006.

Mann, Jim et al. Life in New Zealand Commission Report, Volume V: Health. Dunedin: Otago University Press, 1991. 
Matheson, Anna, and Kevin Dew. "Health, Justice and Politics." In Understanding Health Inequalities in Aotearoa New Zealand, eds. Kevin Dew and Anna Matheson, 9-16. Dunedin: Otago University Press, 2008.

Macguire, Anne. Seven Deadly Sins: The Dark Companions of the Soul. London: Free Association Books, 2004.

Mello, Michelle, David Studdert, and Brennan Troyen. "Obesity - The New Frontier of Public Health Law.” The New England Journal of Medicine, 354, no. 24 (2006): 2601-2610.

Ministry of Transport. Getting there - by Foot, by Cycle: Strategic Implementation Plan 2006-2009. Wellington: Ministry of Transport, 2006.

Morris, Stephen. “The Impact of Obesity on Employment.” Labour Economics 14, no.3 (2007): 413-433.

Murphy, Lawrence. "To the Market and Back: Housing Policy and State Housing in New Zealand.” Geojournal 59 (2003): 119-126.

Murray, Samantha. The Fat Female Body. Basingstoke: Palgrave McMillan, 2008

Murray, Samantha. "Corporeal Knowledges and Deviant Bodies: Perceiving the Fat Body." Social Semiotics 17, no. 3 (2007): 361-373.

Murray, Samantha. "(Un/Be) Coming Out? Rethinking Fat Politics.” Social Semiotics 15, no. 2 (2005) 153-163.

Myers, David. 'Poor Sinning Folk' Confession and Conscience in Counter-Reformation Germany. Ithaca: Cornell University Press, 1996.

National Health Committee. Improving Health for New Zealanders by Investing in Primary Health Care. Wellington: National Health Committee, 2000.

New Revised Standard Version: Holy Bible. New York: American Bible Society, 1991.

Norman, Joanne. "Lay Patronage and the Popular Iconography of the Seven Deadly Sins." In Art into Life: Collected Papers from the Kresge Art Museum Medieval Symposia, eds Carol Garrett Fisher, and Kathleen L. Scott, 213-236. East Lansing: Michigan State University Press, 1995.

Orbach, Susie. Fat is a Feminist Issue: How to Lose Weight Permanently Without Dieting. London: Arrow Books, 1978.

Papas, M., A. Alberg, R. Ewing, K. Helzisour, T. Gary and A. Klassen. "The Built Environment and Obesity.” Epidemiological Reviews 29:1 (2007): 1-15.

Parry, Jim, Mark Nesti, Simon Robinson and Nick Watson. Spirituality and Sport: An Introduction. London: Routledge, 2007.

Pausé, Caitlin. Invisible Women: Exploring Weight Identity in Morbidly Obese Women. Texas: Texas Tech University, 2007. (Unpublished Doctoral Dissertation) 
Pearce, Michelle, Juli Boergers, and Mitchell J. Prinstein. "Adolescent Obesity, Overt and Relational Peer Victimisaton, and Romantic Relationships.” Obesity Research 10 (2002): 386 393.

Pickett, Kate, Shona Kelly, Eric Brunner, Tim Lobstein, and Richard Wilkinson. "Wider Income Gaps, Wider Waistbands? An Ecological Study of Obesity and Income Inequality." Journal for Epidemiology and Community Health 59 (2005): 670-674.

Pieterman, Roel. "The Construction of Fat: Care and Control in the Public Concern for Healthy Behaviour.” Sociology Compass 1 (2007): 309-321.

Polivy, Janet, and David Garner. "Causes and Consequences of the Current Preference for Thin Female Physiques.” In Physical Appearance, Stigma and Social Behaviour: The Ontario Symposium, Volume Three, eds Edward Higgins, Peter Herman and Marc Zanna, 123-132. New York: Lawerance Erlbaum Associates, 1986.

Ponticus, Evagrius. The Praktikos: Chapters on Prayer. Translated by J. E. Bamberger. Michigan: Cistercian Publications, 1981.

Pool, Ian. “Cross-Comparative Perspectives on New Zealand's Health.” In Social Dimensions of Health and Disease: New Zealand Perspectives, eds John Spicer, Andrew Trlin, Jo Ann Walton, 16 -49. Dunmore Press, Palmerston North, 1994.

Popenoe, Rebecca. "Ideal.” In Fat: The Anthropology of an Obsession, eds Don Kulick \& Anne Meneley, 9-28. Penguin Books, New York, 2005.

Popkin, Barry, and Colleen Doak. "The Obesity Epidemic is a Worldwide Phenomenon." Nutrition Reviews (1998): 106-114.

Prentice, Andrew, and Susan Jebb. "Obesity in Britain, Gluttony or Sloth?" British Medical Journal 311 (1995): 437-439.

Puhl, Rebecca, and Kelly D. Brownell. "Bias, Discrimination, and Obesity.” Obesity Research 9:12 (2001): 788-805.

Raphael, Dennis. "Social Determinants of Health: Present Status, Unanswered Questions, and Future Directions.” International Journal of Health Services 36, no. 4 (2006): 651-677.

Rasanathan, Kuman, Shanthi Ameratunda, Janet Chen et al. A Health Profile of Young Asian New Zealanders who Attended Secondary School: Findings from Youth 2000. Auckland: University of Auckland, 2006.

Ritzer, George. The McDonaldisation of Society: an Investigation into the Changing Character of Contemporary Social Life. Thousand Oaks: Pine Forge Press, 1996.

Robson, Bridget. "What is Driving the Disparities?" In Understanding Health Inequalities in Aotearoa New Zealand, eds. Kevin Dew and Anna Matheson, 19-31. Dunedin: Otago University Press, 2008. 
Roux, Larissa and Cam Donaldson. "Economics and Obesity: Costing the Problem or Evaluating Solutions?” Obesity Research 12, no. 2 (2004): 173-179.

Rush, Elaine, Ismael Frietas and Lindsay Plank. "Body Size, Body Composition, and Fat Distribution: Comparative Analysis of European, Maori, Pacific Island and Asian Indian adults.” British Journal of Nutrition 102 (2009): 632-641.

Russell, David, Anthony Worsley and Noella Wilson. The Cost of Doing Nothing: An Assessment of Initiatives in Fitness and Health for the Hillary Commission. Dunedin: University of Otago, 1987.

Ryall, Tony. Better, Sooner, More Convenient Health Discussion Paper. Wellington: The Office of the Leader of the Opposition, 2007.

Schimmel, Soloman. The Seven Deadly Sins, Jewish, Christian and Classical Reflections on Human Psychology. New York: Oxford University Press, 1997.

Schlosser, Eric. Fast Food Nation: The Dark Side of the American Meal. USA:Houghton Mifflin, 2001.

Scott, John. "The Relationship of Dietary Fats to Health." In Are We Really What We Eat? Food Choice as a Basis for Better Health, ed. J A Birkbeck, 82-95. Auckland: Dairy Advisory Bureau, 1987.

Scott Bellar, Anne. Fat and Thin: A Natural History of Obesity. New York: Farrar, Strauss and Giroux, 1997.

Schultz, Jimaima Tanidau. Workshop on Obesity Prevention and Control Strategies in the Pacific. Apia: World Health Organisation Regional Office for the Western Pacific et al., 2000.

Scragg, Robert and Alokandanda Maitra. Asian Health in Aotearoa: An Analysis of the 2002/03 New Zealand Health Survey. Auckland: The Asian Network Inc, 2005

Scwartz, Hillel. Never Satisfied, A Cultural History of Diets, Fantasies and Fat. New York: Doubleday, 1986.

Shieff, Sarah. "Devouring Women: Corporeality and Autonomy in Fiction by Women since 1960." In Bodies Out of Bounds: Fatness and Transgression, eds. Jana Braziel and Kathleen Lebesco, 214-230. Berkley: University of California Press, 2001.

Sibley, Chris, G. Niki Harre, William. J. Hoverd and Carla Houkamau. "The Gap in Subjective Wellbeing of Maori and New Zealand Europeans Widened from 2005 - 2009.” Journal for Social Indicators Research (2010): 1-13.

Soloman, Robert. Wicked Pleasures: Meditations on the Seven "Deadly" Sins. Maryland: Rowman and Littlefield Publishers, 1999.

Sinclair, Keith. A History of New Zealand (revised edition). Auckland: Penguin Books, 2000.

Speakman, John. "Obesity Part one - The greatest health threat facing mankind." Biologist Journal 50, no. 1 (2003). 13. 
Sluyter, John, David Schaaf, Robert K. R. Scragg, and Lindsay D. Plank. "Body Mass Index and Percent Body Fat in a New Zealand Multi-ethnic Adolescent Population.” International Journal of Pediatric Obesity. 6, no. 1 (2010): 1-9.

Statistics New Zealand. The New Zealand Census of Population and Dwellings, 1996: National Summary. Wellington: Statistics New Zealand, 1997.

Stewart, Iain, and Romesh Vaitilingam. Seven Deadly Sins: A New Look at Society Through An Old Lens. Swindon: Economic and Social Research Council, 2005.

Sunstein, Cass, and Richard Thaler. "Liberarian Paternalism is not an Oxymoron." The University of Chicago Law Review 30, no. 4 (2003): 1159-1202.

Swinburn, Boyd, Garry Egger and Fezeela Raza. "Dissecting Obsesogenic Environments: The Development and Application of a Framework for Identifying and Prioritising Environmental Interventions for Obesity." Preventative Medicine 29 (1999): 563-570.

Swinburn Boyd, S.J. Ley, H.E. Carmichael, and L.D. Plank. "Body Size and Composition in Polynesians." International Journal of Obesity 23 (1999):1178-83.

Swinburn, Boyd, Lisa Walter, Heather Ricketts, Gary Whitlock, Bonnie Law, Robyn Norton, Rod Jackson and Stephen MacMahon. "The Determinants of Fat Intake in a Multi-ethnic New Zealand Population.” International Journal of Epidemiology 27 (1998): 416-421.

Swinburn, Boyd, Toni Ashton, Julie Gillespie, Brian Cox, A. Menon, David Simmons and John Birkbeck. "Health Care Costs of Obesity in New Zealand." International Journal of Obesity 21 (1997): 891-896.

Swinburn, Boyd, P. L. Craig, R. Daniel, D. P. D. Dent and B. J. Strauss. "Body Composition Differences between Polynesians and Caucasians Assessed by Bioelectrical Impedance." International Journal of Obesity 20(1996): 889-894.

Taylor, Gabrielle. Deadly Vices. New York: Oxford University Press, 2006.

The Medical Research Council of New Zealand. Adequacy of Medical Statistics in New Zealand. Wellington: The Medical Research Council, 1969.

The National Heart Foundation of New Zealand. Eat Well, Weight Less Using the Healthy Food Pyramid. Auckland: National Heart Foundation of New Zealand, 1990.

The National Heart Foundation of New Zealand. Eat to Beat: Guidelines for Healthy Eating. Auckland: The National Heart Foundation of New Zealand, 1988.

The New Zealand Oxford Dictionary, eds. Tony Deverson and Graeme Kennedy. Melbourne: Oxford University Press, 2005.

Thompson, David and Anne Wolf. "The Medical-care Cost Burden of Obesity." Obesity Reviews 2 (2001): 189-197. 
Townend, Louise. “The Moralizing of Obesity: A New Name for an Old Sin?" Critical Social Policy 29 (2009): 171-190.

Turner, Bryan. The Body and Society: Explorations in Social Theory, Second Edition. London: Sage Publications, 2004.

Turner, Bryan. "The Discourse of Diet.” In The Body, Social Process and Cultural Theory, eds. Mike Featherstone, Mike Hepworth and Bryan S Turner, 157-169. London: Sage Publications 1991.

Turner, Bryan. Medical Power and Social Knowledge. London: Sage Publications, 1987.

Upton, Simon. "Forward.” In Life in New Zealand Summary Report, eds. Noella Wilson, David Russell, and Judy Paulin, et al. Dunedin: University of Otago Press, 1990.

U.S. Department of Health and Human Services. Physical Activity and Health: A Report of the Surgeon General, 1996. Washington: U.S. Department of Health and Human Services, 1996

Veblen, Thorstein. The Theory of the Leisure Class: An Economic Study of Institutions. New York: Random House, 1922.

Walker-Bynum, Caroline. The Religious Significance of Food to Medieval Women. Berkley: University of California Press, 1988.

Waxman, Amelia. "Why a Global Strategy on Diet, Physical Activity and Health? The Growing Burden of Non-communicable Diseases.” Public Health Nutrition 7, no. 3 (2005): 381 383.

Weber, Max. The Protestant Ethic and the Spirit of Capitalism. London: Routledge, 1992.

White, Kevin. "Theories about Health and Society." In Health and Society in Aotearoa, New Zealand, eds. Peter Davis and Kevin Dew, 19-34. Auckland: Oxford University Press, New Zealand, 1999.

Whorton, James. Crusaders for Fitness. The History of American Health Reformers. Philadelphia: Princeton University Press, 1982.

Wilson, Nick, Louise Signal, Sarah Nicholls, and GeorgeThompson. "Marketing Fat and Sugar to Children on New Zealand Television.” Journal of Preventive Medicine 42 (2006): 96-101.

Wilson, Noella, David Russell, Judy Paulin, et al. Life in New Zealand Summary Report. Dunedin: University of Otago Press, 1990.

Withrow, D. and David Alter. "The Economic Burden of Obesity Worldwide: a Systematic Review of the Direct Costs of Obesity.” Obesity Reviews (2010): 1- 11.

Wright, Jan, and Valarie Harwood (eds). Biopolitics and 'the Obesity Epidemic: Governing Bodies. New York: Routledge, 2009. 
Wolf, Anne and Graham Colditz. "Current Estimates of the Economic Cost of Obesity in the United States.” Journal of Obesity Research 6, no. 2 (1998): 173-175.

Wolf, Naomi. The Beauty Myth. How Images of Beauty Are Used Against Women. London: Vintage Books, 1991.

World Health Organisation, "Appropriate Body-mass Index for Asian Populations and its Implications for Policy and Intervention Strategies.” Lancet (Jan 10, 2004):157-63.

World Health Organisation. Global Strategy on Diet, Physical Activity and Health. Geneva: World Health Organisation, 2004.

World Health Organisation. Diet, Food Supply and Obesity in the Pacific. Manila: World Health Organisation Regional Office for the Western Pacific, 2003.

World Health Organisation. Obesity in the Pacific: too Big to Ignore. Manila: World Health Organization, Regional Office for the Western Pacific, 2002.

World Health Organisation. Obesity: Preventing and Managing the Global Epidemic. Report of a WHO Consultation on Obesity. Geneva: World Health Organisation, 2000.

Yach, Derek, David Stuckler and Kelly Brownell. "Epidemiological and Economic Consequences of the Global Epidemic of Obesity and Diabetes.” Nature Medicine 12, no. 1 (2006) 62-66.

\section{New Zealand Ministry of Health Sources}

Delamere, Tuariki. "Foreword." In New Zealand Food: New Zealand People: Key results of the 1997 National Nutrition Survey. Wellington:Ministry of Health, 1999.

Department of Health. Health Facts: Weight and Health. Wellington: Department of Health, 1987.

Hodgson, Peter. Implementing the New Zealand Health Strategy 2005. Wellington: Ministry of Health, December 2005.

King, Annette. Implementing the New Zealand Health Strategy 2003: The Minister of Health's third report on the New Zealand Health Strategy. Wellington: Ministry of Health, December 2003.

King, Annette. Implementing the New Zealand Health Strategy 2002: The Minister's second report on progress on the New Zealand Health Strategy. Wellington: Ministry of Health, December 2002.

King, Annette. Pacific Health Action Plan. Wellington: Ministry of Health, 2002.

King, Annette. Implementing the New Zealand Health Strategy 2001: the Minister of Health's first report on progress on the New Zealand Health Strategy. Wellington: Ministry of Health, December 2001. 
King, Annette. The Primary Health Care Strategy. Wellington: Ministry of Health, February 2001.

King, Annette. The New Zealand Health Strategy, 2000. Wellington: Ministry of Health, December 2000.

McCully, Murray and Wyatt Creech. Physical Activity: Joint Policy Statement by the Minister of Sport, Fitness and Leisure and the Minister of Health. Wellington: Ministry of Health April 1999.

Minister of Health and Minister of Pacific Island Affairs. 'Ala Mo'ui: Pathways to Pacific Health and Wellbeing 2010-2014. Wellington: Ministry of Health, January 2010.

Ministry of Health. A Focus on the Health of Maori and Pacific Children Key Findings of the 2006/07 New Zealand Health Survey. Wellington: Ministry of Health, December 2009.

Ministry of Health. Body Size Technical Report. Wellington: Ministry of Health, 2008.

Ministry of Health. Briefing for the Incoming Minister of Health. Wellington: Ministry of Health, November 2008.

Ministry of Health. Healthy Eating - Healthy Action - Oranga Pumau: Progress on Implementing the HEHA Strategy 2008. Wellington: Ministry of Health, November 2008.

Ministry of Health. Food and Nutrition Guidelines for Healthy Pregnant and Breastfeeding Women: A Background Paper. Wellington: Ministry of Health, November 2008.

Ministry of Health. National Nutrition Guidelines for Healthy Infants and Toddlers (Aged O-2): A Background Paper. Wellington: Ministry of Health, May 2008.

Ministry of Health. Food and Nutrition Guidelines for Healthy Infants and Toddlers (Aged O-2) A Background Paper: Draft for Consultation. Wellington: Ministry of Health, June 2007.

Ministry of Health. Healthy Eating - Healthy Action Oranga Kai - Oranga Pumau: Progress on Implementing the HEHA Strategy 2007. Wellington: Ministry of Health, March 2007.

Minister of Health. Implementing the New Zealand Health Strategy 2006: The Minister of Health's Sixth Report on Progress on the New Zealand Health Strategy. Wellington: Ministry of Health, December 2006.

Ministry of Health. "Embodying Social Rank: How Body Fat Varies with Social Status, Gender and Ethnicity in New Zealand.” Public Health Intelligence Occasional Bulletin 34. Wellington: Ministry of Health, October 2006.

Ministry of Health. "Food and Nutrition Monitoring Report 2006." Public Health Intelligence Monitoring Report 9. Wellington: Ministry of Health, October 2006.

Ministry of Health. "Asian Health Chart Book 2006." Public Health Intelligence Monitoring Report 4. Wellington: Ministry of Health, July 2006.

Ministry of Health. Statement of Intent 2006 to 2009. Wellington: Ministry of Health, May 2006. 
Ministry of Health. Fruit in Schools, A How to Guide. Wellington: Ministry of Health, April 2006.

Ministry of Health. Health and Participation: An Active Agenda. Advice to the incoming Minister of Health. Wellington: Ministry of Health, October 2005.

Ministry of Health. The Health of Pacific Peoples. Wellington: Ministry of Health, April 2005.

Ministry of Health. "Tracking the Obesity Epidemic: New Zealand 1977 - 2003.” Public Health Intelligence Occasional Bulletin 24. Wellington: Ministry of Health, December 2004.

Ministry of Health. "A Portrait of Health: Key Results of the 2002/03 New Zealand Health Survey." Public Health Intelligence Occasional Bulletin 21. Wellington: Ministry of Health, August 2004.

Ministry of Health. Healthy Eating - Healthy Action: Oranga Kai - Oranga Pumau, Implementation Plan: 2004-2010. Wellington: Ministry of Health, June 2004.

Ministry of Health. The Health of New Zealand, Total Population. Wellington: Ministry of Health, June 2004.

Ministry of Health. Tackling Inequalities: Moving Theory To Action, A Final Report on Health Inequalities Awareness Workshops For The Health Sector. Wellington: Ministry of Health, 2004.

Ministry of Health. Key Results of the 2002 National Children's Nutrition Survey. Wellington: Ministry of Health, November 2003.

Ministry of Health. "Food and Nutrition Monitoring in New Zealand." Public Health Intelligence Occasional Bulletin 19. Wellington: Ministry of Health, October 2003.

Ministry of Health. Food and Nutrition Guidelines for Healthy Adults: A Background Paper. Wellington: Ministry of Health, October 2003.

Ministry of Health and the University of Auckland. Nutrition and the Burden of Disease: New Zealand 1997-2011. Wellington: Ministry of Health, August 2003.

Ministry of Health. "Decades of Disparity: Ethnic Mortality Trends in New Zealand 1980 1999." Public Health Intelligence, Occasional Bulletin 16. Wellington, Ministry of Health, July 2003.

Ministry of Health. New Zealand Health Strategy: DHB Toolkit: Physical Activity, To increase physical activity. Wellington: Ministry of Health, June 2003.

Ministry of Health. Healthy Eating, Healthy Action, Oranga Kai - Oranga Pumau: A background 2003. Wellington: Ministry of Health, March 2003.

Ministry of Health. Asian Public Health Project Report. Wellington: Ministry of Health, 2003. 
Ministry of Health. Healthy Action - Healthy Eating Oranga Pumau - Oranga Kai: Towards an Integrated Approach to Physical Activity, Nutrition and Healthy Weight for New Zealand: A Summary of Feedback on the Draft for Consultation. Wellington: Ministry of Health, December 2002.

Ministry of Health. Reducing Inequalities in Health. Wellington: Ministry of Health, September 2002.

Ministry of Health. Doing Better for New Zealanders: Better Health, Better Participation, Reduced inequalities. Wellington: Ministry of Health, August 2002.

Ministry of Health. New Zealand Census Mortality Study: Socioeconomic inequalities and Adult Mortality 1991 - 94. Wellington: Ministry of Health, June 2002.

Ministry of Health. "An Indication of New Zealanders' Health.” Public Health Intelligence Occasional Report 1. Wellington: Ministry of Health, June 2002.

Ministry of Health. "Modelling Diabetes: The Mortality Burden.” Public Health Intelligence, Occasional Bulletin 8. Wellington: Ministry of Health, March 2002.

Ministry of Health. "Modelling Diabetes: A Summary." Public Health Intelligence Occasional Bulletin 11. Wellington: Ministry of Health, March 2002.

Ministry of Health. Diabetes in New Zealand: Models and Forecasts 1996 - 2011. Wellington: Ministry of Health, March 2002.

Ministry of Health. Healthy Action - Healthy Eating Oranga Pumau - Oranga Kai: Towards an Integrated Approach to Physical Activity, Nutrition and Healthy Weight for New Zealand (Submission Booklet). Wellington: Ministry of Health, February 2002.

Ministry of Health. "Monitoring Ethnic Inequalities in Health." Public Health Intelligence Occasional Bulletin 4. Wellington: Ministry of Health, June 2001.

Ministry of Health. "Priorities for Maori and Pacific Health: Evidence from Epidemiology." Public Health Intelligence Occasional Bulletin 3. Wellington: Ministry of Health, May 2001.

Ministry of Health. "Evidence-based Health Objectives for the New Zealand Health Strategy." Public Health Intelligence, Occasional Bulletin Number 2. Wellington: Ministry of Health, March 2001.

Ministry of Health. "The Burden of Disease and Injury in New Zealand." Public Health Intelligence, Occasional Bulletin 1. Wellington: Ministry of Health, January 2001.

Ministry of Health. "Life Expectancy and Small Area Deprivation in New Zealand." Public Health Intelligence Occasional Bulletin 6. Wellington: Ministry of Health, 2001.

Ministry of Health. Social Inequalities in Health, 1999. Wellington: Ministry of Health, September 2000.

Ministry of Health. Diabetes 2000. Wellington: Health Funding Authority, Te Mana Putea Hauora O Aotearoa, March 2000. 
Ministry of Health. Health Opportunities, Leading in Health and Disability: Briefing Paper for the incoming Minister of Health. Wellington: Ministry of Health, January 2000.

Ministry of Health. Key Findings from Our Health Our Future - Hauora Pakari Koiora Roa: The Health of New Zealanders. Wellington: Ministry of Health, January 2000.

Ministry of Health. Our Health Our Future: Hauora Pakari, Koiora Roa, The Health of New Zealanders 1999. Wellington: Ministry of Health, December 1999.

Ministry of Health. New Zealand Food: New Zealand People: Key results of the 1997 National Nutrition Survey. Wellington: Ministry of Health, 1999.

Ministry of Health. Taking the Pulse - the 1996/97 New Zealand Health Survey. Wellington: Ministry of Health, May 1999.

Ministry of Health. Food and Nutrition Guidelines for Healthy Adolescents: A Background Paper. Wellington: Ministry of Health, June 1998.

Ministry of Health. Food and Nutrition Guidelines for Healthy Children Aged 2 - 12 years: A Background Paper Second Edition. Wellington: Ministry of Health, June 1997.

National Health Committee. Active for Life: A Call for Action. Wellington: Ministry of Health, 1997.

Statistics New Zealand and Ministry of Health. A Picture of Health. Wellington: Ministry of Health, October 1993.

Rutledge, Jo, Sandy Brinsdon, Trace McLennnan, and Barry Borman. Information on New Zealand Health Goals: Update. Wellington: Department of Health, Health Statistical Services, 1991.

Upton, Simon. Your Health and the Public Health. Wellington: Ministry of Health, July 1991.

White Paul, Jinny Gunston, Clare Salmond, June Atkinson and Peter Crampton. "Atlas of Socio-economic Deprivation in New Zealand NZDep2006.” Public Health Intelligence Occasional Bulletin 50. Wellington: Ministry of Health, June 2008.

\section{New Zealand Medical Journal Articles}

Abbott Max and Wilson Young. "Asian Health Chart Book 2006: Foundation for a New Health Agenda in New Zealand?” The New Zealand Medical Journal 119, no. 1244 (October 27, 2006): $1-3$.

Bagshaw, Philip. "Mangerialism in Public Hospitals and Universities in New Zealand", The New Zealand Medical Journal 113, no. 1106 (April 14, 2000): 114. 
Bell, Andrew, Boyd Swinburn, David Simmons, W. Wang and B. Gatland. "Heart Disease and Diabetes Risk Factors in Pacific Islands Communities and Associations with Measures of Body Fat.” The New Zealand Medical Journal 114, no. 1131 (May 11, 2001): 208-213.

Blakely, Tony, Diana Sarfati and Caroline Shaw. "What Proportion of Cancer is Due to Obesity?” The New Zealand Medical Journal 122, no. 1290 (February 27, 2009): 9-13.

Blakely, Tony. "Social Injustice is Killing People on a Grand Scale." The New Zealand Medical Journal 121, no. 1281 (September 5, 2008): 7-11.

Blakely, Tony, Shilpi Ajwani, Bridget Robson, Martin Tobias, Martin Bonne. "Decades of Disparity: Widening Ethnic Mortality Gaps from 1980 to 1999.” The New Zealand Medical Journal 117, no. 1199 (August 6, 2004): 1-21.

Blakely, Tony, Alistair Woodward, Neil Pearce, Clare Salmond, Cindy Kiro, and Peter Davis. "Socio-economic Factors and Mortality among 25-64 Year Olds Followed from 1991 to 1994: the New Zealand Census-Mortality Study." The New Zealand Medical Journal 115, no. 1149 (March 8, 2002): 93-97.

Blakely, Tony. Cindy Kiro, and Alastair Wooward. "Unlocking the Numerator-denominator Bias. II: Adjustments to Mortality Rates by Ethnicity and Deprivation During 1991-1994. The New Zealand Census Mortality Study.” The New Zealand Medical Journal 115, no. 1146 (February 6, 2002): 43-48.

Blakely, Tony, Bridget Robson, June Atkinson, Andrew Sporle and Cindy Kiro. "Unlocking the Numerator-denominator Bias. I: Adjustments Ratios by Ethnicity for 1991 - 1994 Mortality data. The New Zealand Census-Mortality study.” The New Zealand Medical Journal 115, no. 1146 (February 6, 2002): 39.

Crampton, Eric. “Economics can be Good for Health, but it Needn't be so Dismal.” The New Zealand Medical Journal 120, no. 1263 (October 12, 2007): 1-3.

Duncan, Elizabeth, Grant Schofeild, Scott Duncan, Gregory Kolt and Elaine Rush. "Ethnicity and Body Fatness in New Zealanders." The New Zealand Medical Journal 117, no. 1195 (June 4, 2004): 1-9.

Edwards, Richard, Nick Wilson, and Mansoor Osman. "Taxes for Health: the Argument is More about Health than Economics." The New Zealand Medical Journal 120, no. 1264 (October 26, 2007): 1 .

Gorton, Delvina, Helen Etyles, Cliona Ni Mhurchu and Chris Bullen. "Removal of the Requirement for Schools to Only Sell Healthy Food a Giant Leap Backwards." The New Zealand Medical Journal 122, no. 1290 (February 27, 2009): 130 -132.

Hider, Phil. "Improving Maori Health Outcomes with Decision Support." The New Zealand Medical Journal 120, no. 1250 (March 2, 2007): 1-4.

Hohepa, Maea, Grant Schofeild and Gregory Kolt. "Adolescent Obesity and Physical Inactivity.” The New Zealand Medical Journal 117, no. 1207 (December 17, 2004): 1-13. 
Howden-Chapman, Phillipa, Tony Blakely, Alison Blaiklock and Cindy Kiro. "Closing the Gaps.” The New Zealand Medical Journal 113, no. 1114 (July 28, 2000): 301-302.

Kerr, Andrew, Andrew McLachlan, Sue Furness et al. "The Burden of Modifiable Cardiovascular Risk Factors in the Coronary Care Unit by Age, Ethnicity, and Socio-economic Status - Predict CVD-9.” The New Zealand Medical Journal 121, no. 1285 (November 7, 2008): 20-32.

Kingi, Denise. Andy Towers, Renee Seebeck and Ross Flett. "Pacific Women's Decisions about Exercise Adoption: Utilising the Stage-of-Exercise-Adoption Model.” The New Zealand Medical Journal 118, no. 1216 (June 3, 2005):1-9.

Lawes, Carlene, Niki Stefanogiannis, Martin Tobias, Natalie Paki Paki, Cliona Ni Mhurchu, Maria Turley, Stephan Vander Hoorn and Anthony Rodgers. "Ethnic Disparities in NutritionRelated Mortality in New Zealand: 1997 - 2011.” The New Zealand Medical Journal 119, no. 1240 (August 18, 2006): 1-12.

Maher, Anthony, Nick Wilson and Louise Signal. "Advertising and Availability of 'Obesogenic' Foods around New Zealand Secondary Schools: a Pilot Study.” The New Zealand Medical Journal 118, no. 1218 (July 15, 2005): 1-11.

Martin, Iain. "Bariatric Surgery: Folly or the Future?" The New Zealand Medical Journal 117, no. 1207 (December 17, 2004): 1-2.

McCreanor, Timothy and Raymond Nairn, "Tauiwi General Practitioners' Talk about Maori Health: Interpretative Repertoires.” The New Zealand Medical Journal 115, no. 1167 (December 13, 2002): 1-8.

Metcalf, Patricia, Scragg, Robert and Peter Davis. "Relationship of Different Measures of Socioeconomic Status with Cardiovascular Disease Risk Factors and Lifestyle in a New Zealand Workforce Survey.” The New Zealand Medical Journal 120, no. 1248 (January 26, 2007): 1-10.

Mhurchu, Cliona Ni, Derrick Bennett, Ray Lin, Maree Hackett, Andrew Jull, and Anthony Rodgers. "Obesity and Health-related Quality of Life: Results from a Weight Loss Trial." The New Zealand Medical Journal 117, no. 1207 (December 17, 2004): 1-9.

Oliver, Melody, Philip Schluter, Janis Paterson, Gregory S. Kolt and Grant Schofield. "Pacific Islands Families: Child and Parental Physical Activity and Body Size - Design and Methodology.” The New Zealand Medical Journal 122, no. 1298 (July 3, 2009): 48-59.

Paul, Charlotte. "Socio-economic Factors and Death Rates." The New Zealand Medical Journal 115, no. 1149 (March 8, 2002): 91-92.

Pelkowitz Allan and Sue Crengle. "The Orewa Speech.” The New Zealand Medical Journal 117, no. 1205 (November 5, 2004): 1-3.

Quigley, Robert and Carolyn Watts. "Challenging Beliefs about the Marketing of Food.” The New Zealand Medical Journal 118, no. 1218 (July 15, 2005): 1-4. 
Rasanathan, Kumanan, Shanthi Ameratunga and Samson Tse. "Asian Health in New Zealand Progress and Challenges.” The New Zealand Medical Journal 119, no. 1244 (October 27, 2006):1-8.

Reremoana Theodore, John Thompson, Clare Wall, David Becroft, Elizabeth Robinson, Phillipa Clark, Jan Pryor, Chris Wild and Ed Mitchell. "Dietary Patterns of New Zealand European Preschool Children.” The New Zealand Medical Journal 119, no. 1235 (June 2, 2006): $1-10$.

Richards, Rosalina, Anthony Reader and Helen Darling. "Interest and Participation in Selected Sports among New Zealand Adolescents.” The New Zealand Medical Journal 117, no. 1195 (June 4, 2004): 1-7.

Riddell, Tania. "Heart Failure Hospitalisations and Deaths in New Zealand: Patterns by Deprivation and Ethnicity." The New Zealand Medical Journal 118, no. 1208 (Jan 28, 2005): 1 10.

Ridley-Smith, Roger. “The 'Weighting' List.” The New Zealand Medical Journal 118, no. 1243 (October 13, 2006): 1.

Ryall, Tony. "The National Party's Solutions for New Zealand's Health Care System.” The New Zealand Medical Journal 121, no. 1283 (October 3, 2008): 15-18.

Schofield, Grant. "Push Play: What's Under the Umbrella?" The New Zealand Medical Journal 116, no. 1179 (August 8, 2003): 1-3.

Sharpe, Norman and Gerard Wilkins. "Quality and Equity in Cardiovascular Health in New Zealand: the Need for Agreed Achievable Standards of Care, Cohesive Planning, and Action.” The New Zealand Medical Journal 117, no. 1197 (July 9, 2004): 4.

Shaw, Caroline. "(Non)regulation of Marketing of Unhealthy Food to Children in New Zealand.” The New Zealand Medical Journal 122, no. 1288 (January 23, 2009): 76-86.

Simmons, David and Trish Harry. "Prevalence of Known Diabetes in Different Ethnic Groups in Inner Urban South Auckland.” The New Zealand Medical Journal 112, no. 1094 (August 24, 1999): 316-319.

Sporle, Andrew, Neil Pearce and Peter Davis. "Social Class Mortality Differences in Maori and Non-Maori Men Aged 15-64 During the Last Two Decades.” The New Zealand Medical Journal 115, no. 1150 (March 22, 2002): 130.

Swann, Judith, Steven Lillis and David Simmons. "Investigating the Accuracy of Ethnicity Data in New Zealand Hospital Records: Still Room for Improvement.” The New Zealand Medical Journal 119, no. 1239 (August 4, 2006): 1-7.

Swinburn, Boyd. "Using the Body Mass Index: Weigh then Weigh Up.” The New Zealand Medical Journal 111, no. 1075 (October 9, 1998): 377-379.

Thornely, Simon, and John Windsor. "The Role of Surgery in the Management of Obesity." The New Zealand Medical Journal 113, no. 1122 (November 24, 1998): 445-448. 
Towns, Cindy, Nathan Watkins, Arapera Salter, Patricia Boyd and Lianne Parkin. "The Orewa Speech: Another Threat to Maori Health?” The New Zealand Medical Journal 117, no. 1205

(November 5, 2004): 1-7.

Utter, Jennifer, Robert Scragg, Teuila Percival and Robert Beaglehole. "School is Back in New Zealand - and so is the Junk Food.” The New Zealand Medical Journal 122, no. 1290 (February 27, 2009): 5-8.

Utter, Jennifer, David Scahaaf, Cliona Mhurchu and Robert Scragg. "Food Choices Among Students Using the School Food Service in New Zealand.” The New Zealand Medical Journal 120, no. 1248 (January 26, 2007): 1-11.

Wilson, Barry, Noela C. Wilson, David Russell. "Obesity and Body Fat Distribution in the New Zealand Population.” The New Zealand Medical Journal 114, no. 1128 (March 23, 2001): 127-130.

Wilson, Nick. Richard Edwards, and Mansoor Osman. "Economics can be Good for Health: Need for Rational Policy without the Influence of Vested Interests." The New Zealand Medical Journal 120, no. 1263 (October 12, 2007):1-4.

Wilson, Nick, George Thomson and Gabrielle Jenkin. "More Evidence for Action on New Zealand's Obesogenic School Environment and Food Pricing.” The New Zealand Medical Journal 120, no. 1248 (January 26, 2007): 1-4.

Wilson, Nick, Carolyn Watts, Louise Signal and George Thomson. "Acting Upstream to Control the Obesity Epidemic in New Zealand.” The New Zealand Medical Journal 117, no. 1207 (March 31, 2006): 1-6.

Wilson, Nick, Osman Mansoor and George Thomson. "Key Arguments for Increasing New Zealand's Health Development Assistance in the Pacific." The New Zealand Medical Journal 117, no. 1191 (April 2, 2004): 1-6.

\section{Websites}

ACT Party. "Front Page" http://www.act.org.nz/ (accessed October 27, 2008).

ACT Party. "Health Policy." http://www.act.org.nz/health-policy (accessed October 27, 2008).

Big Fat Facts. "Critiques of the Obesity Epidemic and Research." http://www.bigfatfacts.com/ (accessed October 21, 2009).

Brash, Don. "Orewa Speech - Nationhood."

http://www.national.org.nz/speech article.aspx?ArticleID=1614 (accessed November 11, 2011).

Canterbury District Health Board. "Implications of the Removal of National Administrative Guideline 5 (iii) on the Work of the Education Team at Community and Public Health.” 
http://www.cdhb.govt.nz/corpbrd/CPHDSACMeetings/2009/01@February19/Item\%208 \%20-\%20App1\%20Healthy\%20Eating\%20in\%20Schools.pdf (accessed January 13, 2010).

Capital and Coast PHO. "Pasefika Healthy Lifestyle Programme"

http://www.capitalpho.org.nz/Home/services (accessed March 11, 2010).

Carter, Chris. "Education Minister Promotes Child Obesity."

http://www.scoop.co.nz/stories/PA0902/S00085.htm (accessed December 9, 2009).

Clark, Helen."Prime Minister's Post-Budget Speech To Parliament."

http://www.beehive.govt.nz/node/7715 (accessed March 11, 2010).

Close Up News. "Being Fat Your Own Fault.” http://tvnz.co.nz/close-up/being-fat-yourown-fault-2778376/video (accessed January 31, 2011).

Coca Cola Amatil (NZ) Limited and Furcor Beverages Group Limited. "Companies Remove Full Sugar Drinks from Schools.” http:/ / www.infonews.co.nz/news.cfm?id=45831 (accessed March 8, 2010).

Douglas, Roger. "ACT's Analysis of New Zealand's Economic Situation.”

http://www.act.org.nz/blog/roger-douglas/act-analysis-of-current-new-zealand-economicsituation (accessed December 11, 2008).

Dyson, Ruth. "Obesity Strains Health Services." http://www.scoop.co.nz/stories/PA0907/S00209.htm (accessed December 9, 2009).

Dyson, Ruth. "National Fails to Understand Importance of Obesity."

http://www.scoop.co.nz/stories/PA0907/S00162.htm (accessed December 9, 2009).

Dyson, Ruth. "Do Reduced Health Targets Signal Budget Cuts?"

http://www.scoop.co.nz/stories/PA0905/S00148.htm (accessed December 9, 2009).

Farrar, David. “Obesity.” http://www.kiwiblog.co.nz/2009/05/obesity.html (accessed January 31, 2011).

Green Party. “Front Page.” http://www.greens.org.nz/front (accessed October 27, 2008).

Green Party. "Green Party Health Policy.” http://www.greens.org.nz/policy/health (accessed October 30, 2008).

Green Party. "Green Party Preventative Health Strategy."

http://www.greens.org.nz/sites/default/files/preventativehealth.pdf (accessed October 30, 2008).

Gustafson, Barry. "Savage, Michael Joseph.” www.dnzb.govt.nz.http://www.dnzb.govt.nz/DNZB/alt essayBody.asp?essayID=4S9 (accessed November 25, 2009). 
Harward, Esther. "Kiwis Still Hooked on the Most Unhealthiest Food."

http:/ / www.stuff.co.nz/sunday-star-times/1753378/Kiwis-still-hooked-on-the-

unhealthiest-food (accessed March 9, 2008).

Hill, Ruth. "Obesity: A Heavy Burden."

http://www.stuff.co.nz/dominion-post/local/2906245/Obesity-A-heavy-burden (accessed September 28, 2009).

Johns, Geraldine and Anna Leask. "Expert: It's Your Fault if You're a Fatty."

http: / / www.nzherald.co.nz/nz/news/article.cfm?c id =1\&objectid $=10575537$ (accessed

October 7, 2010).

Kedgley, Sue. "Coca Cola and Pepsi Move Just Fizzy PR Spin.”

http://www.greens.org.nz/press-releases/coca-cola-and-pepsi-move-just-fizzy-pr-spin

(accessed March 10, 2010).

Kedgley, Sue. "Report Highlights Government Stupidity on Obesity."

http://www.scoop.co.nz/stories/PA0907/S00151.htm (accessed December 9, 2009).

Kedgley, Sue. "Government going Backwards on Obesity."

http://www.greens.org.nz/node/21094 (accessed December 9, 2009).

Kedgley, Sue. ”National Brings Back Junk Food, say Greens.”

http://www.greens.org.nz/node/20540 (accessed December 7, 2009).

Kedgley, Sue. "Let Them Eat Cake, Drink Cola, and Go Nuts."

http://www.greens.org.nz/node/20594 (accessed December 7, 2009).

Key, John. "Securing a Brighter future, Social Issues, Our 2010 Priorities."

http://www.national.org.nz/files/2010/2010 SocialIssues.pdf (accessed March 10, 2010).

Key, John. "2008: Sport for Young Kiwis: a National Priority.”

http://www.national.org.nz/Chapter.aspx?ChapterId=28150 (accessed October 27, 2008).

King ,Annette. "King Launches Strategy to Tackle Obesity, Improve Nutrition and Increase Physical Activity." http://www.beehive.govt.nz/node/16181 (accessed October 4, 2010).

Labour Party. "Health Policy."

http://www.labour08.co.nz/news/Labour+releases+comprehensive+Health+Policy

(accessed October 27, 2008).

Maori Party. "Health Policy" http://www.maoriparty.org/ (accessed October 27, 2008).

McCully, Murray. "Kiwisport Provides More Funding for All School Kids."

http: / / www.national.org.nz/Article.aspx?articleId=30609 (accessed December 9, 2009).

Ministry of Education. "National Administrative Guidelines."

http://www.minedu.govt.nz/NZEducation/EducationPolicies/Schools/PolicyAndStrategy/ PlanningReportingRelevantLegislationNEGSAndNAGS/TheNationalAdministrationGuidelines NAGs.aspx\#NAG5 (accessed January 13, 2010). 
National Party. "Front Page.” http://www.national.org.nz/ (accessed October 27, 2008).

New Zealand Cricket. "PM Joins 50th Test Celebrations."

http://www.blackcaps.co.nz/news/international/1/pm--joins-50th-test-

celebrations/6158/article.aspx (accessed December 9, 2009).

Obesity Action Coalition. "Media Analysis - March 2009."

http://www.obesityaction.org.nz/docs/OACMediaAnalysisMarch09.pdf (accessed

December 9, 2009).

OECD Health Data. "How Does New Zealand Compare?"

http://www.oecd.org/dataoecd/43/22/40905041.pdf (accessed December 9, 2009).

Pausé, Cat. "Homepage." http://www.massey.ac.nz/massey/learning/colleges/collegeeducation/about/staff/adhe/en/pause-caitlin.cfm (accessed January 31, 2011).

Quigley and Watts Ltd. “About Us.” http://www.quigleyandwatts.co.nz/about us.php (accessed July 19, 2010)

Rich, Katherine. "Govt, Companies, Removing Fizzy from Schools."

http://www.scoop.co.nz/stories/ED0912/S00027.htm (accessed March 10, 2010).

Rich, Katherine. "No Evidence School Lunches Less Healthy."

http://www.scoop.co.nz/stories/GE1001/S00012.htm (accessed March 10, 2010).

Ryall, Tony. "Fruit in Schools Future Confirmed."

http://www.national.org.nz/Article.aspx?articleId=31211 (accessed December 9, 2009).

Ryall, Tony. "Address to the Lean Healthcare Summit: The Current and Future Demands on our Healthcare System and the Need for Redesign."

http://www.national.org.nz/Article.aspx?articleId=30171 (accessed December 9, 2009).

Ryall, Tony. "Speech Notes from Address to the DHB Chairs in Wellington."

http://www.national.org.nz/Article.aspx?articleId=29009 (accessed December 7, 2009).

Ryall, Tony. "Why a Strong Economy is Good for your Health."

http: / / www.national.org.nz/Chapter.aspx?ChapterId=28442 (accessed October 27, 2008).

Sport and Recreation New Zealand. "Sport and Recreation New Zealand: Post Election Briefing for the Incoming Minister for Sport and Recreation"

http://beehive.govt.nz/sites/all/files/SPARC BIM.pdf (accessed December 9, 2009).

Sturgiss, Leigh. "Health Group says Decision to Reintroduce Unhealthy Food at Schools 'Peculiar' Obesity Action,"

http://www.obesityaction.org.nz/media/090205Decisionpeculiar.pdf (accessed December 9, 2009).

Tolley, Anne. "Schools no Longer Required to be Food Police."

http: / / www.national.org.nz/Article.aspx?articleId=29288 (accessed December 7, 2009). 
Toomath, Robyn. "New Zealand: More Sport Won't Stop the Obesity Epidemic." http: / / foe.org.nz/2009/08/12/nz-more-sport-won\%e2\%80\%99t-stop-the-obesityepidemic/ (accessed December 9, 2009).

Toomath, Robyn. "National Reversal on Healthy Foods in Schools Incredible." http:/ / foe.org.nz/2009/02/18/national-reversal-on-healthy-food-in-schools-incredible/ (accessed December 7, 2009).

Turei, Metira. "Inequality in Aotearoa: A Brief History of Inequality."

http://blog.greens.org.nz/2010/04/06/inequality-in-aotearoa-a-brief-history-of-inequality/ (accessed October 7, 2010).

Watkins, Tracy. " $\$ 82 \mathrm{~m}$ Funding Boost for School Sports." http:/ / www.stuff.co.nz/national/education/2742110/82m-funding-boost-for-school-sports. (accessed December 7, 2009).

World Health Organisation. "Global Burden of Disease (GBD)." http://www.who.int/healthinfo/global burden disease/en/ (accessed February 21, 2011).

World Health Organisation. "World Health Organisation Global Strategy on Diet, Physical Activity and Health." http://apps.who.int/gb/ebwha/pdf files/WHA57/A57 R17-en.pdf (accessed April 1, 2010).

\section{New Zealand Legislation and Treaties}

Taxation (Working for Families) Act 2004

Sport and Recreation Act 2002

Health and Disability Services Act 1993

Sports, Fitness, and Leisure Amendment Act 1992

Sport and Recreation Act 1987

Social Security Act 1938

\section{Filmography}

Fast Food Nation (2006)

Supersize Me (2004)

Mc Libel (1997) 